(1)

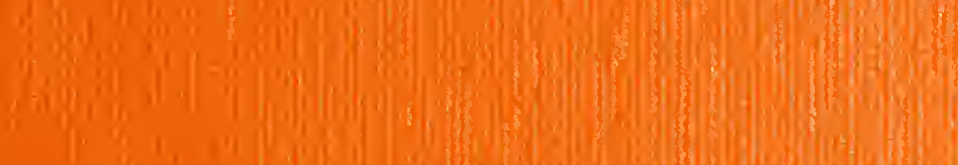

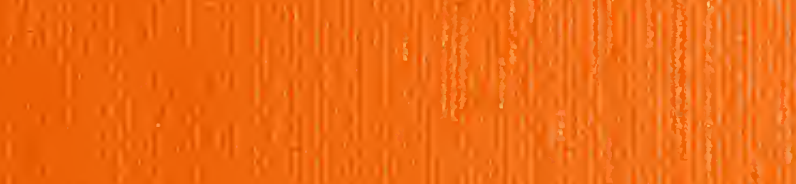

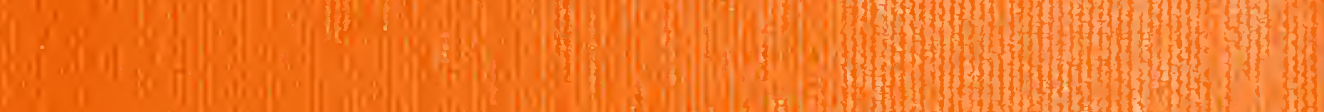

His

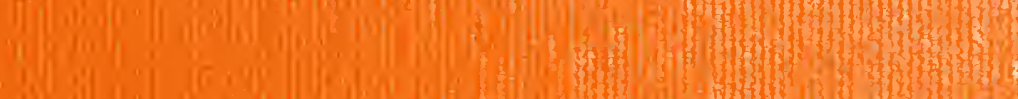
(6. 4:

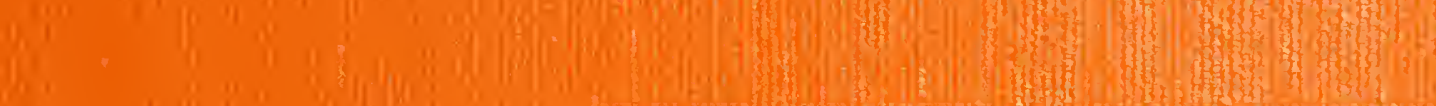

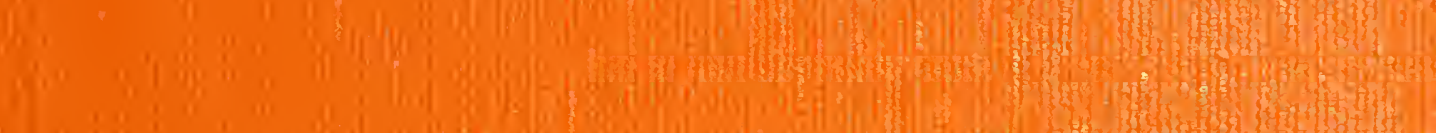
4,

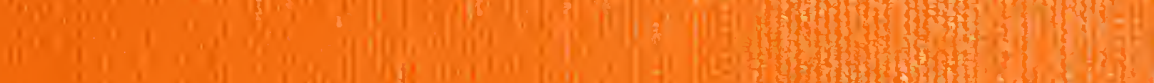

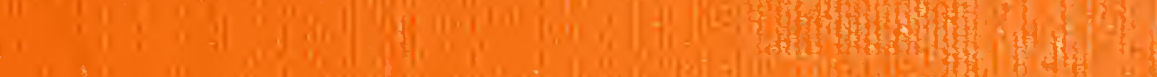

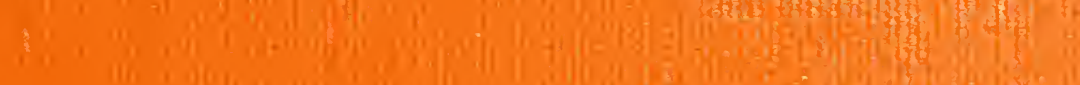
16:

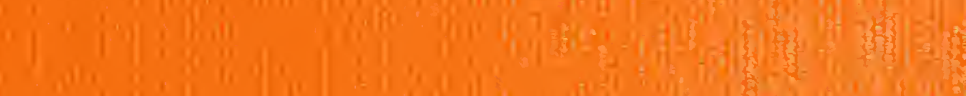
(1) :

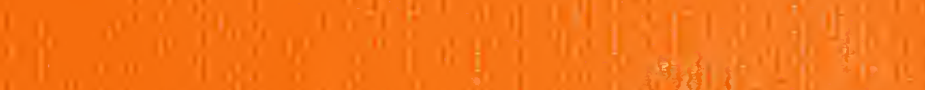

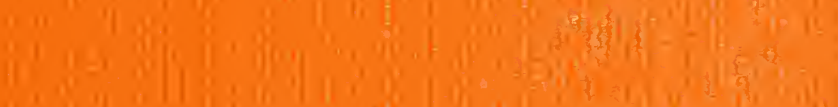

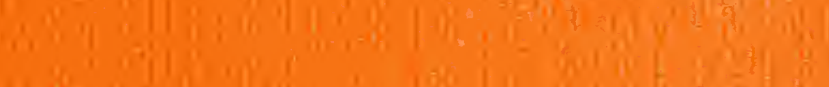

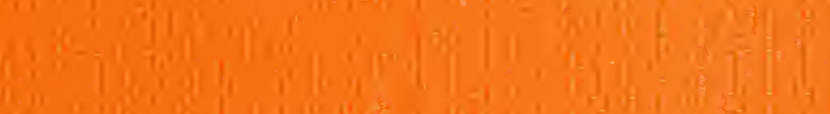
I. 3i :

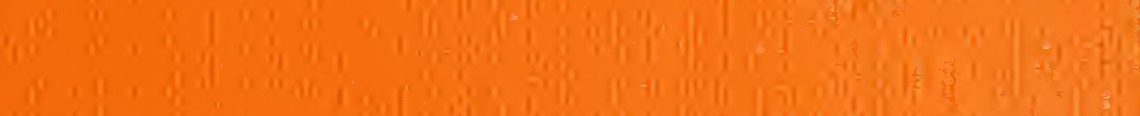

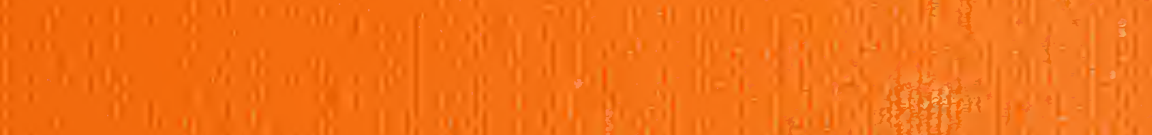
20.

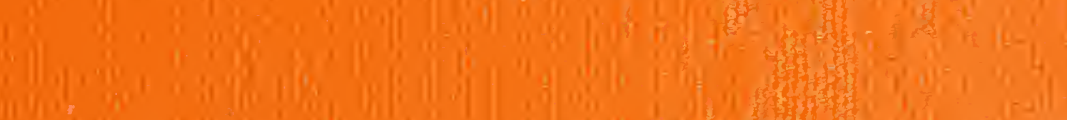
a

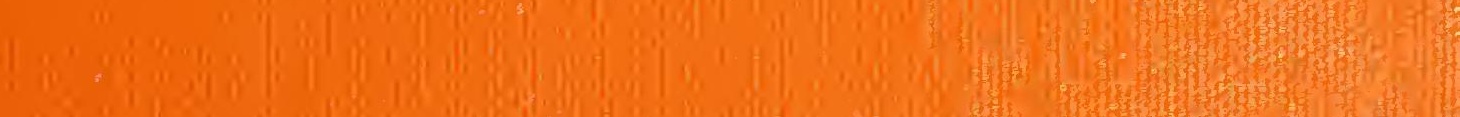

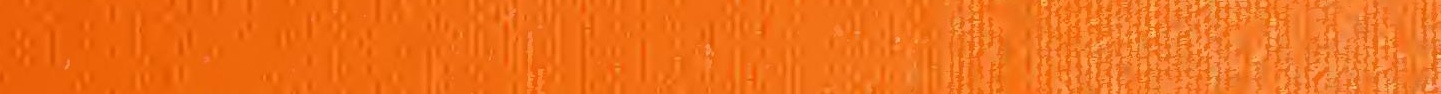

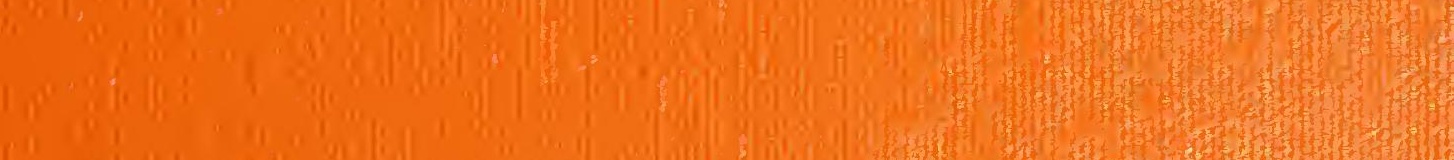
I: : 190

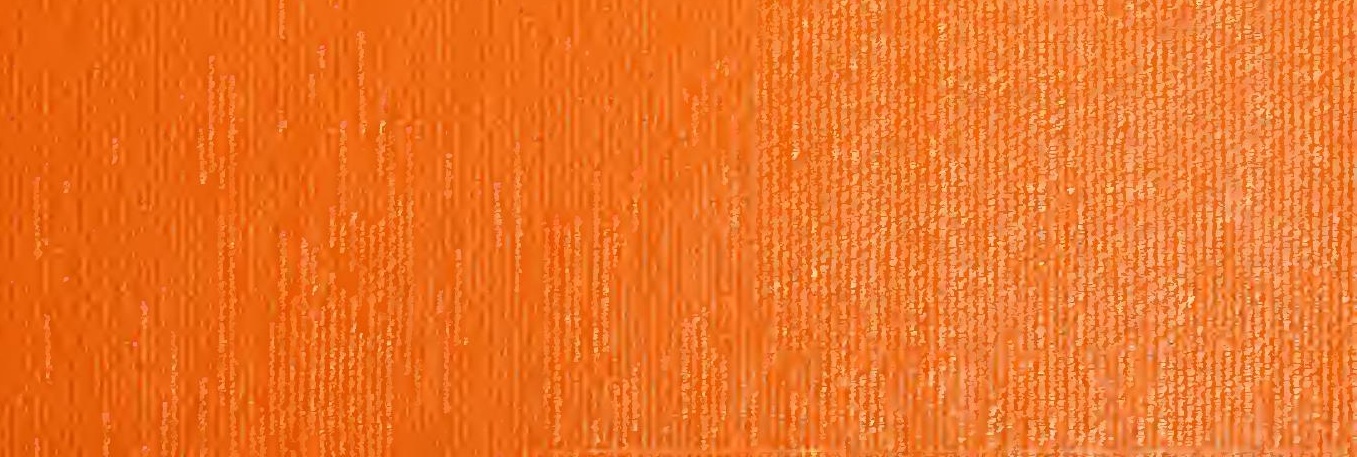






\title{
NBSIR 75.688
}

\section{Performance of Mobile Homes - A Field Inspection Study}

\author{
L. F. Skoda \\ J. H. Pielert \\ W. E. Greene \\ W. G. Street
}

Office of Building Standards and Codes Services and Office of Housing Technology Center for Building Technology Institute for Applied Technology National Bureau of Standards

Washington, D. C. 20234

June 1975

Interim Report

Prepared for

Office of Policy Development and Research

Department of Housing and Urban Development

Washington, D. C. 20410 

NBSIR 75-688

PERFORMANCE OF MOBILE HÖMES A FIELD INSPECTION STUDY
L. F. Skoda
J. H. Pielert
W. E. Greene
W. G. Street

Office of Building Standards and Codes Services and

Office of Housing Technology

Center for Building Technology

Institute for Applied Technology

National Bureau of Standards

Washington, D. C. 20234

June 1975

Interim Report

Prepared for

Office of Policy Development and Research

Department of Housing and Urban Development

Washington, D. C. 20410

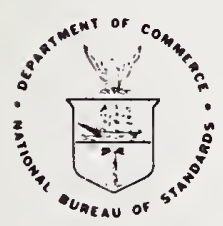

U.S. DEPARTMENT OF COMMERCE, Rogers C.B. Morton، Secretary

NATIONAL BUREAU OF STANDARDS, Richard W. Roborts. Director 


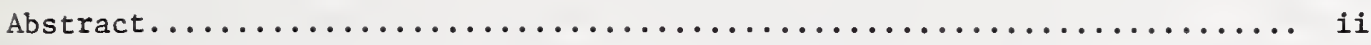

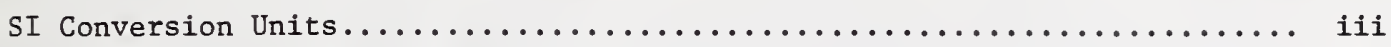

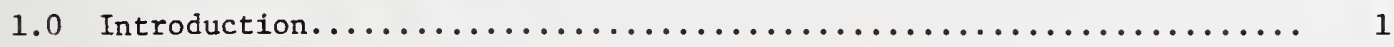

1.1 Mobile Home Industry............................. 1

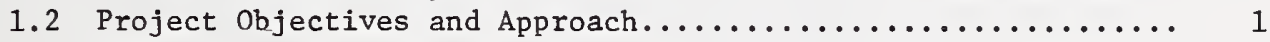

1.3 Field Inspection Task............................ 1

2.0 Summary of Field Inspection Procedures......................

2.1 Interdisciplanary Team Approach...................... 2

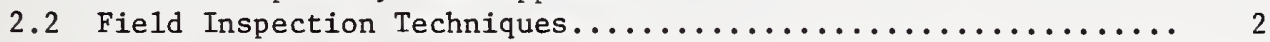

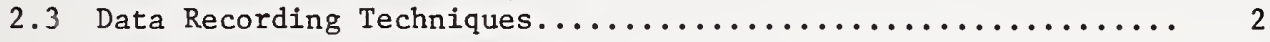

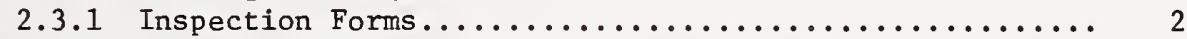

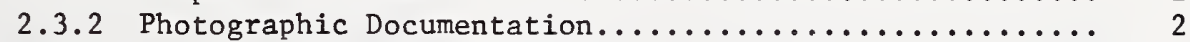

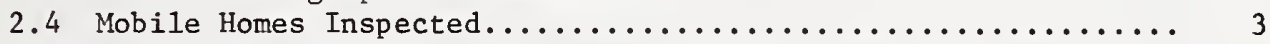

3.0 Characteristics of Field Inspected Mobile Homes................

3.1 Manufacturing Characteristics....................... 3

3.2 ANSI A119.1 Standard Compliance Data................... 3

4.0 Data Analysis Methodology ............................. 4

4.1 Problem Catalog Development........................ 4

4.2 Computer Techniques............................ 4

5.0 Problem Summation Tables..............................4

5.1 Organization and Usage of Tables.................... 4

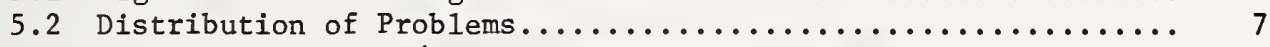

5.2.1 ANSI A119.1/Enforcement Process Related

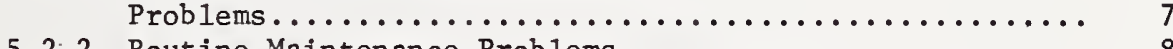

5.2 .2 Routine Maintenance Problems.................... 8

5.2.3 Mechanical/Electrical Appliance Problems............ 9

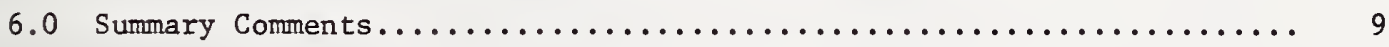

References......................................... 10

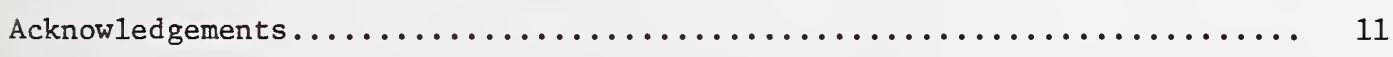

Tables............................................. 12

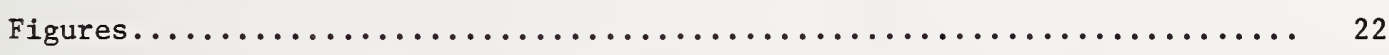

Appendix A - Field Inspection Forms......................... 28

Appendix B - Performance Problem List and Rank Ordered Summations....... 37

Appendix C - Photographic Documentation....................... 57 


\section{Abstract}

A field inspection study of mobile homes was conducted for the Department of Housing and Urban Development. The obfective of the study was to evaluate the causes of mobile home problems by physically inspecting avallable units at various locations in the United States. A total of 257 units were inspected consisting mostly of mobile homes purchased by HUD and used as temporary housing for victims of the 1972 Hurricane Agnes disaster. The total number of problems found was 3,528 for the 257 units inspected. Of these problems, 2120 were directly related to inadequacies in the ANSI Al19.1 Standard for Mobile Homes or the mobile home enforcement process (plan review, certification of designs, plant inspection), 934 were routine maintenance problems, and 374 were attributed to mechanical/electrical appliances and equipment. This report presents a computer listing of all problems plus photographic examples of observed problems.

The number of mob1le homes included in this study is small when compared to the total number of mobile homes now in use in the United States. Additionally, this was a problem orfented study and did not attempt to document the many areas of satisfactory mobile home performance.

Key Words: Enforcement process; field inspection; house trailers; housing; Hurricane Agnes; mobile homes; performance data; standards. 


\section{SI Conversion Units}

In view of the present accepted practice in this country for building technology, common U.S. units of measurement have been used throughout this publication. In recognition of the position of the United States as a signatory to the General Conference on Weights and Measures, which gave official status to the metric SI system of units in 1960, appropriate conversion factors have been provided in the table below. The reader interested in making further'use of the coherent system of SI units is referred to:

NBS SP330, 1972 Edition, "The International System of Units"

E380-72 ASTM Metric Practice Guide (American National Standard 2210.1)

Table of Conversion Factors to Metric (S.I.) Units

\begin{tabular}{|c|c|c|c|}
\hline $\begin{array}{l}\text { Physical } \\
\text { Quantity }\end{array}$ & $\begin{array}{l}\text { To convert } \\
\text { from }\end{array}$ & to & multiply by \\
\hline Length & $\begin{array}{l}\text { inch } \\
\text { foot }\end{array}$ & $\begin{array}{l}\text { meter } \\
\text { m }\end{array}$ & $\begin{array}{l}2.54 * \times 10^{-2} \\
3.048 * \times 10^{-1}\end{array}$ \\
\hline Area & $\begin{array}{l}\text { Inch } 2 \\
\text { foot } 2\end{array}$ & $\begin{array}{l}\mathrm{m}^{2} \\
\mathrm{~m}^{2}\end{array}$ & $\begin{array}{l}6.4516 * \times 10^{-4} \\
9.290 \times 10^{-2}\end{array}$ \\
\hline Volume & $\begin{array}{l}\operatorname{lnch}^{3} \\
\text { foot }^{3}\end{array}$ & $\begin{array}{l}\mathrm{m}^{3} \\
\mathrm{~m}^{3}\end{array}$ & $\begin{array}{l}1.639 \times 10^{-5} \\
2.832 \times 10^{-2}\end{array}$ \\
\hline Temperature & Fahrenheit & Celsius & $t_{c}=\left(t_{F-32}\right) / 1.8$ \\
\hline Temperature difference & Fahrenheit & Kelvin & $\mathrm{K}=(\Delta \mathrm{t} F) / 1.8$ \\
\hline Pressure & inch $\mathrm{Hg}(60 \mathrm{~F})$ & newt on $/ \mathrm{m}^{2}$ & $3.377 \times 10^{3}$ \\
\hline Mass & $1 \mathrm{bm}$ & $\mathrm{kg}$ & $4.536 \times 10^{-1}$ \\
\hline Mass/unit area & $1 \mathrm{bm} / \mathrm{ft}^{2}$ & $\mathrm{~kg} / \mathrm{m}^{2}$ & 4.882 \\
\hline Moisture content rate & $1 \mathrm{bm} / \mathrm{ft}^{2}$ week & $\mathrm{kg} / \mathrm{m}^{2} \mathrm{~s}$ & $8.073 \times 10^{-6}$ \\
\hline Density & $1 \mathrm{bm} / \mathrm{ft}^{3}$ & $\mathrm{~kg} / \mathrm{m}^{3}$. & $1.602 \times 10^{1}$ \\
\hline Thermal conductivity & Btu/hr ft ${ }^{2}$ (F/inch) & $\frac{\mathrm{w}}{\mathrm{mK}}$ & $1.442 \times 10^{-1}$ \\
\hline U-value & $\mathrm{Btu} / \mathrm{hr} \mathrm{ft}^{2} \mathrm{~F}$ & $\frac{W}{m^{2} k}$ & 5.678 \\
\hline Thermal resistance & $\mathrm{F} /\left(\mathrm{Btw} / \mathrm{hr} \mathrm{ft}^{2}\right)$ & $\mathrm{K} /\left(\mathrm{W} / \mathrm{m}^{2}\right)$ & $1.761 \times 10^{-1}$ \\
\hline Heat Flow & $\mathrm{Btu} / \mathrm{hr} \mathrm{ft}^{2}$ & $\mathrm{~W} / \mathrm{m}^{2}$ & 3.155 \\
\hline
\end{tabular}

*Exact value; others are rounded to fourth place. 



\subsection{Introduction}

1.1 MOBILE HOME INDUSTRY. One of the solutions to the lower-cost housing shortage in the United States today is the use of mobile homes as permanent dwellings. Mobile homes represent one-fifth of all housing units produced in each of the last five years (1970 through 1974 ) and included $96 \%$ of houses under $\$ 20,000$ produced in 1973 . The production of mobile homes increased dramatical1y from 100,000 units in 1960 to around 600,000 units in 1973 . This growth has resulted primarily from the mobile home industry's ability to produce adequate housing at lower initial cost as compared to conventional housing. The production of mobile homes is regulated at the state and local level. An existing standard, ANSI A119.1 Standard for Mobile Homes [1] 1 , , has been adopted in total, or with slight modifications, by 45 states for use in mobile home enforcement programs.

1.2 PROJECT OBJECTIVES AND APPROACH. Recently, many individuals and groups have questioned the effectiveness of mobile homes in providing safe, adequate and low-cost shelter. Although life-safety aspects such as questionable fire safety and susceptibility to wind damage receive the most publicity, functional characteristics appear to be of broader concern to mobile home owners. It is recognized that the mobile home supply process (manufacturing, transportation, siting $2 /$ ) differs greatly from conventional housing and is partly responsible for some of their unique performance problems. Unfortuanately, there is a 1imited amount of organized documentation of these problems making it difficult to pinpoint which aspect of the mobile home supply process may be deficient.

In response to this recognized problem of lack of information, a project funded by the Department of Housing and Urban Developments' Office of Policy Development and Research, was structured around the following objectives:

A. Identification and documentation of the significant mobile home performance problems.

B. Determine the relationship of these identified problems to provisions of the ANSI A119.1 Standard for Mobile Homes, the mobile home enforcement process (plan review, certification of designs, plant inspection), and durability of materials (mortgage insurance concern).

C. Identification of needed areas of research relative to the mobile home supply process.

To achieve these objectives the project was divided into three principal tasks. Task .I was organized to collect and analyze problem data in the structural, electrical, heating, plumbing and transportation areas. The object of Task II was to evaluate the cause of mobile home problems by physically inspecting mobile homes. Task III will summarize the data obtained in Tasks I and II and determine if a relationship exists between the identified problems, the Standard, and/or the enforcement process. Reference [2] out1ines the data acquisition and analysis methodology developed for these tasks.

1.3 FIELD INSPECTION TASK. Since the degree of problem detail obtained in Task I varied considerably, the field inspecion of mobile homes was necessary to determine specific causes and consequences of the performance problems. Units inspected included those used by HUD for temporary housing following the Hurricane Agnes disaster and mobile homes from the private sector.

This report provides a description and documentation of the field inspection effort entailed in the completion of Task II. The number of mobile homes included in this study is small when compared to the total number of mobile homes now in use in the United States. Additiona11y, this was a problem oriented study and did not attempt to document the many areas of satisfactory mobile home performance.

1/ References are listed at end of report.

2/ Siting encompasses placement and leveling the mobile home on its foundation, installing steps, skirting and connecting utilities. 


\subsection{Summary of Field Inspection Procedures}

2.1 INTERDISCIPLINARY TEAM APPROACH. The personne1 capabilities available at the National Bureau of Standards made it possible to assemble a field inspection team that was interdisciplinary in nature and capable of providing expertise in many phases of the bullding process. The team consisted of a profect manager - structural engineer and five other members with engineering background in the fields of building materials, plumbing, heating, electrical and fire technology.

Prior to initiation of the field inspection task, the inspection team members visited several manufacturing plants in order to become more familiar with the mobile home construction process. Also, facilities established by HUD in Wilkes-Barre, Pennsylvania for training of repair crews that were responsible for maintenance of mobile home heating, plumbing and electrical systems were visited by the field inspection team.

2.2 FIELD INSPECTION TECHNIQUES. Field inspection techniques were developed in WilkesBarre for use in both HUD and private mobile home inspections. Mobile homes in various states of disrepair at several locations around the Wilkes-Barre area were used to develop field inspection techniques. The condition of the units varied from those which were damaged beyond repair to units in good shape that were being kept by HUD for possible use in future disasters. Inspection of severely damaged units made it possible to observe structural framing techniques, plumbing trees, wiring techniques, heat duct assemblies and insulation. Both destructive and non-destructive inspection procedures were developed by the inspection team utilizing these units.

The "non-destructive" inspection procedures used for the vast majority of mobile homes consisted of a visual inspection with no permanent construction removed. Partition construction could be observed in unfinished closets, water heater compartments and furnace enclosures. Plumbing inspections were confined to the hot water heater compartment, under kitchen and bathroom sinks and at washer hookups. Heating system evaluation was confined to the furnace compartment and by removal of floor registers. The electrical system could be evaluated at the load center and by removal of switch plates and duplex outlet covers.

"Destructive" inspection procedures included the selective removal of ceiling panels, wall paneling (interior and exterior), floor decking and underside weather barrier material so that structural framing, insulation, vapor barriers, electrical wiring methods, and plumbing trees could be inspected and overall workmanship evaluated. It was possible to use the "destructive" inspection procedure on eighteen mobile homes set aside for NBS use by HUD at WilkesBarre. While some of these units were damaged, most were in good condition and NBS was granted permission to perform any type of destructive evaluation down to and including complete dismantling of the unit. Samples of materials such as cabinet doors, wall paneling, ceiling material, electrical and plumbing parts and fixtures were removed and returned to NBS for study.

2.3 DATA RECORDING TECHNIQUES. The data recording techniques used in the field inspection effort were both written and photographic. Inspection forms and photographs along with avallable maintenance data (173 of the 257 mobile homes) formed the basis for evaluation of the individual mobile homes examined during the field inspection task.

2.3.1 Inspection Forms. Appendix A contains examples of the inspection forms used in the field inspection effort. A set of these forms were filled out on each mobile home inspected and included unit identification, structural, plumbing, heating and electrical data. These "check 1ist" type forms were designed to obtain as much information as possible without destroying or damaging components of the mobile home. Applicable paragraphs of the ANSI A119.1 Standard are included adjacent to each item on the electrical, plumbing and heating forms whenever possible for reference.

2.3.2 Photographic Documentation. To augment the inspection data and to provide a tool for future evaluation, a photographic record of each mobile home inspection was made. In addition to a photograph to identify the mobile home, photographs were taken of ANSI A119.1 Standard violations, component or system failures and any other unusual conditions related to performance that existed on the interior and exterior of the unit. 
2.4 MOBILE HOMES INSPECTED. A total of 257 mobile homes were field inspected, of which, 237 were HUD Hurricane Agnes units located at Wilkes-Barre. Since these units had been manufactured at approximately the same time and many were transported over unusually long distances and had been sited under emergency conditions, the field study was planned to include units from the private sector. Sources were sought which would allow access to a large number of units at a single location because of the difficulty of locating and arranging inspections of individually owned mobile homes. Also, it was desirable to have access to purchase specifications and maintenance records of any homes inspected.

A privately owned mobile home park was visited in Lexington Park, Maryland consisting of 25 new single wide units which had just been installed and occupied. These duplex rental units had been built to a specification established by the park owner and had unique construction characteristics. Each unit was divided into two living areas with separate bath, kitchen and sleeping facilities. Discussions with the owner and the park maintenance staff and the inspection of the only unoccupied unit revealed no special problems other than those of a routine maintenance nature.

Warren Air Force Base in Cheyenne, Wyoming was visited to obtain data which could be related to durability of mobile homes constructed in 1962 and 1965 . The maximum number of units deployed at Cheyenne was 246. The Air Force was in the process of moving these units to other sites. Four of the 94 mobile homes remaining at Cheyenne were given detailed inspections. Maintenance records for these 4 units, kept since purchase, were also obtained. These units which are being used as housing for families of construction personnel have each been moved 11 times over an average distance of 650 miles per move. The mobile homes were purchased under an Air Force specification and had been maintained for the Government by a private company. Construction characteristics appeared to be significantly better than present mobile home construction, possibly as a result of the unique Air Force procurement and manufacturing requirements.

A private mobile home park containing 200 mobile homes manufactured in 1971 and 1972 was visited in Montgomery, Alabama, and 11 units were physically inspected. These units were owned by the Alabama Farm Bureau (not state affiliated) and rented to Air Force personnel attending 12 week courses at Maxwell Air Force Base. In addition to inspection of these 11 units, maintenance records for one 12 week occupancy period were obtained for all 200 units.

Five mobile homes being modified under a HUD Grant for use by handicapped students were inspected at St. Andrews College in Laurinburg, North Carolina. These units were obtained by the College from the HUD Agnes stockpile and purchase, maintenance, and refurbishment data for the units were available.

\subsection{Characteristics of Field Inspected Mobile Homes}

3.1 MANUFACTURING CHARACTERISTICS. Table 1 identifies the twenty-two states where 188 of

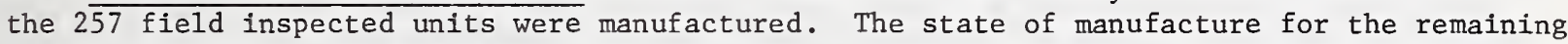
69 units could not be determined. Tables 2 and 3 indicate the year of manufacture and the width of all units in the field inspection study for which this data is available.

Pigure 1 describes the distribution of mobile homes by manufacturer for those units in the field study. The manufacturer was known for 232 units of the 257 units inspected. These 232 units were built by 80 different manufacturers with only 8 manufacturers supplying more than 6 units each.

3.2 ANSI A119.1 STANDARD COMPLIANCE DATA. Certification seals are attached to mobile homes by enforcement officials to indicate that construction of the unit complies with a prescribed code or standard. Seals were found on 173 of the 257 units in the sample. In this report, it is assumed that mobile homes with certification seals were constructed according to the ANSI Al19.1 Standard for Mobile Homes or a modified version of that Standard in effect during the year of manufacture. Table 4 presents the seal data for the field inspected mobile homes. 


\subsection{Data Analysis Methodology}

4.1 PROBLEM CATALOG DEVELOPMENT. Because of the large quantity of data being collected, it was necessary to develop a data handling system using computer techniques. The system devised consisted of a listing of performance problems, a coding technique to record the problems and computer programs to organize and present the data.

The Performance Problem List is organized around three major subsections and a miscellaneous subsection. The mobile home performance problems significant to the project are categorfaed under one of the three major subsections 11 sted below and indicated In figure 2.

\section{A. Problems Related to ANSI A119.1 Standard for Mobile Homes and Enforcement Process \\ B. Routine Maintenance Problems \\ C. Appliance and Equipment Problems}

This categorization of problems allows documentation of all mobile home performance problems encountered during the inspections.

The ANSI Standard A119.1/Enforcement Process Subsection represents virtually the entire 1974 edition of the standard [1], with coding symbols being assigned for appropriate paragraphs. In the case of the Plumbing (Part C), Heating (Part D) and Electrical (Part E), sections of the Standard, the paragraph numbers and key words appear just as they do in the Standard. Construction (Part B) differs in that it is organized around major construction components, such as roof, walls, doors, etc. Therefore, some Standard paragraph numbers which pertain to several components are repeated, $1 . e$., weather resistance. It should be noted that the problems reported under the ANSI Standard A119.1/Enforcement Process Subsection are related either to inadequacies or omissions in the Standard itself or to deficiencies in the Standard enforcement process. No attempt is made in this report to segregate the problems into these two areas. Such an evaluation will be made in a later report of this series where the significant problems will be examined in greater detail by considering all data accumulated in the project.

The Routine Maintenance Subsection is organized under the same general headings as the ANSI A119.1/Enforcement Process Subsection; i.e., construction, plumbing, heating and electrical. The Appliance and Equipment Subsection is grouped by appliance; i.e., furnace, range, hot water heater, refrigerator, exhause fan and smoke detector. Since components of each appliance are listed, it was possible to pinpoint the component problem where the detail of the data permitted.

A problem level concept is employed in the Performance Problem List to organize and assist in the evaluation of the data. Figure 2 illustrates problem levels 1,2 , and 3 and figure 3 isolates ANSI A119.1 (Construction) to illustrate levels 2 through 7. The problem summation lists in Appendix B show the problem level for each item in the last column and in some cases the problem list has been extended to an $8 \mathrm{th}$ leve1. It must be remembered, however, that the problem level concept was established as a tool to order the existing data and does not impart any degree of importance or significance to the individual problems as they relate to one another.

A coding system was developed which facilitated the rapid tabulation of mobile home performance problems. Each problem in the 1ist was represented by an alphanumeric code with which problems were entered by a reviewer on a computer coding sheet along with available identification information (manufacturer, size, year of manufacture, etc.) for each mobile home.

4.2 COMPUTER TECHNIQUES. Data processing programs were developed to process the data and to delineate problem areas. The most important of these was a program which printed out summation tables of the problems relative to the levels within the problem list (Appendix B). In addition, the program rank ordered the problems by "frequency-of-occurrence" within each 1 evel.

\subsection{Problem Summation Tables}

5.1 ORGANIZATION AND USE OF SUMMATION TABLES. Figures 4, 5 and 6 indicate the organization of the problem summation tables. 
Figure 4 - 1st through 3rd level grouping of problems Figure 5 - 2nd through 4th level grouping of problems Figure $6-2$ nd through 8 th level grouping of problems

Each grouping deals with the same problems but progressively more detail is shown in going from the first through the third grouping.

Columns labeled (A), (B), (C), (D), (Homes), (\% Homes), and (Level) in figures 4 , 5 and 6 are defined below.

Column (A) - The code assigned to identify a particular problem.

Column (B) - A brief description of the problem or area of concern including the appropriate part or paragraph number in the ANSI Al19.1 Standard.

Column (C) - The number of problems that have been coded with the code identified on that line in Column A. Reported information on the problem has not allowed coding below the level of detail of the particular line. For example, in figure 4, consider problem code NPL' (Plumbing - Routine Maintenance); 17 of the 216 problems were recorded under the general plumbing category, while problem description allowed the remaining 199 problems to be recorded with greater detail (See page 53 of Appendix B).

Column (D) - The summation of all problems at a discrete level. For example, Figure 4 shows that the total number of problems associated with Routine Maintenance is 934 which is made up of the following:

\begin{tabular}{lr} 
Construction & 550 \\
Plumbing & 216 \\
Electrical & 124 \\
Heating & 44 \\
\hline \multicolumn{1}{c}{ Total } & 934
\end{tabular}

The number of problems at a given level is the summation of problems at the next lower level. As an example, the number of level 1 problems (3528) consists of the following leve1 2 problems: 2120 ANSI A119.1/ Enforcement Process problems, 934 Routine Maintenance problems, 374 Mechanical/Electrical Appliance problems, and 100 Miscellaneous problems.

Column (Homes) - The values in this column indicate the number of mobile homes in the sample that had one or more of the problems identified on each line (235 mobile homes for Construction, ANSI A119.1/Enforcement Process, in fig.4).

Column (\% Homes) - The entries in this column Indicate the percentage of the total number of mobile homes reviewed in the sample which had the problem identified on each line. For example, under Construction, ANSI A119.1/Enforcement Process, in figure 4:

235 homes with problems $\times 100=91.4 \%$

257 homes in sample Column (Level) - These entries define the level of detail of the problem for each
line.

Columns labeled ( $\%$ 2nd) and (\% lst) in figure 4 are defined below:

In figure 4 consider the example of "Construction (CONS) - ANSI Standard Al19.1/Enforcement Process." 
Colum (\% 2nd) - The entrieg in this column are the percentages of 2nd leve1 problems that are contained at the third level of detail.

$$
\frac{\text { Leve1 } 3 \text { Problems }}{\text { Level } 2 \text { Problems }}=\frac{730}{2120} \quad \mathrm{X} \quad 100=34.4 \%
$$

Column (\% 1st) - The entries in this column are the percentages of 1 st level problems that are contained at each lower level of detall.

$$
\frac{\text { Leve1 } 3 \text { Problems }}{\text { Leve1 } 1 \text { Problems }}=\frac{730}{3528} \times 100=20.7 \%
$$

Columns labeled ( $\% 3 \mathrm{rd}),(\% 2 \mathrm{nd})$, and (\% 1st) in figure 5 are defined below:

In figure 5 consider the example of "Exterfor Walls (EXTW) - Construction - ANSI Standard A119.1/Enforcement Process."

Column (\% 3rd) - The entries in this column are the percentages of $3 r d$ level problems which are contained at each 4 th level of detail.

$$
\frac{\text { Leve1 } 4 \text { Problems }}{\text { Leve1 }}=\frac{237}{730} \text { Problems } \times 100=32.5 \%
$$

Column (\% 2nd) - Percentages relating 3 rd and 4 th levels to the 2 nd 1 level of detail.

$$
\frac{\text { Level } 4 \text { Problems }}{\text { Level } 2 \text { Problems }}=\frac{237}{2120} \times 100=11.2 \%
$$

Column (\% 1st) - Percentages relating 2nd, 3rd, and 4th levels to the first level.

$$
\frac{\text { Leve1 } 4 \text { Problems }}{\text { Leve1 } 1 \text { Problems }}=\frac{237}{3528} \times 100=6.7 \%
$$

Columns labeled $(\% 7 t h),(\% 6 t h),(\% 5 t h),(\% 4 t h)$, and $(\% 3 r d)$ on figure 6 are defined below.

In figure 6 consider the example of "Rain Leak at Membrane Joint (RLMP1.) - Roof System Construction, ANSI Standard A119.1/Enforcement Process."

Column (\% 7th) - Entries in this column are percentages denoting the portions of 7 th level problems for each 8 th level problem. This column is blank in figure 6 since there are no 8 th level problems shown on this sample table.

Columns (\% 6th) $,(\% 5 t h),(\% 4 t h),(\% 3 r d)$ - Entries in these columns relate the number of problems at a given level to preceeding levels $(6,5,4$ and 3 ).

$$
\begin{aligned}
& \frac{\text { Leve1 } 7 \text { Problems }}{\text { Leve1 } 6 \text { Problems }}=\frac{2}{7} \times 100=28.6 \% \text { (Column } \% \text { 6th) } \\
& \frac{\text { Level } 7 \text { Problems }}{\text { Level } 5 \text { Problems }}=\frac{2}{162} \times 100=1.2 \% \text { (Column } \% 5 \text { th) } \\
& \frac{\text { Level } 7 \text { Problems }}{\text { Leve1 } 4 \text { Problems }}=\frac{2}{184} \times 100=1.1 \% \text { (Column \% 4th) } \\
& \frac{\text { Level } 7 \text { Problems }}{\text { Leve1 } 3 \text { Problems }}=\frac{2}{730} \times 100=0.3 \% \text { (Column \% 3rd) }
\end{aligned}
$$


5.2 DISTRIBUTION OF PROBLEMS. The summation of all 3528 problems attributed to the 257 mobile homes inspected in the field survey is presented in Appendix B. These data are rank ordered at leve1 2 with $60.1 \%$ of the problems being ANSI Al19.1/Enforcement Process connected, 26.5\% related to Routine Maintenance, $10.6 \%$ included under Mechanical/Electrica1 Appliances and Equipment and $2.8 \%$ classified as Miscellaneous problems. These data are summarized in table 5 and the problems under these main headings are discussed below. The referenced photographs in Appendix $\mathrm{C}$ show construction details along with problems encountered.

5.2.1 ANSI AI19.1/ENFORCEMENT PROCESS RELATED PROBLEMS. Those problems that could be related to the ANSI A119.1 Standard/Enforcement Process category comprised $60.1 \%$ of the total problems. Of these 2120 problems, the rank ordered distribution as summarized in table 6 is 730 construction, 701 plumbing system, 409 heating system and 280 electrical system.

5.2.1.1 Construction. A rank ordering of construction problems through level 4 can be seen on page 39 with expansions to all levels tabulated on pages 42 through 44 . Table 7 shows the distribution of construction problems by building component. Of the 730 construction problems found, 32.5\% were attributed to "Exterior Walls" with a distribution as shown on table 8. Corrosion of exterior fasteners (durability) was the largest problem area (figures $\mathrm{C}-1, \mathrm{C}-2$ and $\mathrm{C}-3$ ) while weather resistance-rain leaks (figures $\mathrm{C}-5$ and $\mathrm{C}-6$ ) was second and wall cladding attachment (figures $\mathrm{C}-4$ and $\mathrm{C}-7$ ) was third. Other exterior wall problems are shown in figure $\mathrm{C}-8$.

The second most troublesome component was the "Roof System" which encompassed $25.2 \%$ of the construction problems. Of the roof problems, $88 \%$ were attributed to rain leaks, i.e., penetration of the water resistant membrane (see figures C-9 through C-18). In this context, the membrane is considered to be the metallic roof material and sealants that forms the covering for the roof truss structural system. Figures $\mathrm{C}-19$ through $\mathrm{C}-28$ are examples of roof construction and some of the problems encountered.

"Partition Walls" at $16.4 \%$ (fig. C-29 through C-33), "Transit Considerations" $11.4 \%$ (fig.C-34 through C-38) and "Floor Systems" 10.3\% (fig. C-39 through C-52) form the bulk of the remaining construction problems. The remaining $4.2 \%$ of the construction problems were attributed to "Exterior Doors," "Windows" and "Tiedowns" and are illustrated in figures C-53 through C-60.

5.2.1.2 Plumbing. The next category in order of frequency-of-occurrence was plumbing. Of the 2120 ANSI A119.1/Enforcement Process related problems, 33.1\% or 701 were attributed to the plumbing system (see table 6). A rank ordering of plumbing problems through level 4 can be seen on page 39 with expansions to all levels tabulated on pages 44 through 48. Table 9 summarizes the problem order. Of the 701 plumbing problems found, $31.0 \%$ were attributed to the "Water Distribution System" with the greatest single problem area being the water outlets and supply connections. These problems were concerned with the absence of adequate marking of the fresh water connection and the lack of a cap for sealing the water inlet. Other "Water Distribution System" problems had to do with water heater relief valves and outlets, figures C-62 through C-64, corrosion of piping, figures C-65 and C-66 and poor workmanship illustrated in figures $\mathrm{C}-61, \mathrm{C}-67$ through $\mathrm{C}-72$.

The second most prevalent plumbing problem area was with the "Drainage System", which encompassed $21.7 \%$ of the problems. The most frequent problem encountered was the absence of quick disconnect couplings for the drainage system. This violation should not be considered serious due to the emergency conditions in Wilkes-Barre that necessitated "hook-up" expedience. Other drainage system violations can be seen in figures $\mathrm{C}-73$ and $\mathrm{C}-74$ where negative slopes of drain pipes are pictured.

In the "Plumbing Fixtures" section (20.4\% of problems), the most frequent violation was the inadequate floor connection of toilets, figure C-79. A submerged ball cock flushing device that could possibly allow flush tank water to back flow into the potable water supply is shown in figure C-78. Other problems were lack of watertightness of shower stall enclosures, figure $\mathrm{C}-32$; and poor access to hot water heaters, figures $\mathrm{C}-80$ and $\mathrm{C}-81$.

"Protective Requirements" were next in order with $7.1 \%$ of the plumbing problems. These were attributed to inadequate rodent resistance, figures $\mathrm{C}-47, \mathrm{C}-48, \mathrm{C}-50, \mathrm{C}-51$ and some freezing of pipes, figure $\mathrm{C}-75$. 
"Venta and Venting" related problems comprise 3.9\% of the plumbing problems. Vent ptpe penetration of the roofing membrane which do not extend above the roof by 2 Inehal al required by the ANSI A119.1 Standard can be seen in figures $\mathrm{C}-14$ and $\mathrm{C}-15$. The Standard requires vent cap to be removable without requiring removal of flashing from the roof. Figures $\mathrm{C}-76$ and C-77 are photographs of a vent cap which violates this requirement.

5.2.1.3 Heating. The next category in frequency of problem occurrence was "Heating Systems." Of the 2120 ANSI A119.1/Enforcement Process related problems, 19.3\% or 409 problems were placed in this category. A rank ordering of heating problems through leve1 4 can be seen on page 39 with expansions to all levels tabulated on pages 48 through 50. The "Heating System" category had only two main divisions, 1.e. "Piping Systems" with $51.3 \%$ of the problems and "Appliances" w1th $48.4 \%$ of the problems as shown in table 10. Piping systems could only be inspected at the furnace connection and uisder the mobile home. Piping system problems are illustrated in figures $\mathrm{C}-82$ through $\mathrm{C}-85$. The misuse of flexible piping and inadequate rodent resistance of floor penentrations were the most prevalent problems.

The "Appliance" section included the air distribution portion of the heating system. Deficlencles are shown in figures C-86 through C-89 where a varlety of problems concerning reglsters and risers are 1llustrated. Inadequate accesslbility to heat producing appliances constituted 50 problems that were mainly attributed to hot water heaters as shown in figures $\mathrm{C}-80$ and $\mathrm{C}-81$.

The remaining problems are shown in figures C-90 through C-94. The venting problems are violations of the ANSI A119.1 Standard (f1gures C-90 and C-91) but the location of the furnace thermostat (f1gure C-92) and the location of furnace registers (figures C-93 and C-94) are not violations in the strict sense but were prevalent enough to be considered omfssions in the Standard or poor construction practice.

\subsubsection{Electrical. On1y 13.2\% of the total ANSI A119.1/Enforcement Process problems} were electrical. Of these 280 electrical problems, 179 were categorized as "Wiring Methods," 36 were "Receptacle Outlets Required" and 19 were 1isted under "Materlals and Equipment." The remaining problems were attributed to Outdoor Outlets, Branch Circuits, Power Supply, Grounding and Bonding, and Lighting Fixtures. The rank ordering of electrical problems through the 4th level can be seen on page 39 with a further breakdown to succeeding levels on pages 50 through 52 . Table 11 summarizes these problem areas.

"Wiring Methods" deficiencies are illustrated in figure C-8 and figures C-95 through C-104. The greatest single problem was loose outlet boxes, fixtures and switch boxes. The most prevalent problem under "Receptacle Outlets Required" was simply the lack of, or Improper placement of, receptacle outlets. The "Materials and Equipment" violations were all attributed to the use of aluminum wire with switches and receptacles not approved for such use (f1gure D-107).

An example of properly grounded and improperly grounded pendant type light fixtures are lilustrated in figures $\mathrm{C}-105$ and $\mathrm{C}-106$. Figure $\mathrm{C}-107$ shows a load center of a $12^{\prime} \times 60^{\prime}$ mobile home with an Insufficlent number of branch clrcuits which constitutes an ANSI Al19.1 Standard violation.

5.2.2 ROUTINE MAINTENANCE PROBLEMS. The 934 problems classifled as Routine Maintenance are grouped as follows: 550 Construction, 216 Plumbing, 124 Electrical and 44 Heating. A rank ordering of Routine Maintenance problems through level 4 can be seen on page 40 with expansion to all levels tabulated on pages 52 through 54.

Problems in the construction area Included exterfor doors (244 or $44.4 \%$ of construction problems), windows (122 or $22.2 \%$ ), exterior stairs (41 or $7.5 \%$ ), partition doors (40 or $7.3 \%)$, skirting (32 or $5.8 \%$ ), hot water heater compartment (27 or $4.9 \%$ ) and blocking (20 or $3.6 \%)$. Predominate problems with exterfor doors included hardware, improper f1t, and glass breakage. Partition door problems were all related to hardware and improper fit. Window problems included reglazing, hardware, and improper fit causing water and air leakage. Hot water heater compartment problems included the lack of proper thermal insulation and repairs to exterfor access doors. 
The majority of plumbing problems were involved with water supply piping ( 79 or $36.6 \%$ of Routine Maintenance plumbing problems), fixtures (69 or $31.9 \%$ ) and drainage piping ( 30 or $18.1 \%$ ). Water supply piping problems were ranked as follows; general exterior piping (64) and exterior frozen piping (18). Other problem areas included leaking, clogged or frozen drains, faucet assembly and flushing device malfunctions, and the site water supply.

The 124 electrical problems were distributed as follows; distribution panel board (55 or $44.4 \%$ ), receptacle outlets (33 or $26.6 \%$ ), power pole/lifeline (18 or $14.5 \%$ ), switches (7 or $5.6 \%$ ) and exterior light fixtures ( 3 or $2.4 \%$ ).

The 44 heating problems consisted mainly of gas and oil supply piping concerns.

5.2.3 MECHANICAL/ELECTRICAL APPLIANCE PROBLEMS. The 374 problems in this area were separated by appliance type; furnace ( 181 or $48.4 \%$ of all Appliance problems), hot water heater (82 or $21.9 \%$ ), range (72 or $19.3 \%)$, exhaust fan (25 or $6.7 \%$ ), refrigerator (10 or $2.7 \%$ ), and smoke detector ( 2 or $0.8 \%$ ). A rank ordering of these problems through level 4 can be seen on pages 40 and 41 with expansion to all levels tabulated on pages 54 through 56. The major malfunctioning components of the furnace were the pilot (40), burner and blower controls (35), fuel gun (32), thermostat (21), and blower motor (4). Hot water heater problems were mainly with heating elements (electric), pilots (gas), and pressure relief valves. Pilot light, temperature control and gas leak problems were the major complaints attributed to ranges.

\subsection{Summary Comments}

A field inspection data collection effort has been described which had as its objective the identification of mobile home performance problems. These data will compliment the Task I performance data and allow a determination of the cause and consequence of the problems which will then be related to Standards, Enforcement and Durability aspects of mobile home construction. A unique interdisciplinary field inspection procedure was developed to efficiently accumulate problem data. Computer techniques were used to organize and assist in the evaluation of these data. The extensive photographic documentation presented in Appendix $C$ is valuable in this evaluative process.

It is important to keep in mind that the number of units included in the field survey is small when compared to the total number of mobile homes now being occupied in the U. S. This study concentrated on problems with mobile homes that owners may not have even realized existed and does not reflect the many cases where mobile home occupants have been satisfied with the performance of their units. 
References

1. Standard for Mobile Homes (NFPA 501B, 1973 and ANSI A119.1, 1974) are ava1lable from National Flre Protection Assoclation, 470 Atlant1c Avenue, Boston, Massachusetts 02210; Mobile Home Manufacturers Association, 14650 Lee Road, Chant1lly, V1rginia 22021; and the Traller Coach Association, 3855 E. LaPolma Avenue, Anaheim, California 92806.

2. Plelert, J.H., Greene, W.E., Skoda, L.F., Street, W.G.; Performance of Mobile Homes Data Acquisition and Analysis Methodology; NBSIR 75-641, National Bureau of Standards, Washington, D.C. 20234, February 1975. 
The authors are indebted to many persons for contributions and guidance that made this report possible. Special thanks are given to NBS staff members who participated in the regulatory and field inspection activity and provided invaluable assistance in the data reduction effort discussed in this report. Staff members from the Center for Building

Technology included R. Beausoliel, T. Ray, and W. Niessing. E. Budnick and J. Scott of the Center for Fire Research provided expertise in Fire Protection Engineering and $\mathrm{J}$. Peebles of Plant Division was responsible for the electrical discipline. M. Vogt of Technical Analysis Division prepared the computer programs used for data analysis. $J$. Finnan and $T$. Porter, working under outside contracts, provided valuable support to important project tasks.

The outstanding cooperation of John Gibson, Director of the Office of Emergency Preparedness (OEP) of the Department of Housing and Urban Development and his staff, both in Washington, D. C. and at Wilkes-Barre, Pennsylvania, contributed significantly to the success of this project. Mr. James McCollom of HUD, Office of Policy Development and Research provided liaison between NBS staff and OEP operations personnel as well as valuable technical advise resulting from a previous HUD study of the Hurricane Agnes mobile homes.

A special thanks is due to those private and governmental organizations which provided mobile homes for field inspection at various locations around the country. 
TABLE 1

Number of Un1ta vo. State of Manufacture

Fleld Data

No. of Units

Alabama
Arkansas
Florida
Georgia
Illinois
Indiana
Kentucky
Maryland
Michigan
Minnesota
Mississippi
Missouri
North Carolina
North Dakota
Ohio
Pennsylvania
South Carolina
Tennessee
Texas
Utah
Virginia
Wisconsin
Unknown


Table 2

Year of Manufacture vs. Number of Units

\begin{tabular}{|l|r|}
\hline Year & No. of Units \\
\hline & \\
1962 & 2 \\
1965 & 2 \\
1971 & 7 \\
1972 & 154 \\
1973 & 1 \\
Unknown & 91 \\
\hline Tota1 & 257 \\
\hline
\end{tabular}

$\underline{\text { Table } 3}$

Width vs. Number of Units

\begin{tabular}{|c|c|}
\hline Width & No. of Units \\
\hline 10 foot & 2 \\
12 foot & 255 \\
\hline Tota1 & 257 \\
\hline
\end{tabular}


TABLE 4

Seals of Certifying Agencies

Field Data (257 Units)

Agency Type of Agency

Number of

Seals

$\begin{array}{llr}\text { Alabama } & \text { State } & 40 \\ \text { Florida } & \text { State } & 2 \\ \text { Georgia } & \text { State } & 5 \\ \text { Mississippi } & \text { State } & 3 \\ \text { Tennessee } & \text { State } & 7\end{array}$

TOTAL STATE

57

Nationwide Consumer Testing Lab Third Party 3

Underwriters Lab

Third Party

10

TOTAL THIRD PARTY 13

MHMA/TCA $1 /$

Trade Association

137

TOTAL TRADE ASSOCIATION

137

OVERALL TOTALS

207 (173 units)

Units With No Seals Attached ${ }^{2 /} 84$ TOTAL SEALS ${ }^{3 /} 291$

1/ Trade Association - Mobile Home Manufacturers Association and Trailer Coach Association.

2/ Field Inspection revealed no attached seals.

3/ Exceeds 257 field inspected units because some units had more than one seal. 


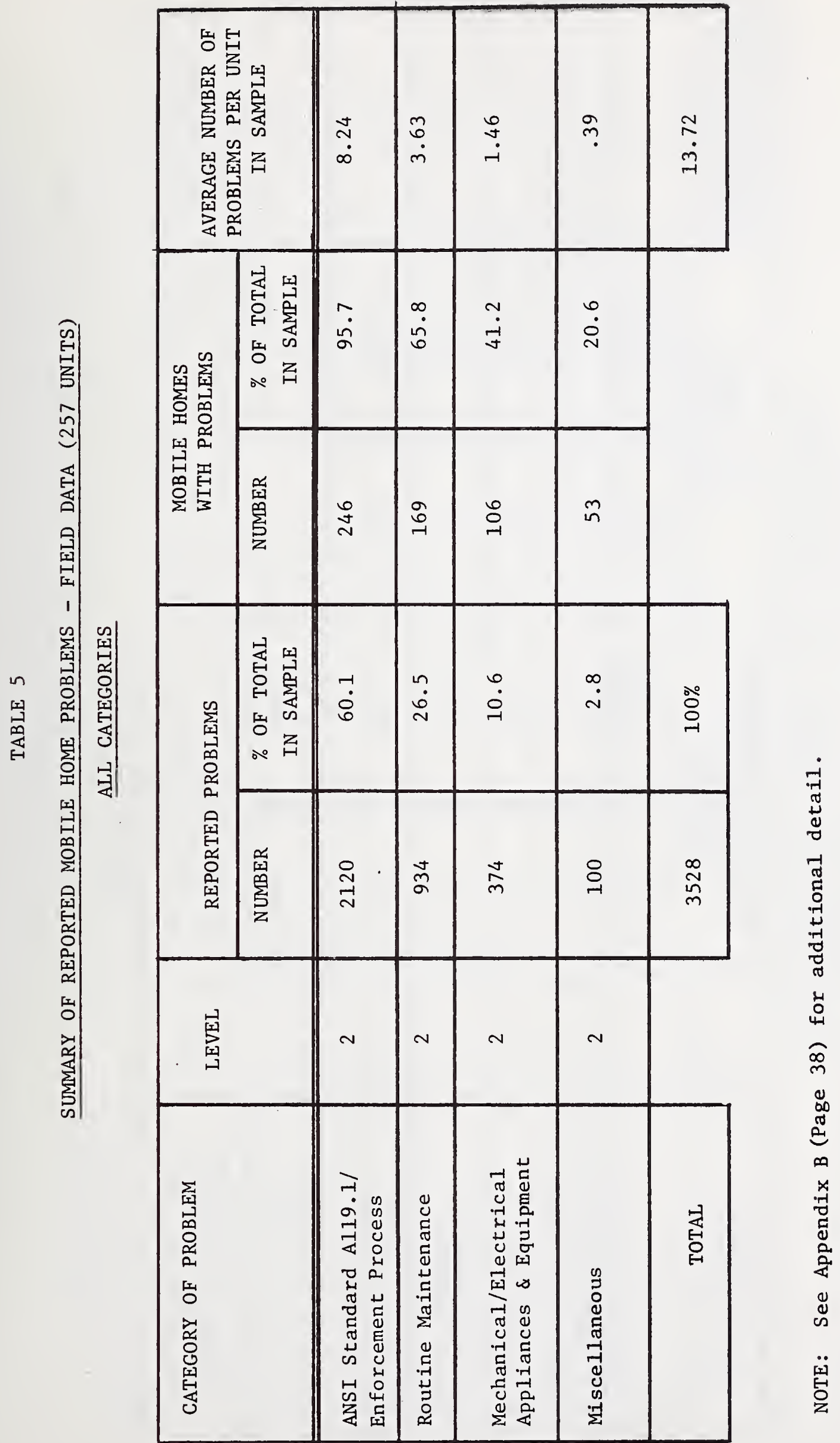




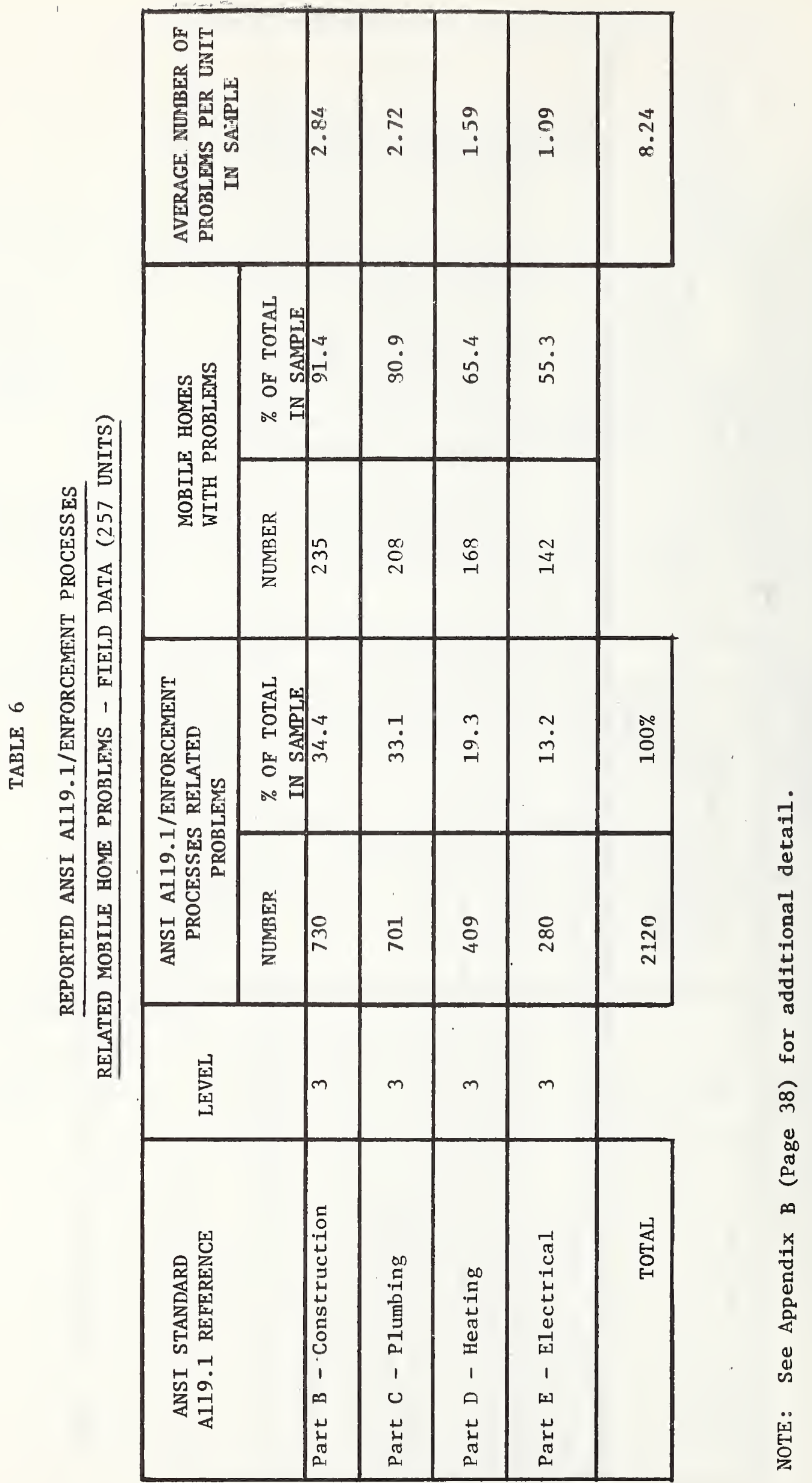




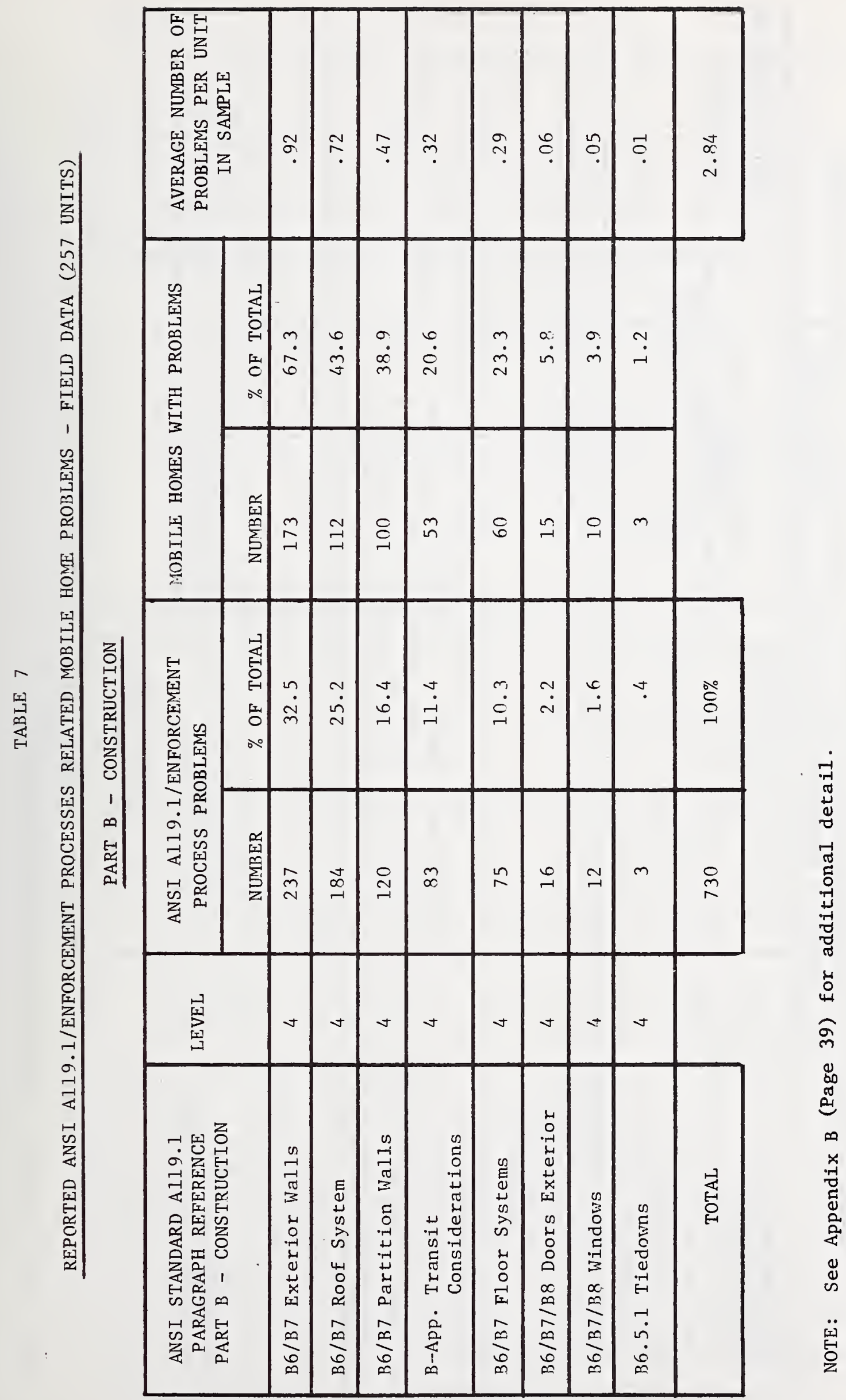




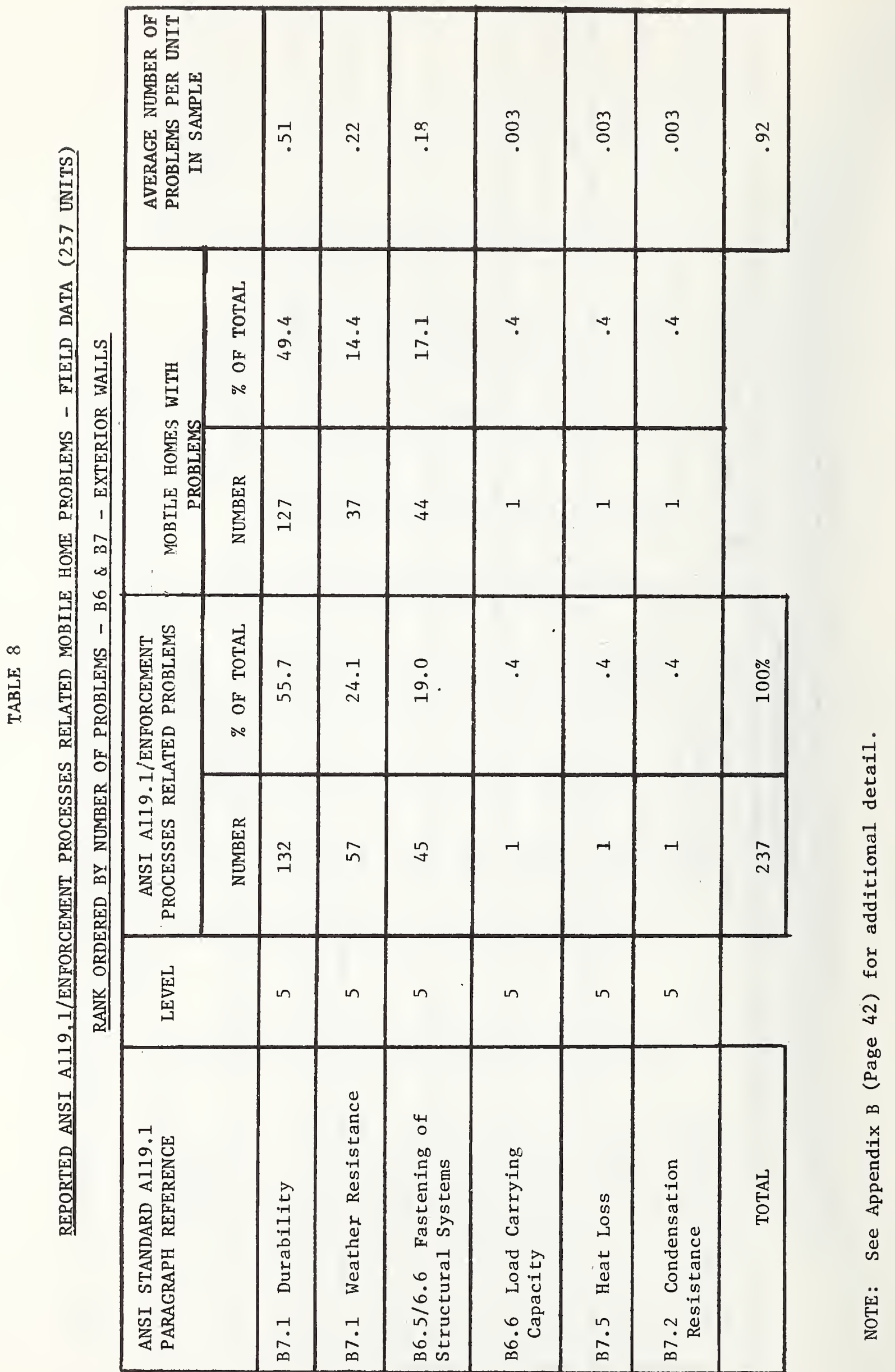




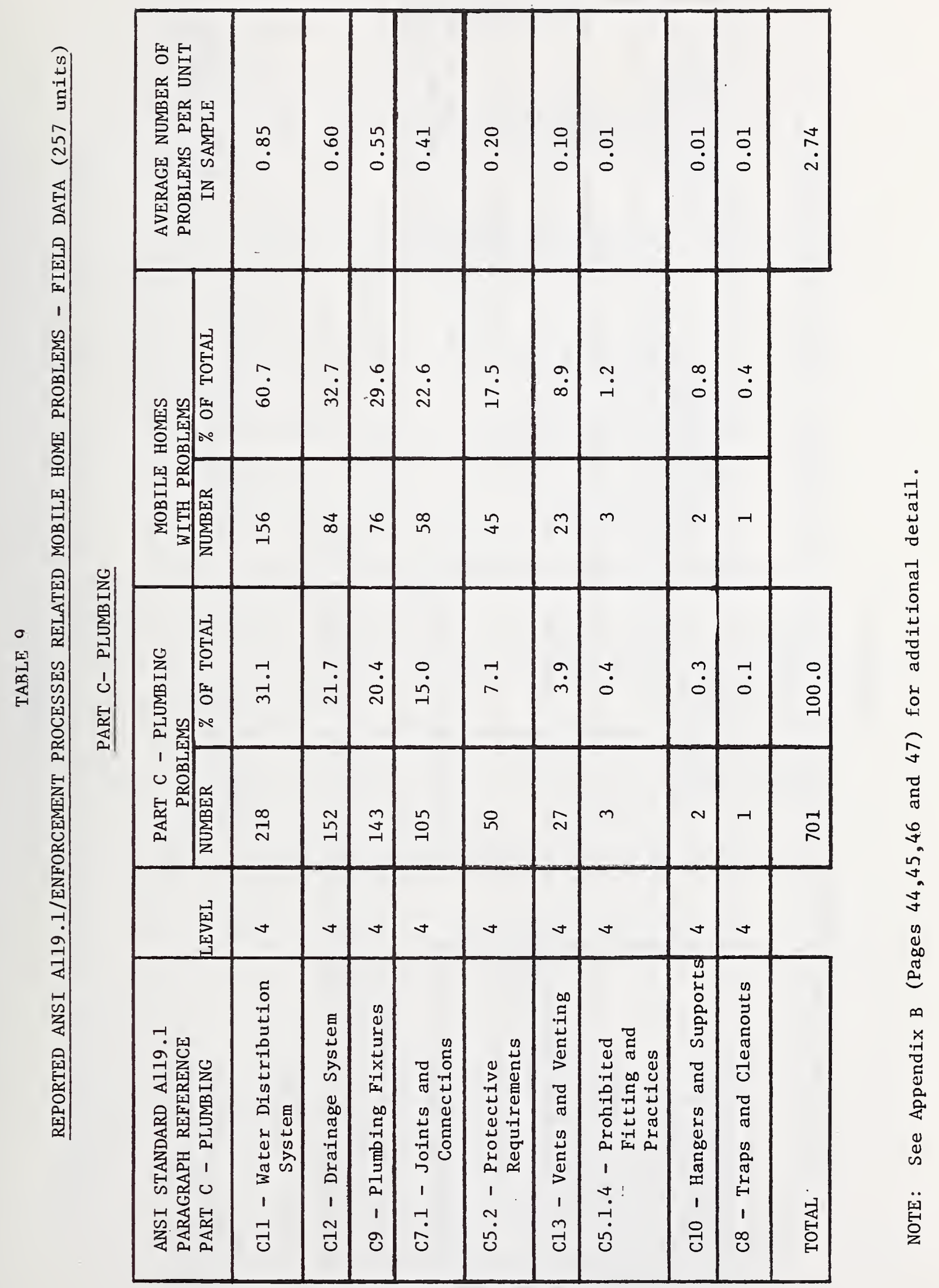




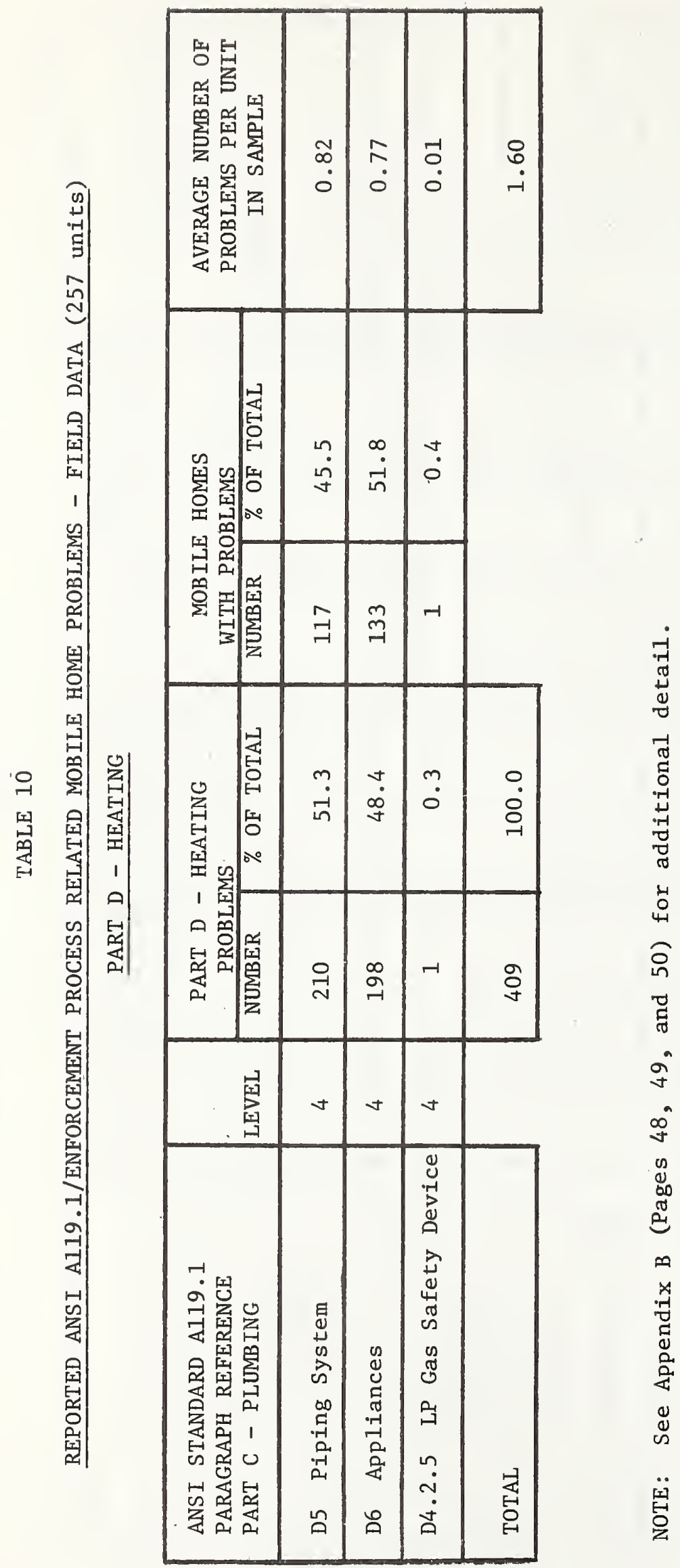




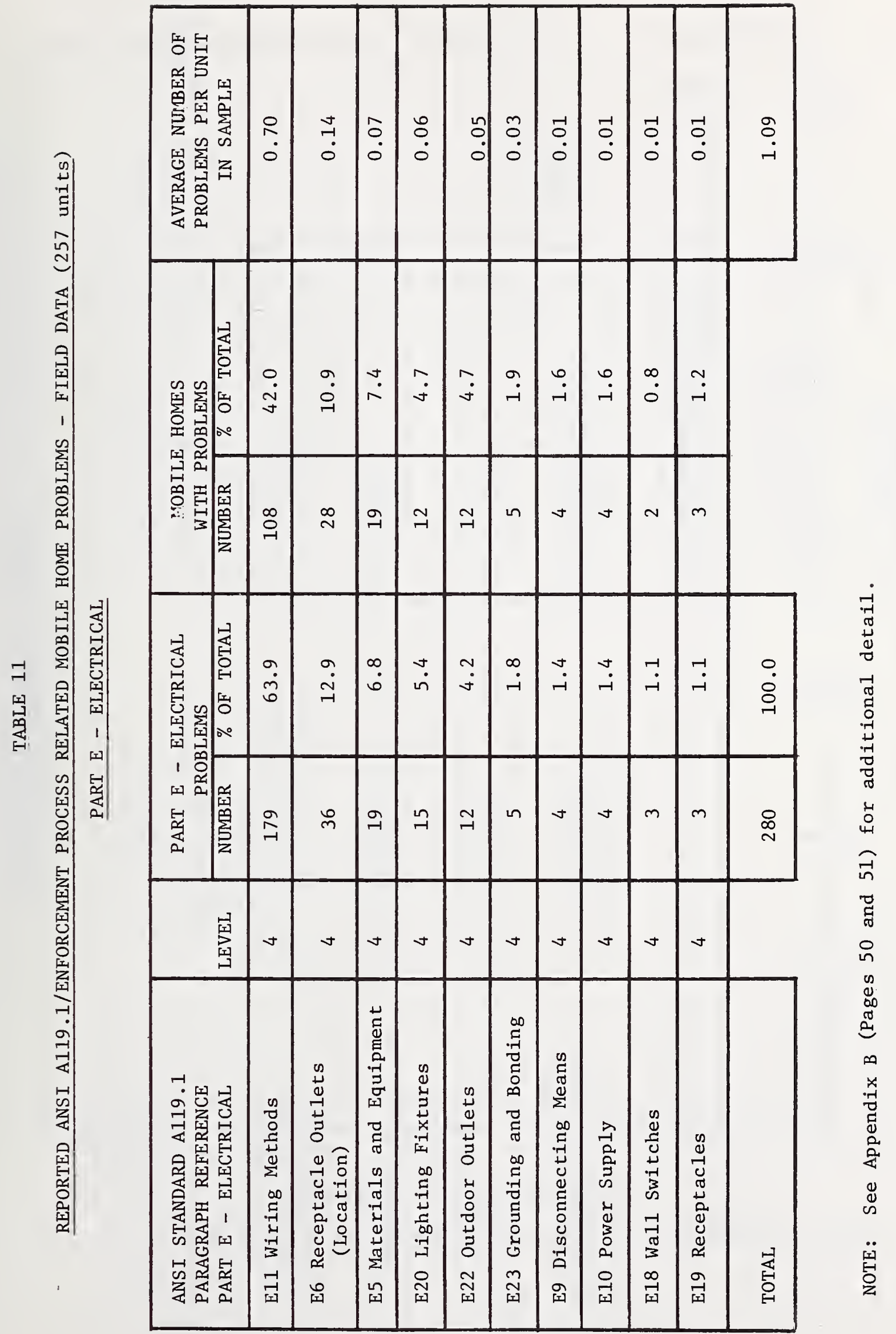




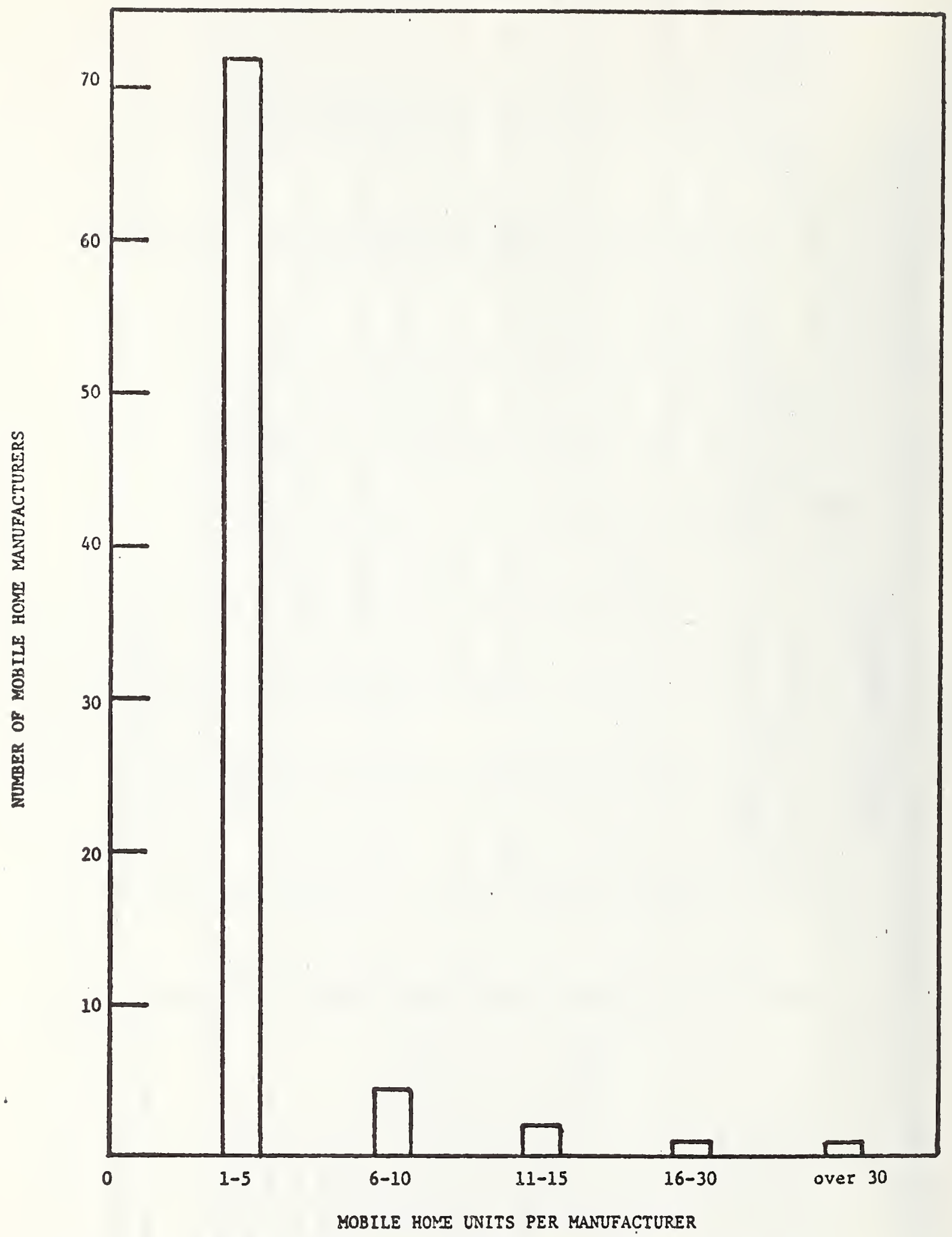

Eigure 1 - Distribution of Moblle Homes by Manufacturer In Fleld Study 


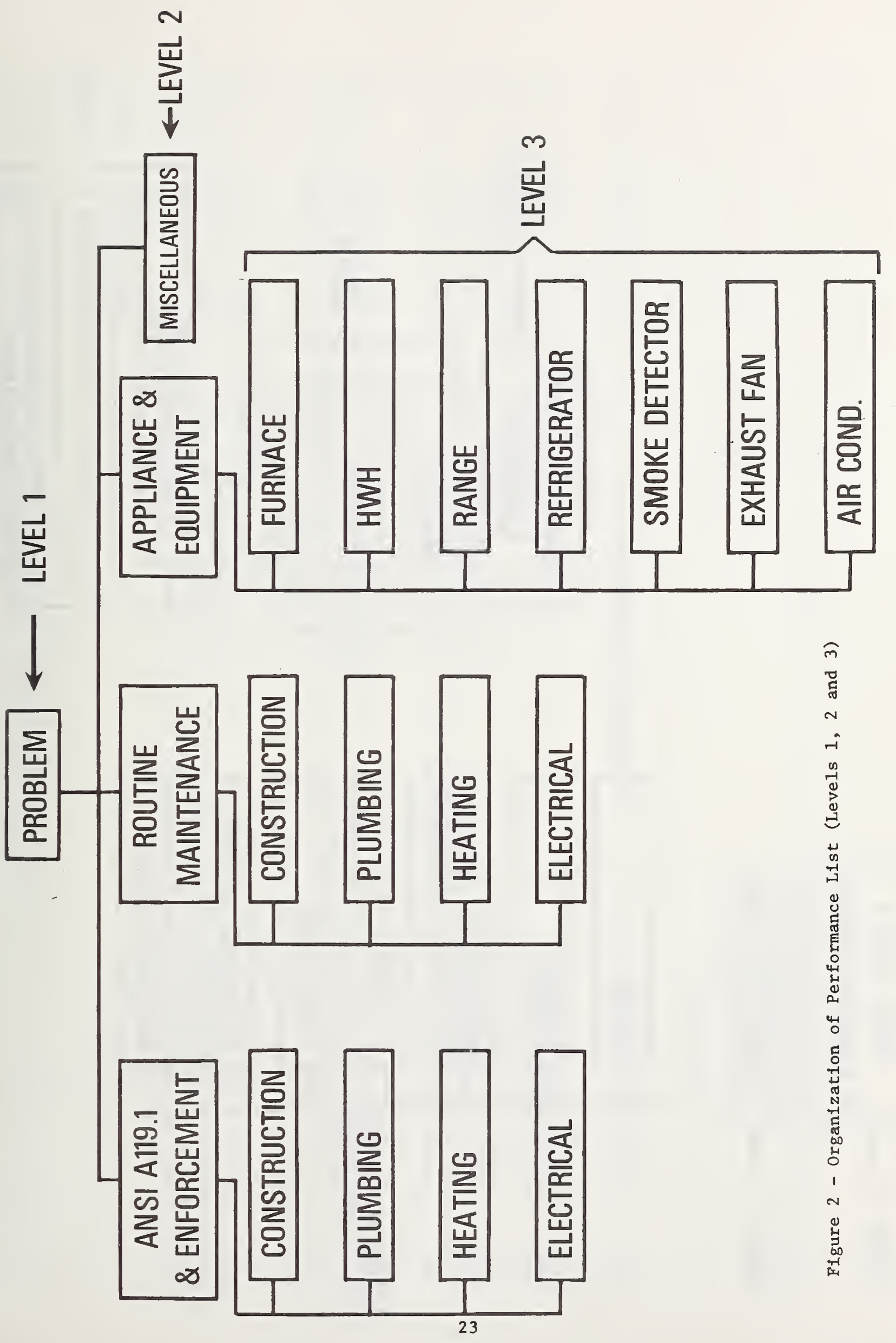




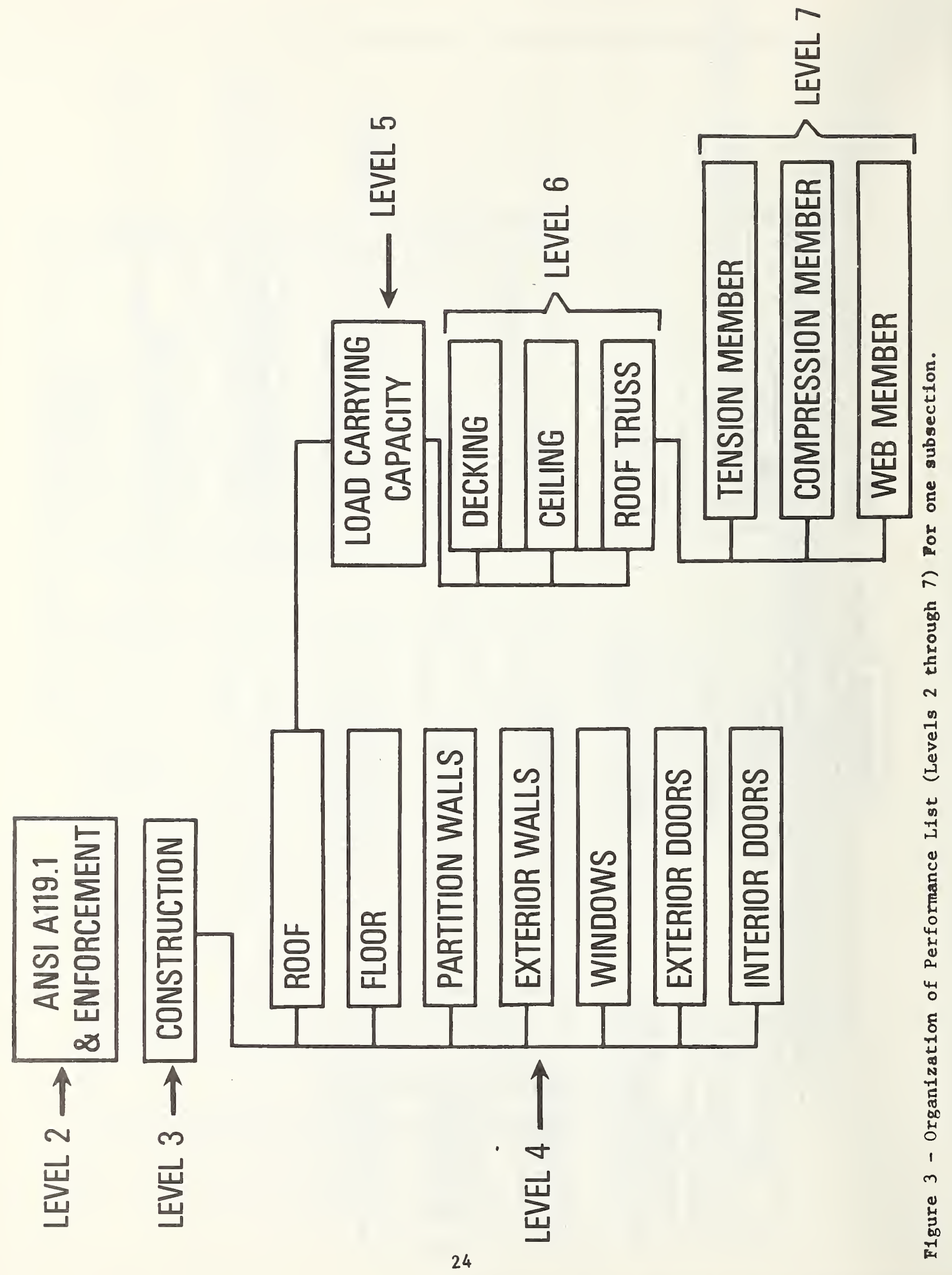




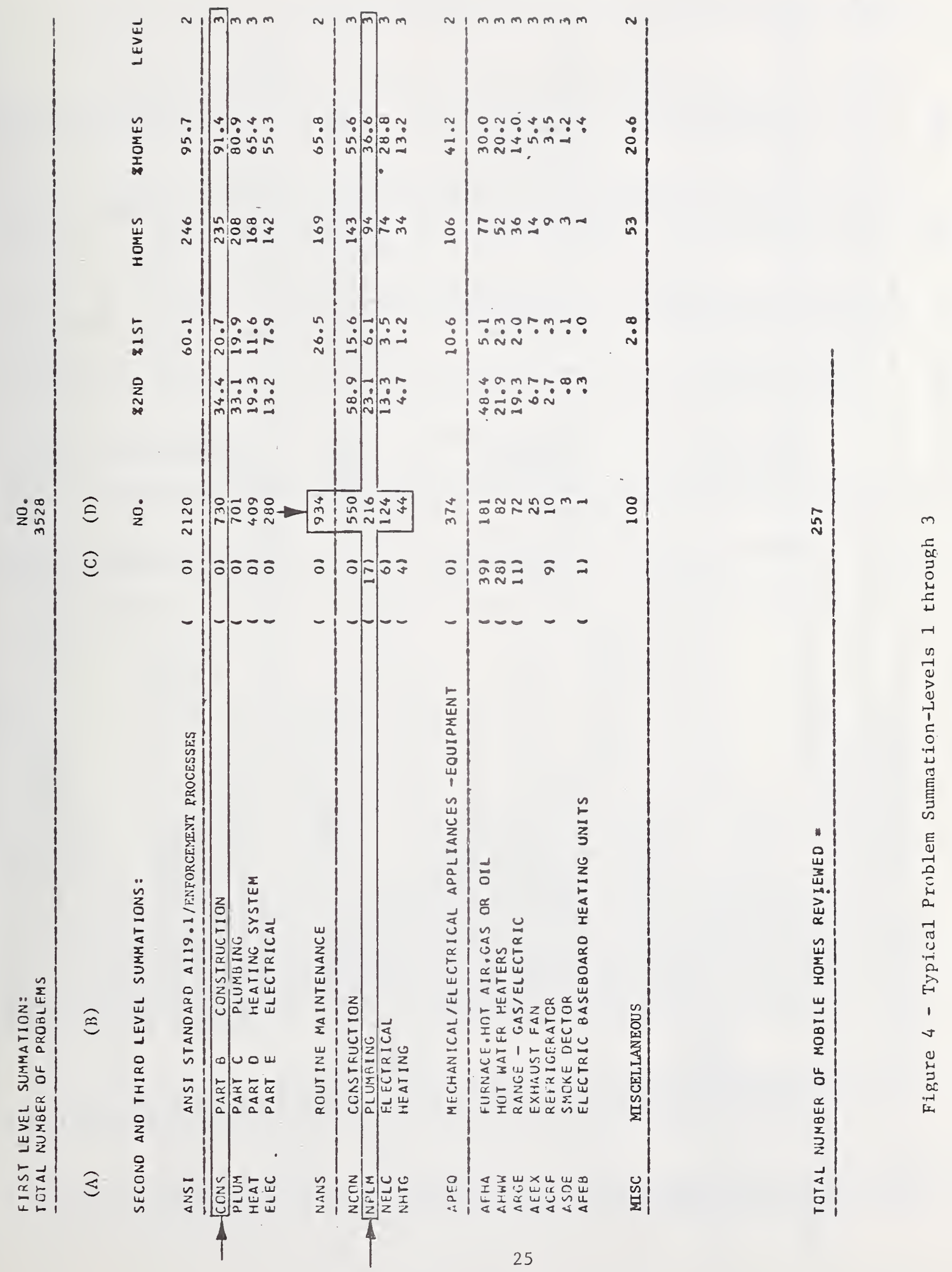




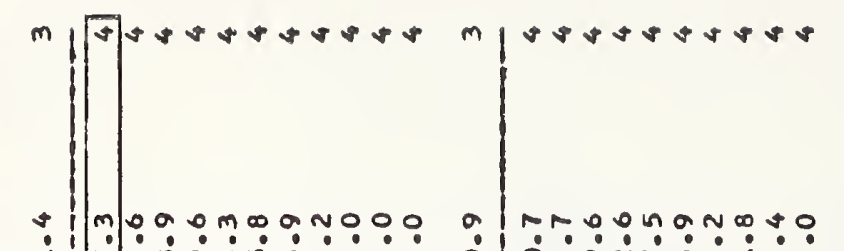

-

வ

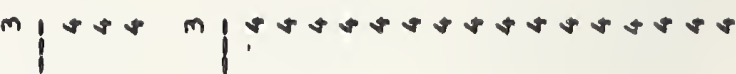

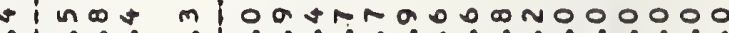
กิ กิ ที่

n momonomooo

$\stackrel{n}{\sim} N \cong 0$ in

osominmmato

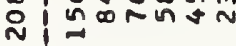

$\infty n$

$\sum_{0}^{\infty}: m_{-1}^{m}$

$\sim$ mannM $n$ Nmo 00000<smiles>[Mg]=C1CCCCC1</smiles>

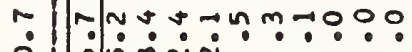

$\because \div m \div 0 \div \div \div \div 00$

0,000

$\because \rightarrow 0 n \div m \rightarrow \because \neg \neg \div 000 ? 00$

D

$* \because \div \because 0 n \infty 0 \div 0 \% 0$

$m$

- $m$ mino

$\because m \sim \because 0 \div m \because \div 00$

$m$ O OND U N

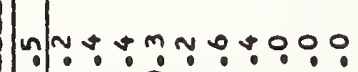

Niñ

ㄴm

$m i m \infty$

in

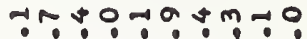
m

- DNmnONmna

- $\operatorname{Nin}^{2} \pm 0$

- 010000500000

o)

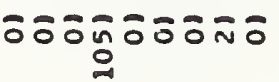

$-1-\infty \cdots-\infty$

$-$
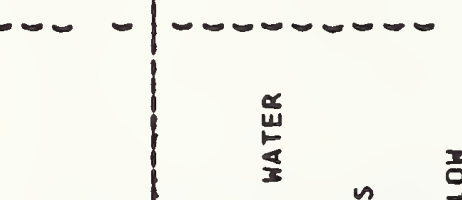

$\sum_{0}^{n}$

$\sum_{0}^{n}$

ปูป ํㅕㅁ

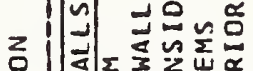

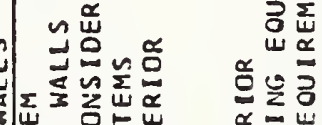

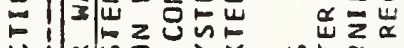

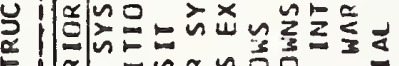

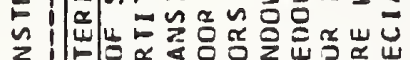

z |

$\mid$

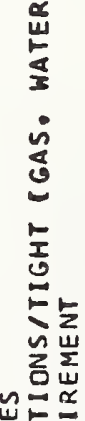

药

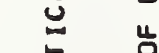

m

- 1 in

-

$m$

$\min$

$\sin _{0} \sin m \leqslant \rightarrow 7000000$

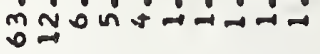

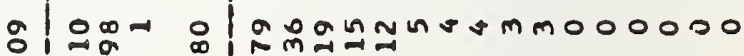

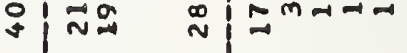

o - o-

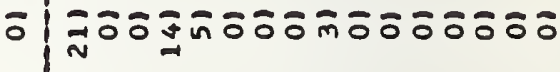

$-\infty$

$-$

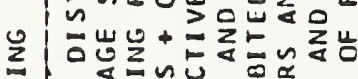

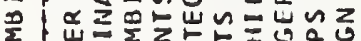

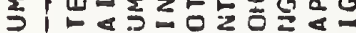

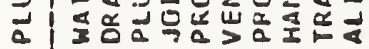

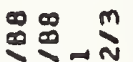

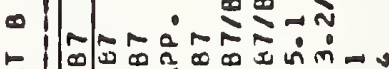

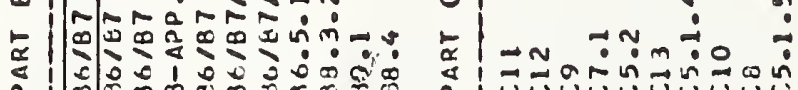

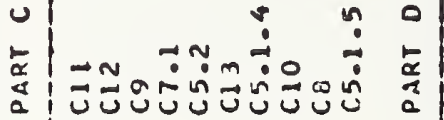

药

选

- : ONm o o a nms n

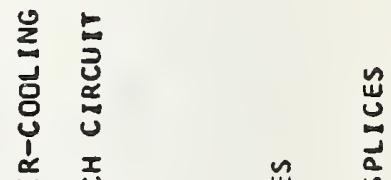
c

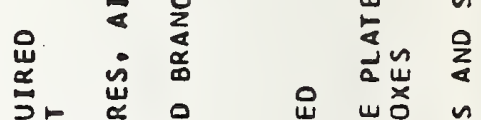

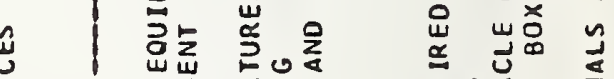

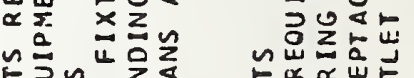

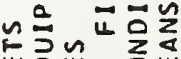

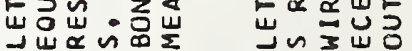

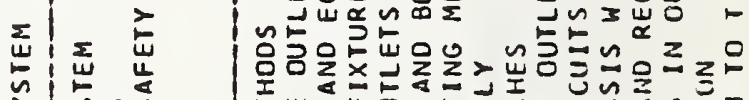
$\approx 1 \pi n \backsim$

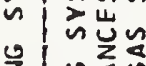
2)

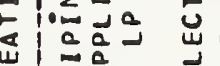

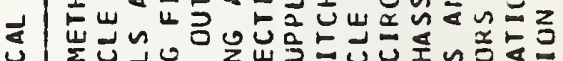

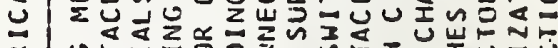

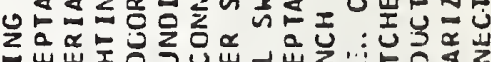

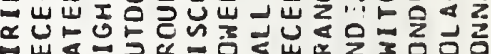

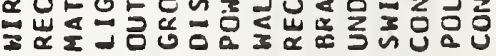
○อำ

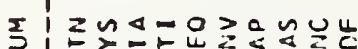

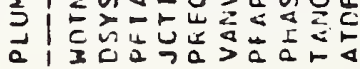

¿ 更a

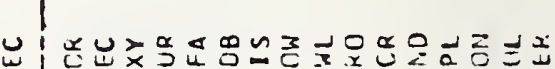

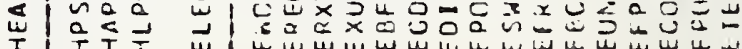

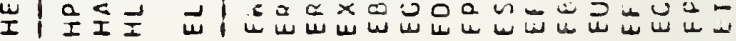


m t ano

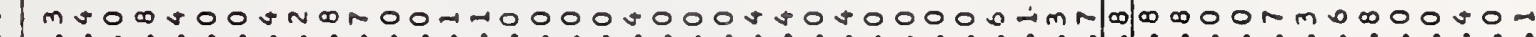

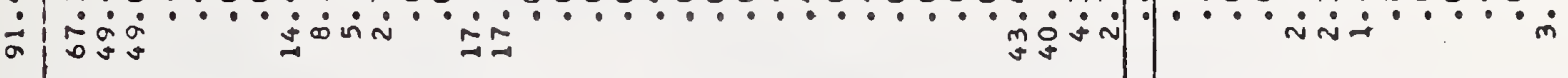

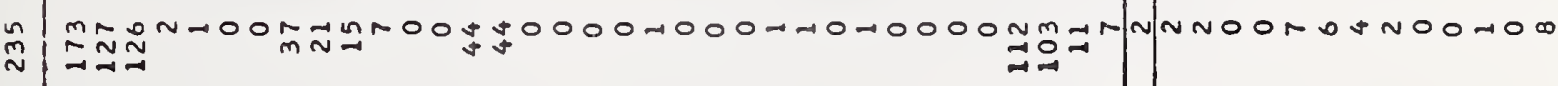

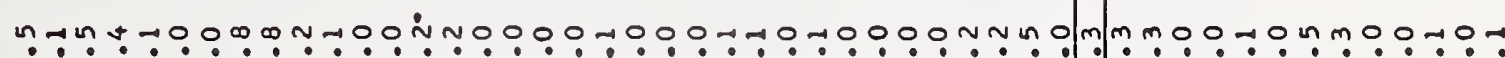
imin

ก.: nี่

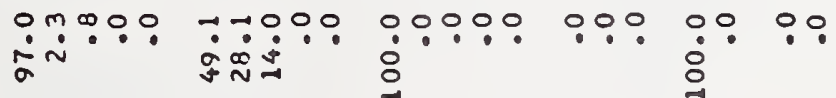

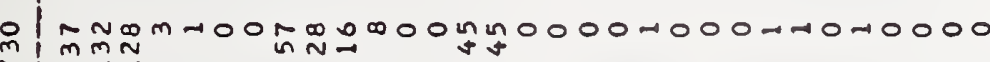

$\stackrel{m}{\sim} \underset{\sim}{m} \mathbb{N}$

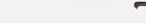

\section{$\overline{0} \overline{0}$ \\ in \\ $\overline{0}$

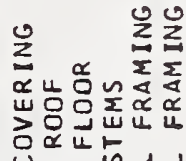 \\ .

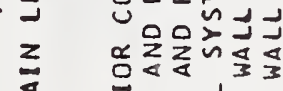

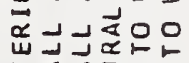

$=0$

|

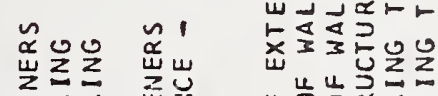

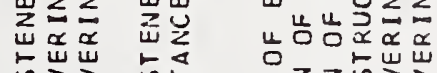

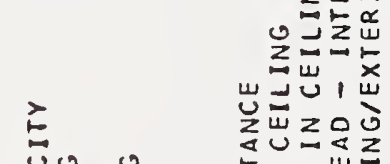

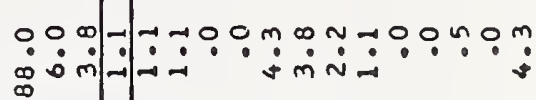

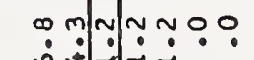

$\operatorname{no0} 0.00$

$\dot{0}+1 \div \div$

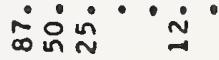

$0: 00$

$\stackrel{\infty}{\infty}$

$\because \because ?:$ $\sim \sim \sim$

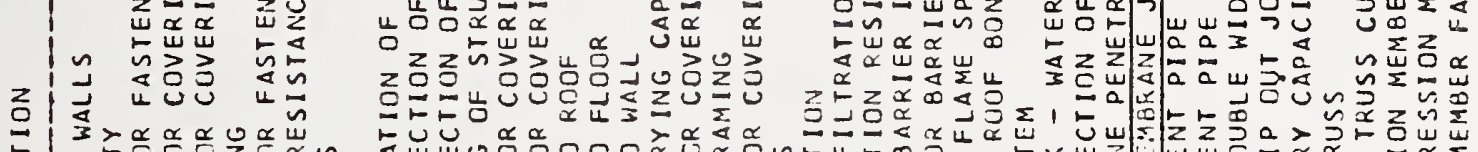

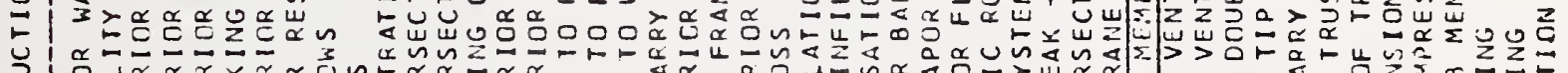

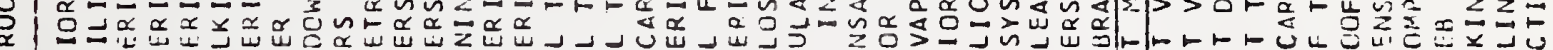

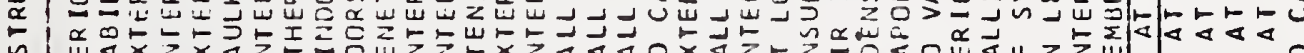

\section{0} வ0்0்

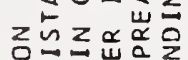

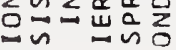
$\rightarrow$ 
Appendix A

Field Inspection Forms 
HUD No.

Date of Inspection

\section{Construction Data}

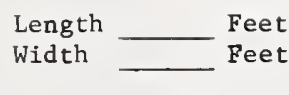

Manufacturer
Mode1
Serial Number

Year

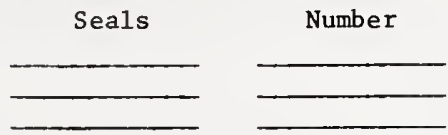

1. Under Frame

Number of Axles

Type of Outrigger

Z Mẹmber

C Member

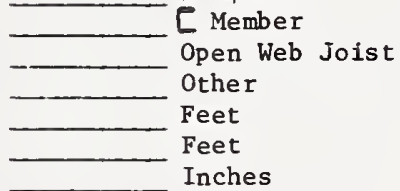

Outrigger Spacin

Beam Spacin

Long Beam Depth

Inches

Metal Under Frame Damage

Moisture Barrier Damage

Hurricane Straps

Number

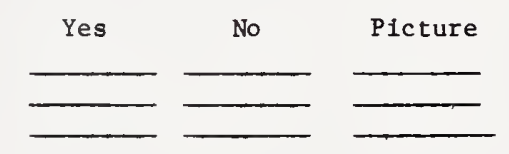

2. Wa11 Framing

Exterior Wall

Interior Wall

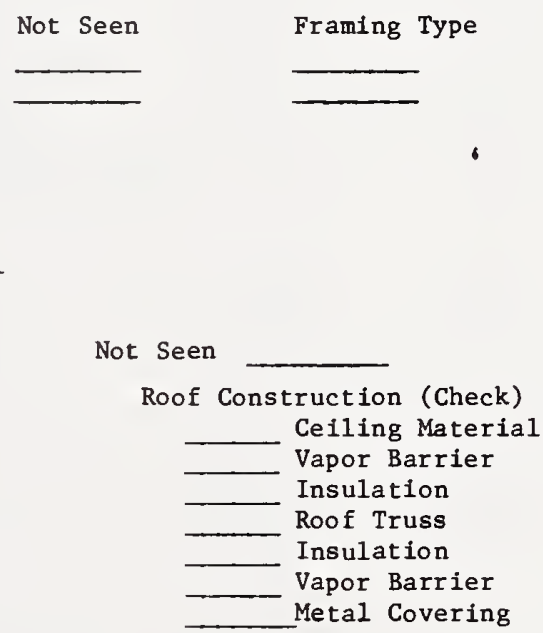

5. Flame Spread

Ceiling

Gypsum Bb .

Veg. Fiberbd.

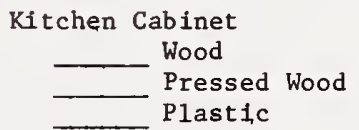

Paneling

Fire Rated

Not F.R.

Flame Spread
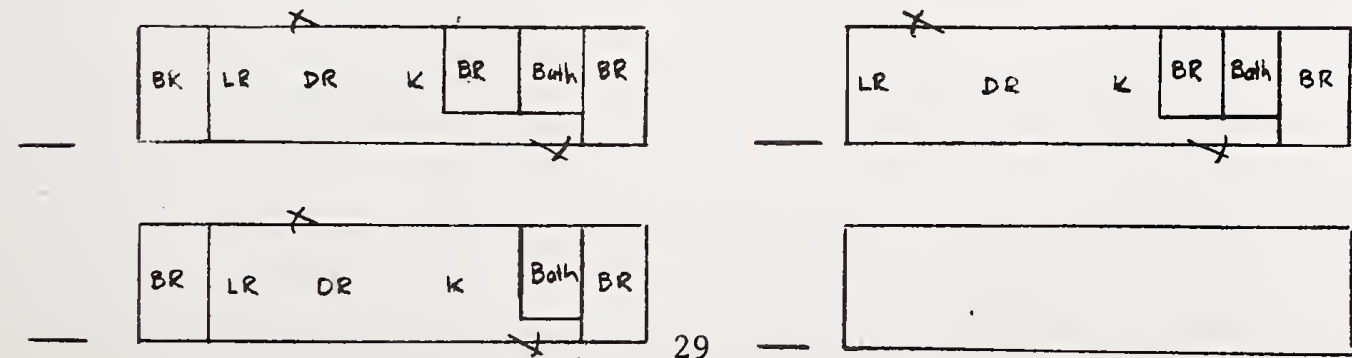
6. General
Rusted Exter1or Fasteners
Yes No Picture
Interior Rain Leaks
No Picture
Emergency Egress Window
Good (No obstructions)
Bad (Obstructions)

Comments: 
HUD No.

Date of Inspection

\section{Electrical Data}

1. Distribution Panel Box (Part E-9 - 10)

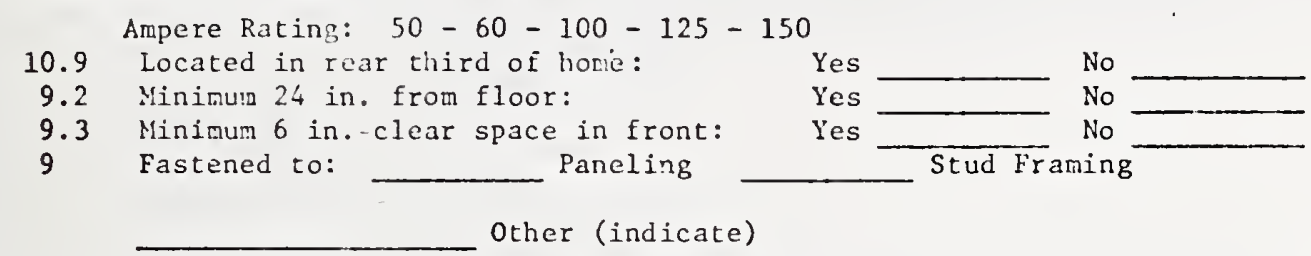

2. Type of Wire: Copper Aluninum $\mathrm{Cu}$ Clad Aluminum

3. Branch Circuits (Part E-7)

4-15 Amp. Circuits: Yes

2-20 Amp. Circuits: Yes

No

No

4. Receptacle Outlets Required (Part E-6)

Receptacles Approved for wire used:

6.1 Naximum 12 foot spacing:

6.1a. Counter tops in kitchen:

$6.1 \mathrm{~b}$ Adjacent to refrigerator and range:

6.1c Built-in vanities:

6.1d Counter tops under all cabinets:

6.2 Within/adjacent shower/tub space:

Outside Fixture: Yes ___ No ___ Weathertight: Yes _ _ No

Yes No

5. Wiring Methods (pari E-11)

11.3 Nomet. cable with nomet. boxes:

11.4 Outlet boxes flush with surface:

11.5 Boxes securely fastoned:

11.6 Continued sheath between boxes:

11.7 Cable thru studs protected:

11.9 .Cable supported within 12" boxes, etc.:

11.10 Support nonmet. cable $8^{\prime \prime}$ :

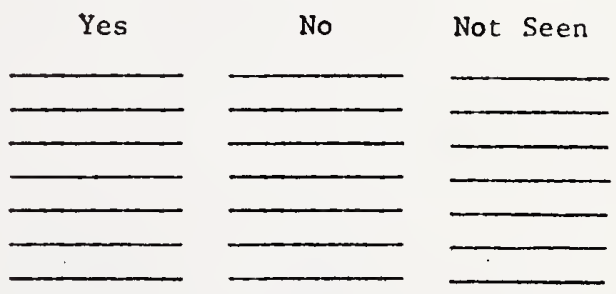

Lighting Fixture (Part E-20)

Celling fixture securely fastened: Yes

No

6. Hot Water Heater Enclosure

A. Accessibility: Good Interfor

Bad Exterior

B. Enclosure Construction Unfinished (backside of paneling, exposed studs) Paneled - Thickness Gypsua hallboard - Thickness Insulation - Foil backed

Cable across hilil door: Yes No 
7. R.1119:0

Name Brand

llodel nio.

Fuel

Clearances:
8. Mufrinuilfue

Name Brand

Sludel No.

Naturil

Uverhead DLsance to Cibinets

Exhaust hood (lics or No)

Charring of adjacent cabinets: les

No

\section{Corments:}


1. Heating System

Name Brand

Model No.

Fuel Type

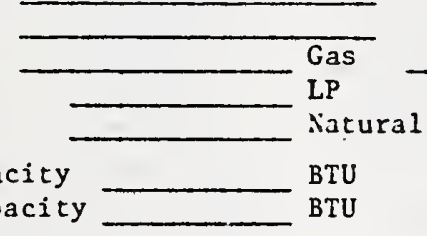
011 Electric

Input Capacity

Output Capacity BTU

\section{Heating Unit Enclosure Construction}

Unfinished (backside of paneling, exposed studs) Paneled - Thickness

Gypsum Wallboard - Thickness

Insulation - Foil backed

Certificate: Yes

Where:

No Furnace Company Electric Panel others

Wall thermostat

$3 \mathrm{ft}$. or more from furnace

Floor register w/dampers

Smooth riser connection

(5.1.1.1) Combust. intake rodent proof $(6.4 .2 b)$ Drafthood allgned \& secured

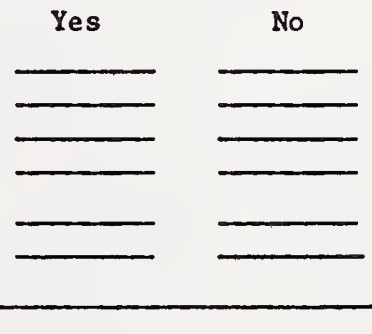

Plpe material and size

Fitting material

2. Fuel Burning Appliances

A. Information on clearances, Input, etc., attached to appliance $(6 \cdot 6.1)$

B. Type of fuel marked on each fuel burning appliance (6.6.2)

C. Appliance accessible for Inspection, repair, replacement w/o removing construction $(6.7)$

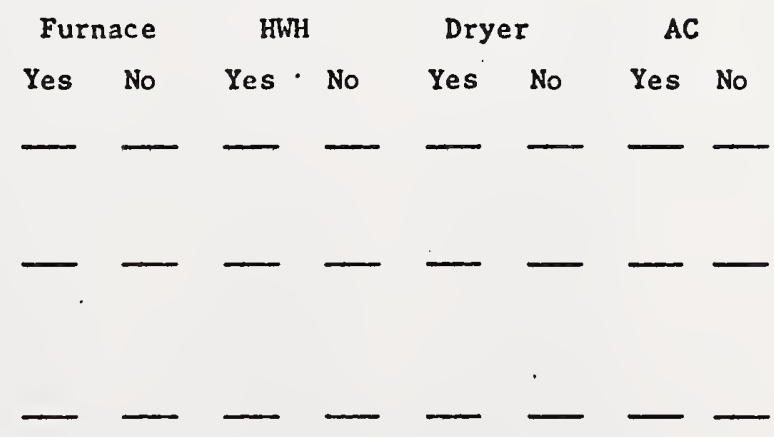


3. LP - Natural Gas Pinlng

(5.1.10.1) Supply location on "A" frame 18 " from roadside

(5.1.11) Metal tag at gas supply con.

(5.1.2.2) Alum. connectors used ourdoors

(5.1.16) Gas plping used for electrle ground

$(5.1 .18)$ Adequate pipe hangers d'supports

4. Outside Vencinz

Furnace vent roof jack

Secured

EWH drafthood allgned/secured

Roof jack secured

Veat terminating under mobile home

$3 \mathrm{ft}$. or more from air Intake

Cooking App1. vent within $10 \mathrm{ft}$.

Wa11

Celling

Attic vents

Eaves

Roof

Roof Jack secured

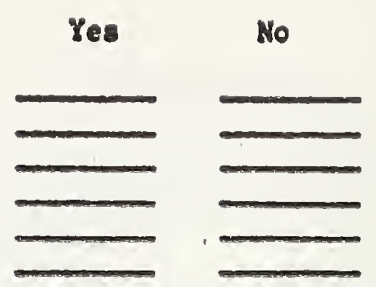

No Roof Inspect 1on

No Not Seen

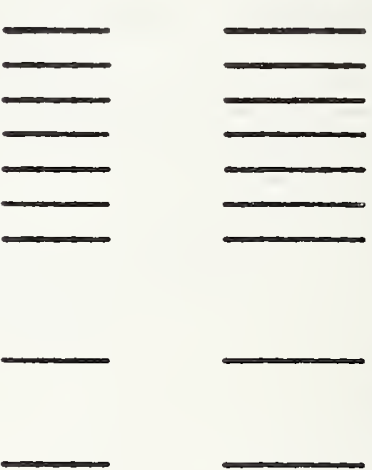

\section{Comments:}


1. Approved Materials (Table C-l Appendix C)

DWV Piping

Water Piping

Valves

Water Closet

Lavatory

Bath Tub

Kitchen Sink

2. Plumbing Facilities

At Least One Water Closet

At Least One Lavatory

At Least One Kitchen Sink

Adequate Washer Drain

Adequate Washer Water Supply

Accessible Facilities

3. Water Distribution (Part $\mathrm{C}-11$ )

Minimum Size Piping (11.1.1)

Proper Water Connection Location

(11.2.1)

Cap and Chain

Tagged

Minimum Size

Backflow Protection (11.2.2.1)

Adequate air gaps (11.2.3)

Anti-siphon Ball Cock (11.2.6)

Dishwasher $(11.2 .4)$

Clothes Washer $(11.2 .4)$

\section{Types of Piping Materials}

Copper

Galv. Street

Plastic

Indication of External Corrosion Indication of Frozen Water Piping

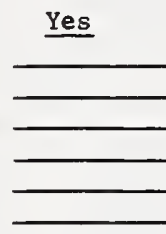

Yes

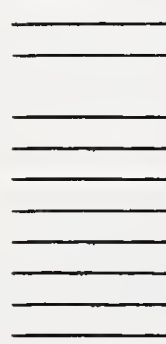

Location

Location

Location
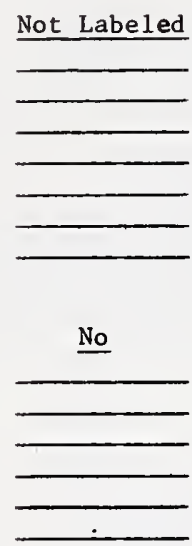

№

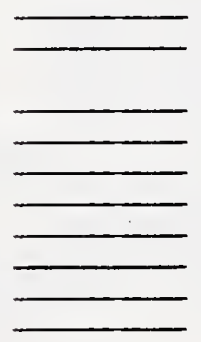

Not Seen

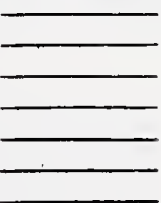

Missing

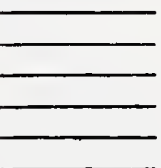

Not Seen

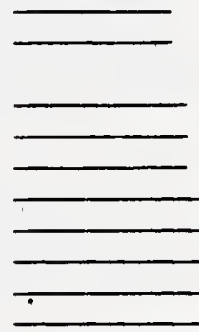

4. Hot Water Heater (11.3)

Gas

Interior Access

Exterior Access

Not Accessible

Missing

Labeled Heater

$\underline{\text { Ye8 }}$

No

Valve(s) T\&P Relief (11.3.1.1)

Approved \& Listed T\&P Valves

$(11.3 .1 .1)$

Proper Location T\&P Valves

(11.3.1.2)

Proper Location Relief Valve

Drain (11.3.1.3)

Threated End (11.3.1.3)

Terminated in floor

5. Drainage System (Part $\mathrm{C}-12$ )

Drain Outlets

Drain Outlets

Proper Location (12.2.1)

Eroper Clearance (12.2.2)

Hose Coupler (12.2.3)

Cap and Chain (12.3.3)

Min. Outlet Size (12.3.3.3)

Proper Trap Arm Length (12.5.3)

Adequate Traps (8.1)

Clean Outs ( 8.2$)$

Trap Arm Grade (8.1.9.1)
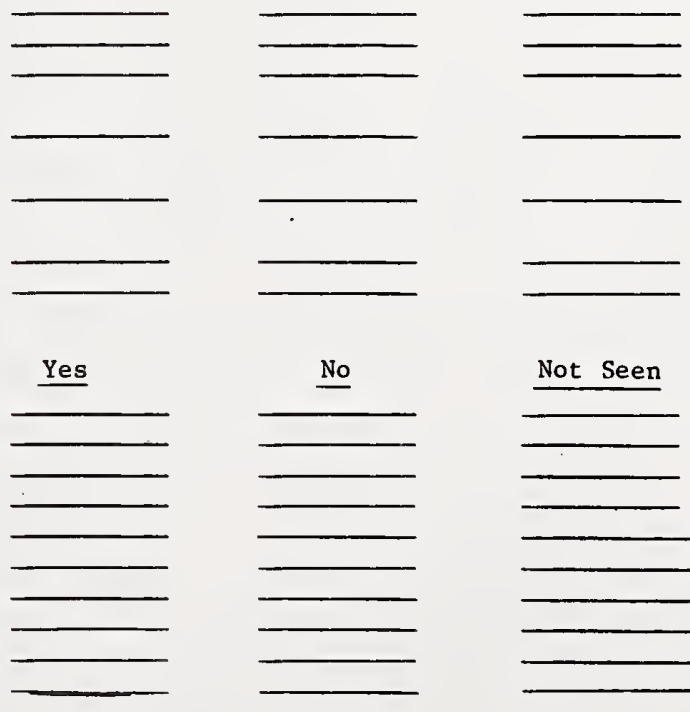

Not Seen
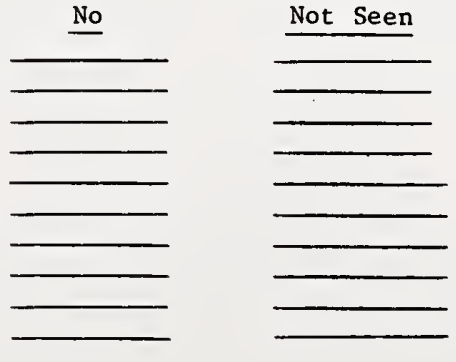

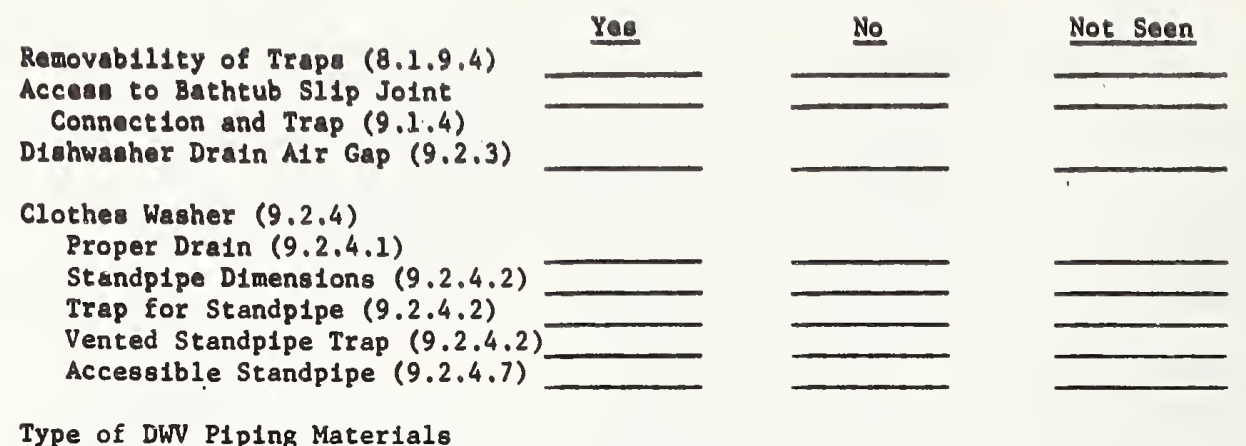

Type of DWV P1ping Materials ABS PVC

6. Vents and Venting (Part C-13)
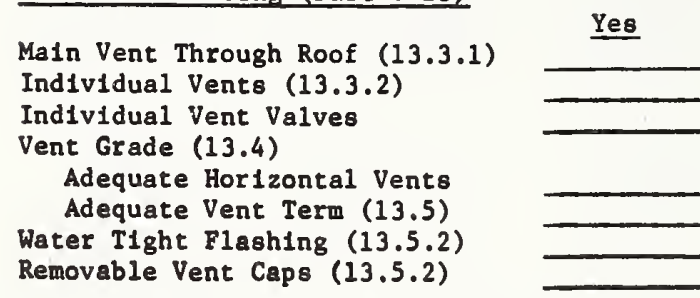

No

Not Seen

7. Protect1ve Requ1rements (Part C-5.2)

Protection of P1ping/Weather

$\underline{\text { Yes }}$

No

Not Seen

Protection of P1ping/Road Damage

Rodent Resistance

\section{Commente:}


Appendix B

Performance Problem List and Rank

Ordered Summation 


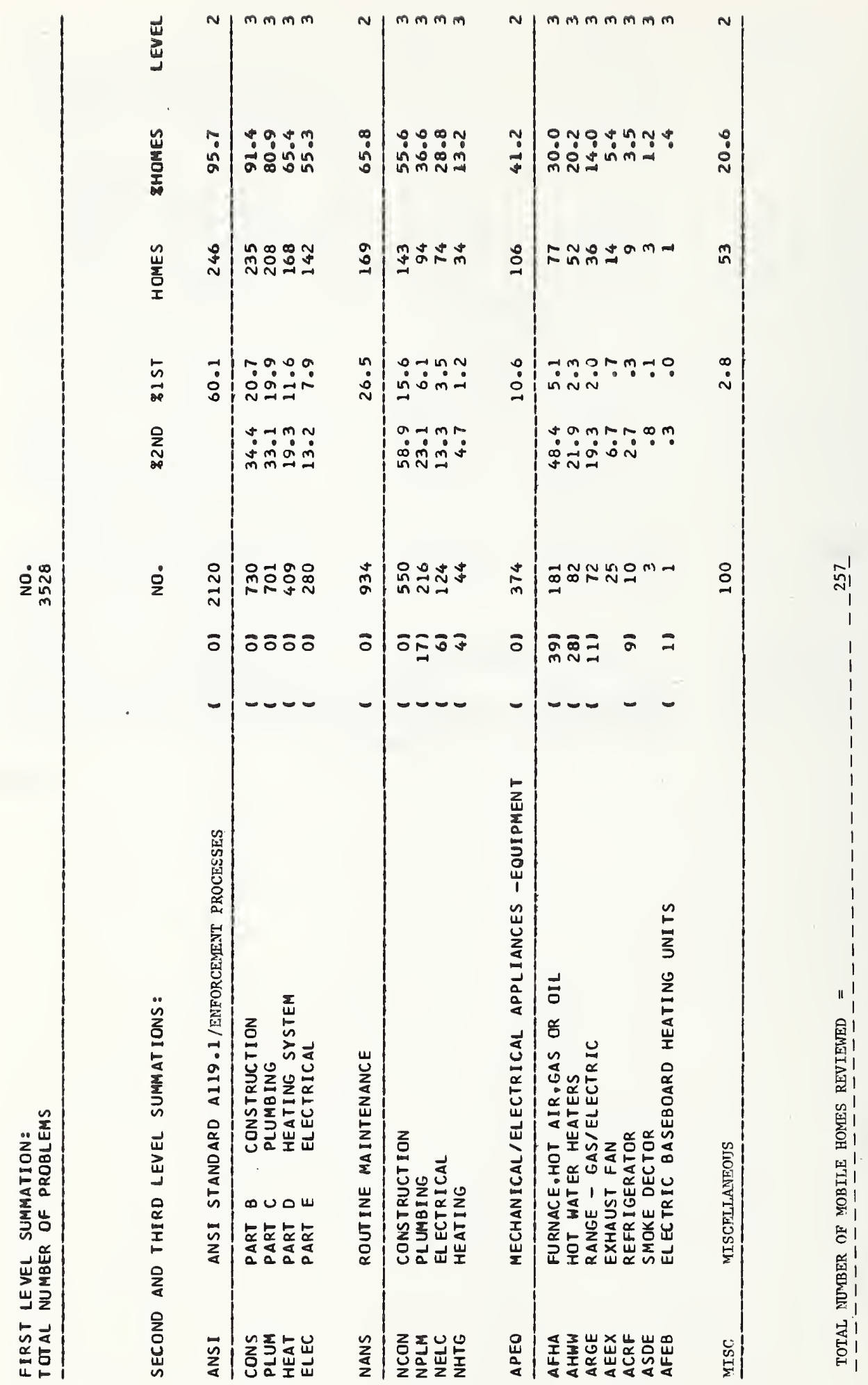




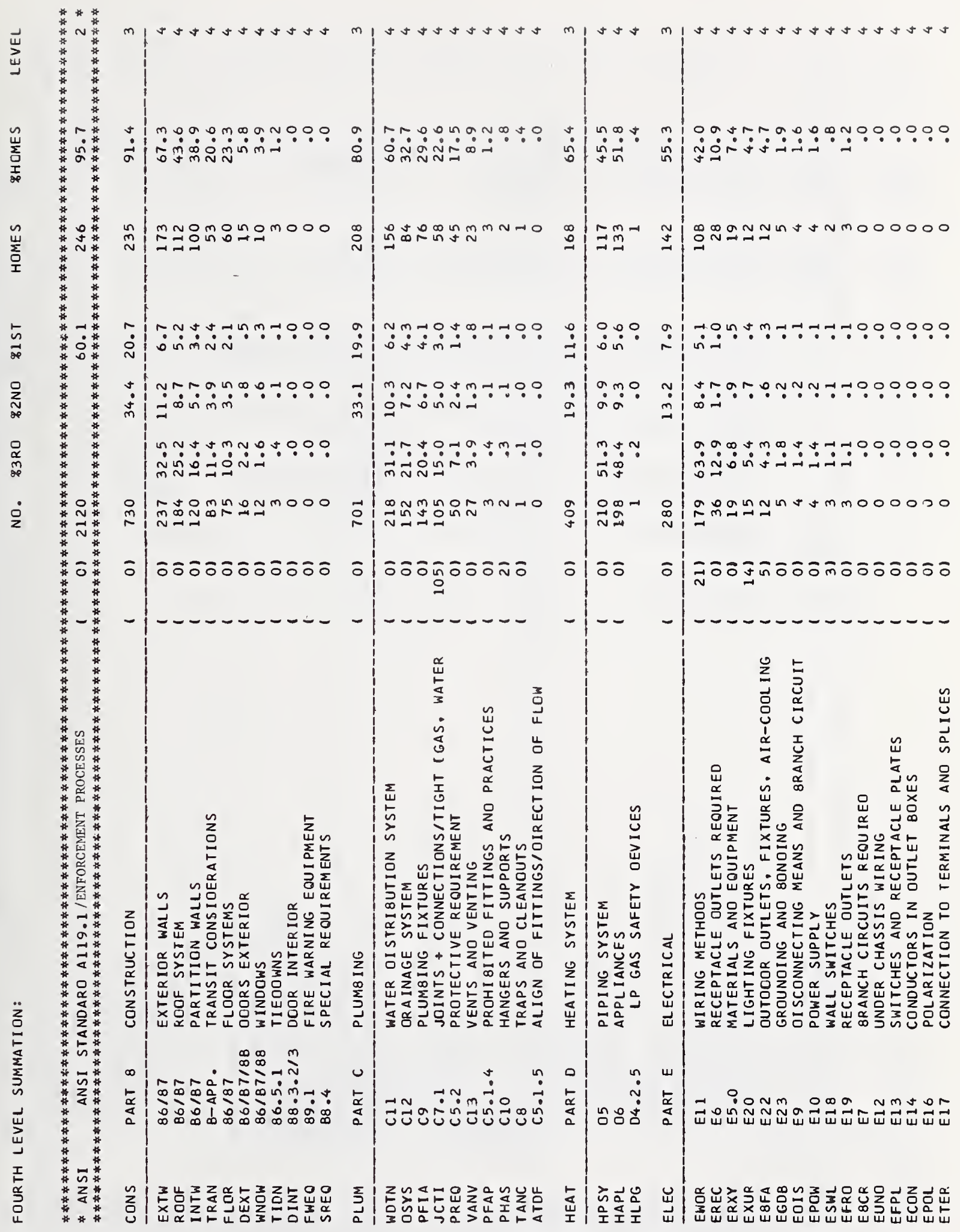




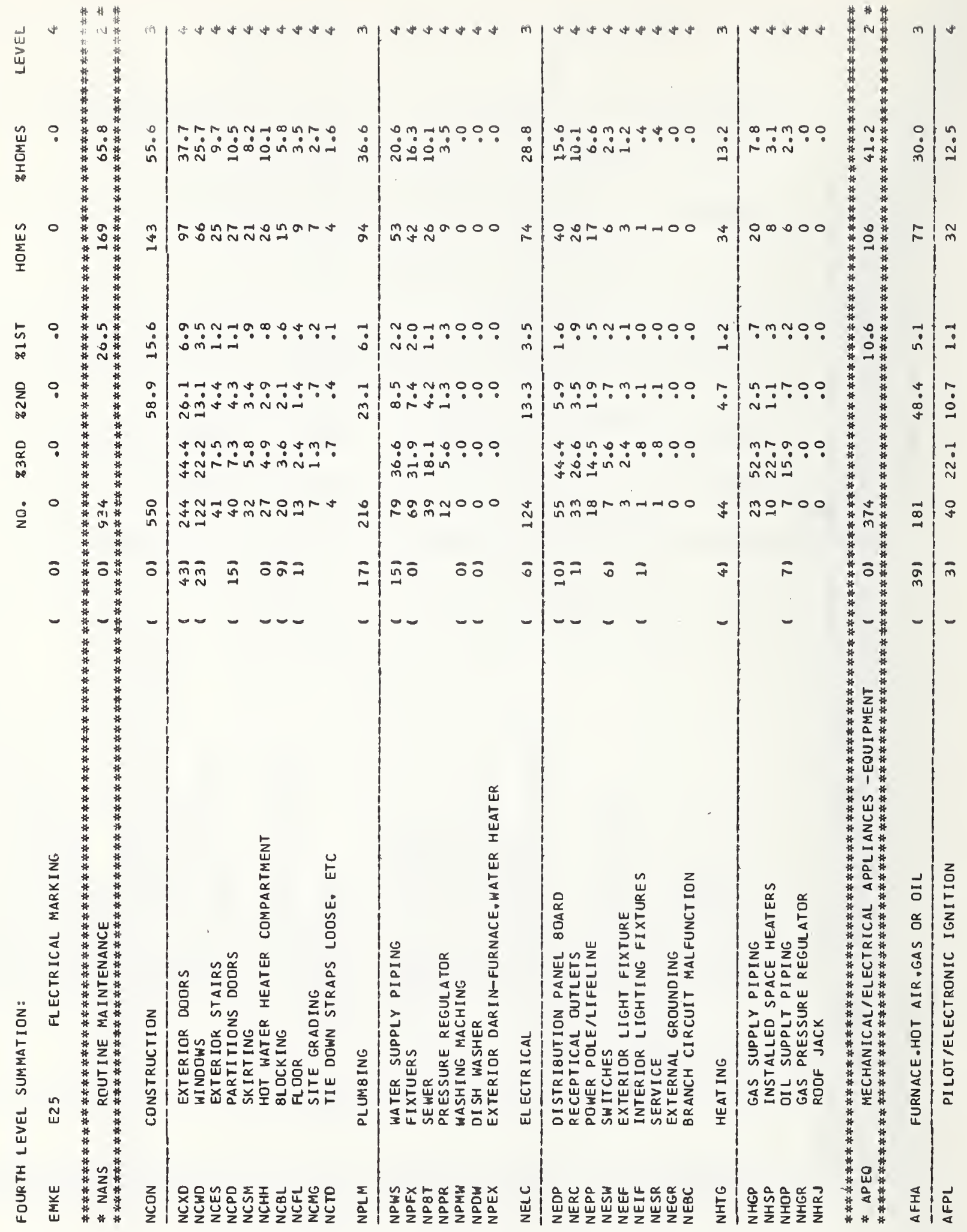




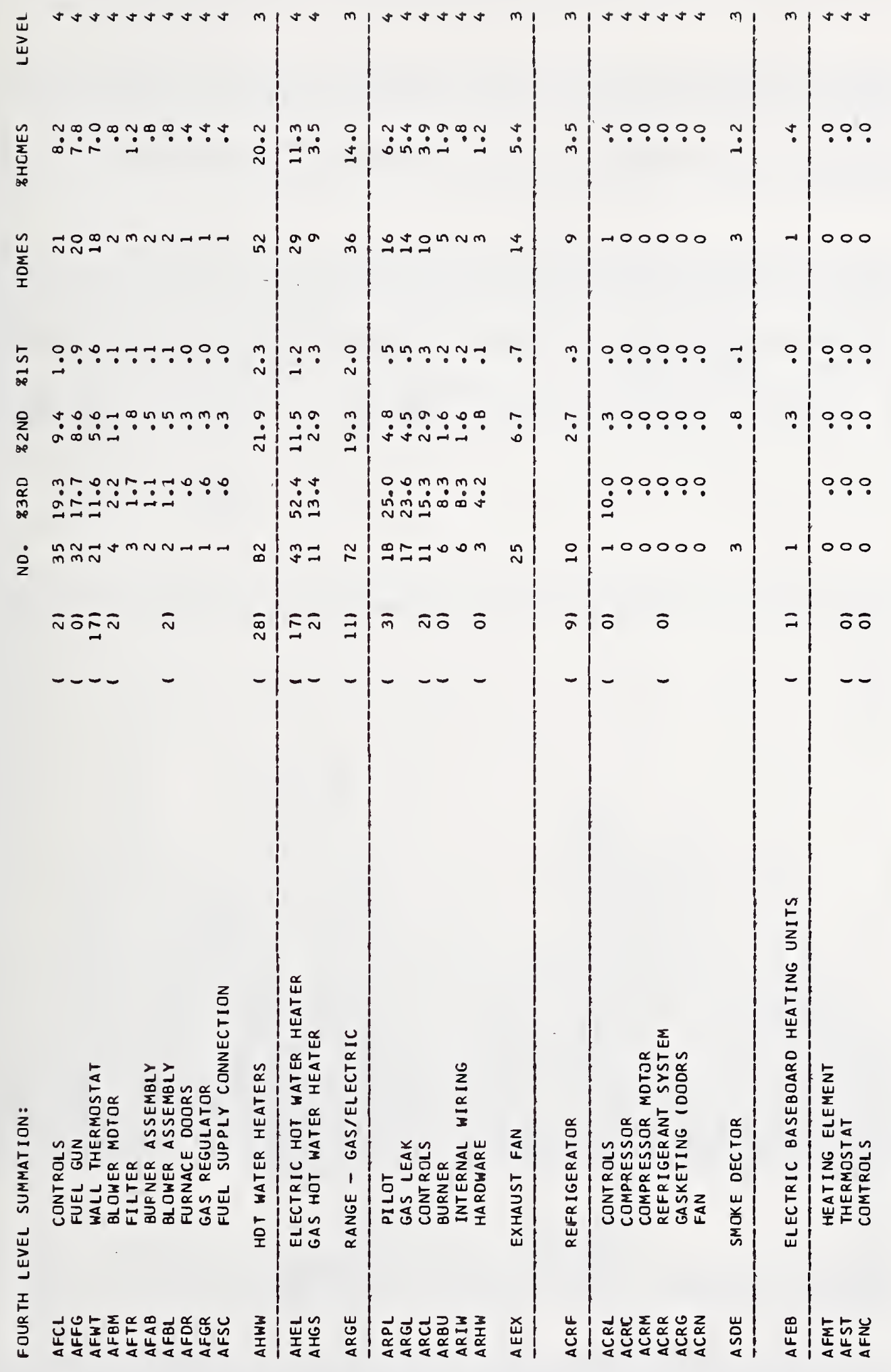




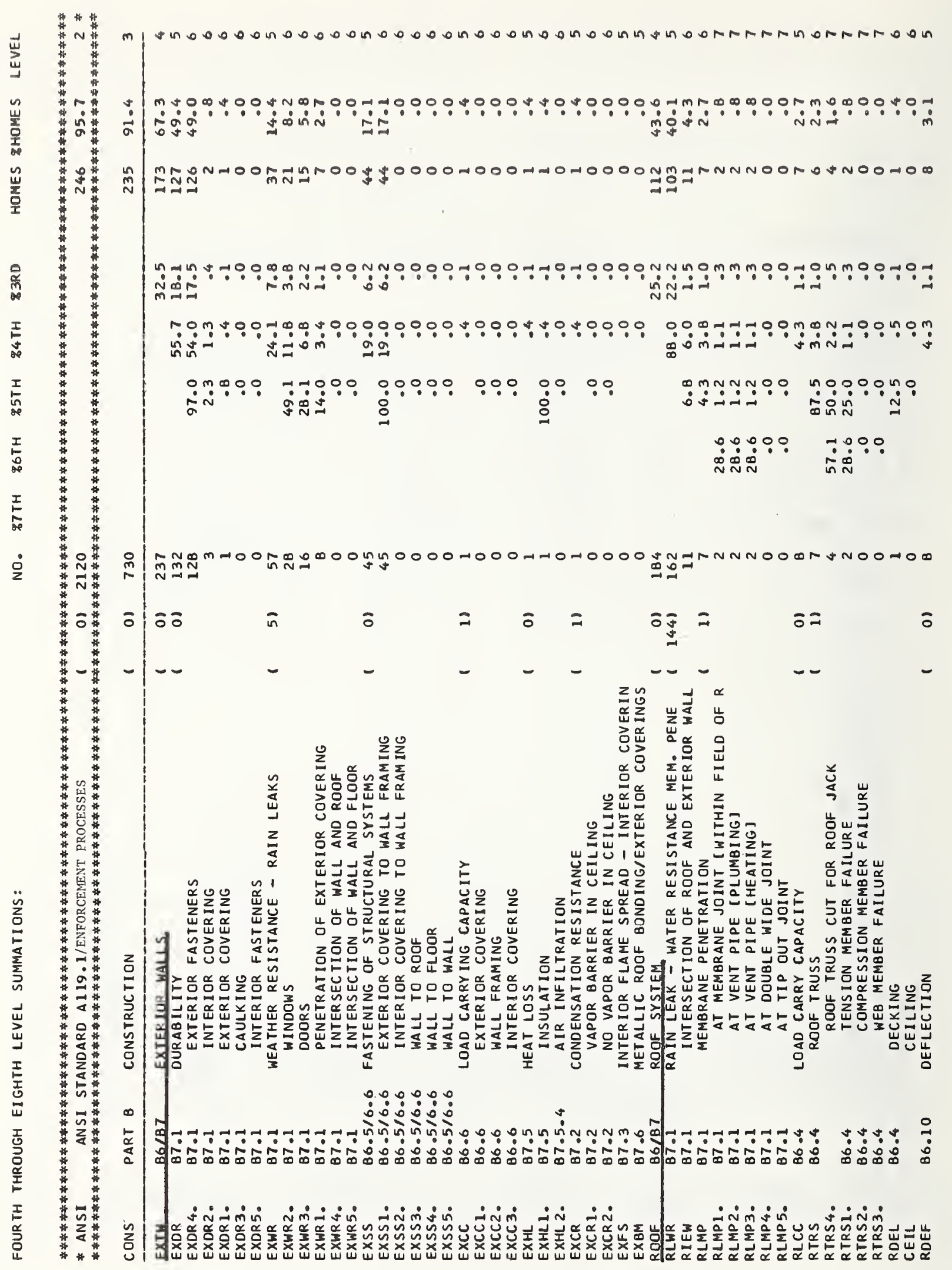


non

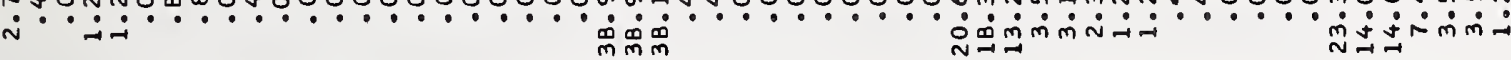

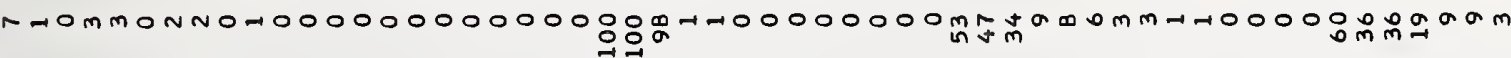

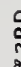

I

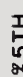

I

$\stackrel{I}{E}$

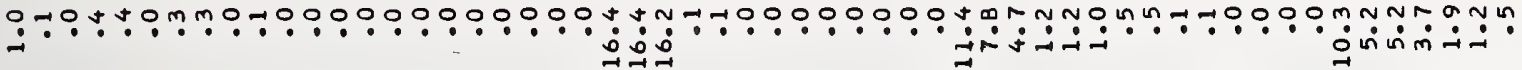

$0 m \infty 00000000$

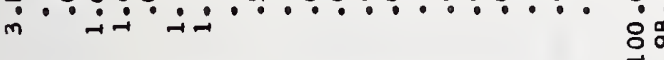
용

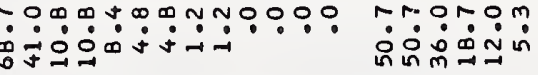

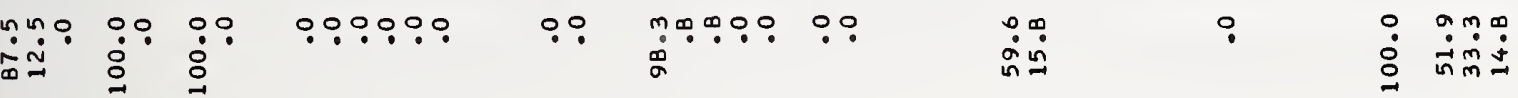

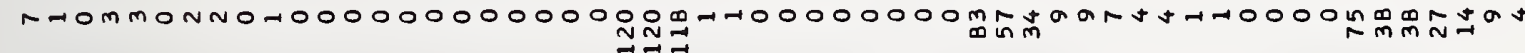
$\overline{0} 0$ j 0 oj 0 o
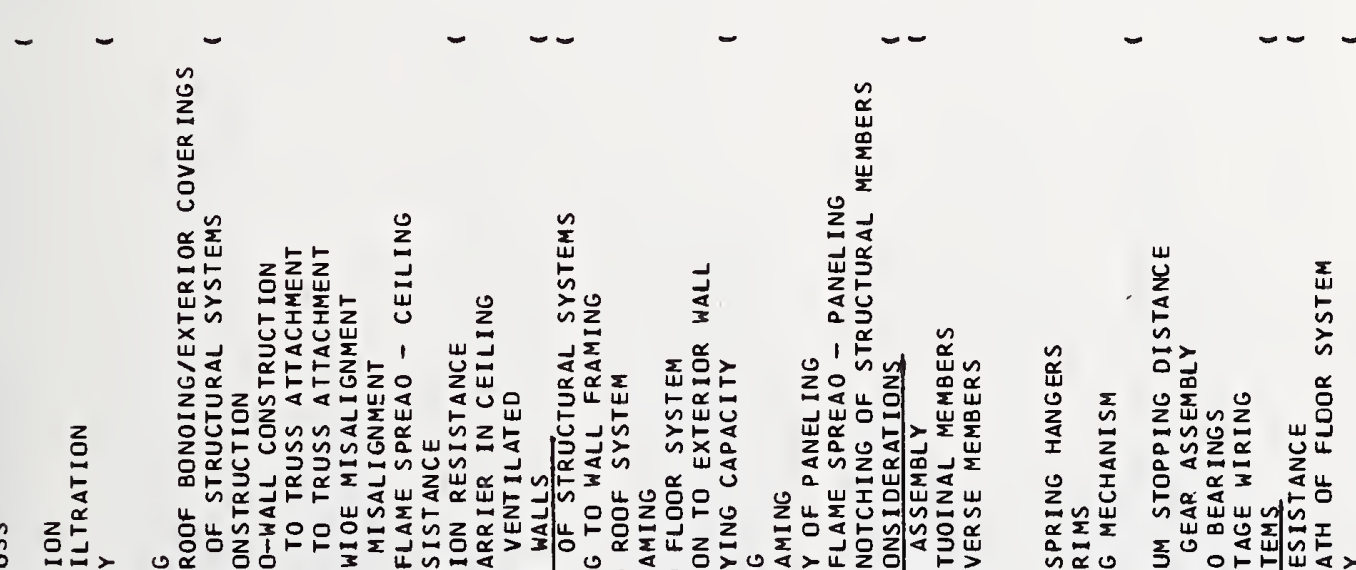

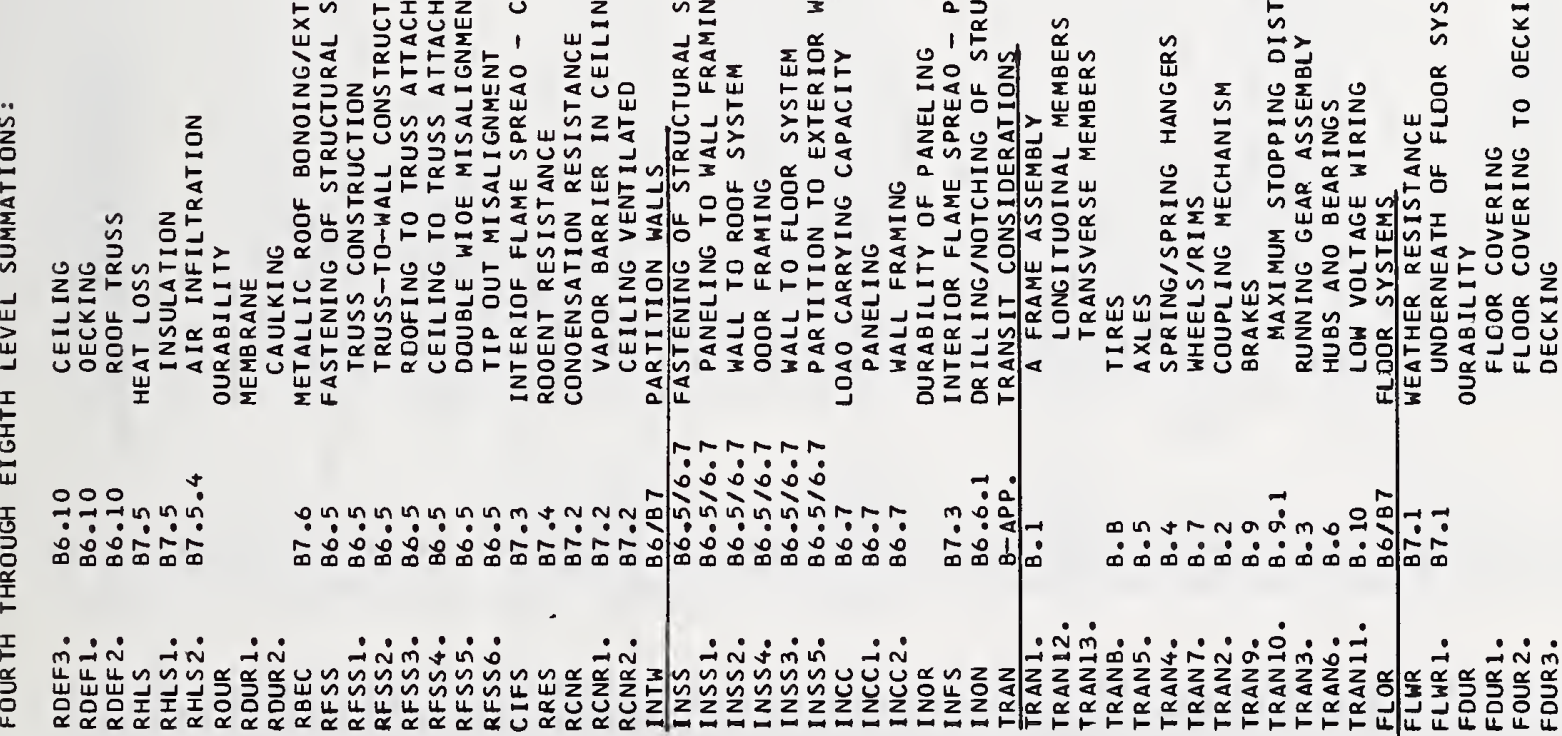




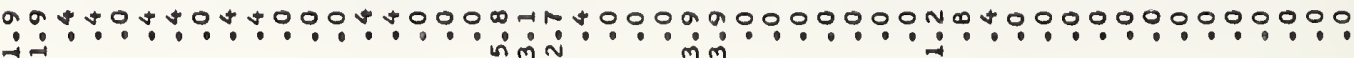

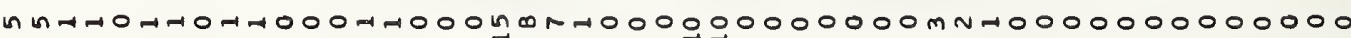

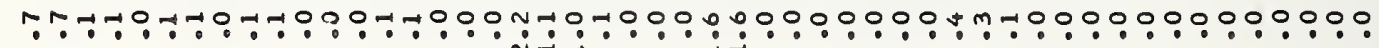

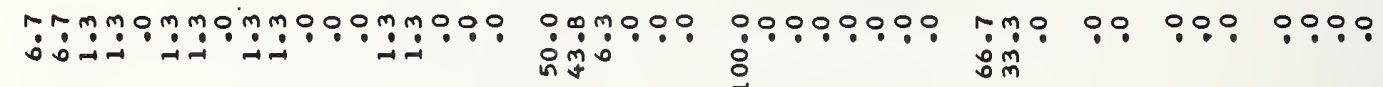

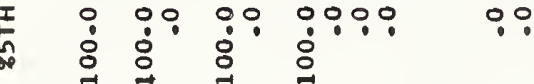

동

$\underset{1}{I}$ $\dot{0}$

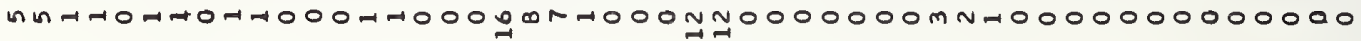

$\overline{0} \overline{0} \overline{0}$

$\overline{0} \overline{0}$

$\hat{0}$

$\overline{0} \overline{0}$

$\ddot{\dot{m}} \dot{0}$

뭉

$\stackrel{\sim}{*}$

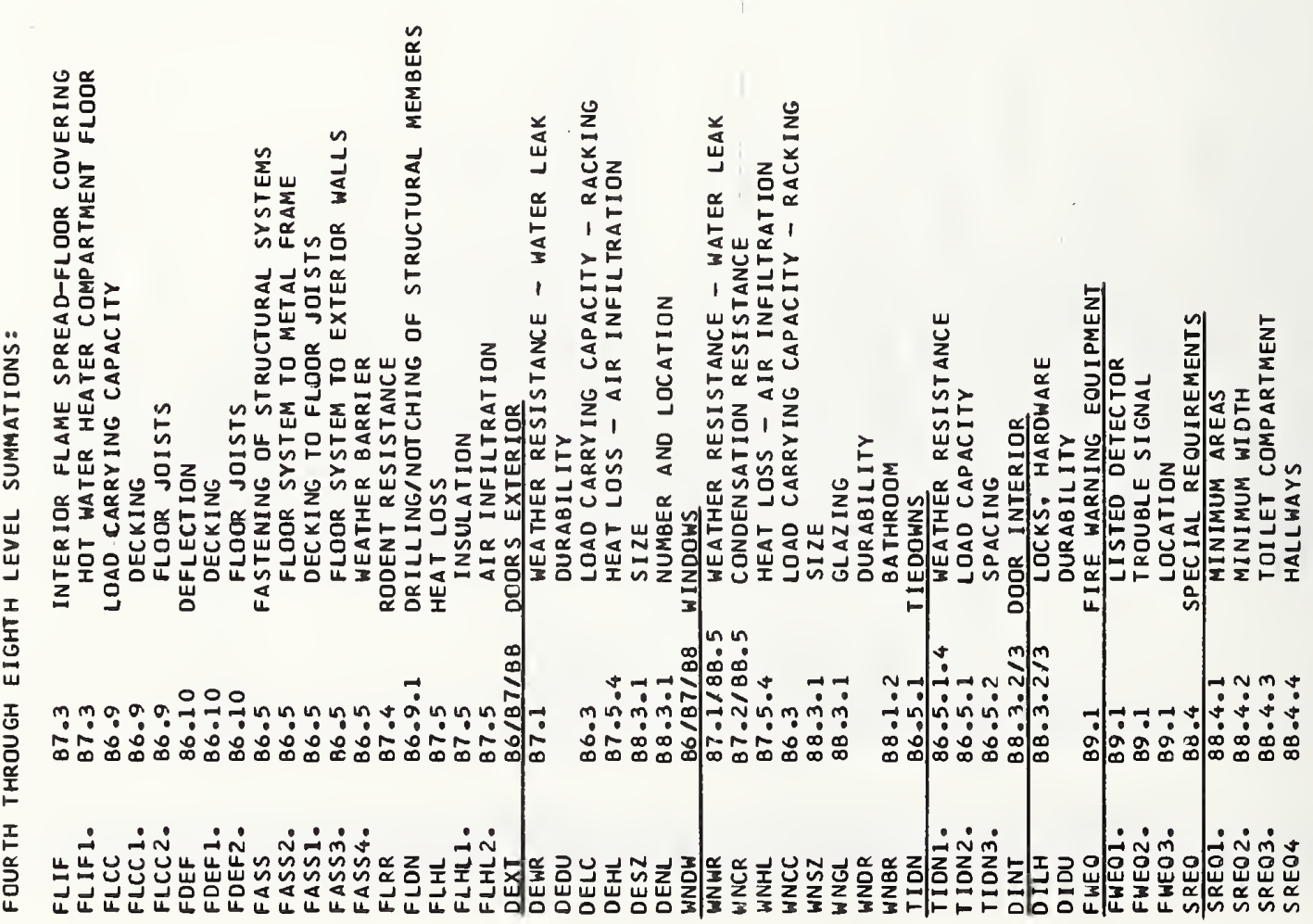

-

50

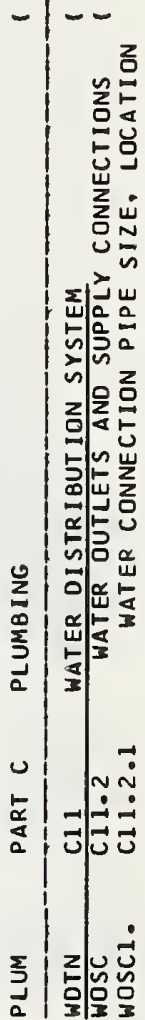




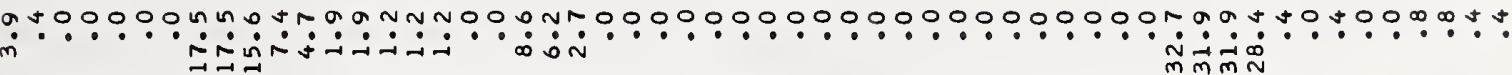

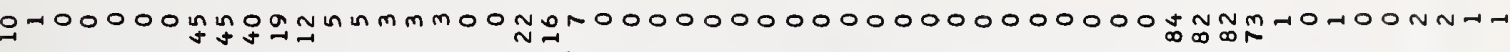

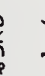

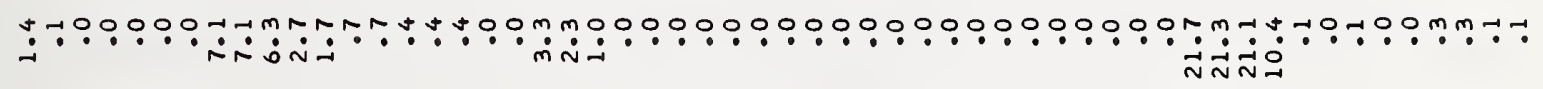

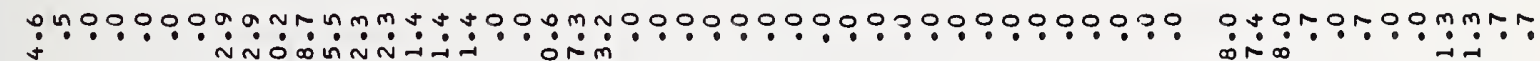 j. ñ

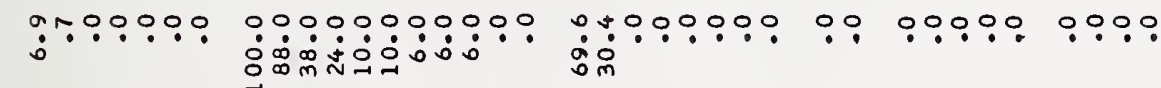
mo:
I
$\because:$

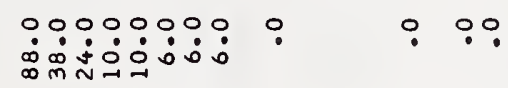
$\because \because$

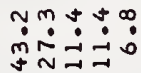
$\underset{g}{g} \sim \stackrel{0}{g}$
in in

\&

I

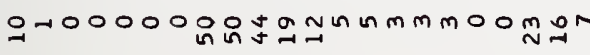

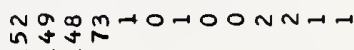

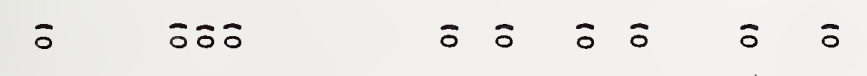

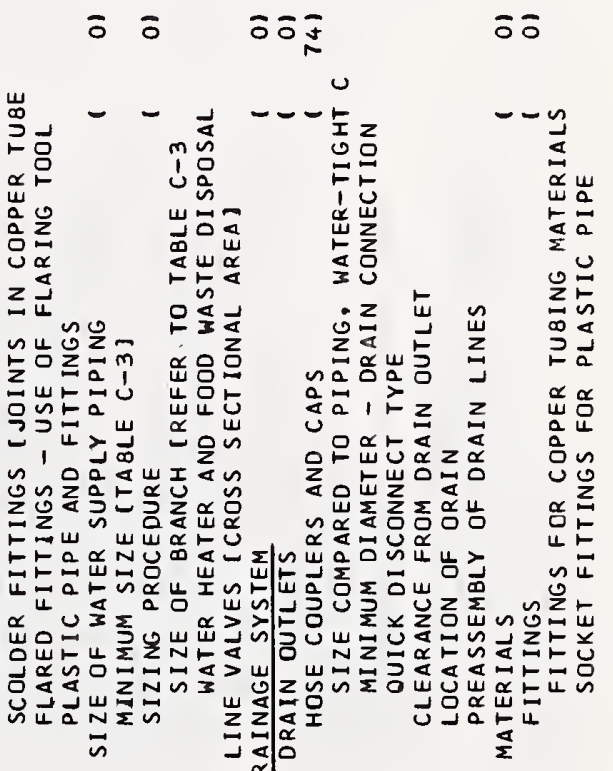

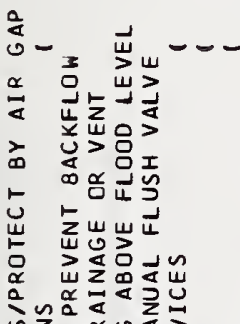

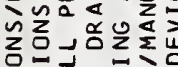

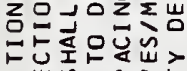

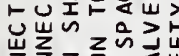

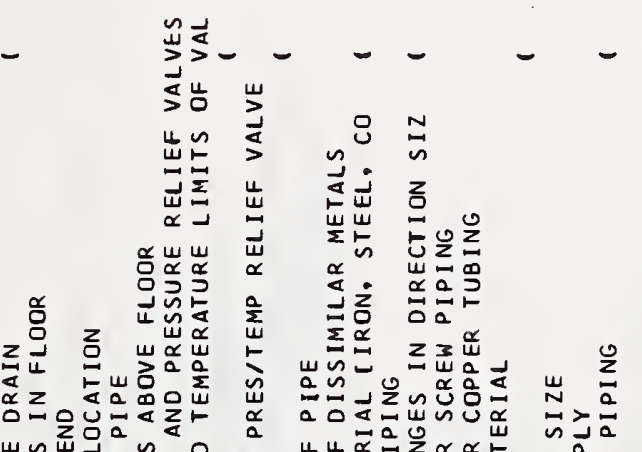

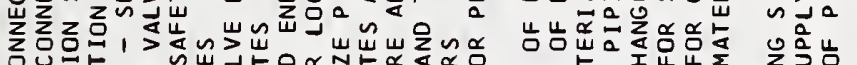

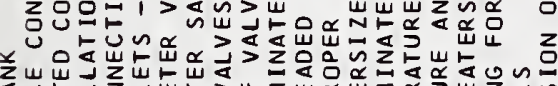

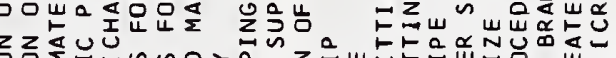

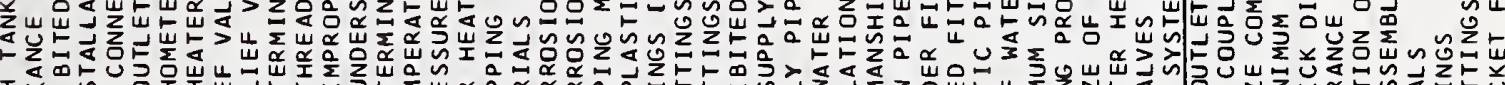
I

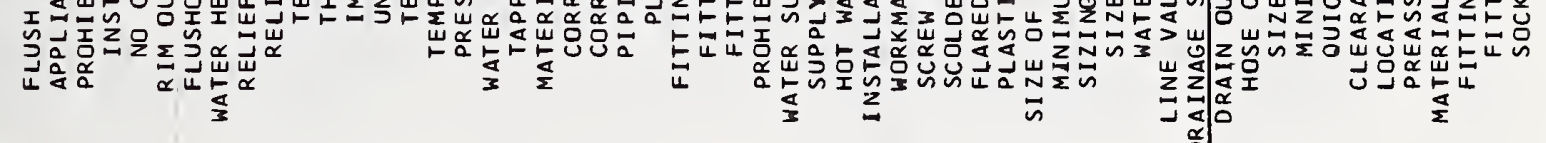

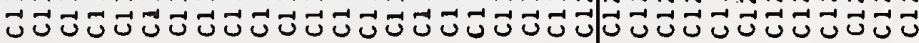

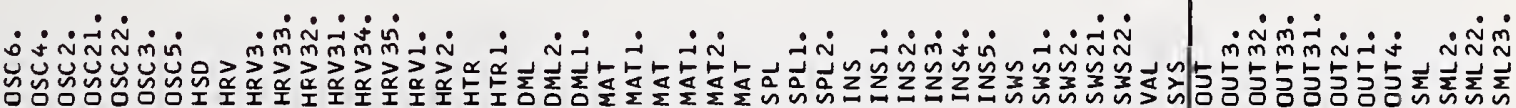

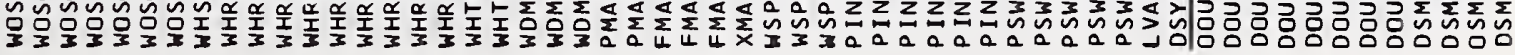


$00000000000000000000000 m+00000 n m 000000000000000000000000$

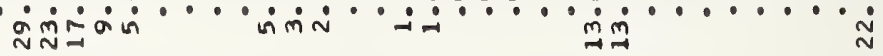

$0000-000000000000000$ Rin

尊 $\stackrel{\text { I }}{\stackrel{5}{5}}$

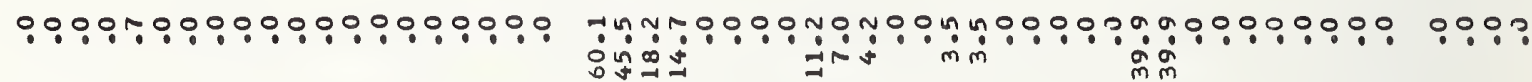
$\stackrel{\text { I }}{\stackrel{5}{6}}$

$$
\text { I }
$$

$\stackrel{\text { I }}{\stackrel{5}{L}}$

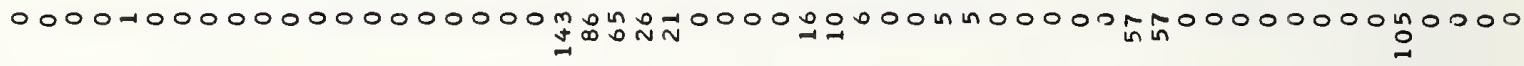

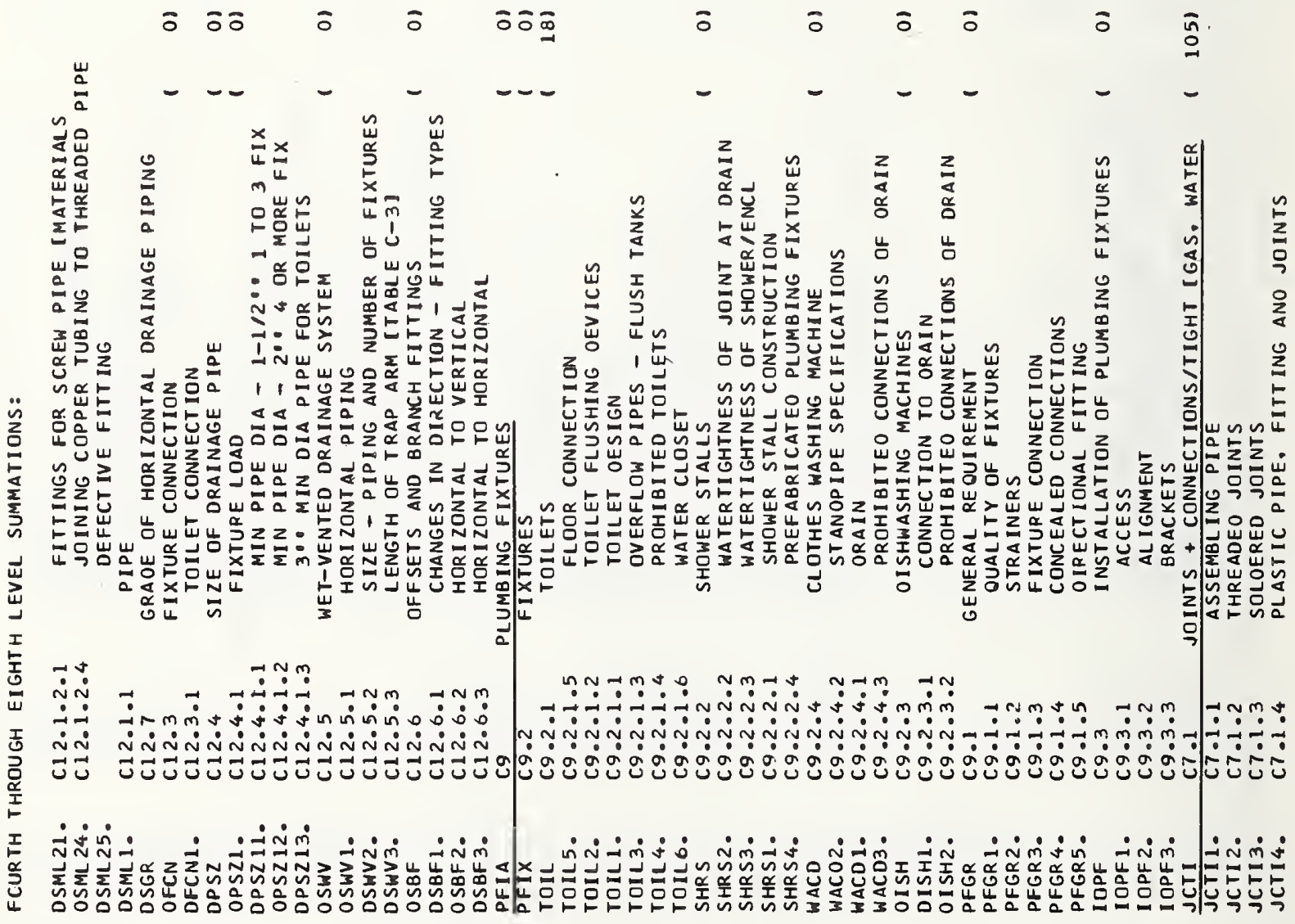


0.00 m

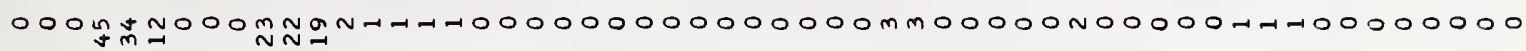

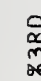

s.

$\underset{1}{\stackrel{I}{1}}$

$\underset{⿱ ⺊}{D}$

$\stackrel{I}{\leftarrow}$ $\dot{q}$

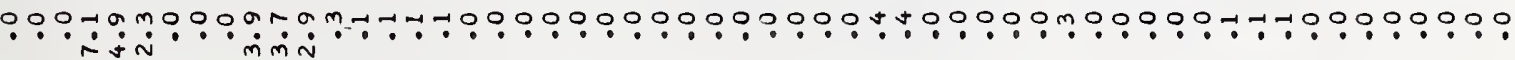

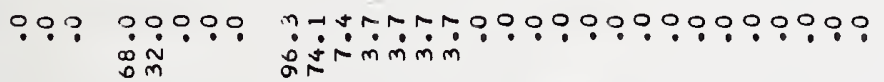

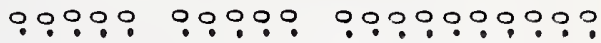
온 옹으

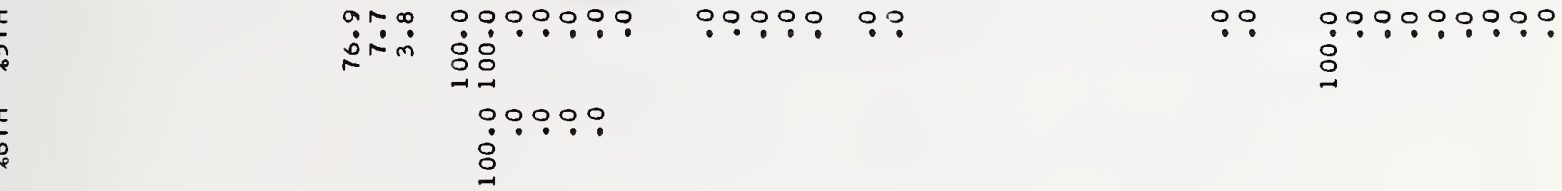

ấ

$\because \circ \circ \circ:$ $\stackrel{8}{\circ}$

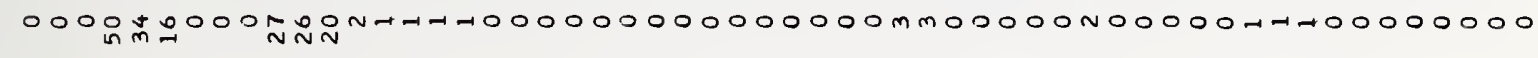
$\hat{0} \quad \overline{0} \quad \hat{m}$ o 00 $\bar{\sim} \overline{0}$ o

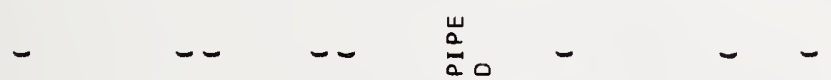

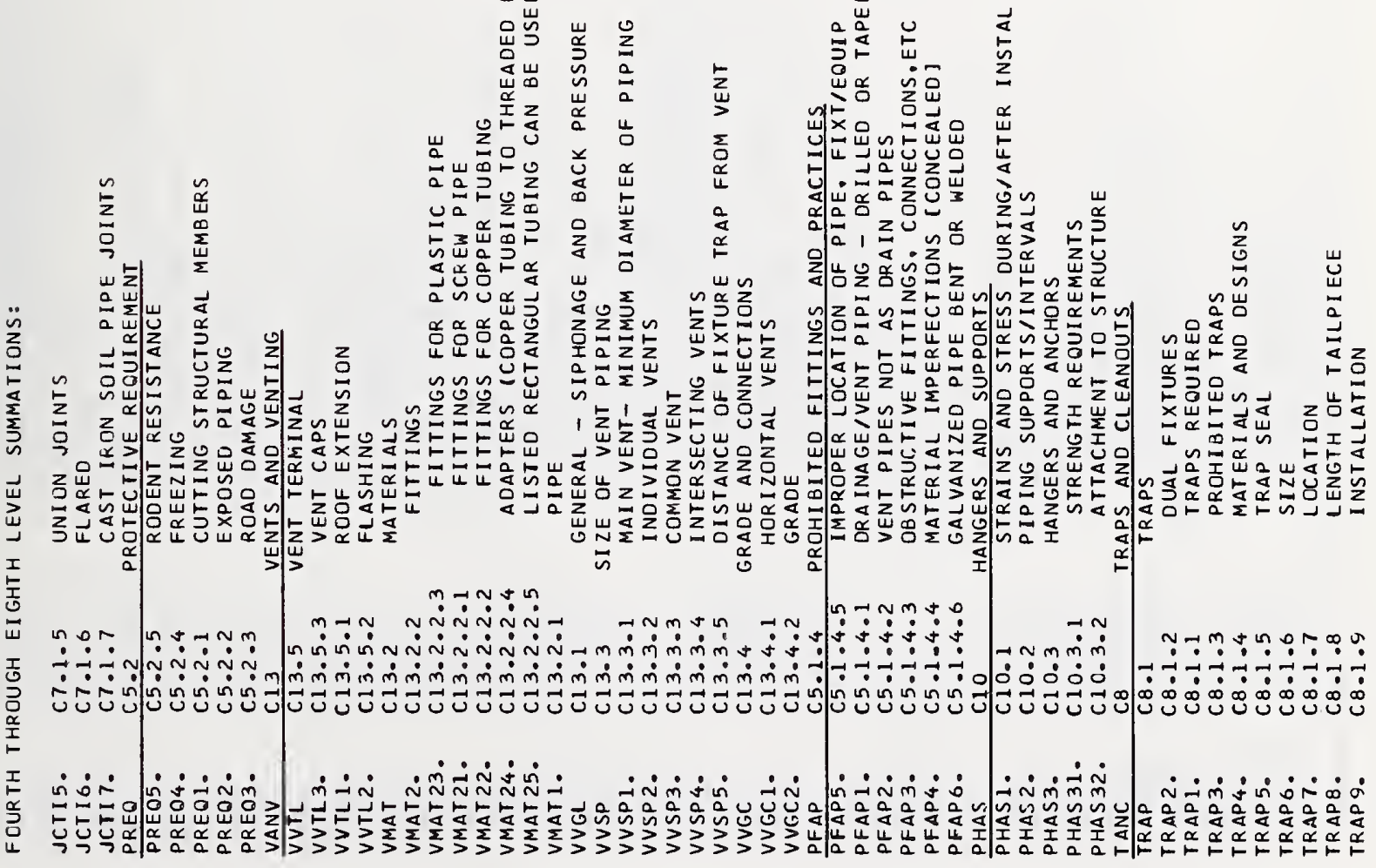



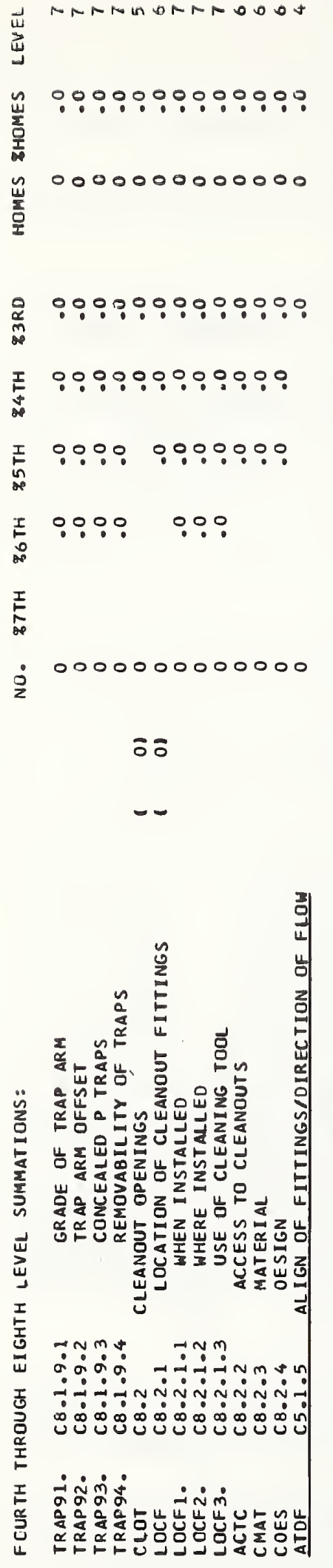

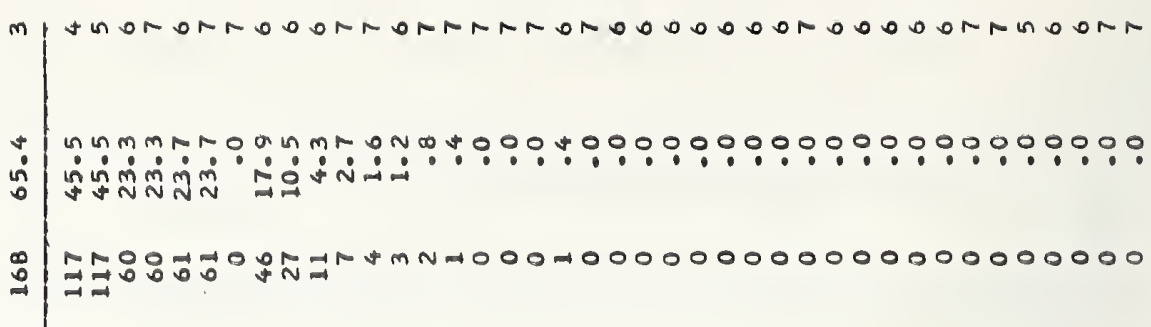

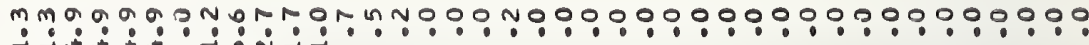

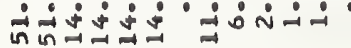

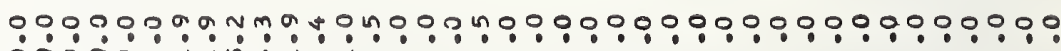
ㅇํำ

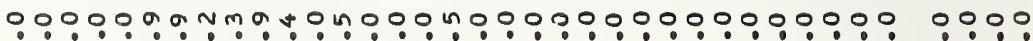

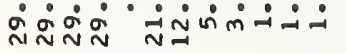

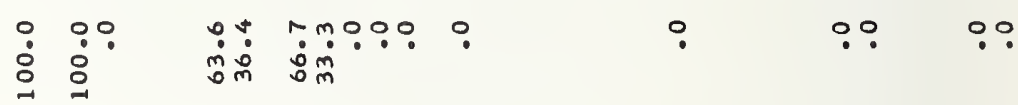

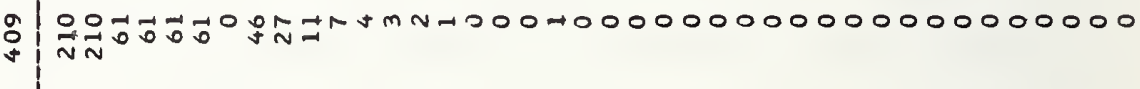
ธิธอธ ธ ธ ธ

$=1000$

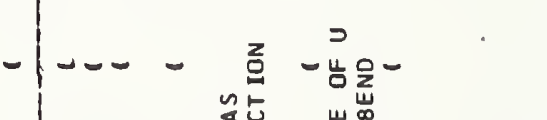

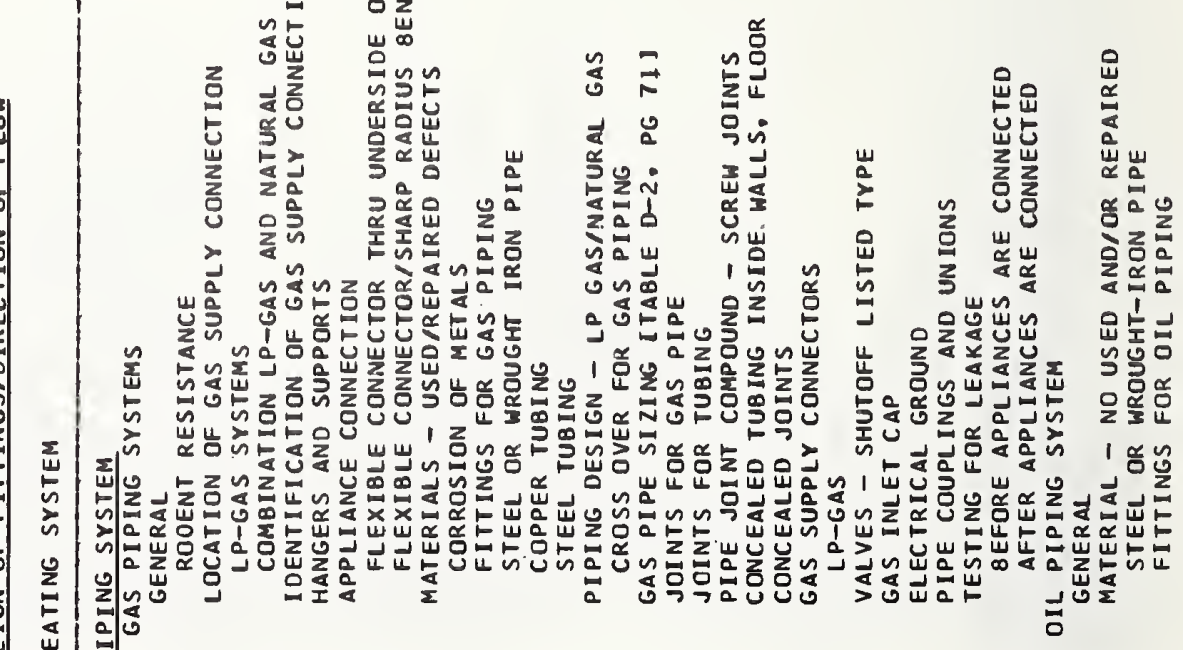

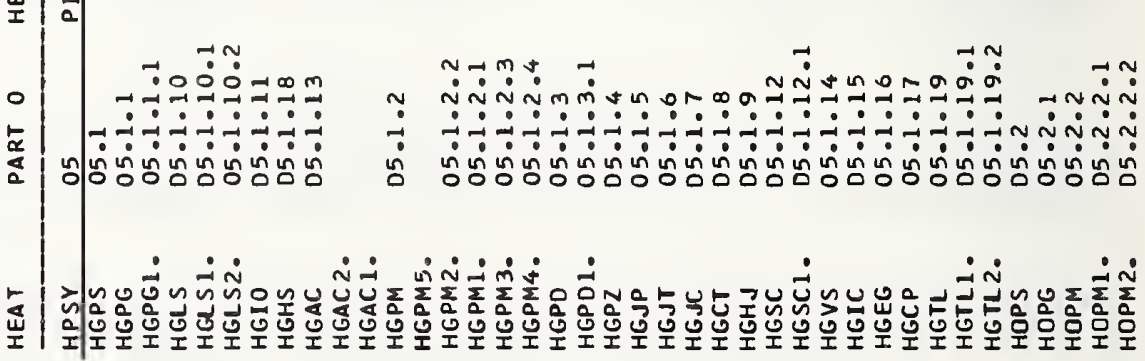




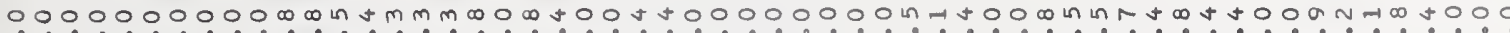

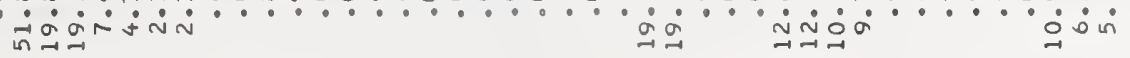

$0000000000 \mathrm{~m}$ m

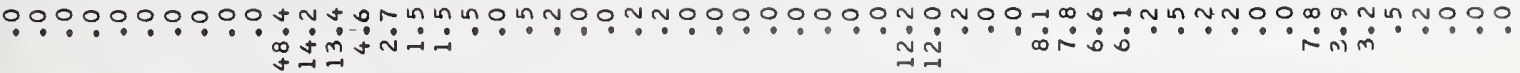

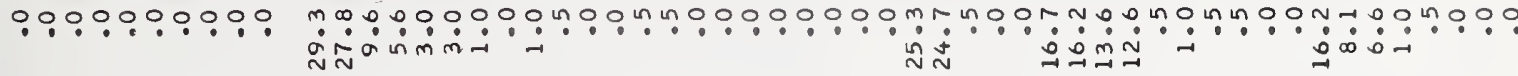

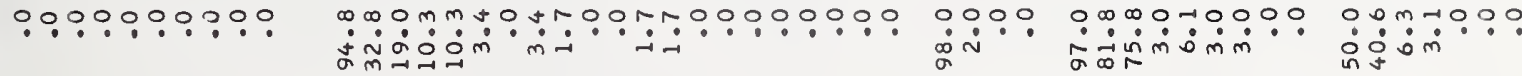

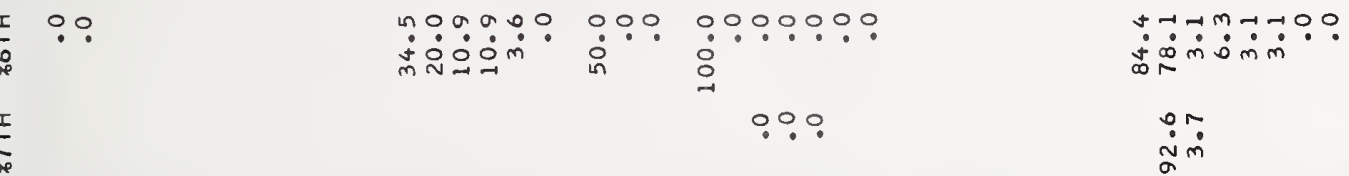

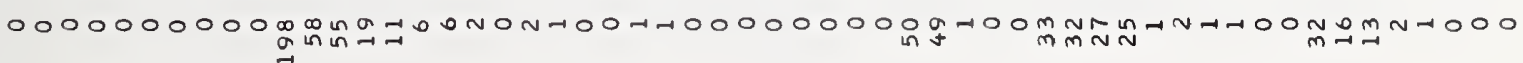

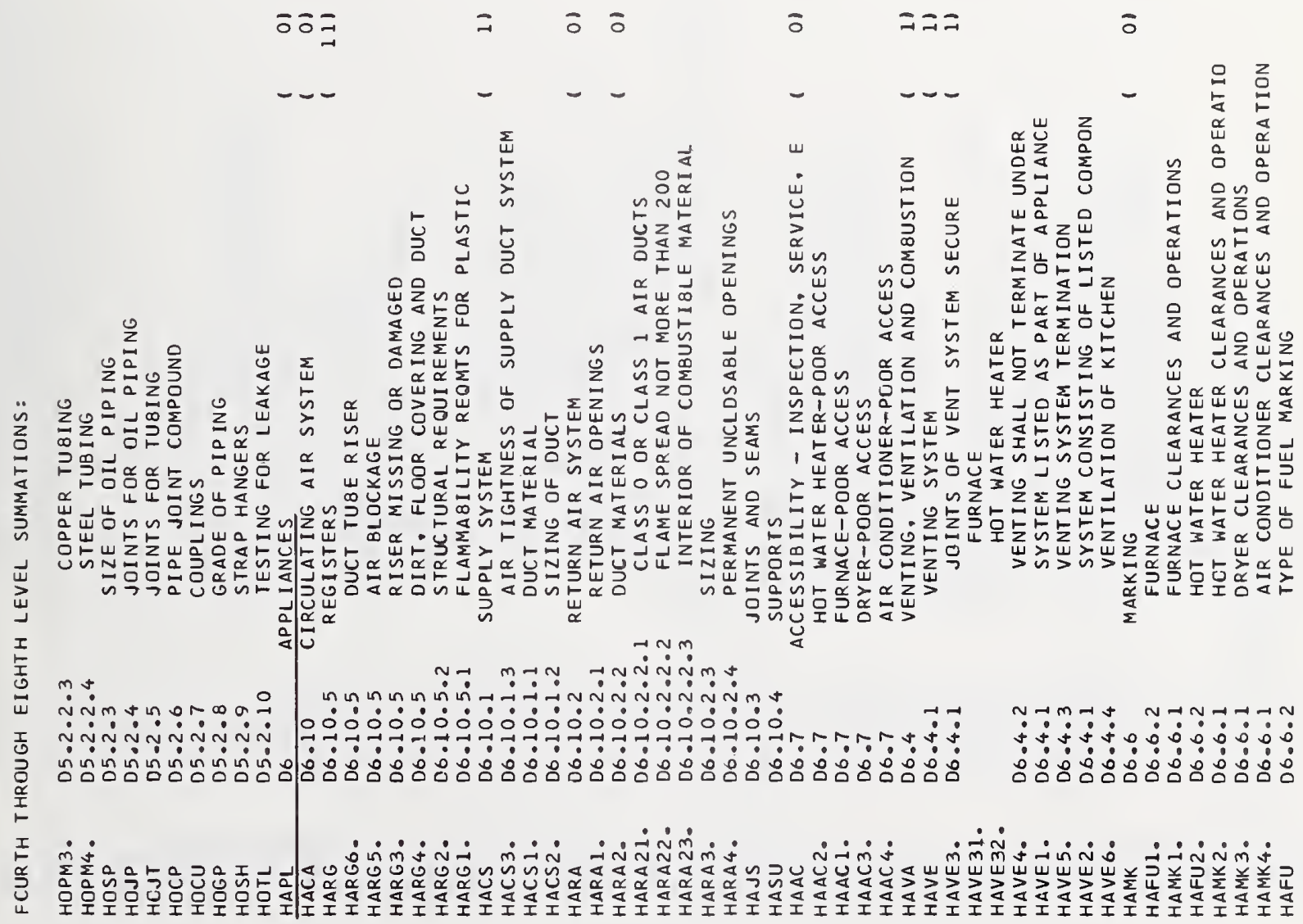

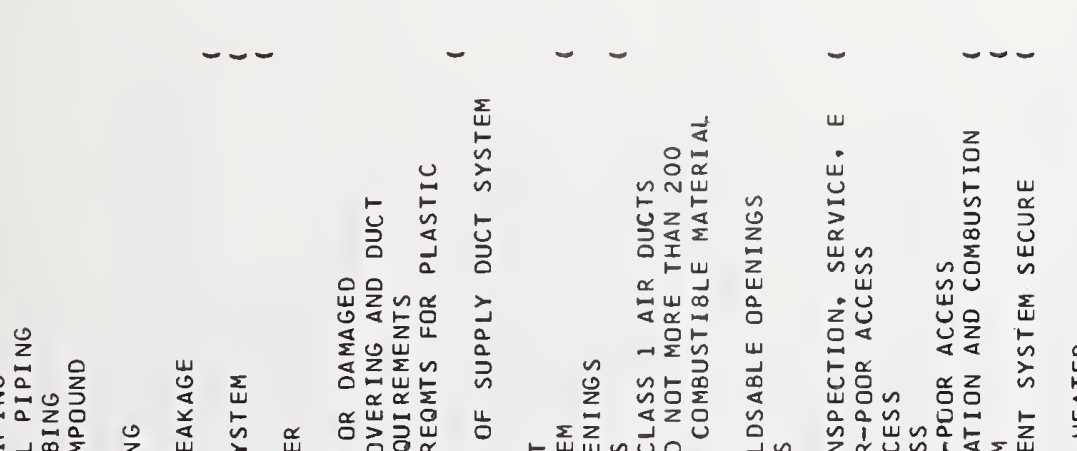

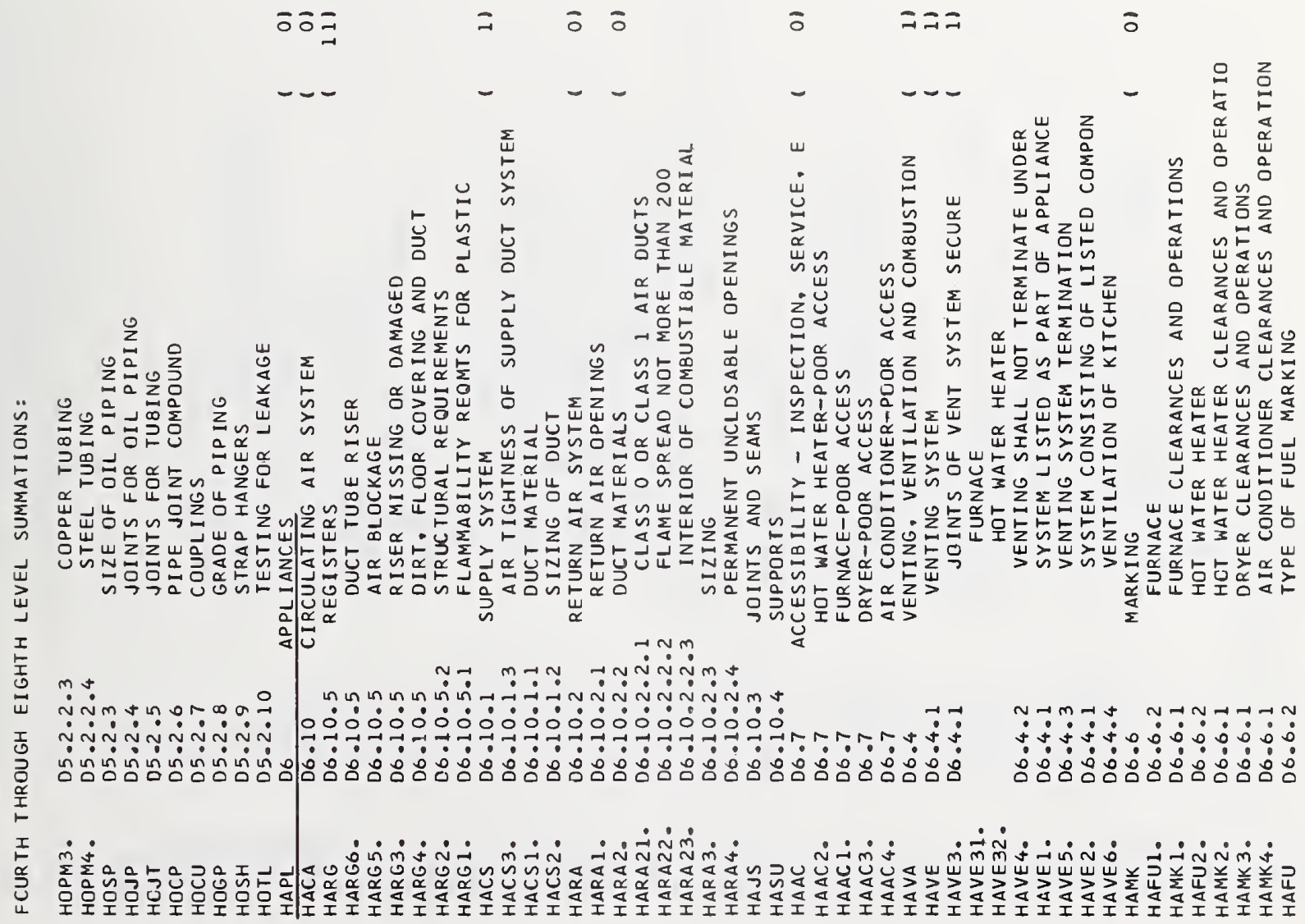


$$
\text { (1) }
$$

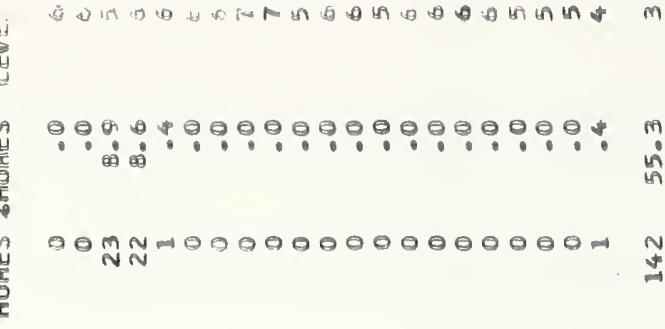

(

I

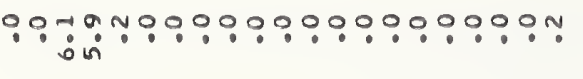

0.0.1 0.0000000000000 $N N$

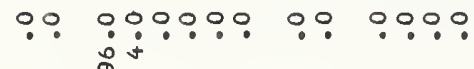

$\because ?$

$00 \ln ^{n} \pi 000000000000000 \pi$

6 505

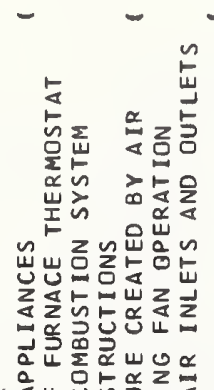

望

$\underset{w}{\mathbb{W}}$

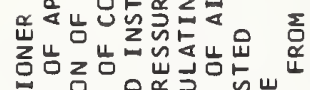

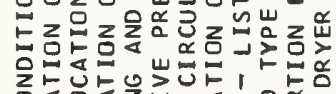

耑

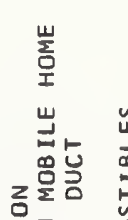

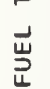

는

岁

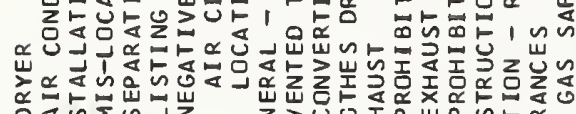

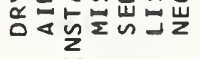

岁>U巳寸

$\underset{\frac{I}{5}}{I}$

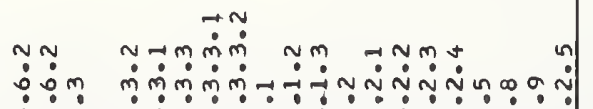

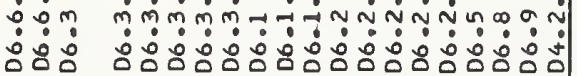
$\stackrel{\alpha}{I}$

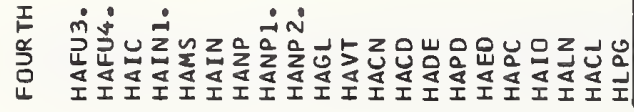

ח

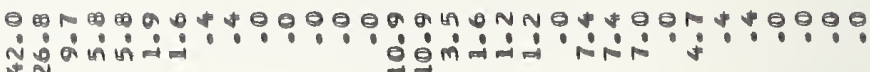

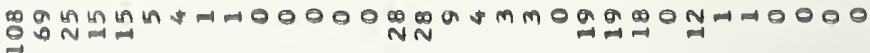

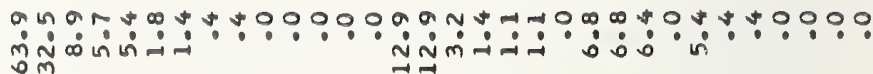

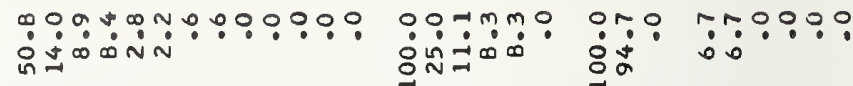

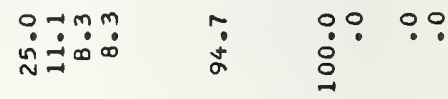

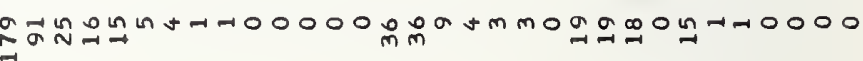
$\overline{-} \overline{\mathrm{N}}$

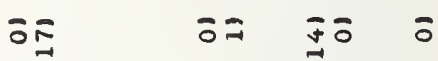

$-1-$

点

z㞾

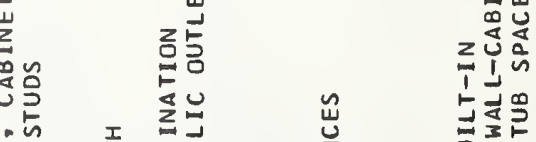

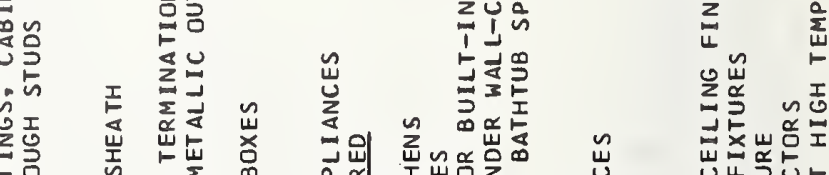

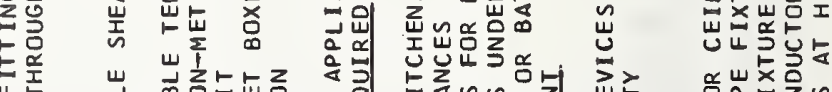

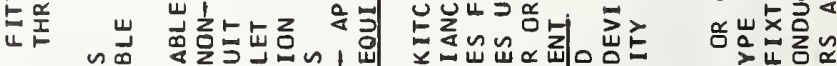

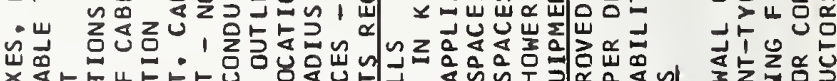

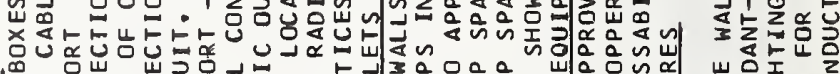

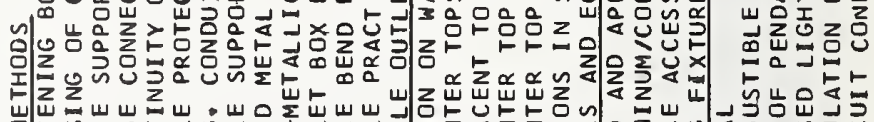

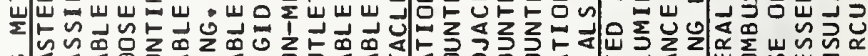

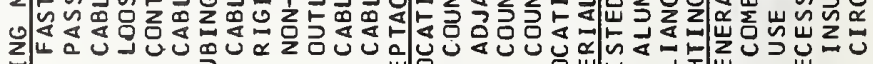

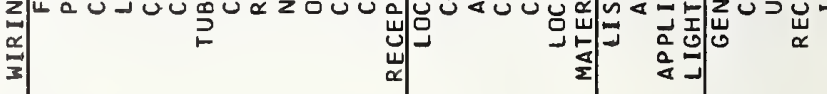

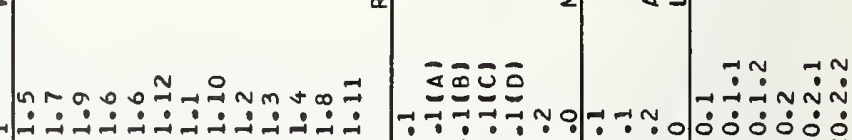
委 等 


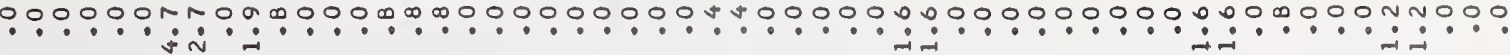

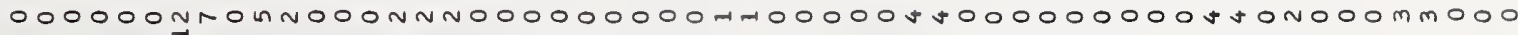

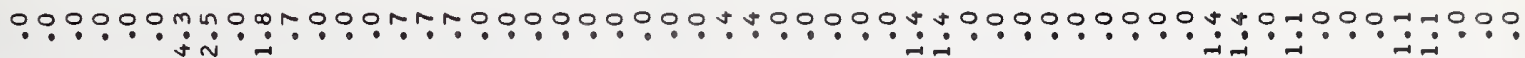

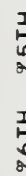

$\underset{1}{1}$

$\underset{B P}{I}$

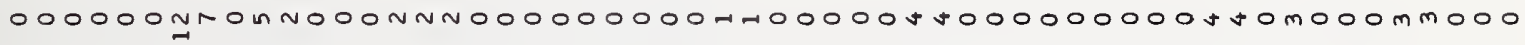

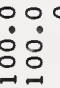

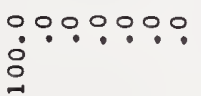

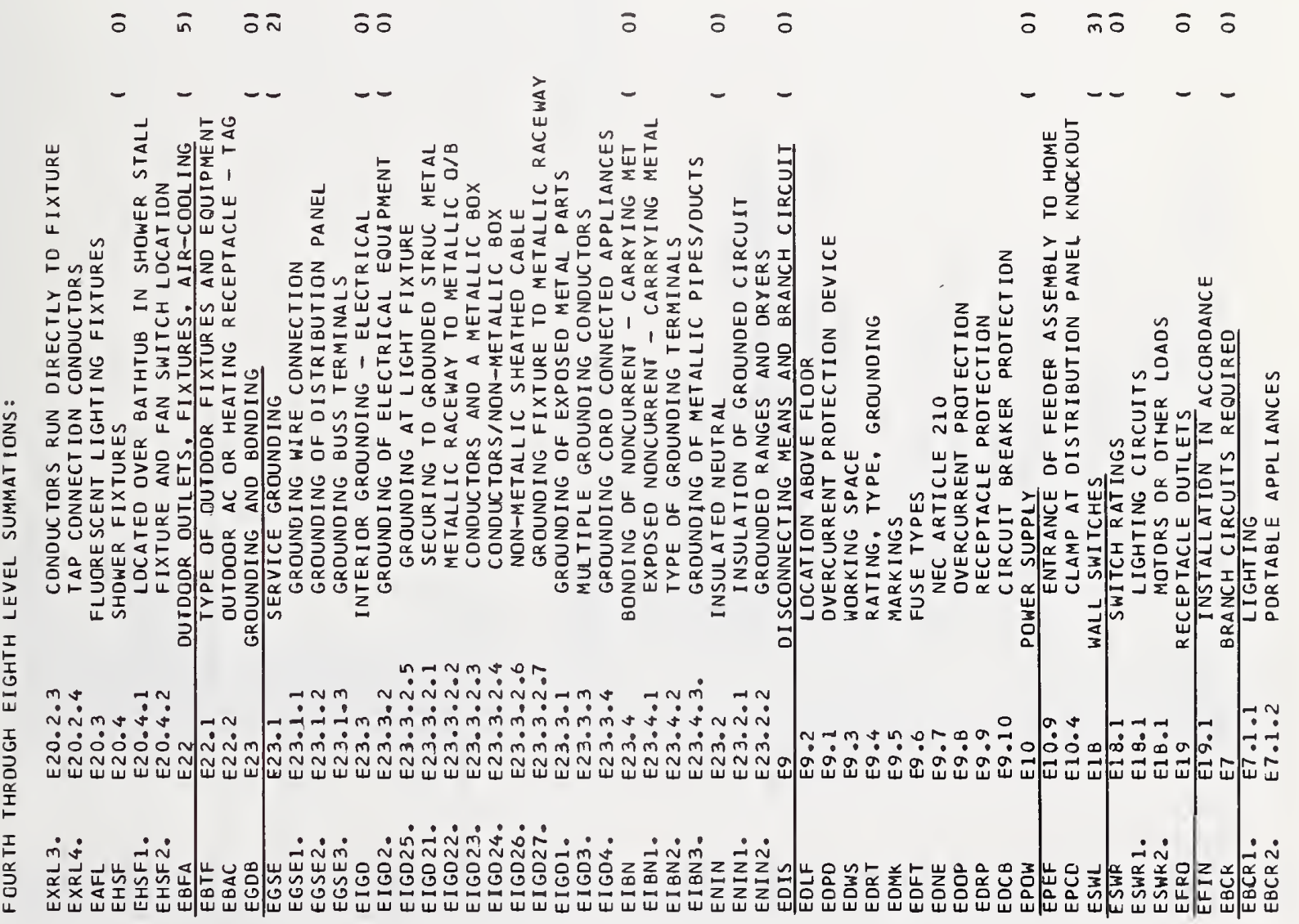




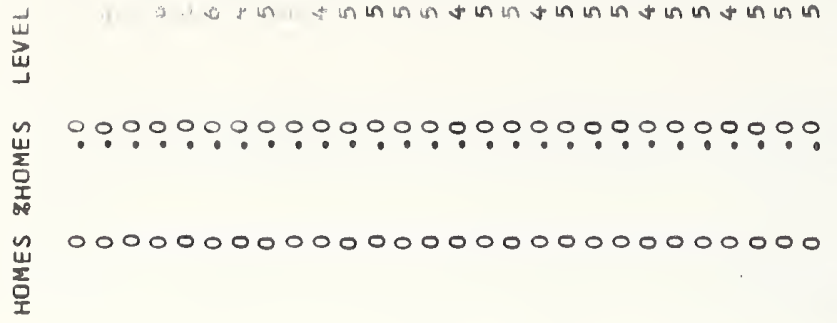

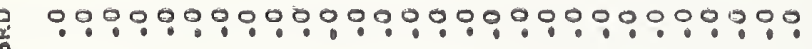

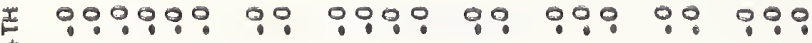
$\stackrel{4}{*}$

I $: 0 \%: 0$

$\stackrel{I}{5}$

I

0000000000000000000000000000 $\stackrel{\varrho}{z}$

虽

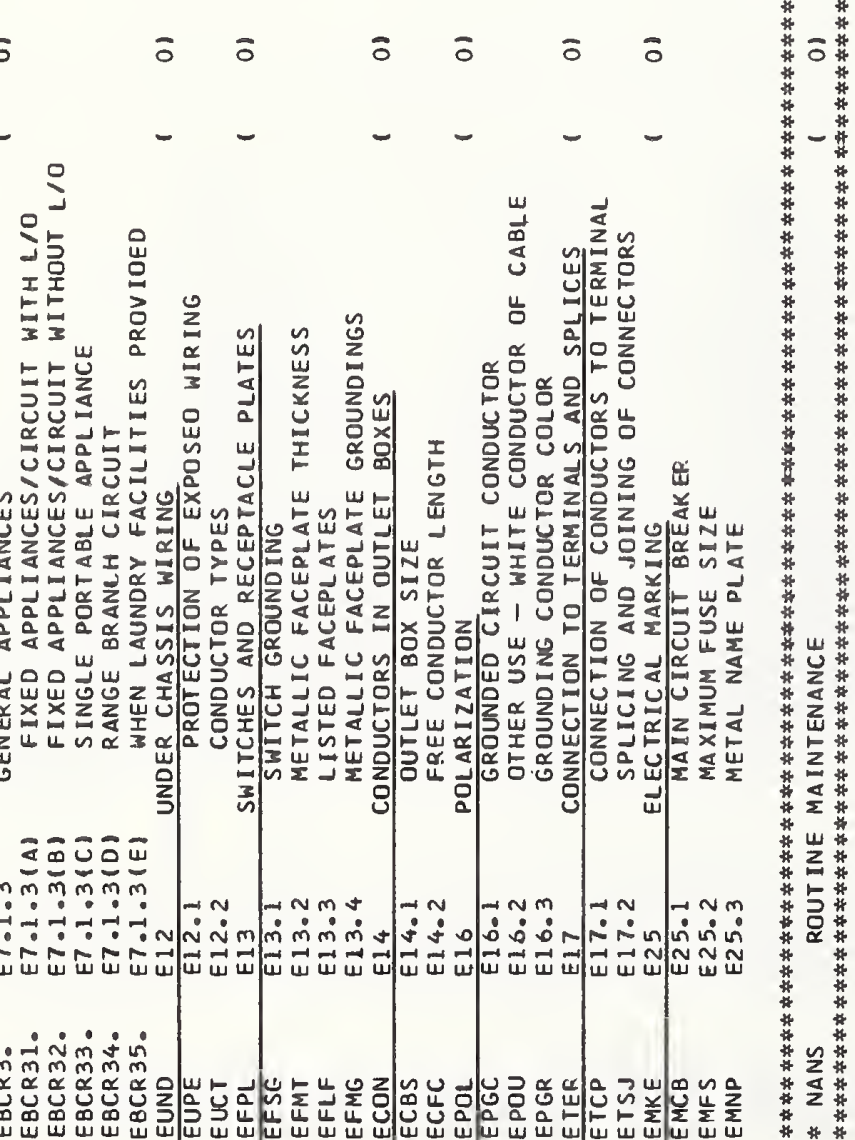

o

$$
\text { 논 }
$$

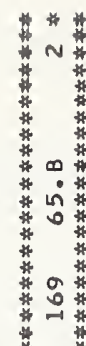

|

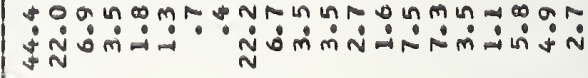

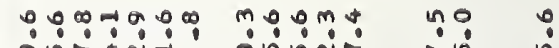

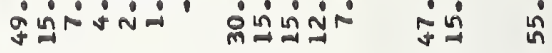

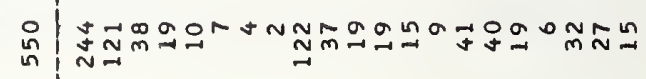

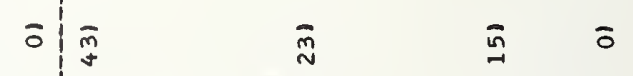

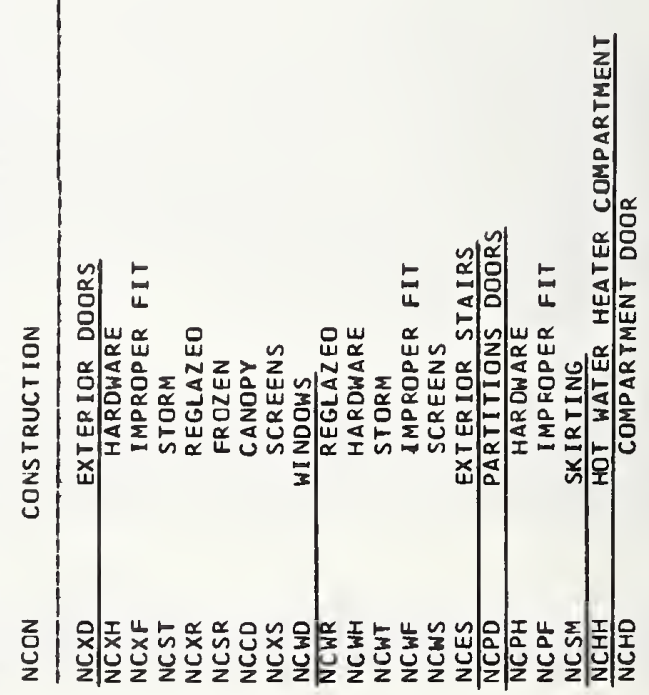




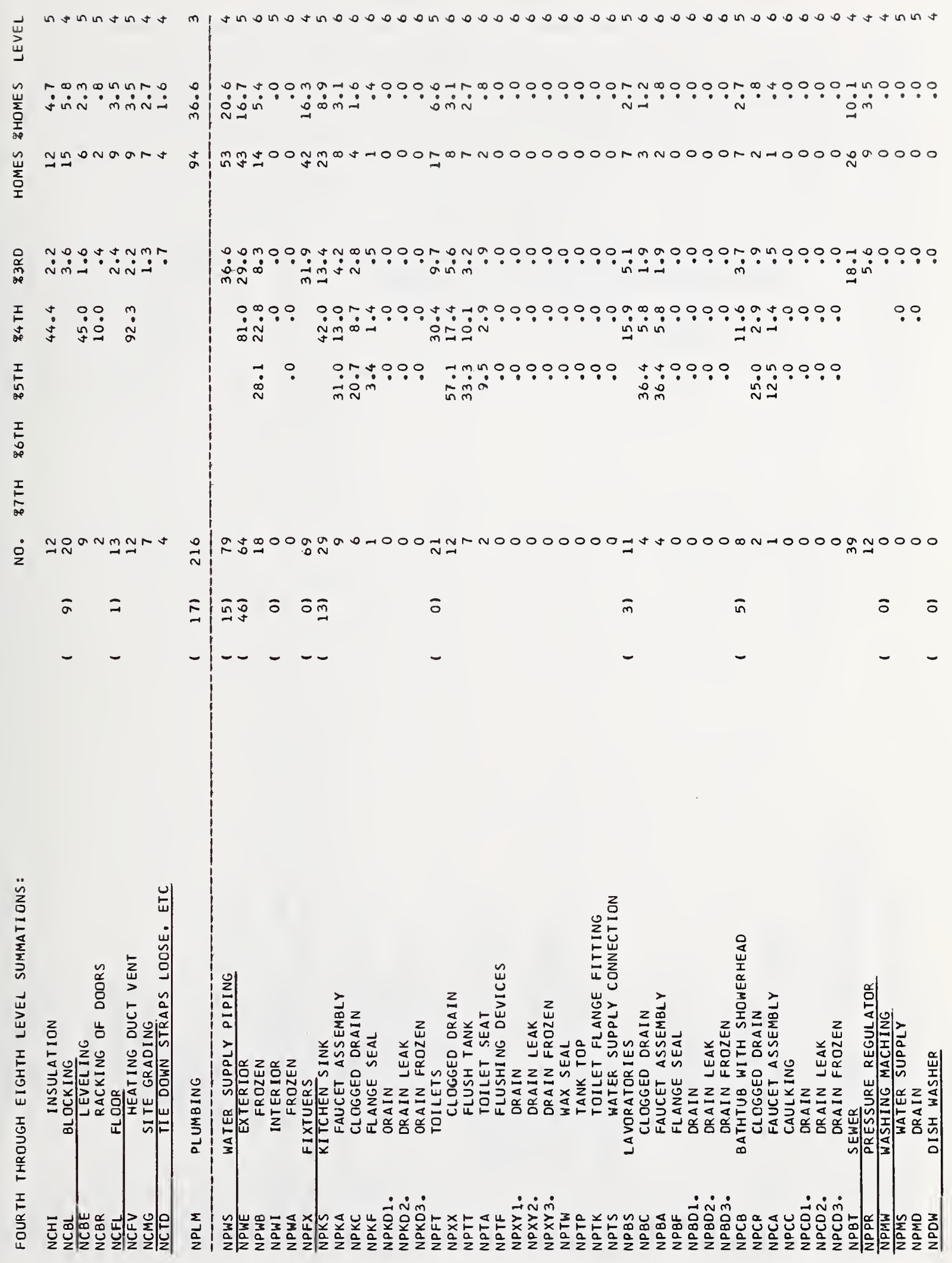



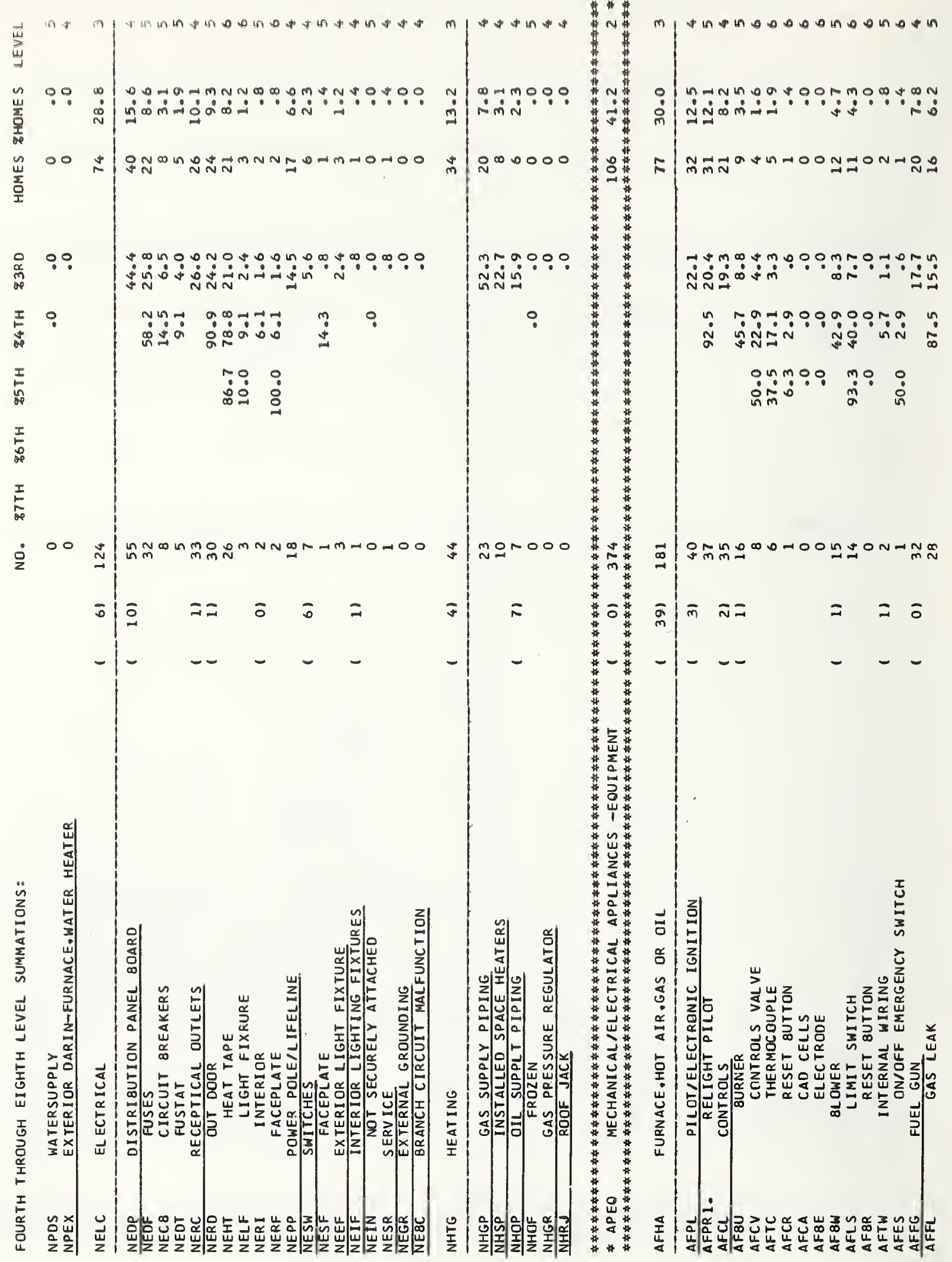


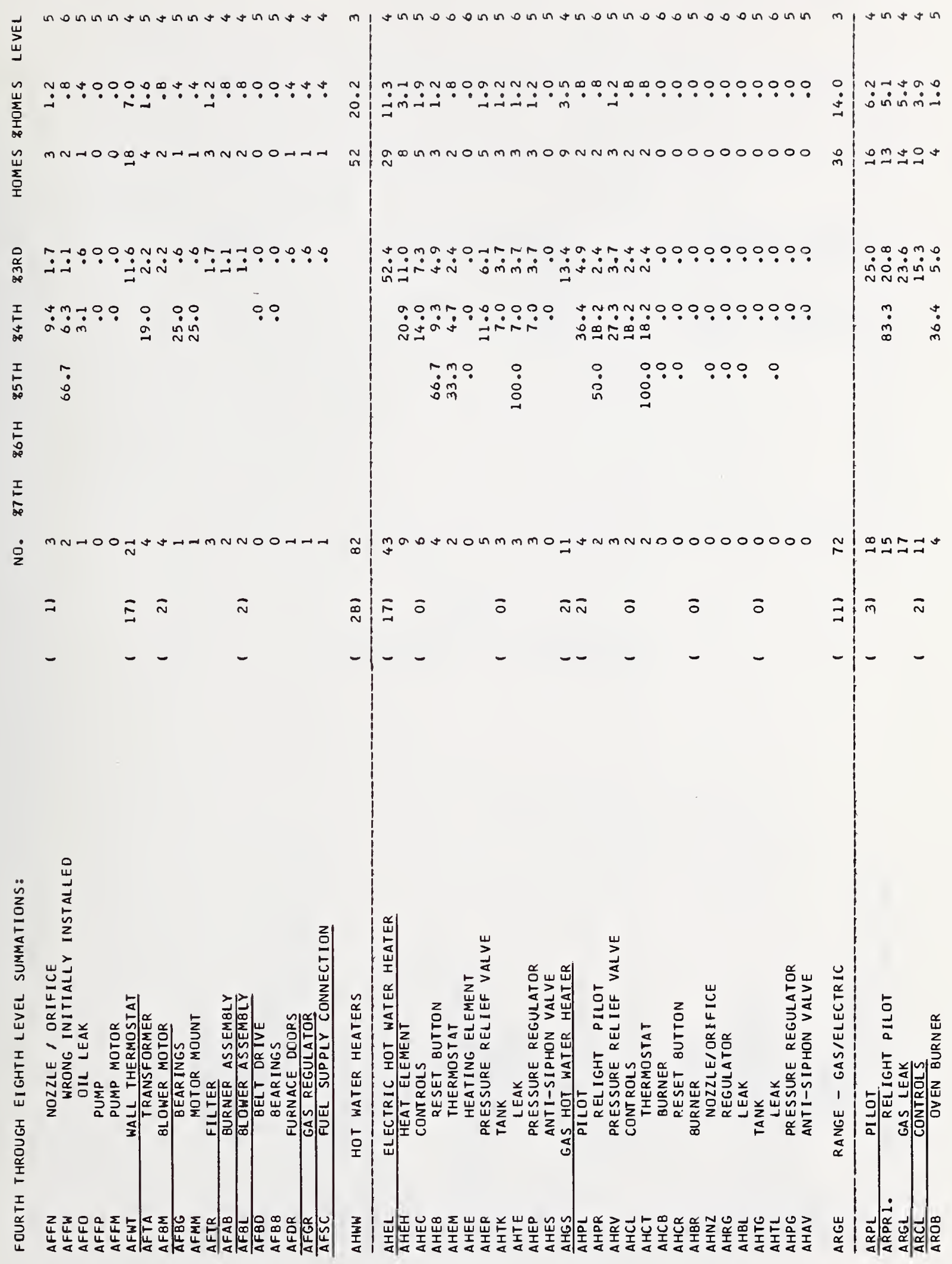




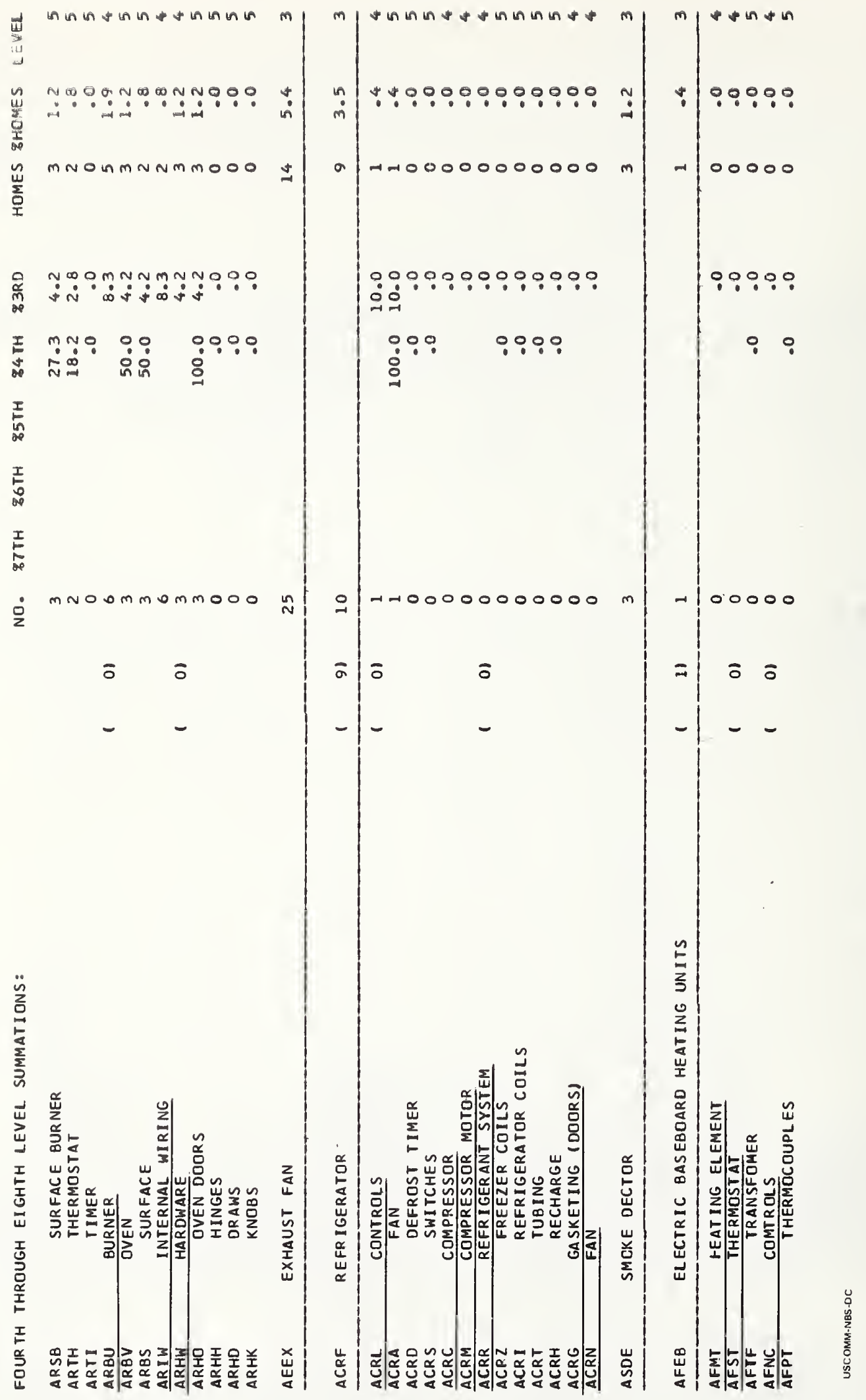


Appendix C

Photographic Documentation 


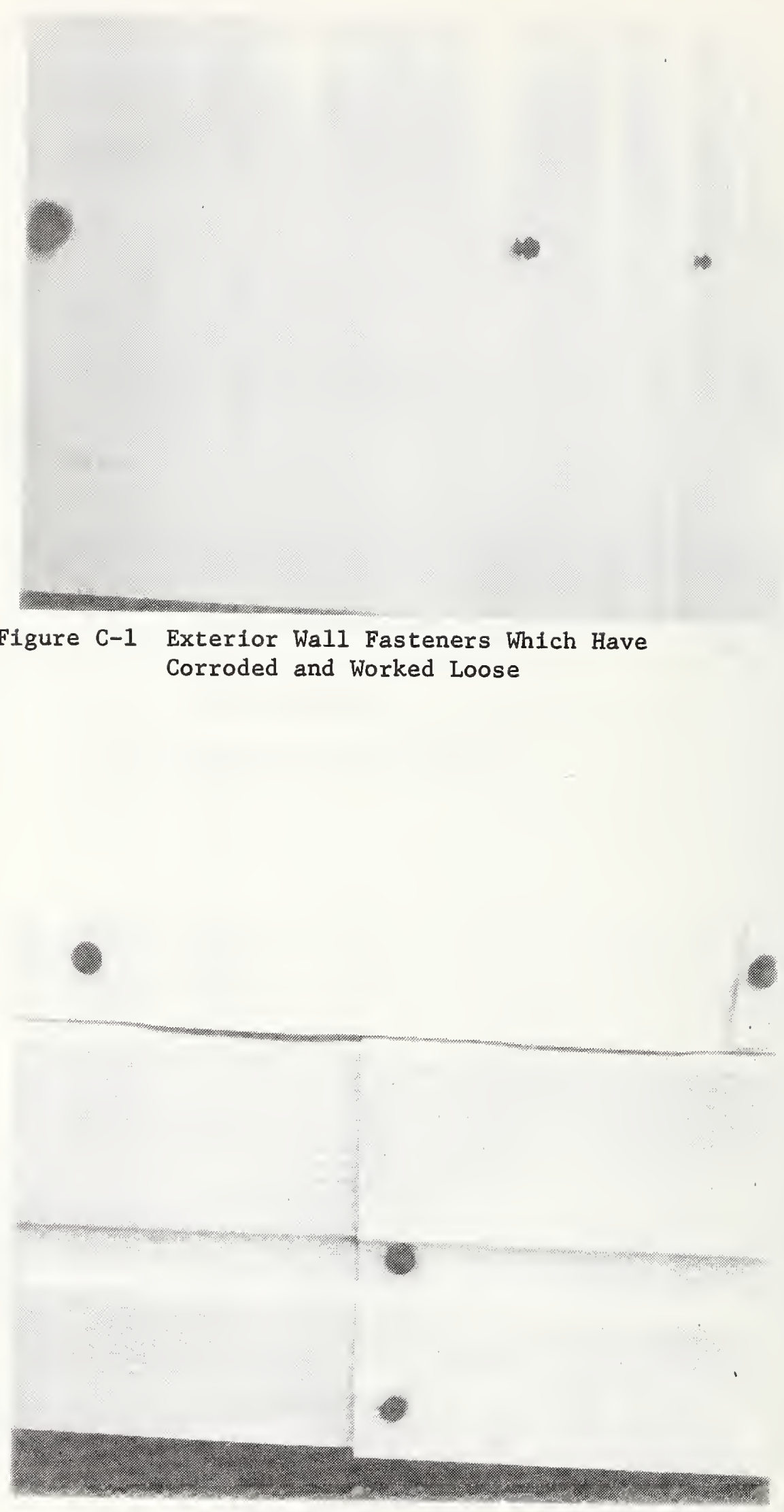

Figure C-2 Rusted Exterior Fasteners 


\author{
Figure C-3 Rusted Exterior Fasteners \\ Causing Staining of Siding
}
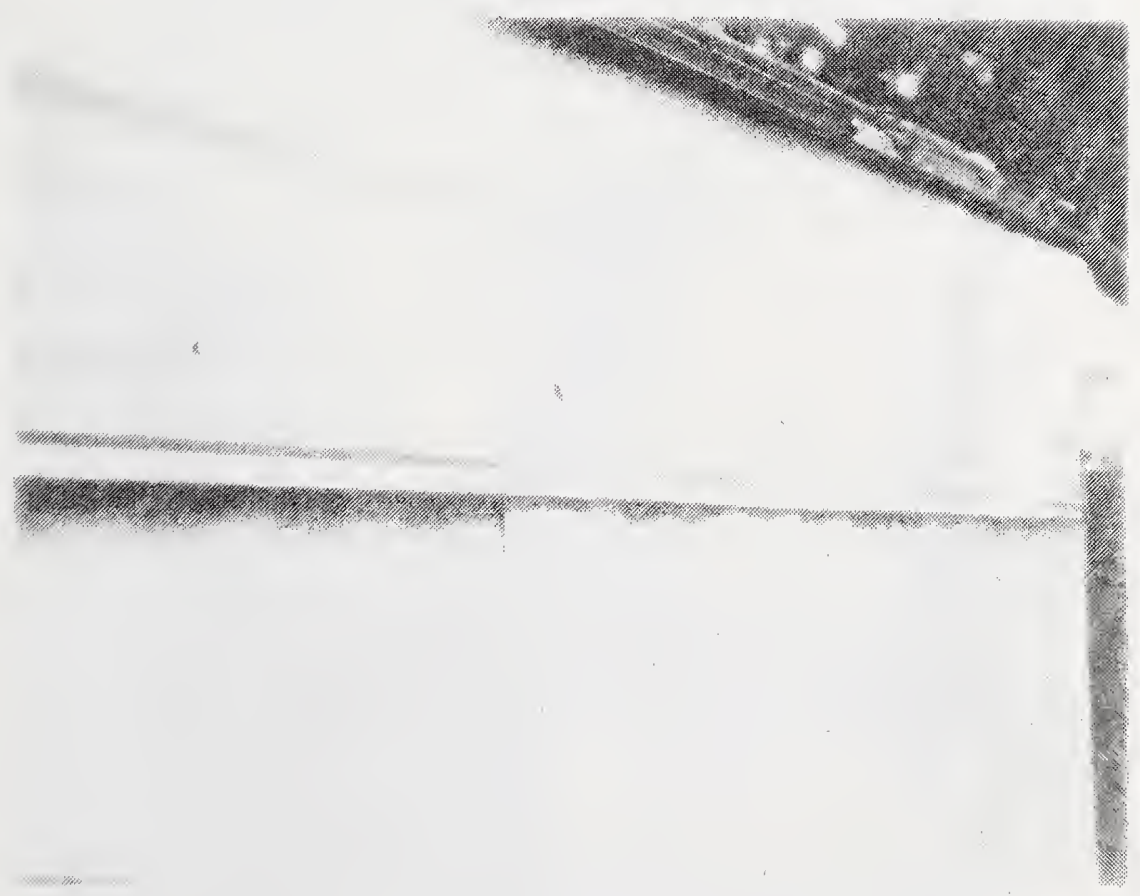

Figure C-4 Exterior Fasteners Pulled Through Exterior Siding 


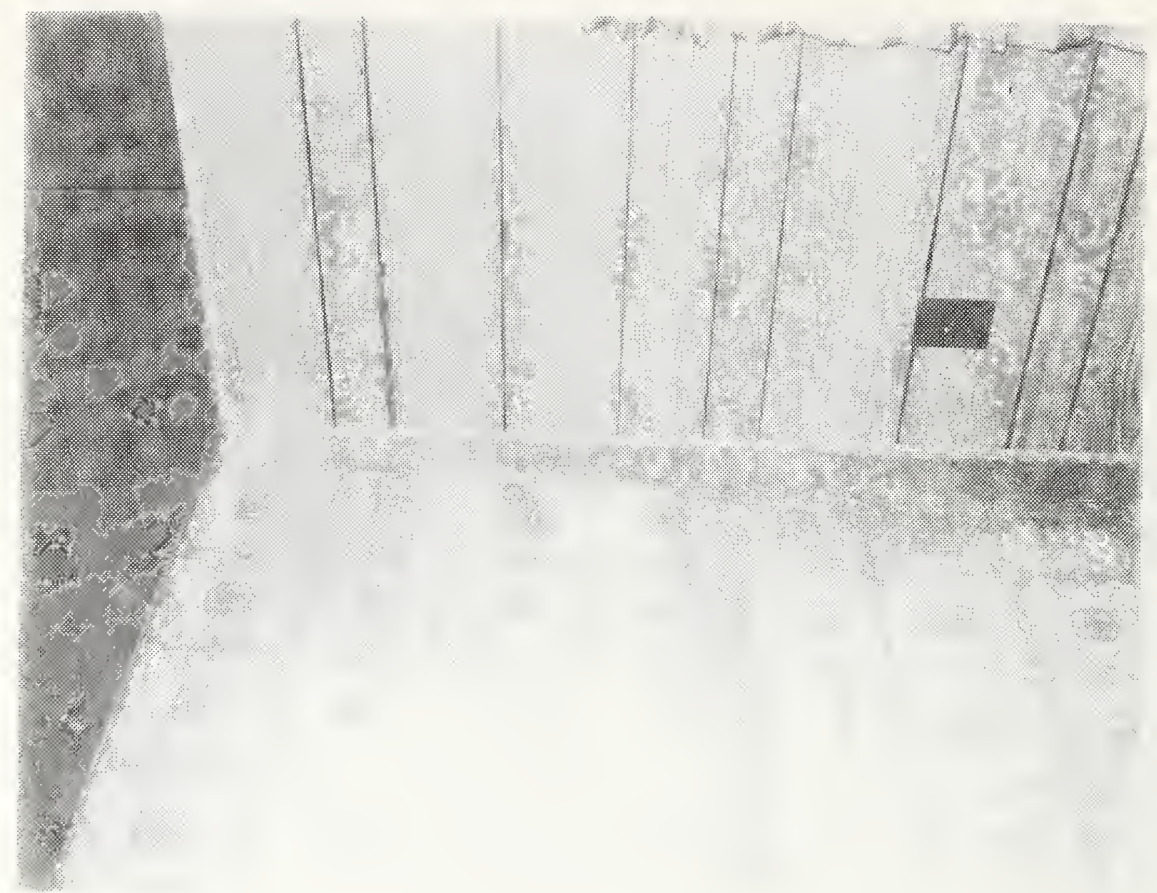

Figure C-5 Water Staining At Wall-Floor Due to Rain Leak Through Exterior Wall

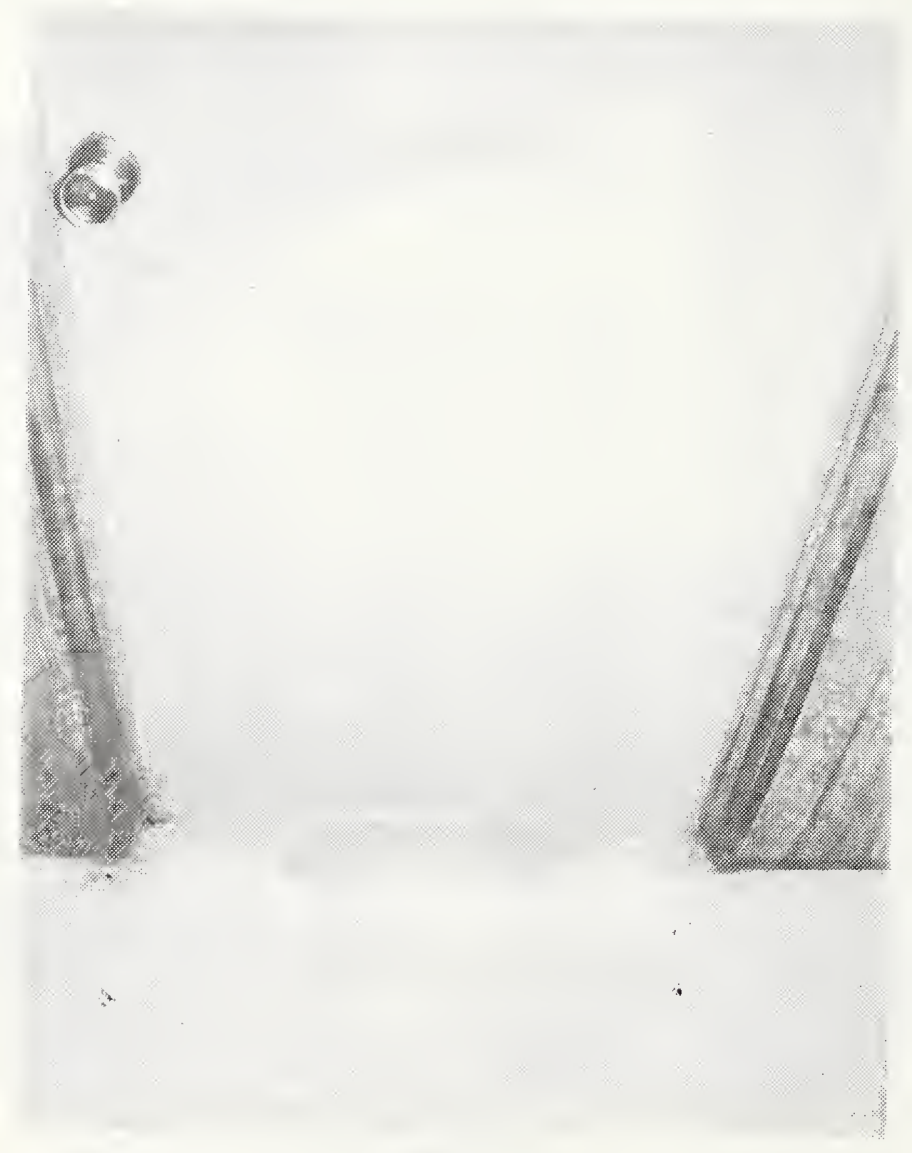

Figure C-6 Rain Leak Staining at

Exterior Door 60 


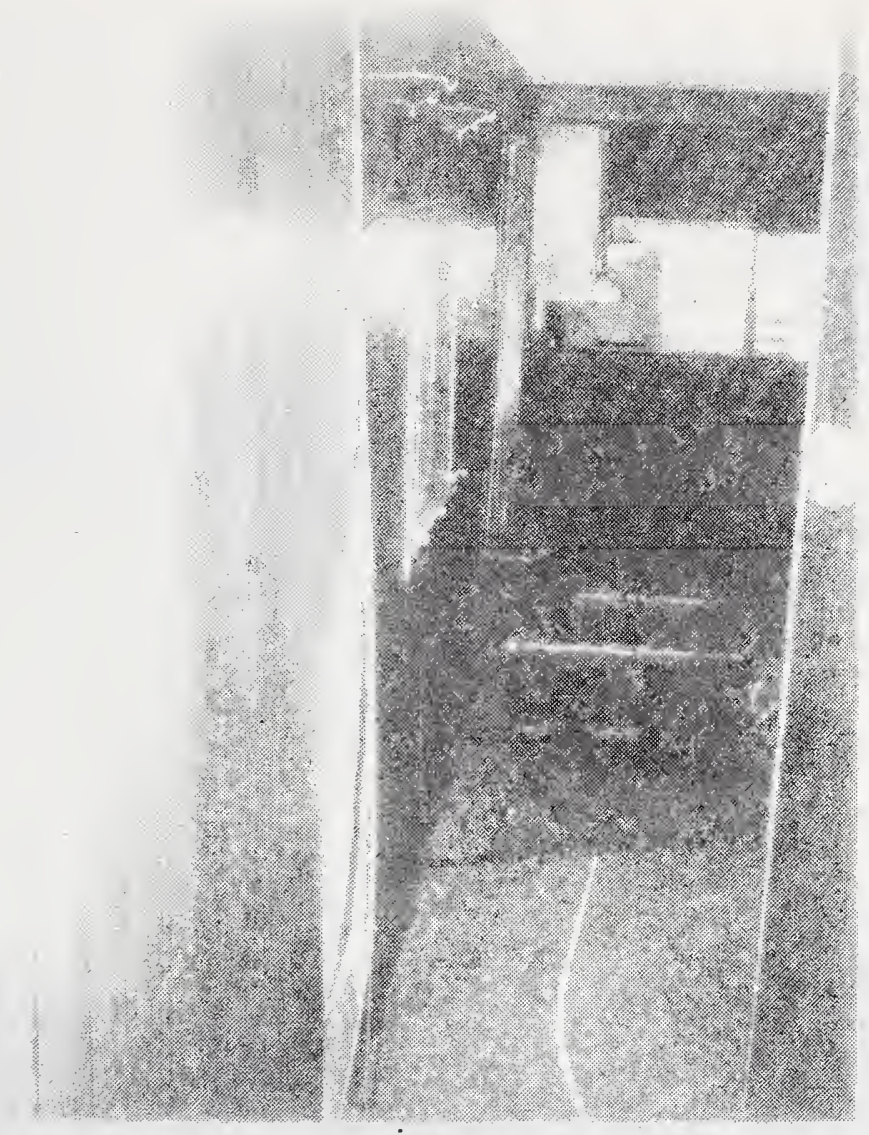

Figure C-7 Buckled Interior Wall Paneling on Exterior Wa11 Due to Water Penetration of Exterior Skin.

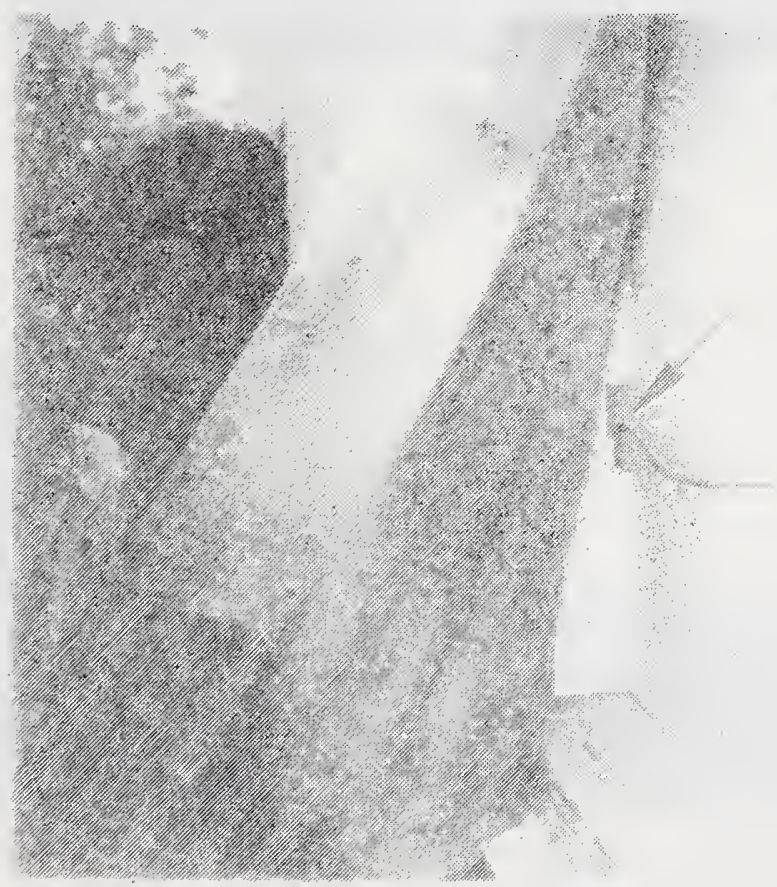

Figure C-8 No Insulation in Exterior Wall Stud Space and Unprotected Electrical Wire Running Through Notched Stud 


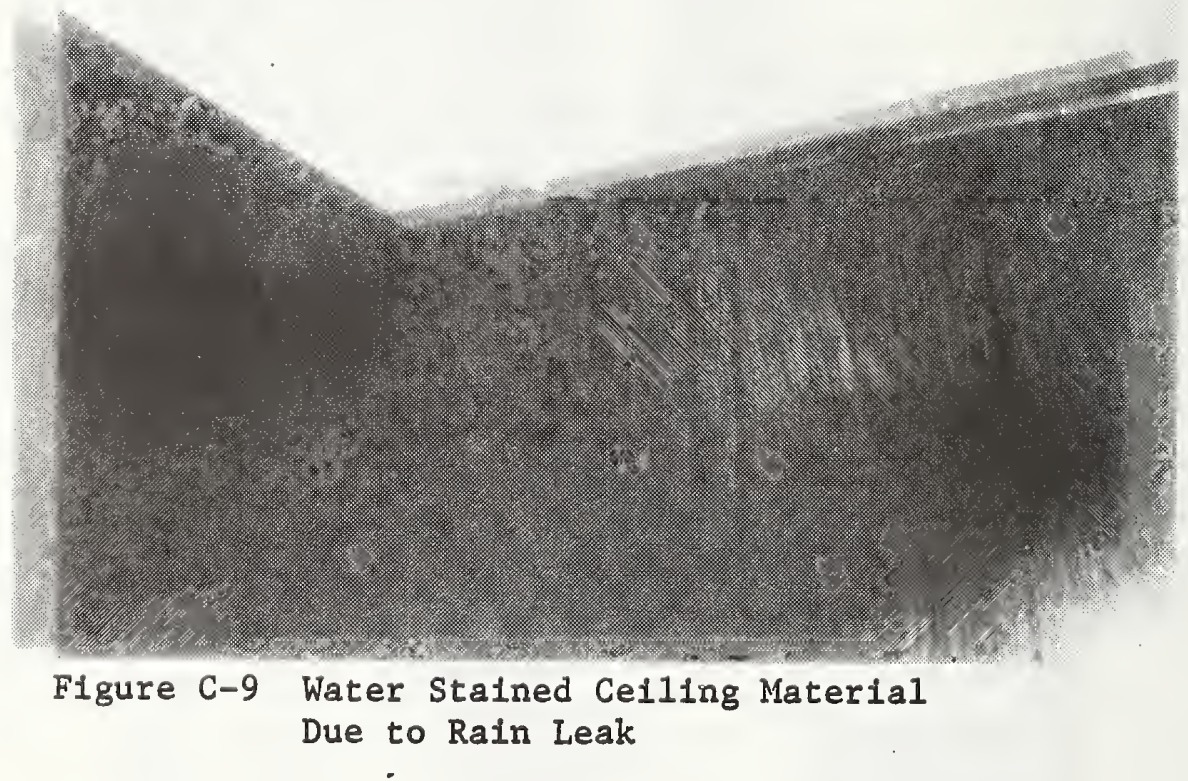




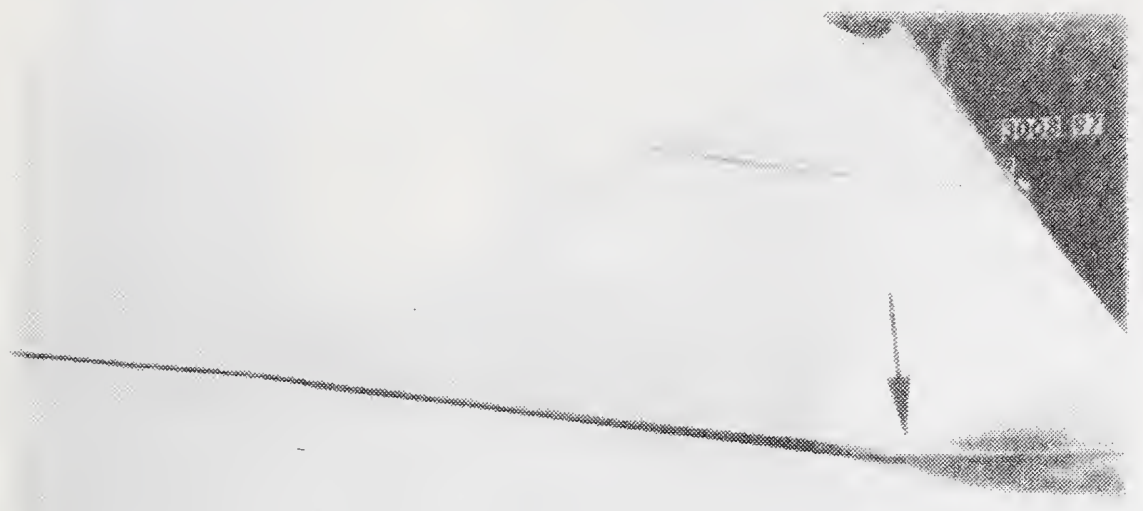

Figure C-10 Damaged Metal Roof Allowing Rain Leak With Resulting Damage Shown in Figure $\mathrm{C}-11$

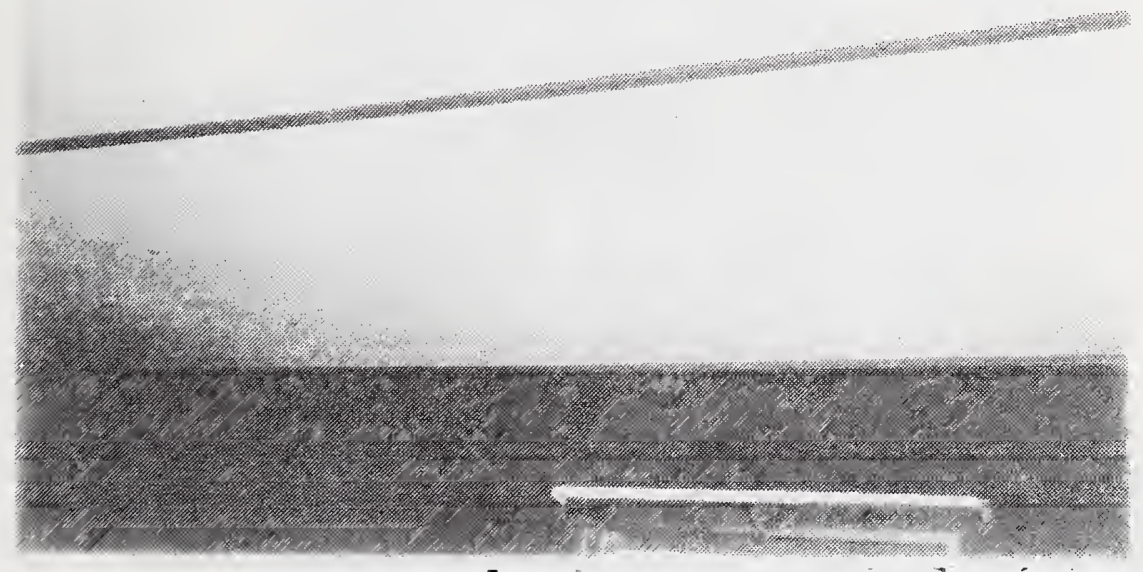

Figure C-11 Water Damage to Ceiling Due to Rain Leak at Roof Membrane Joint 


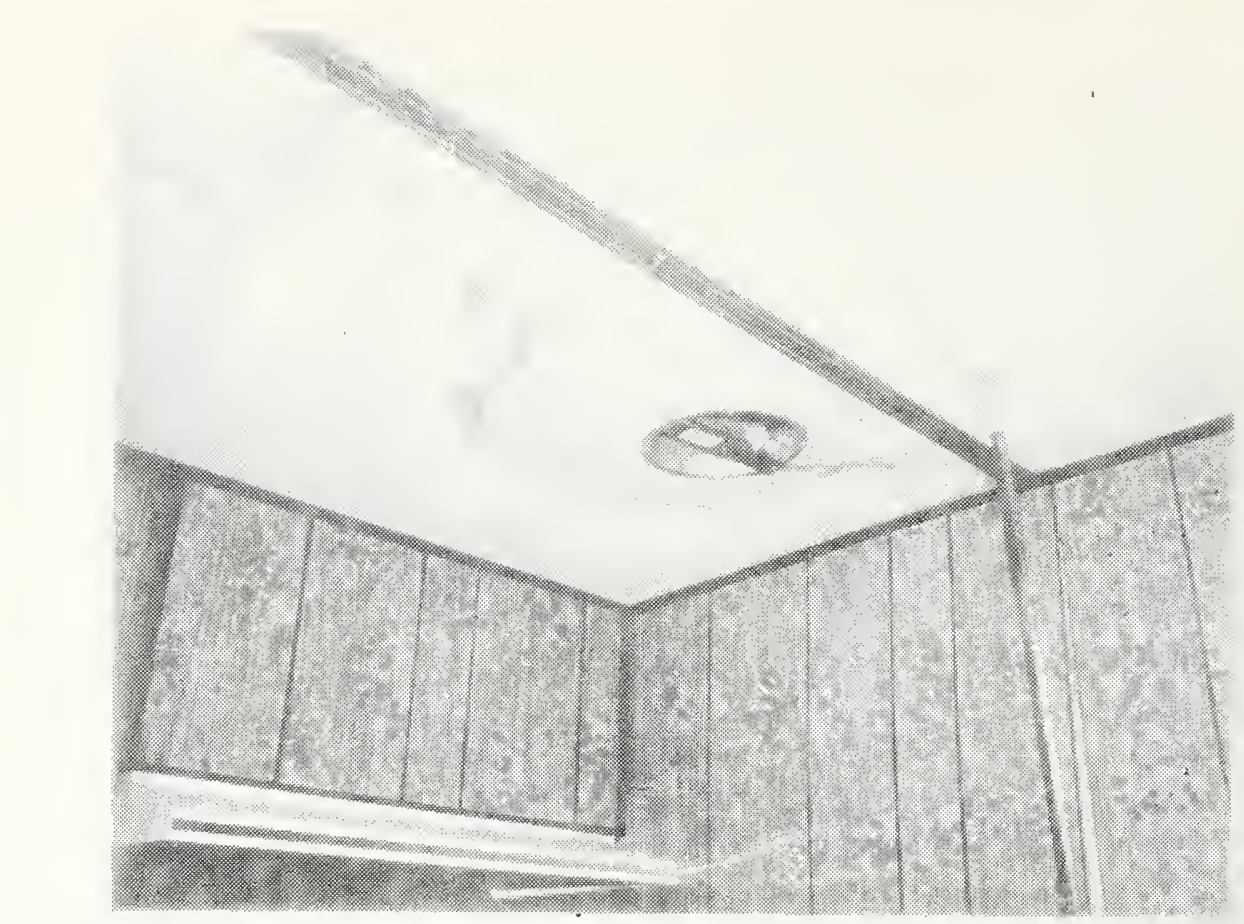

Figure C-12 Water Damage to Ceiling Due to Rain Leak at Vent Stack Penetration Through Roof

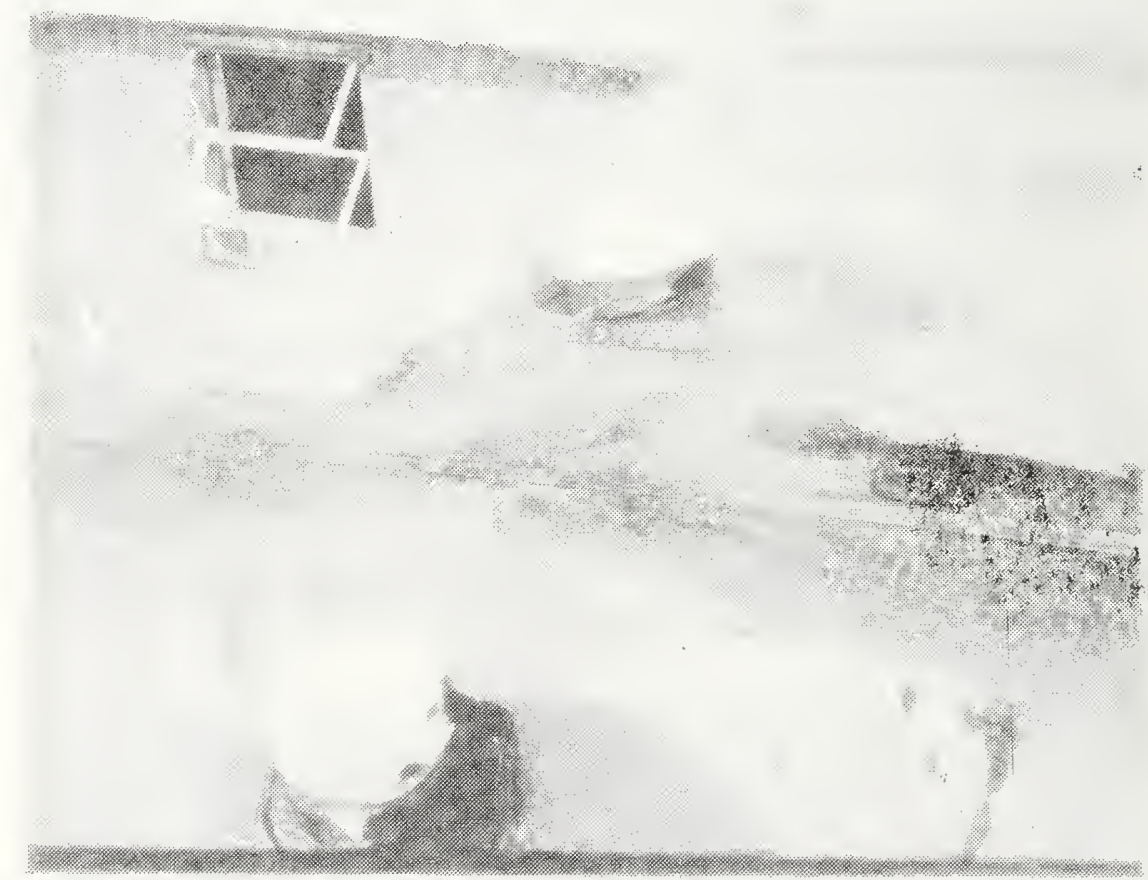

Figure C-13 Application of Coating Material' to Vent Stack Penetration in Roof to Correct Rain Leak 


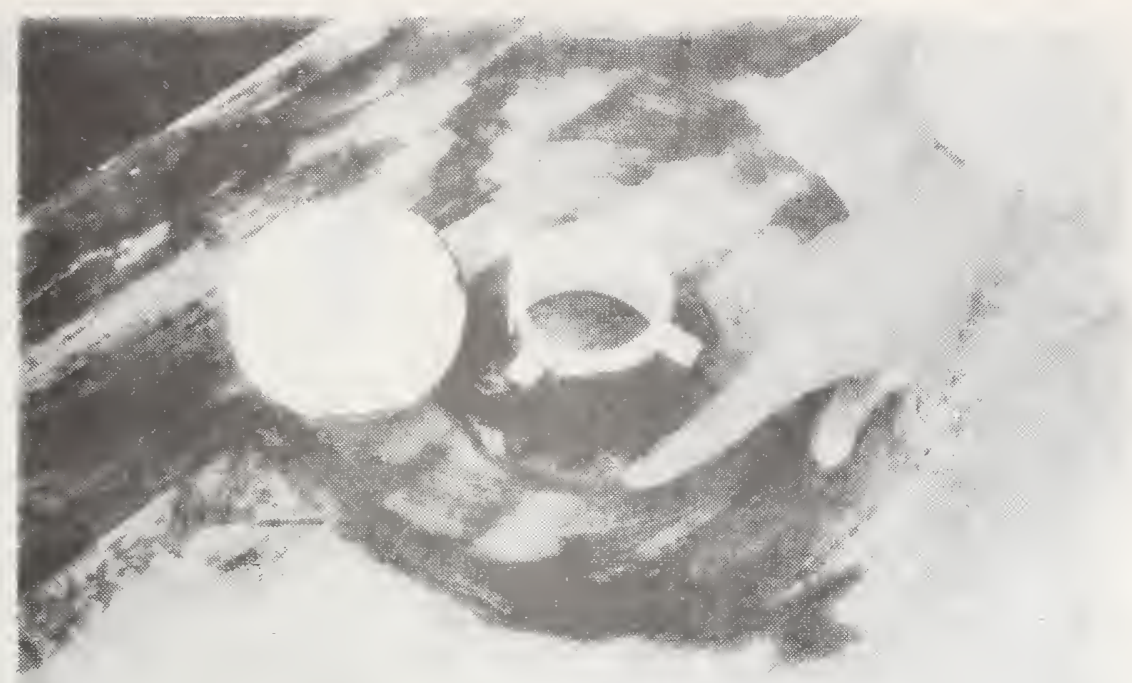

Figure C-14 Rain Leak at Flashing of i Plumbing Vent Pipe

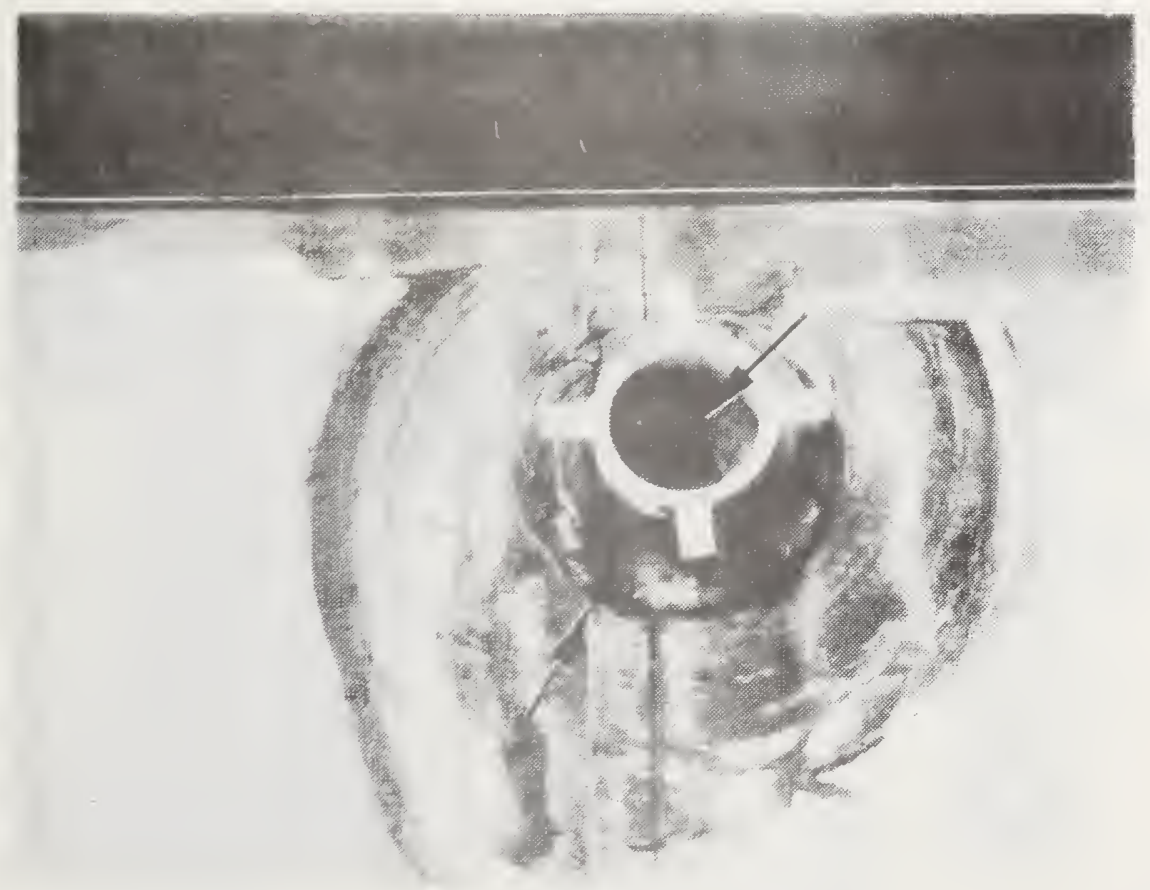

Figure C-15 Rain Leak at Plumbing Vent Pipe Flashing Located at Joint of Metal Roofing. Also, Vent Pipe Does Not Penetrate Roof Coyering 


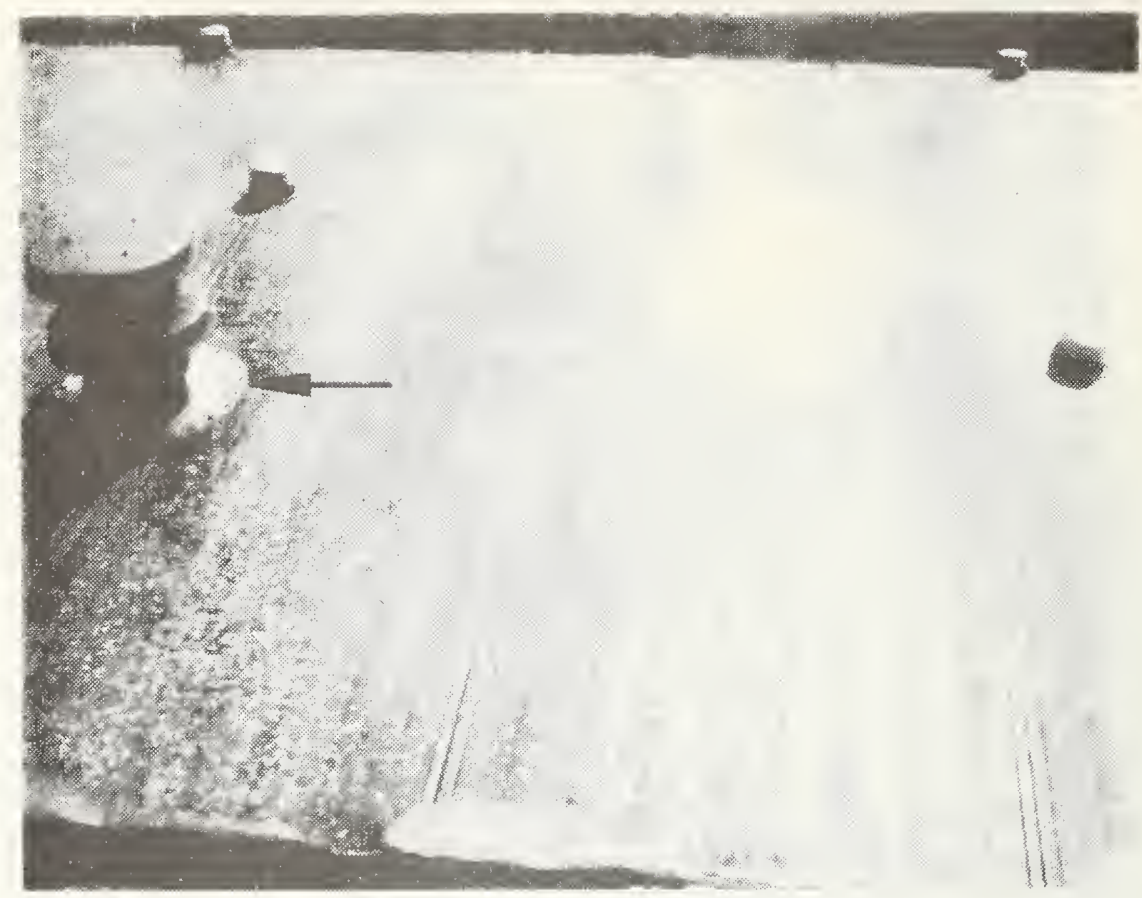

Figure C-16 Ungasketed Heating Vent Pipe Attached With Sheet Metal Screws to Metal Roofing

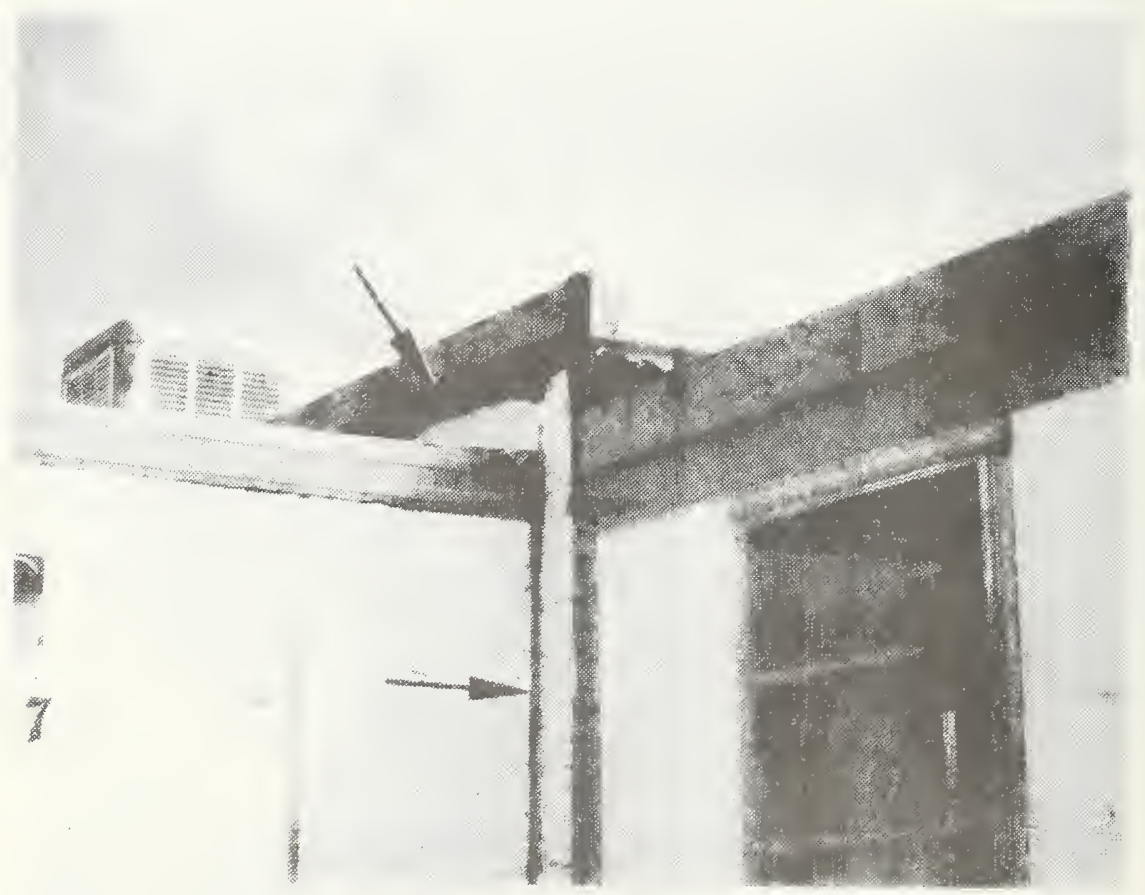

Figure C-17 Application of Coating Material to Repair Water Leak at Tip-out Joint 


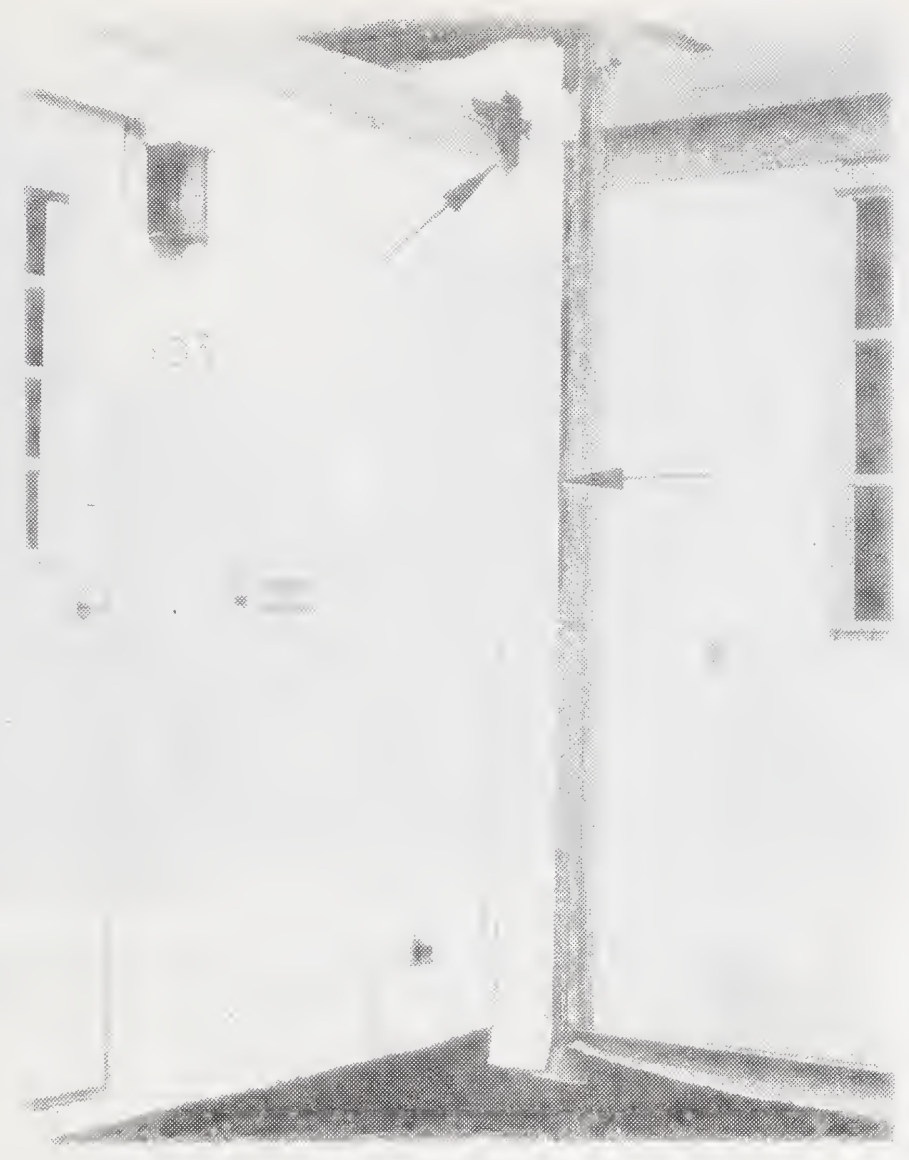

Figure C-18 Location of Rain Leak at Tip-out Joint

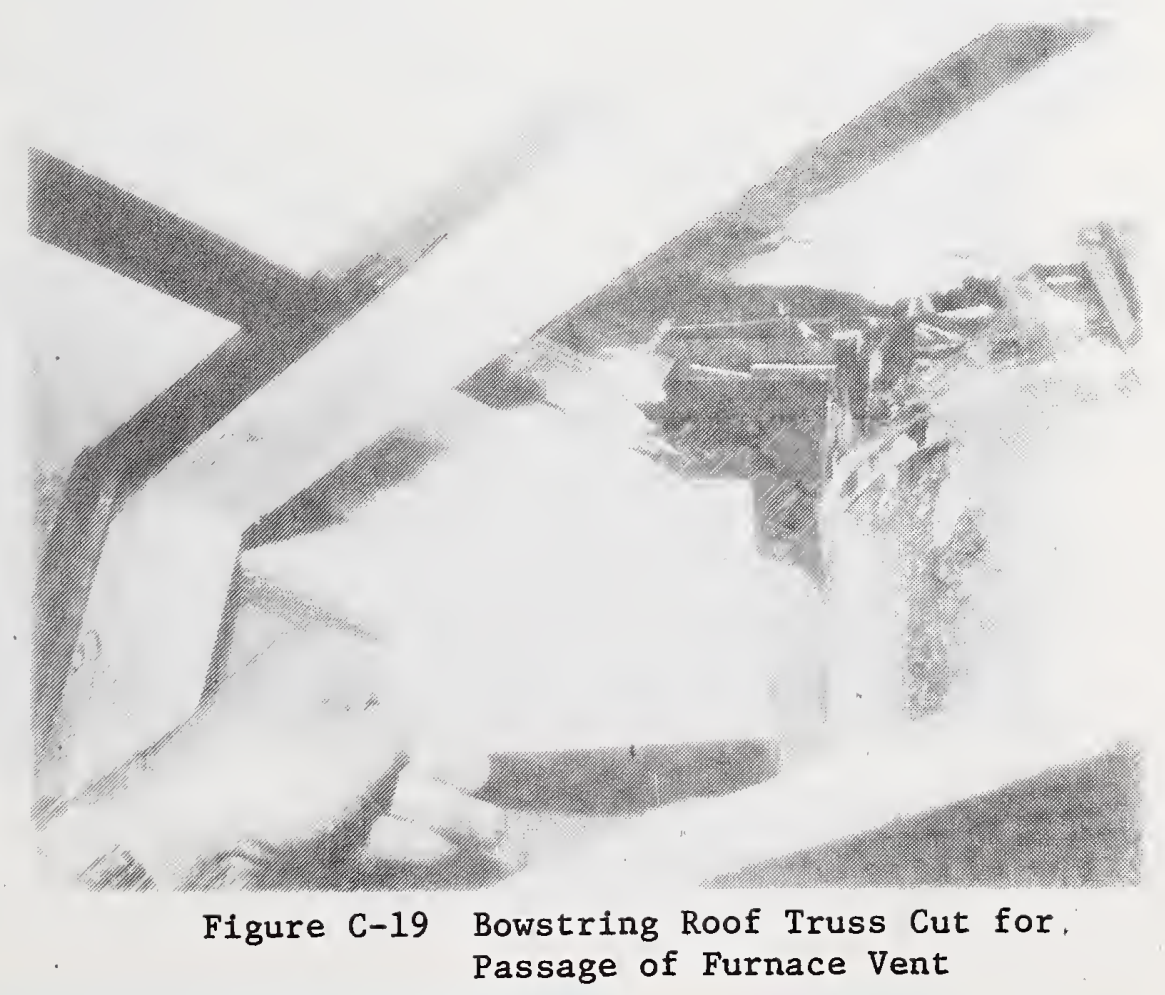




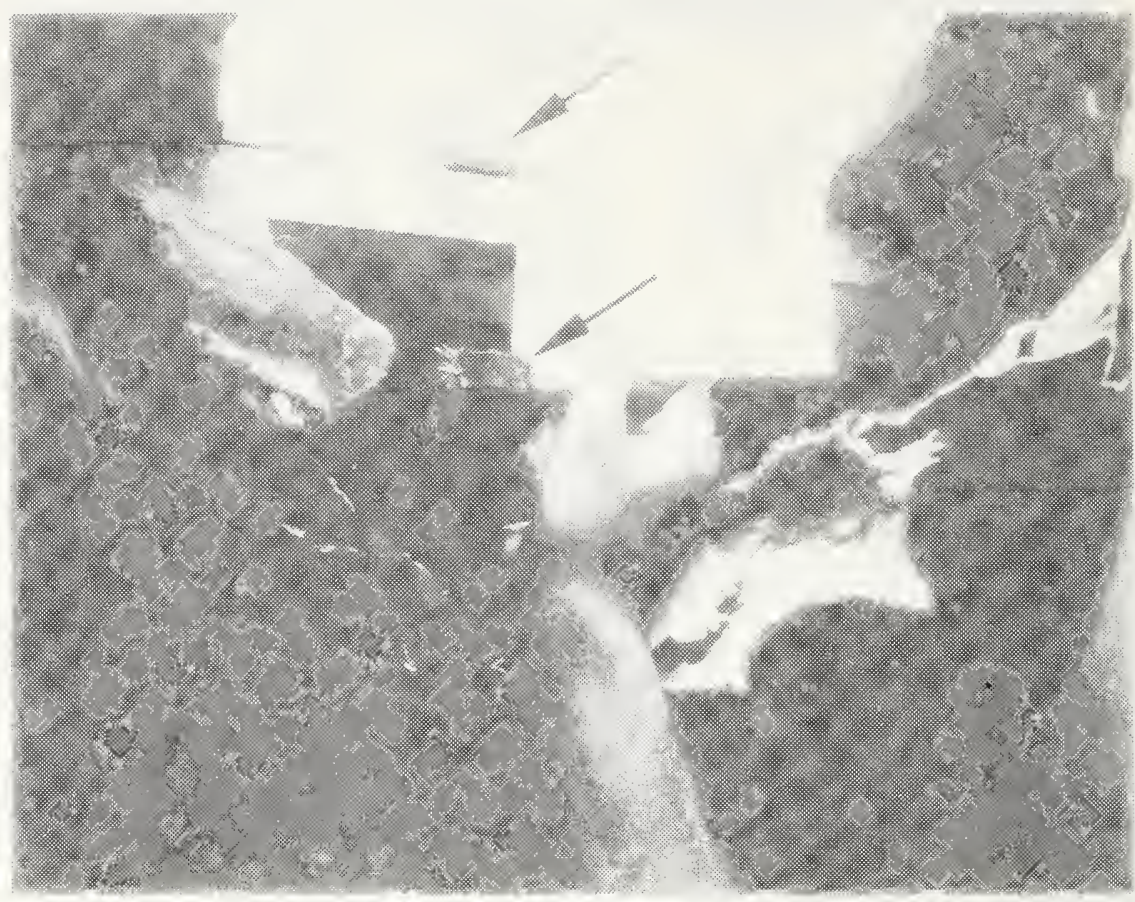

Figure C-20 Compression and Tension Chords of Bowstring Roof Truss Cut for Passage of Furnace Vent

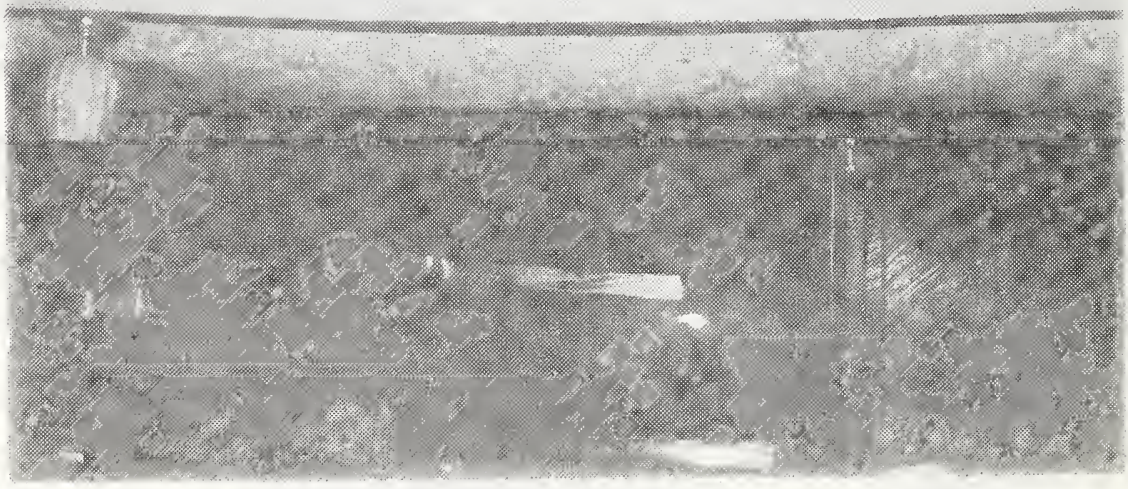

Figure C-21 Deflection of Ceiling Indicating Failure of Attachment to the Roof Truss. 


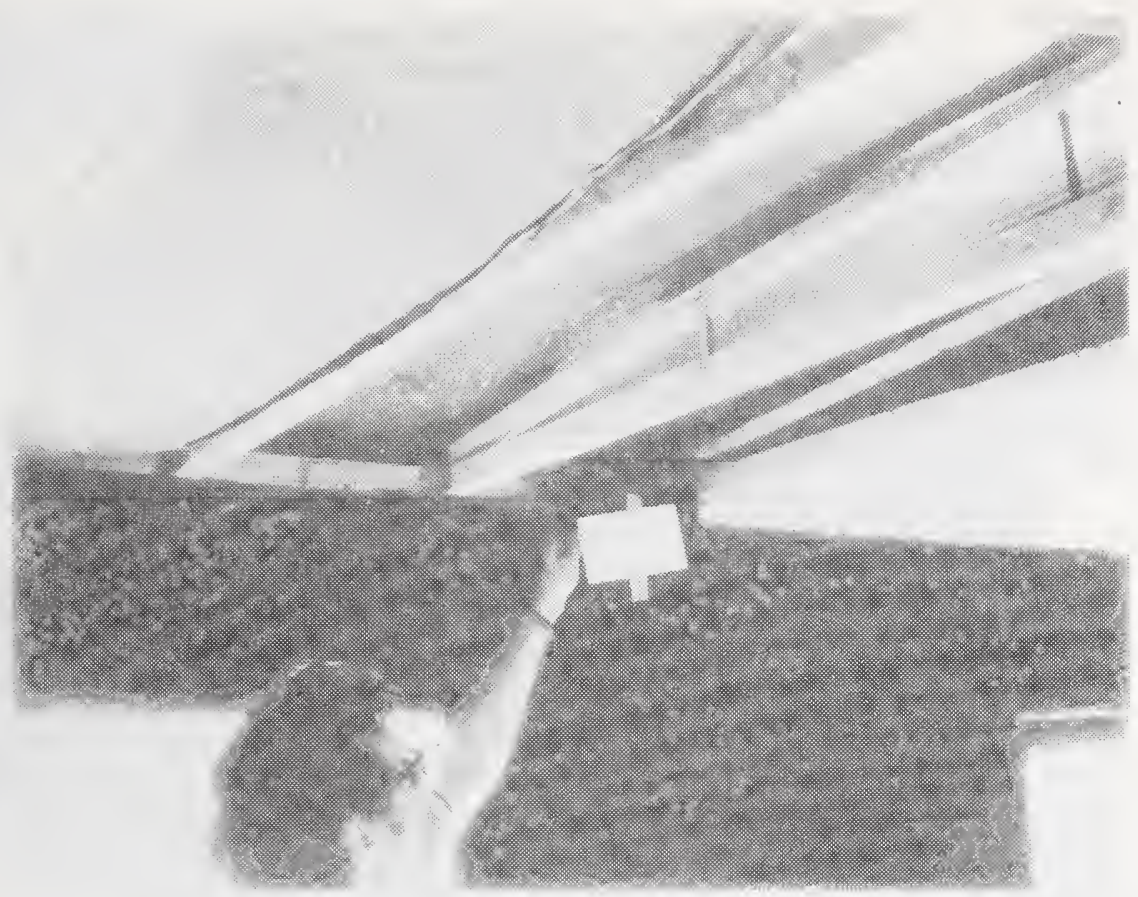

Figure C-22 Insulation Missing in Roof System. Note Metal Roofing Loosely Lying on Roof Truss Which Would Likely Result in "Roof Rumble" in Windy Condition
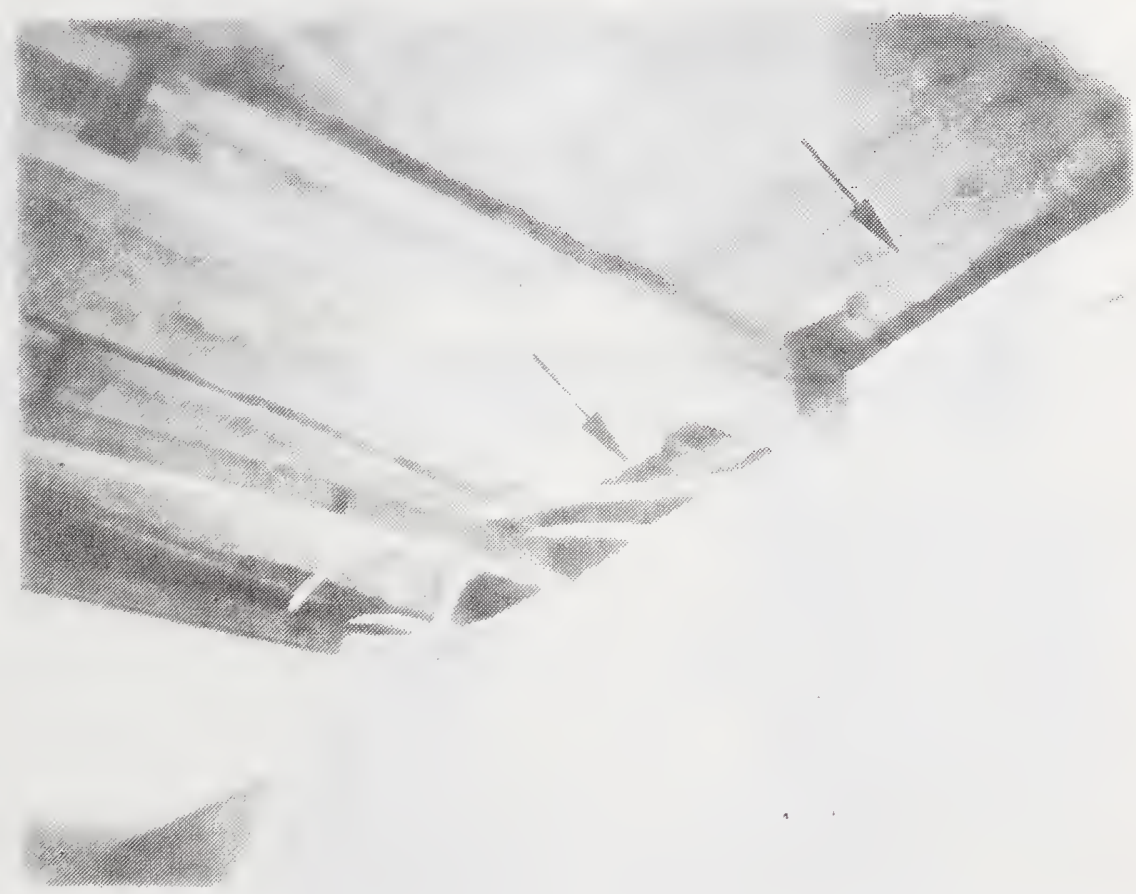

Figure C-23 Insulation Cut Short at Juncture of Roof Truss and Exterior Wall 


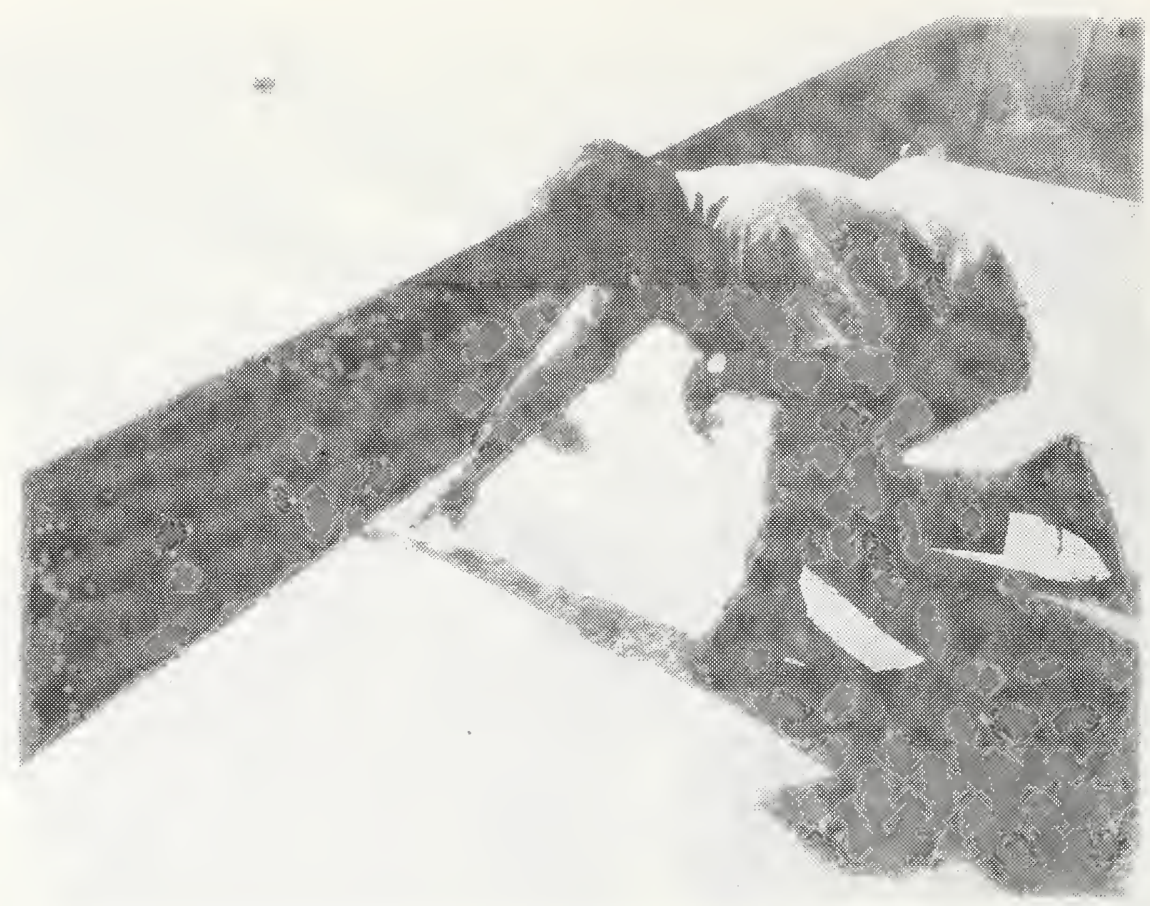

Figure C-24 Improperly Crimped Metal

Membrane at Roof Edge

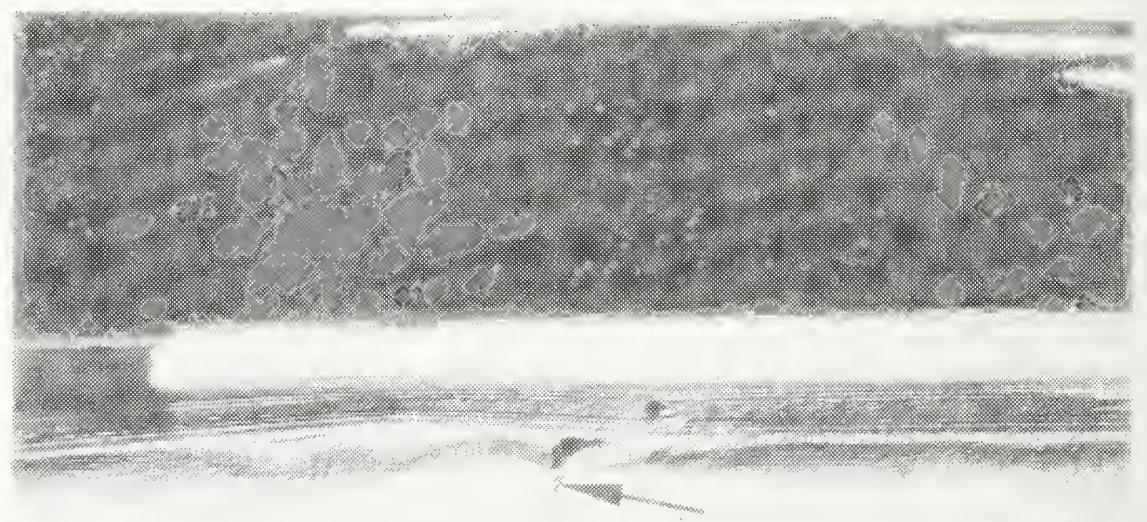

F1gure C-25 "Crack in Crimped Steel Roof Membrane-Water Leak Potential 


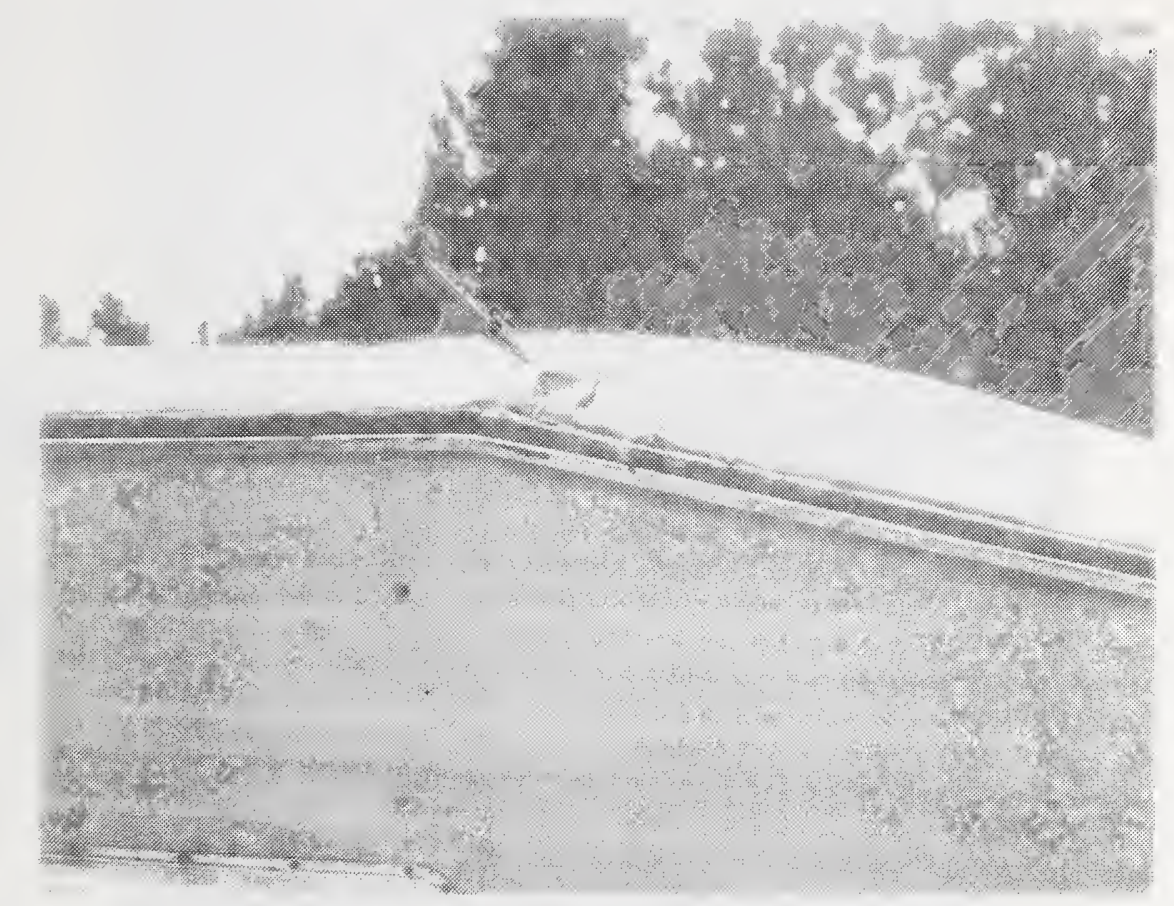

Figure C-26 Crimped Steel Membrane at Change in Słope of Roof
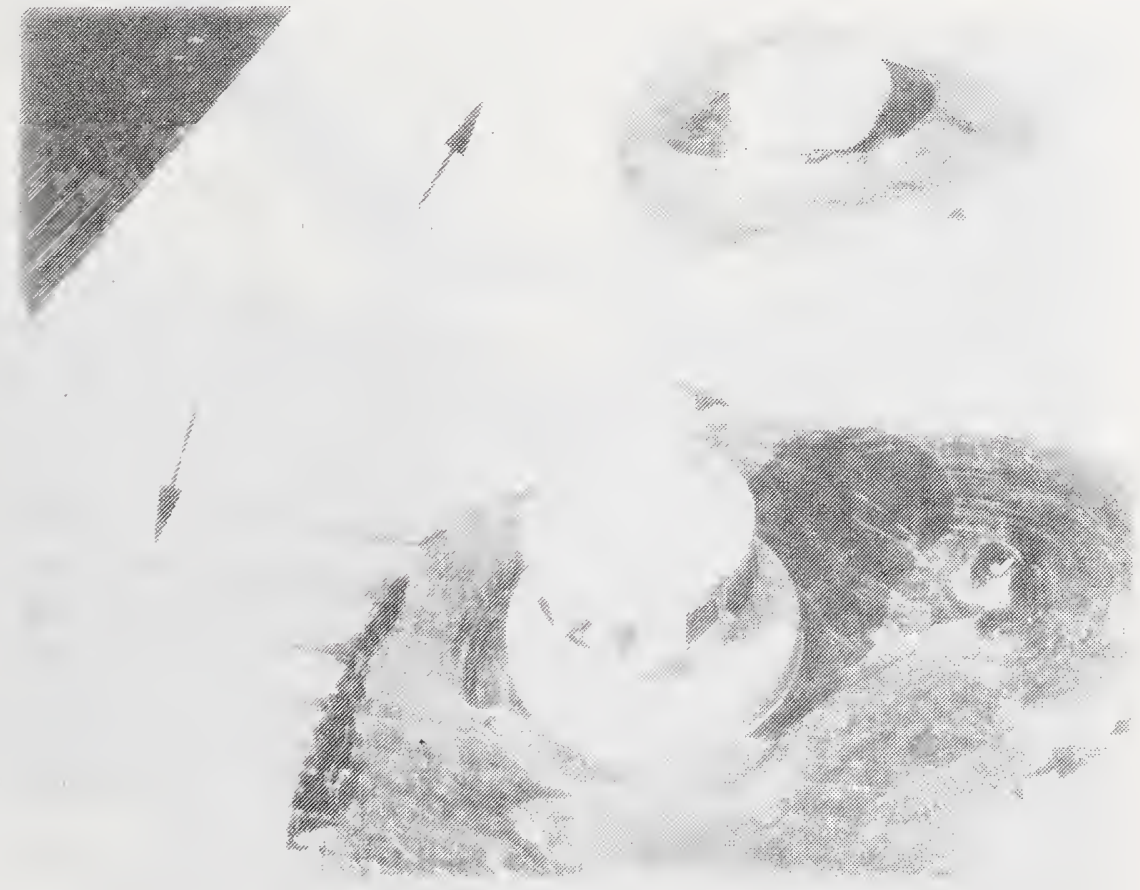

Figure C-27 Rusting Steel Roofing Membrane Near Roof Penetrations Which Have Been Coated With Roofing Sealant 


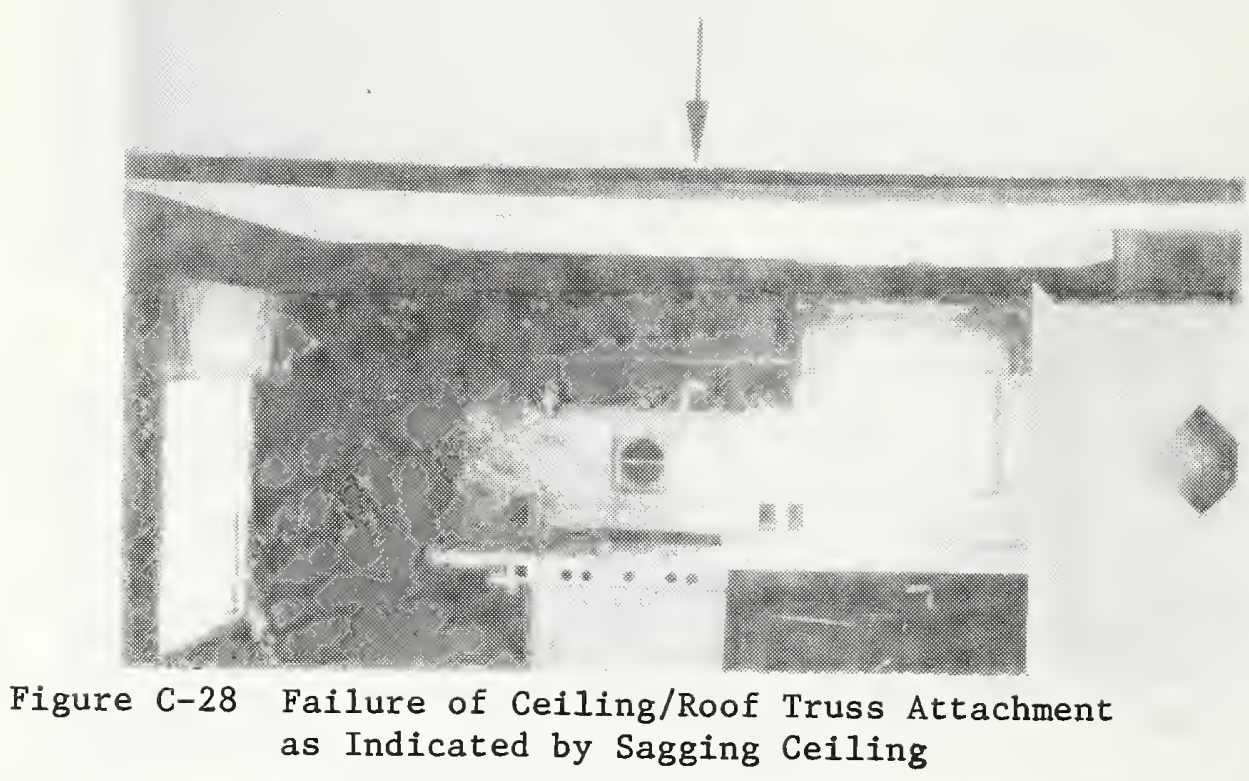

Figure C-29 Loose Interior Paneling to Wall Framing Attachment At Intersection of Exterior Wall and Ceiling 


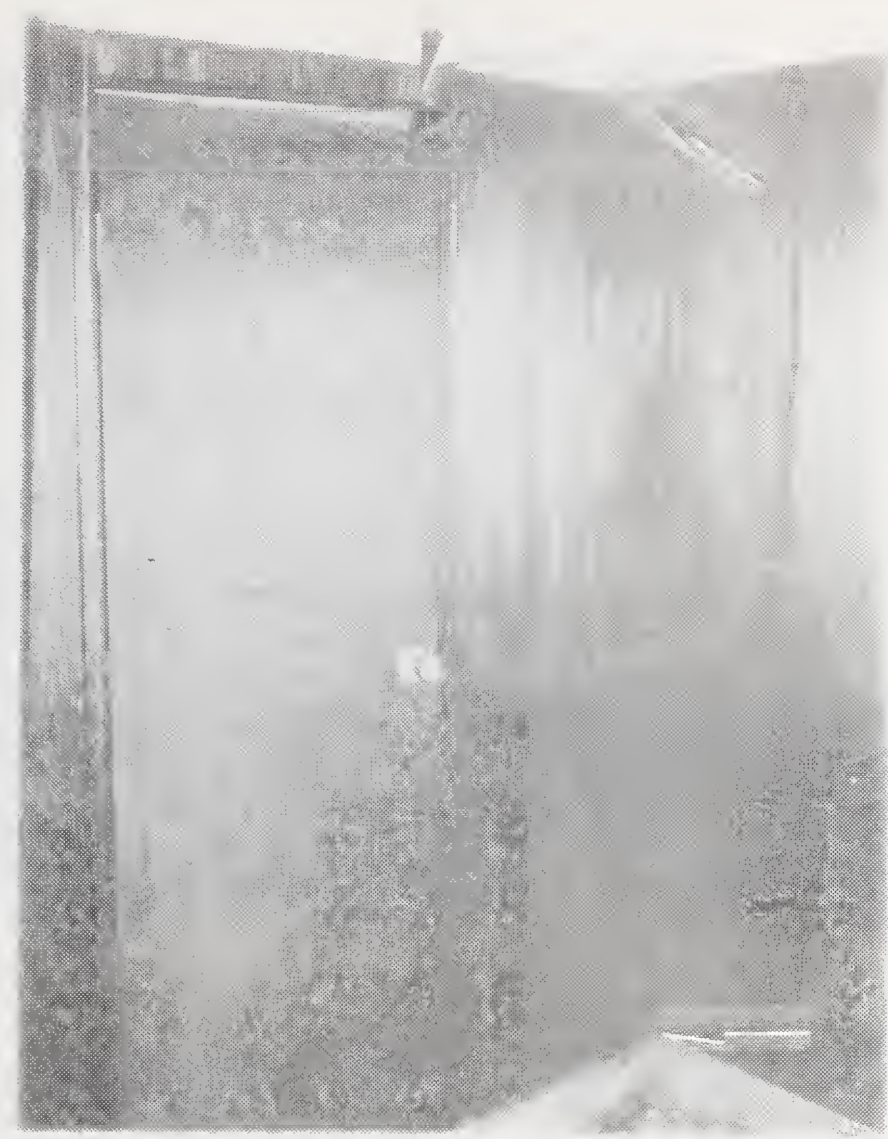

Figure C-30 Distortion of Interior Partition With Door - Due to Undercarriage Damage.

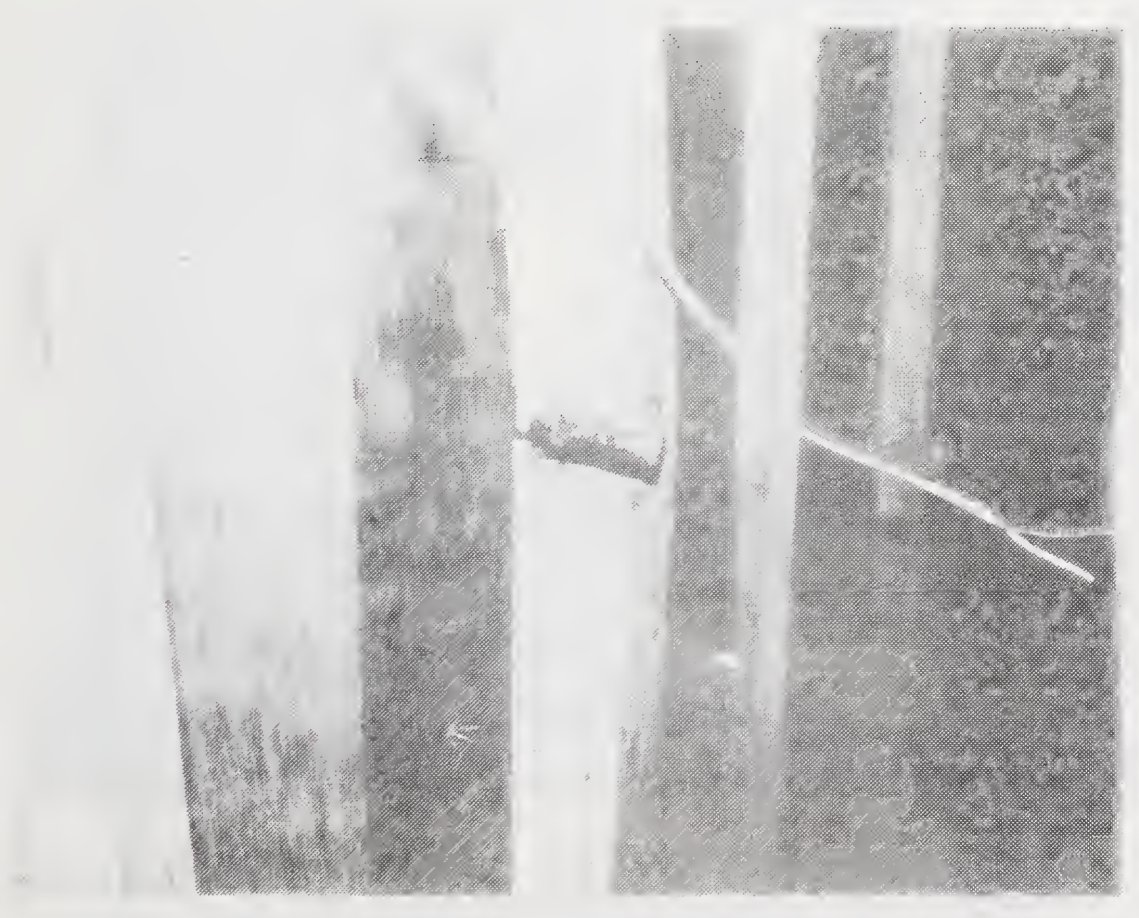

Figure C-31 Load Carrying Failure of Partition Wall Structural Member Due to Inferior Lumber Grade 


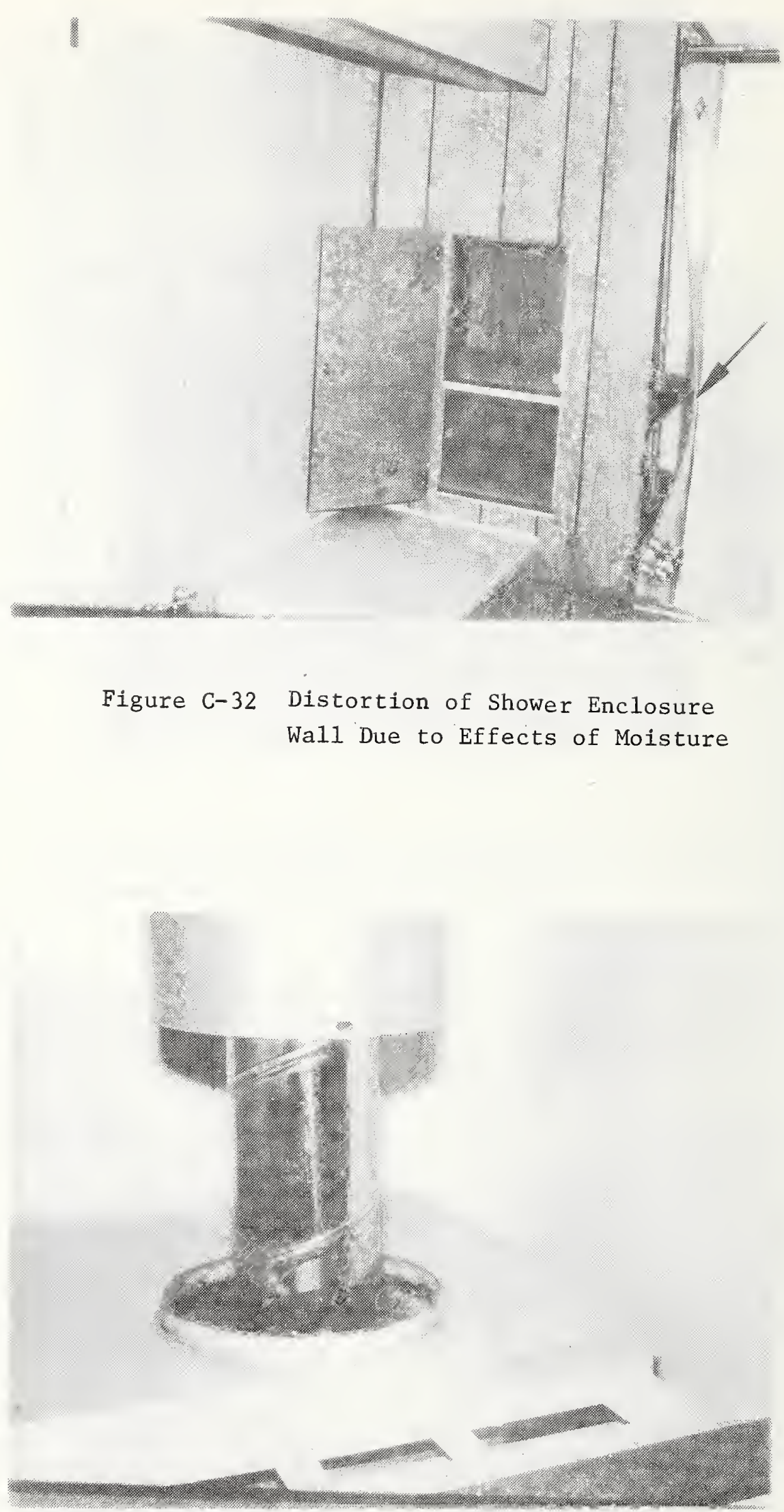

Figure C-33 Construction Detail - Gypsum Board Lining of Furnace Enclosure Wall 


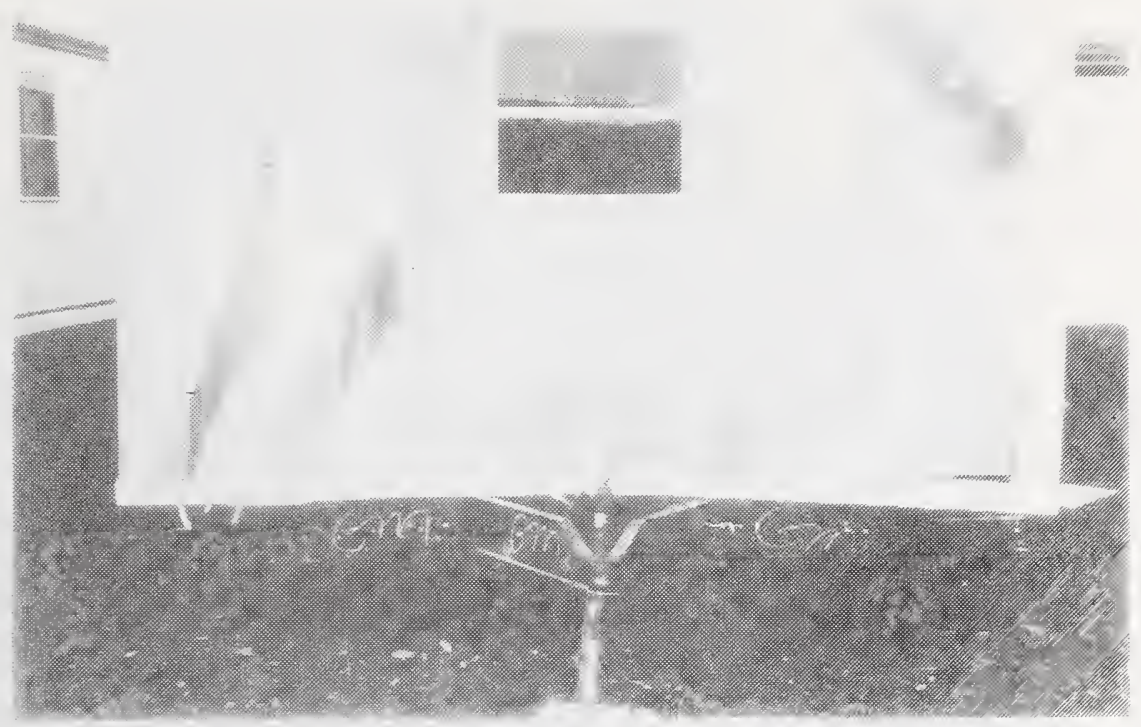

Figure C-34 A-Frame Assembly and Outrigger Failure
Resulting in Damage to Mobile Home - Exterior View.

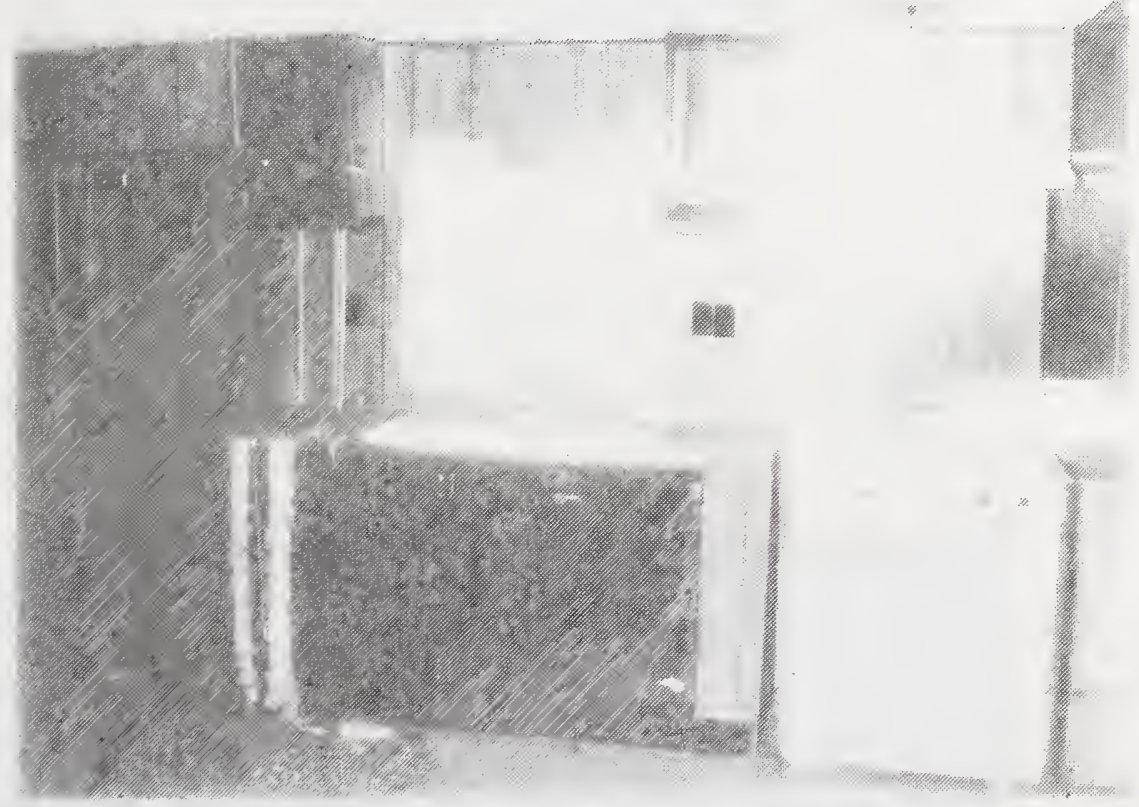

Figure C-35 Result of A-Frame Assembly and Outrigger Failure - Interior View Looking Toward Tongue End of Home Shown in Figure C-34. 


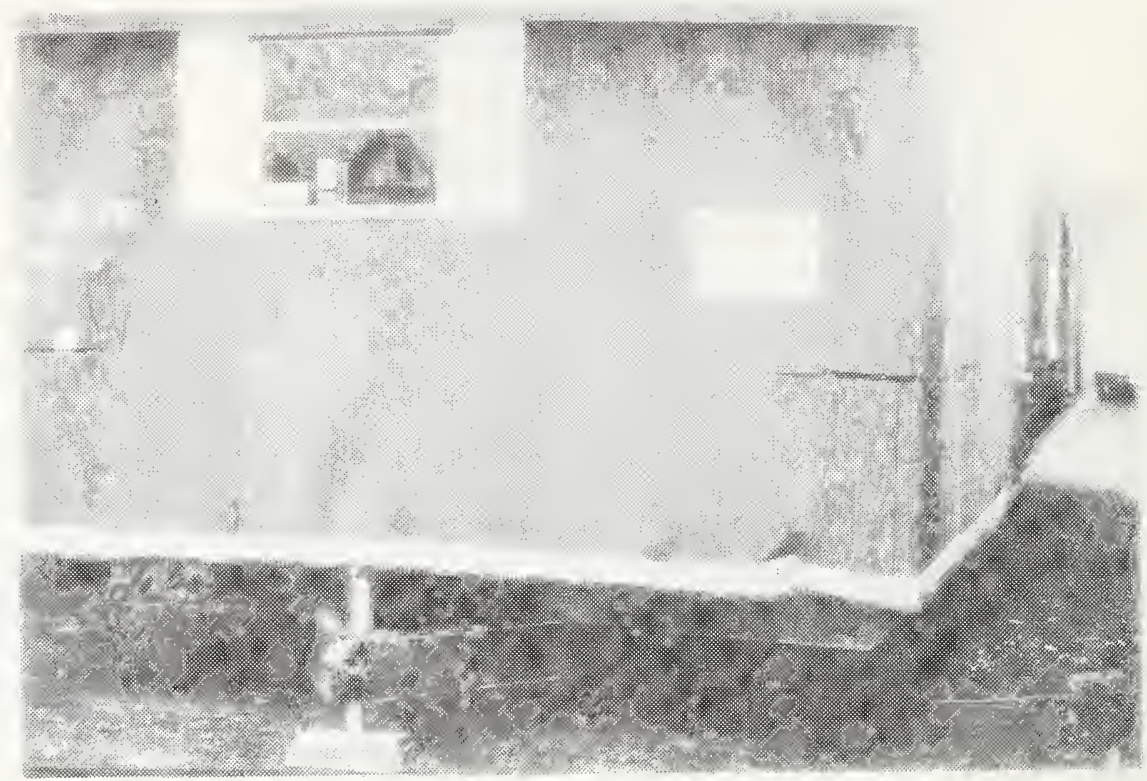

Figure C-36 A-Frame Assembly Failure

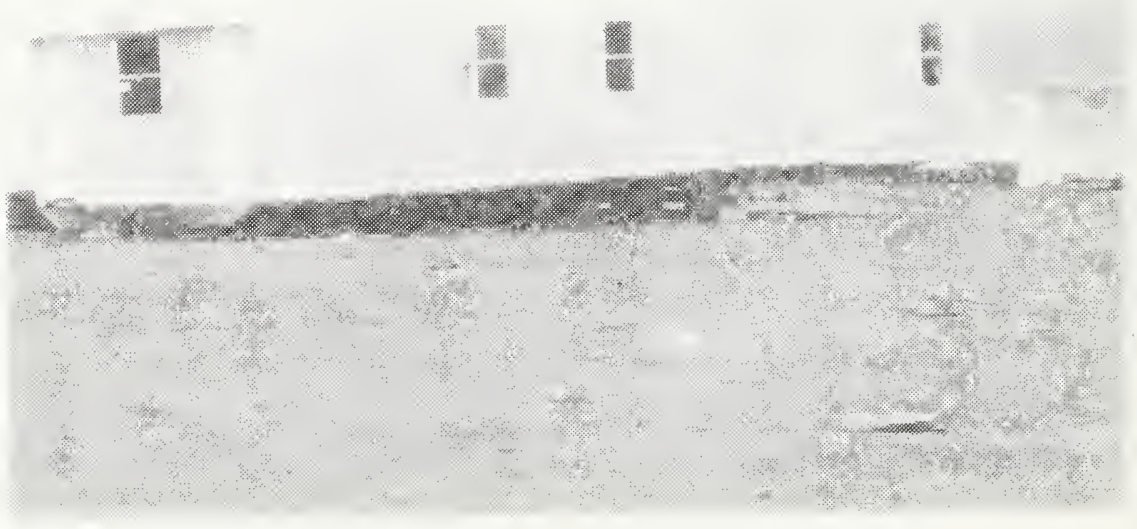

Figure C-37 Longitudinal Member Failure. 


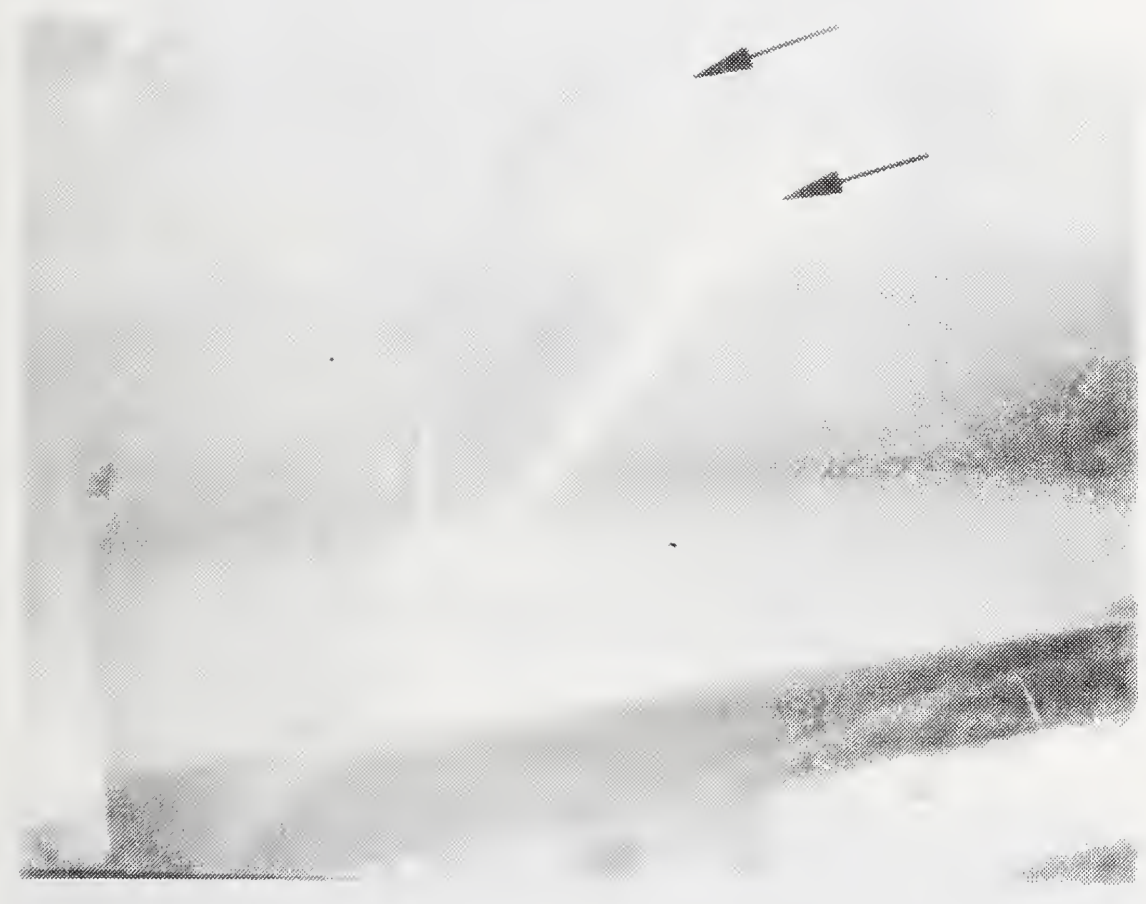

Figure C-38 View of Underside of Mobile Home Weld Failure of Open Web Outrigger. 

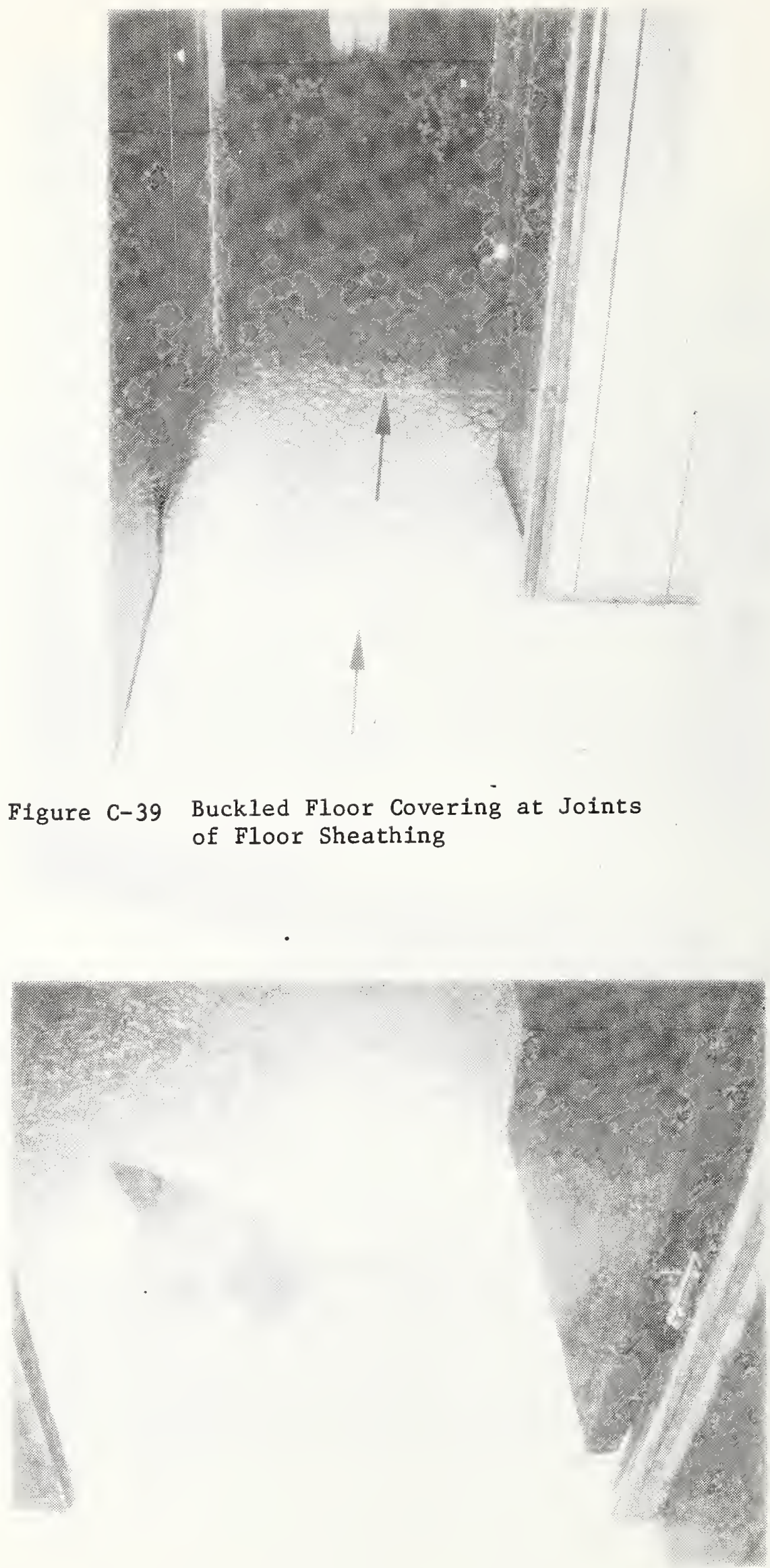

Figure C-40 Damaged Floor Covering at Entrance to Bedroom 


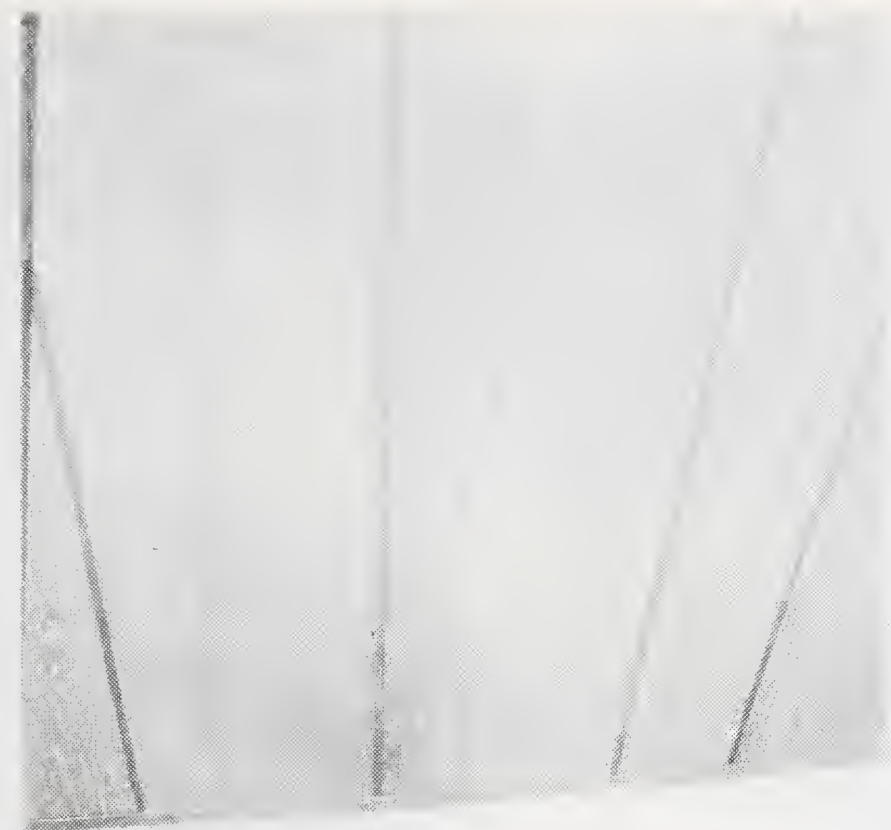

Figure C-41 Damaged Floor Covering

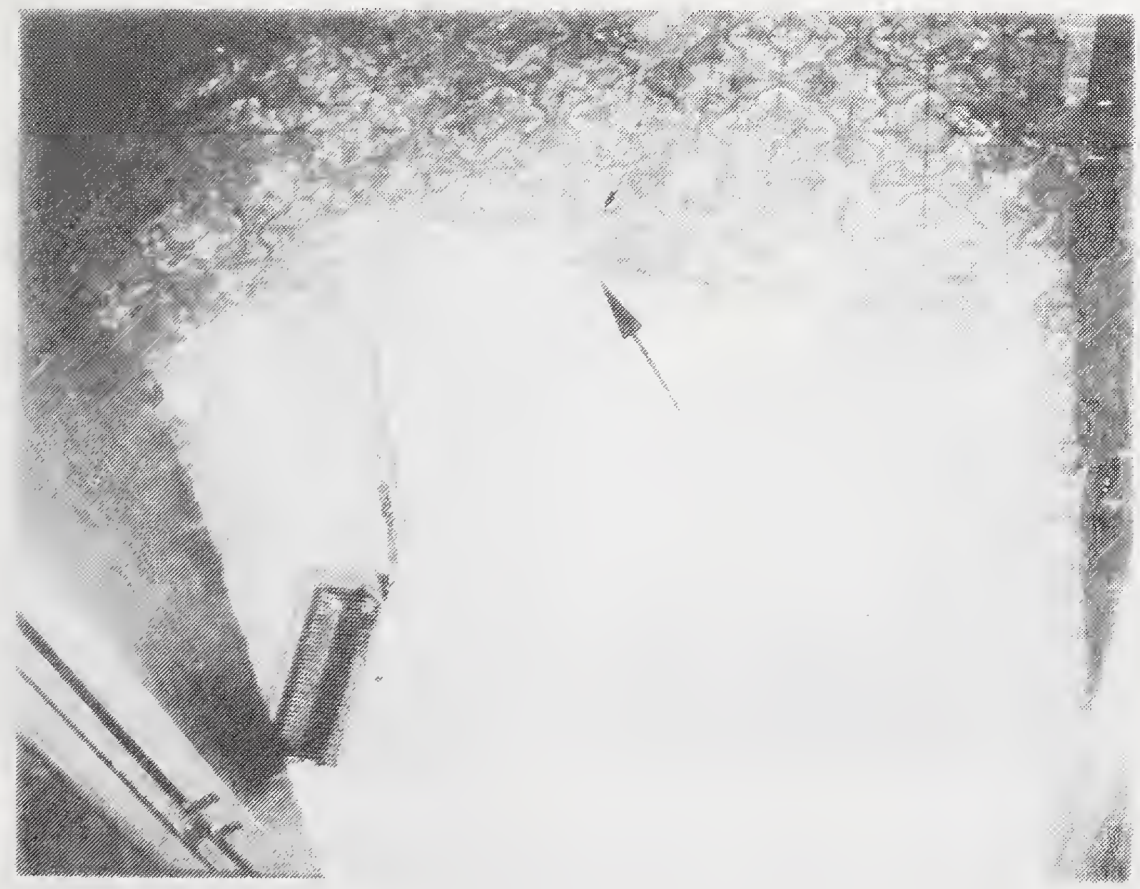

Figure C-42 Buckled Flooring and Covering Due to Distortion of Floor System Caused by Undercarriage Damage 


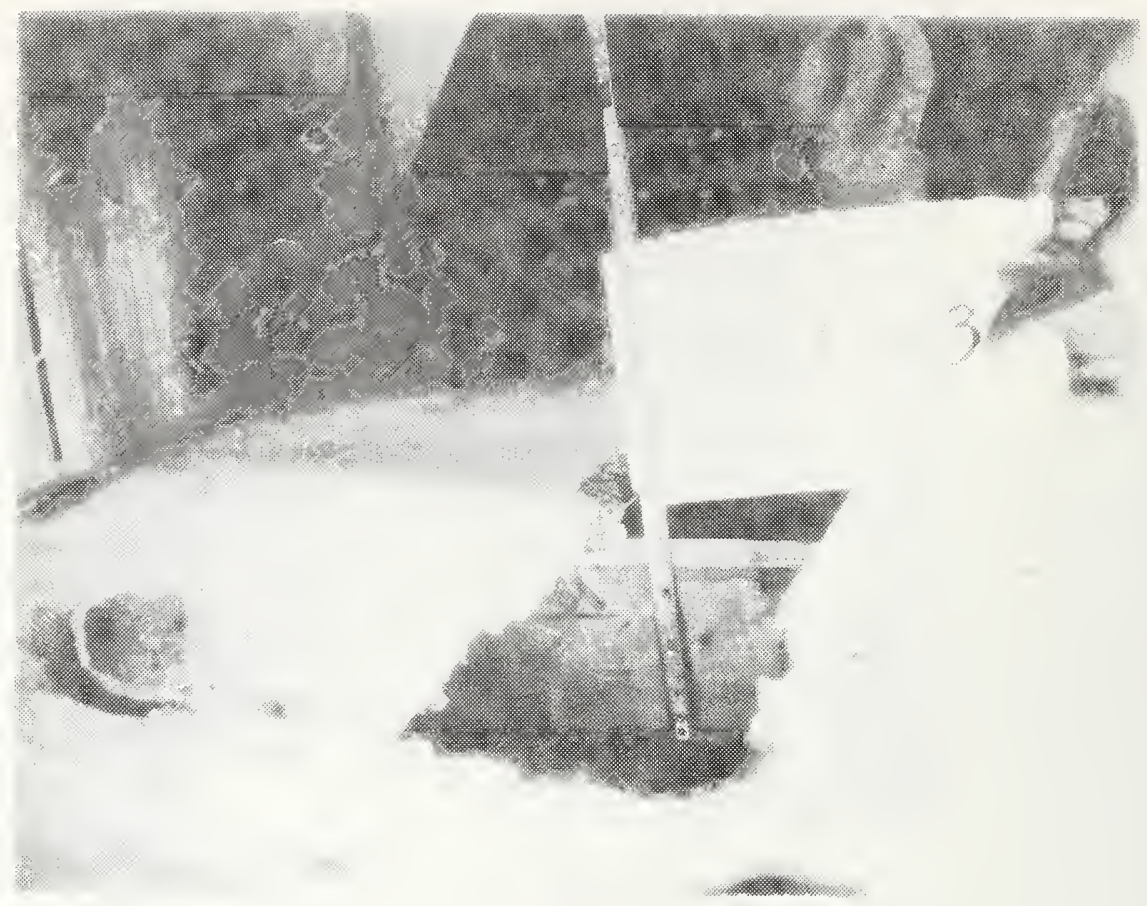

Figure C-43 Buckling of Particle Board Floor Decking Due to Water Damage Caused by Plumbing Malfunction

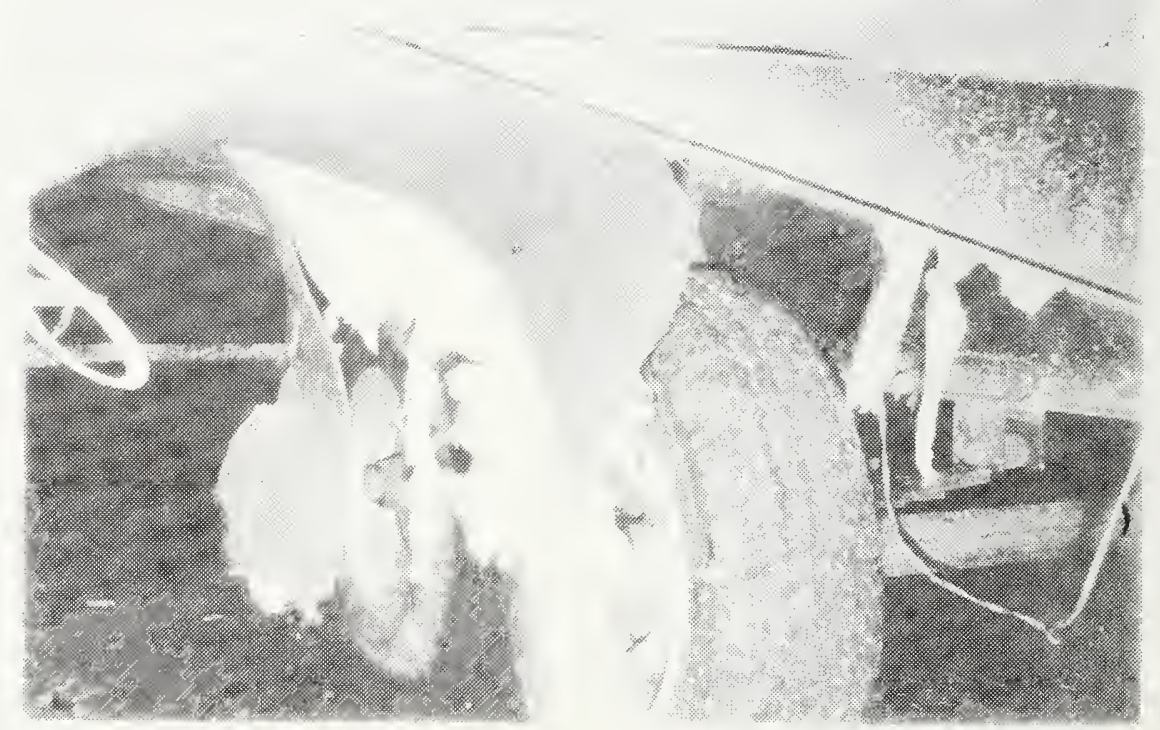

Figure C-44 Damage to Bottomboard on Underside of Mobile Home Exposing Floor Insulation Resulting in Diminished Rodent Resistance and Excessive Air Infiltration. 


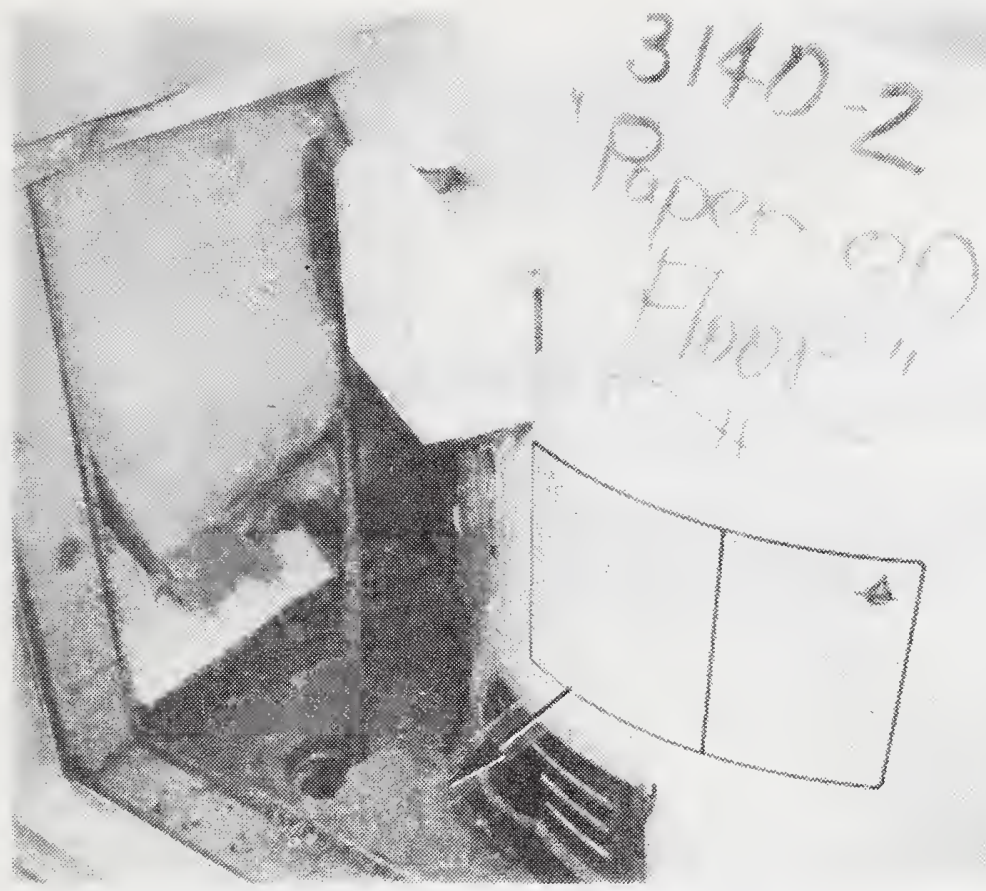

Figure C-45 Combustible Material on Hot Water Heater Compartment

Floor

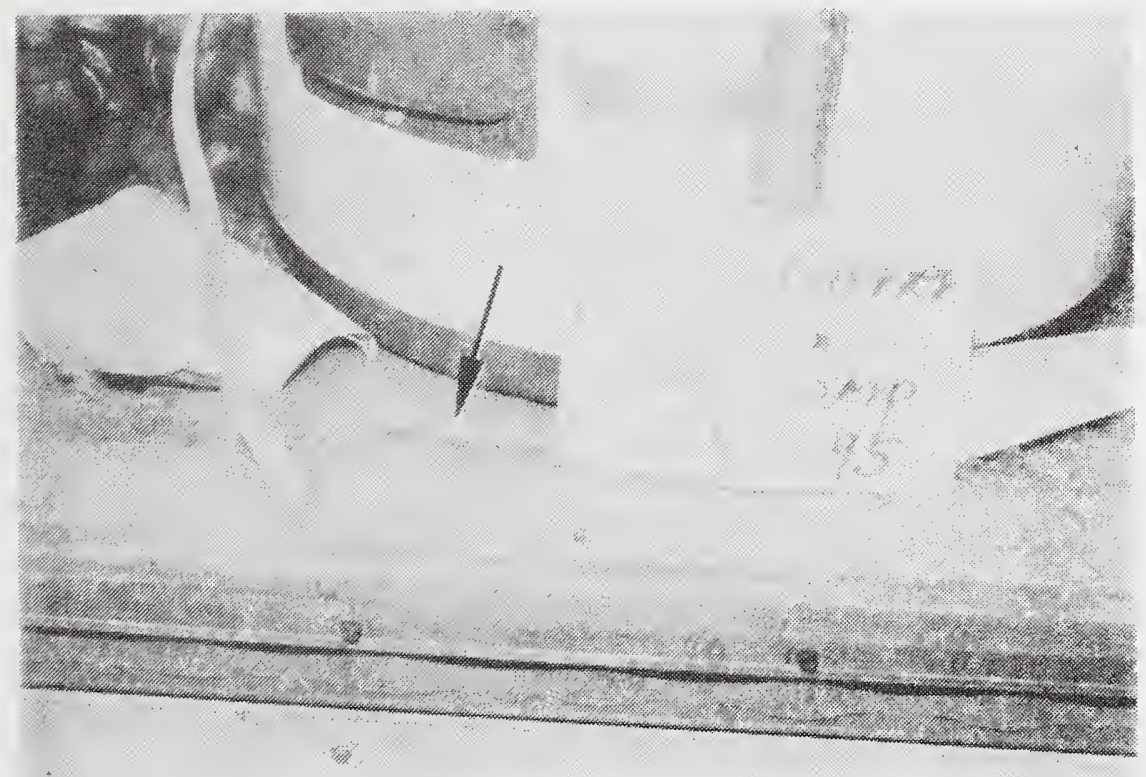

Figure C-46 Combustible Material on Hot Water Heater Compartment Floor 


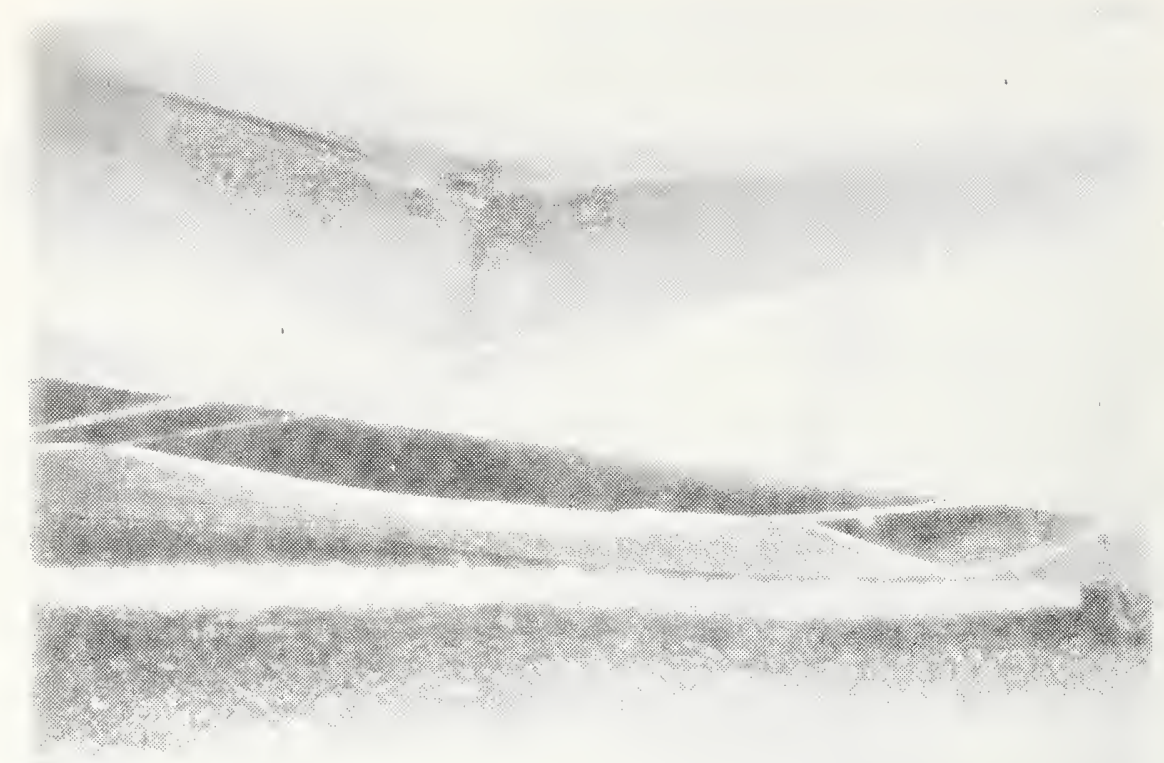
$\begin{array}{ll}\text { Figure } \mathrm{C}-47 & \text { Failure of Fastening of Bottomboard } \\ \text { to Underside of Floor. }\end{array}$

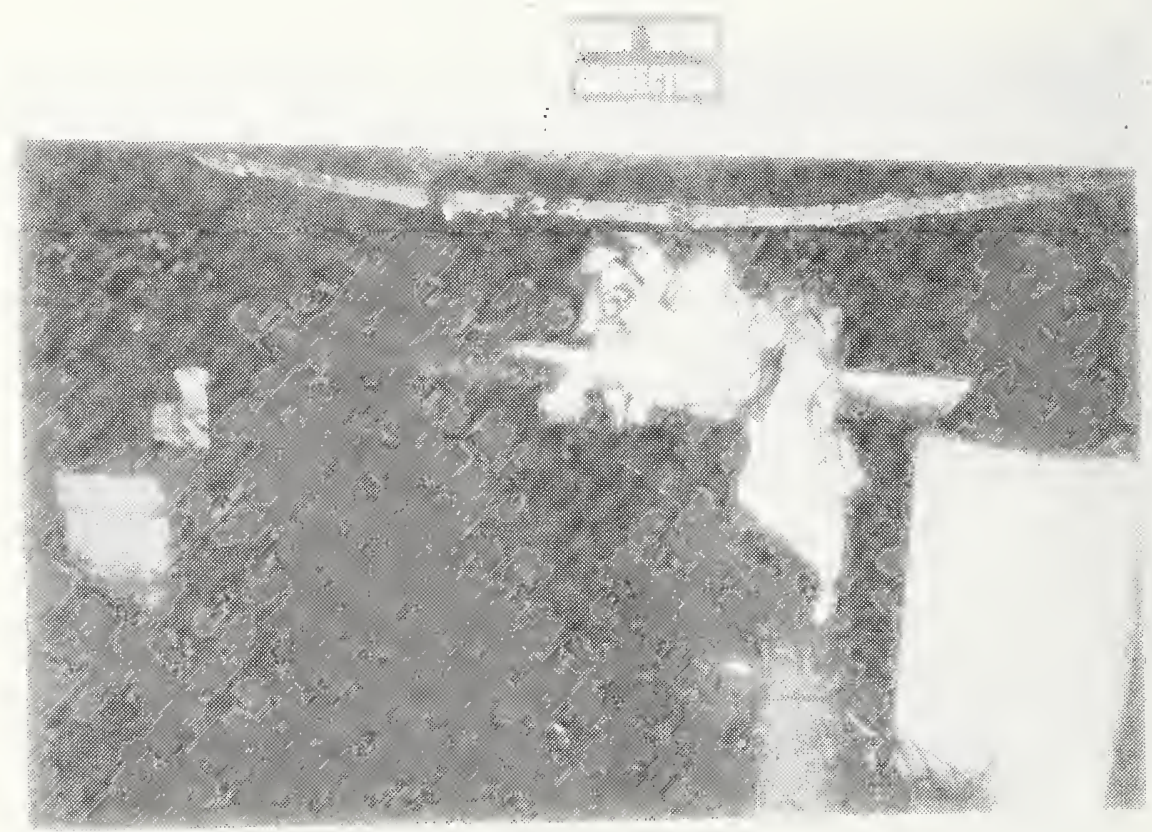

Figure C-48 Failure of Fastening of Bottomboard to Underside of Floor. 


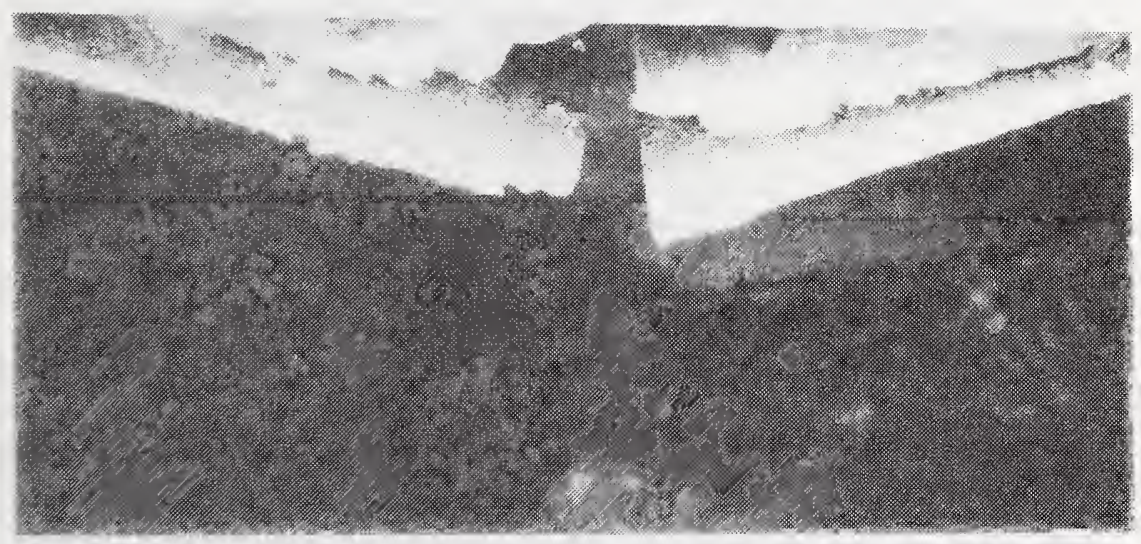

Figure C-49 Failure of Fastening of Bottomboard to Underside of Mobile Home 


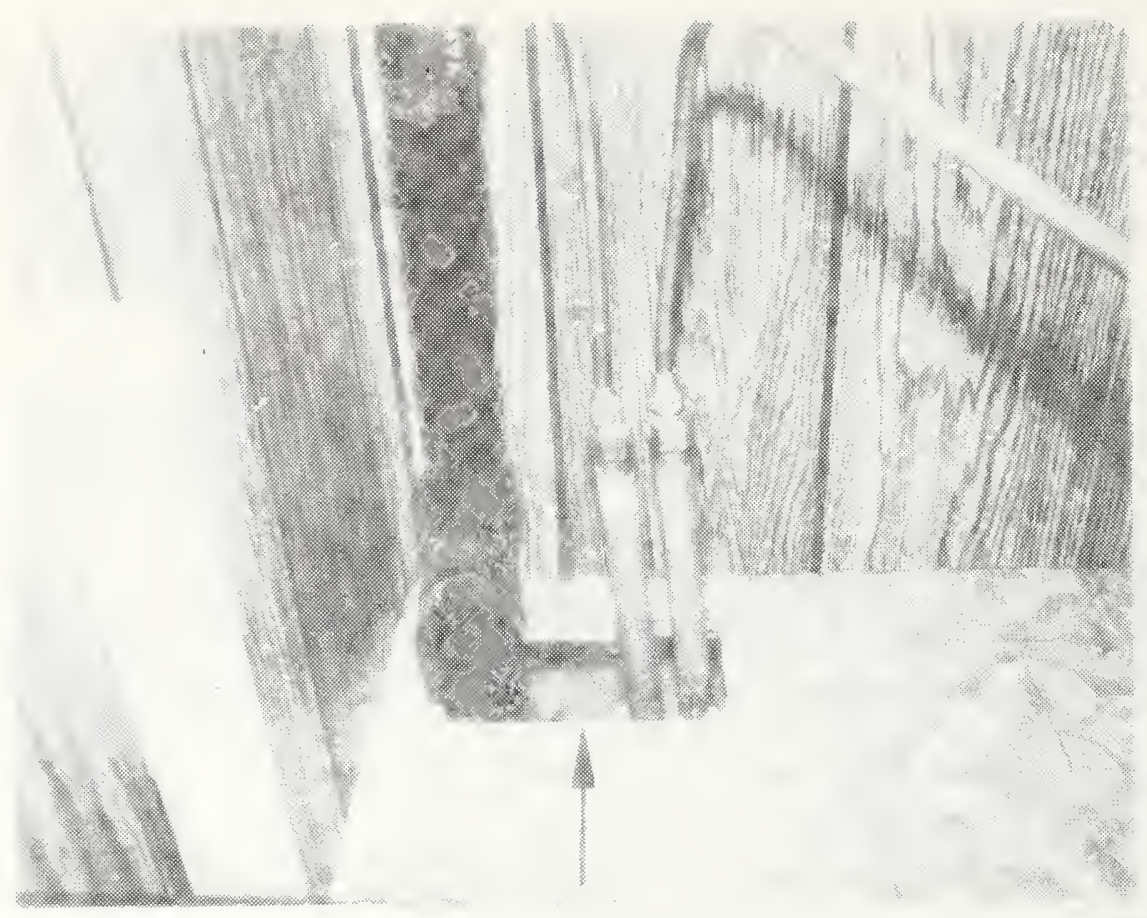

Figure C-50 Inadequate Rodent Resistance Due to Oversize Hole Cut for Passage of Plumbing Piping. No Attempt Was Made to Seal Holes.

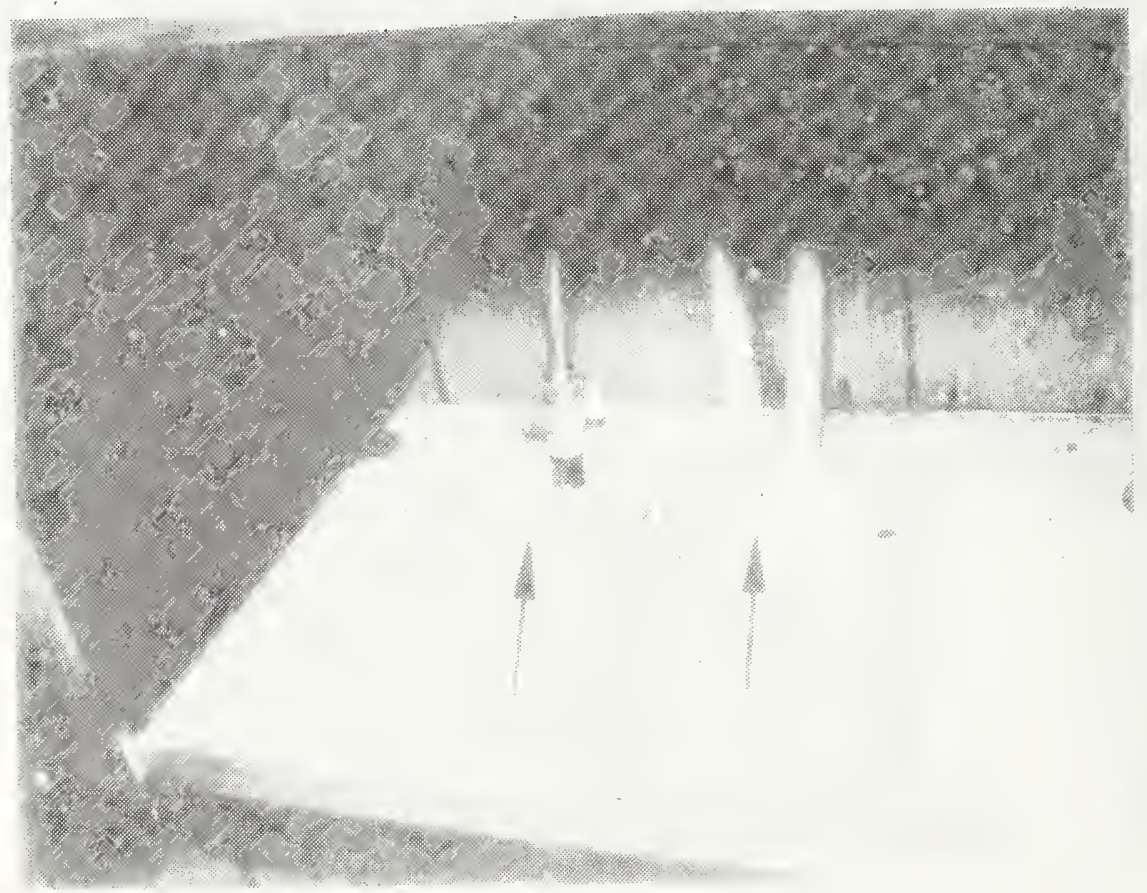

Figure C-51 Rodent Protection Was Provided at These Pipe Penetrations 


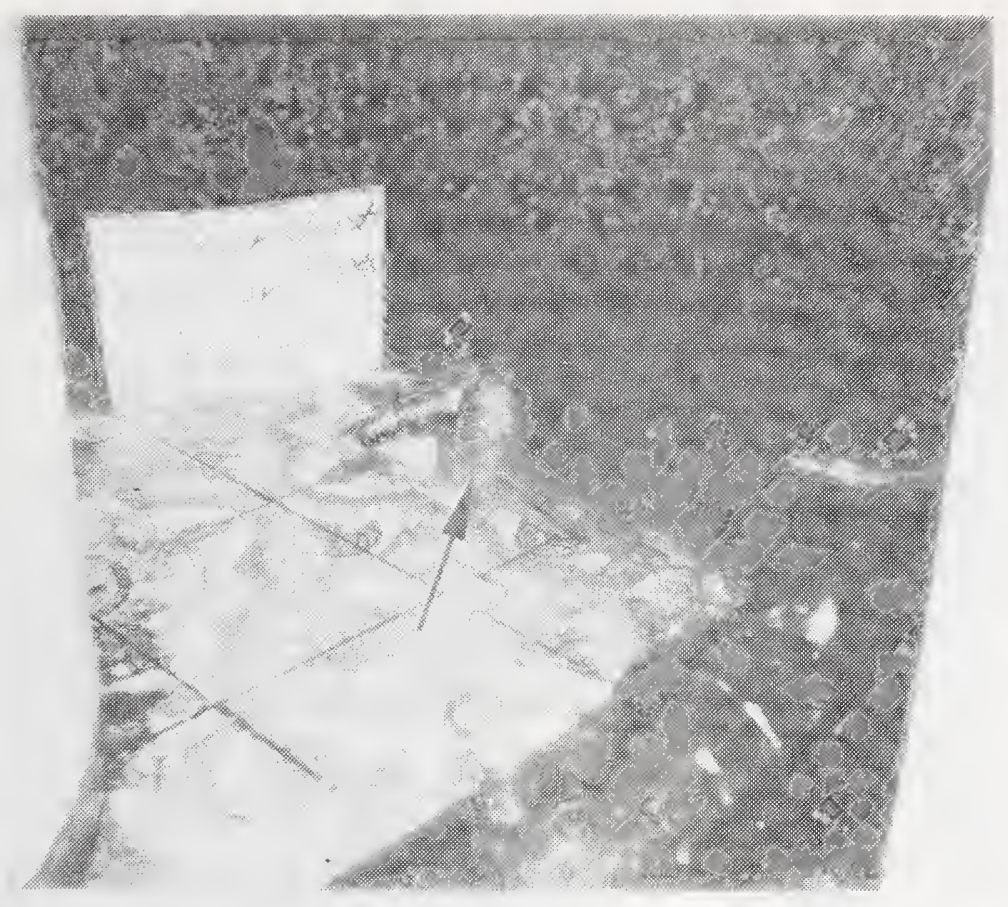

Figure C-52 Notching of Floor Joists for Passage of Plumbing Piping

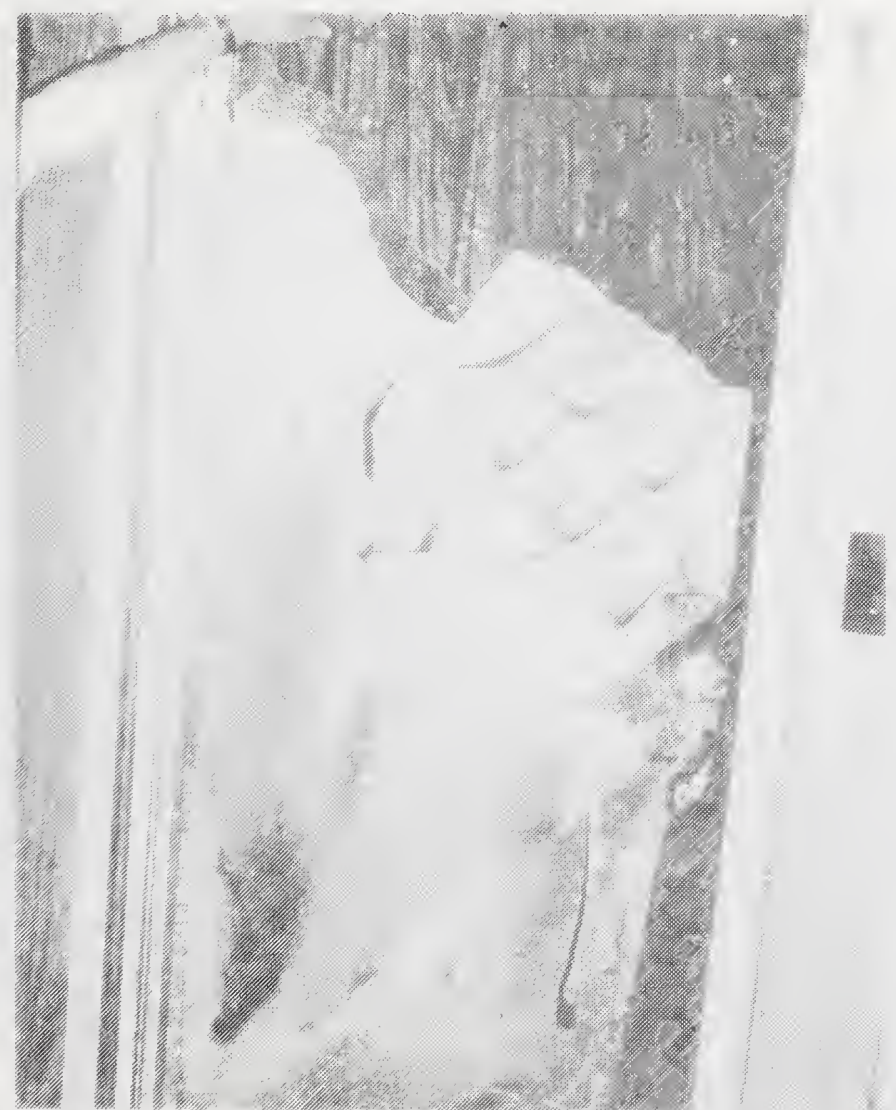

Figure C-53 Exterior Door Construction of Paper Honeycomb Core and Vegetable Fiber Board Skins. (This Mobile Home Had Been Abused and Experienced Exterior Water Damage) 


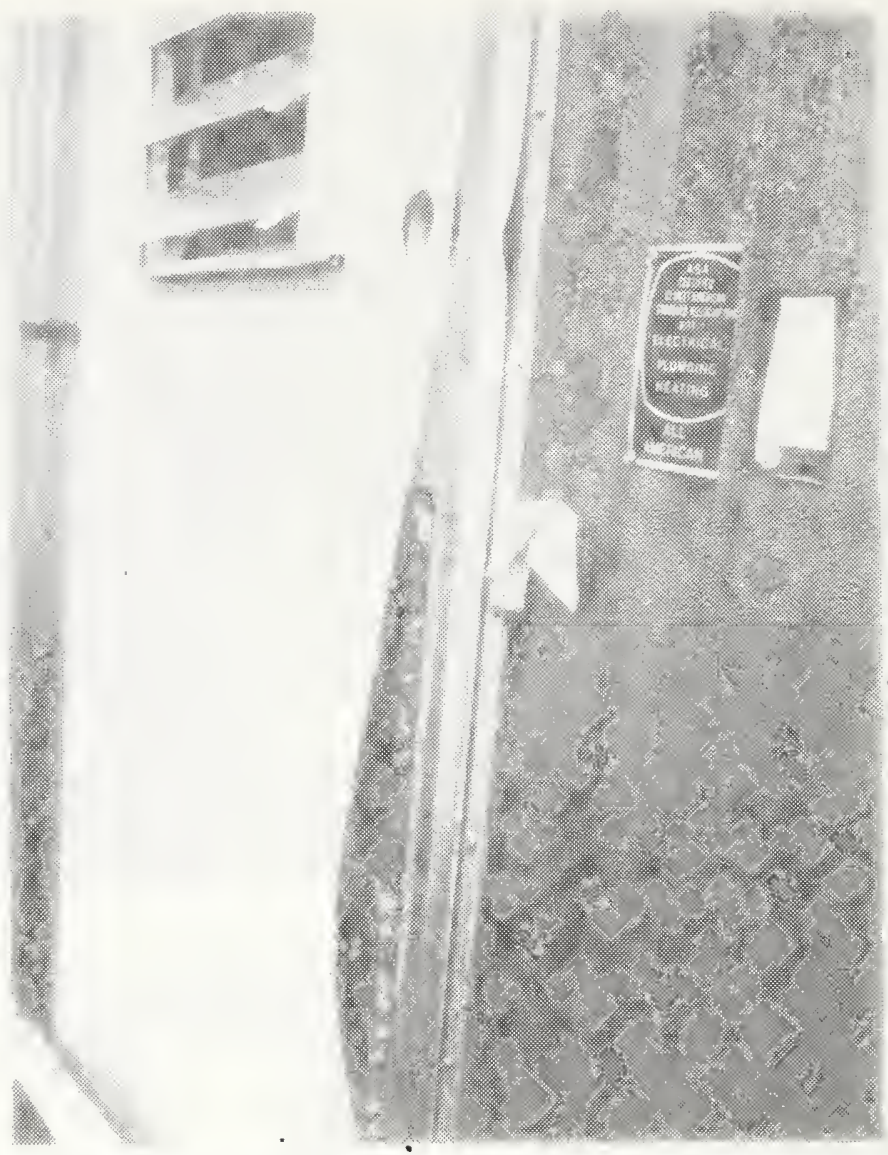

Figure C-54 Exterior Door Construction of Paper Honeycomb Core and Aluminum Skins - Exterior Skin Was Buckled.

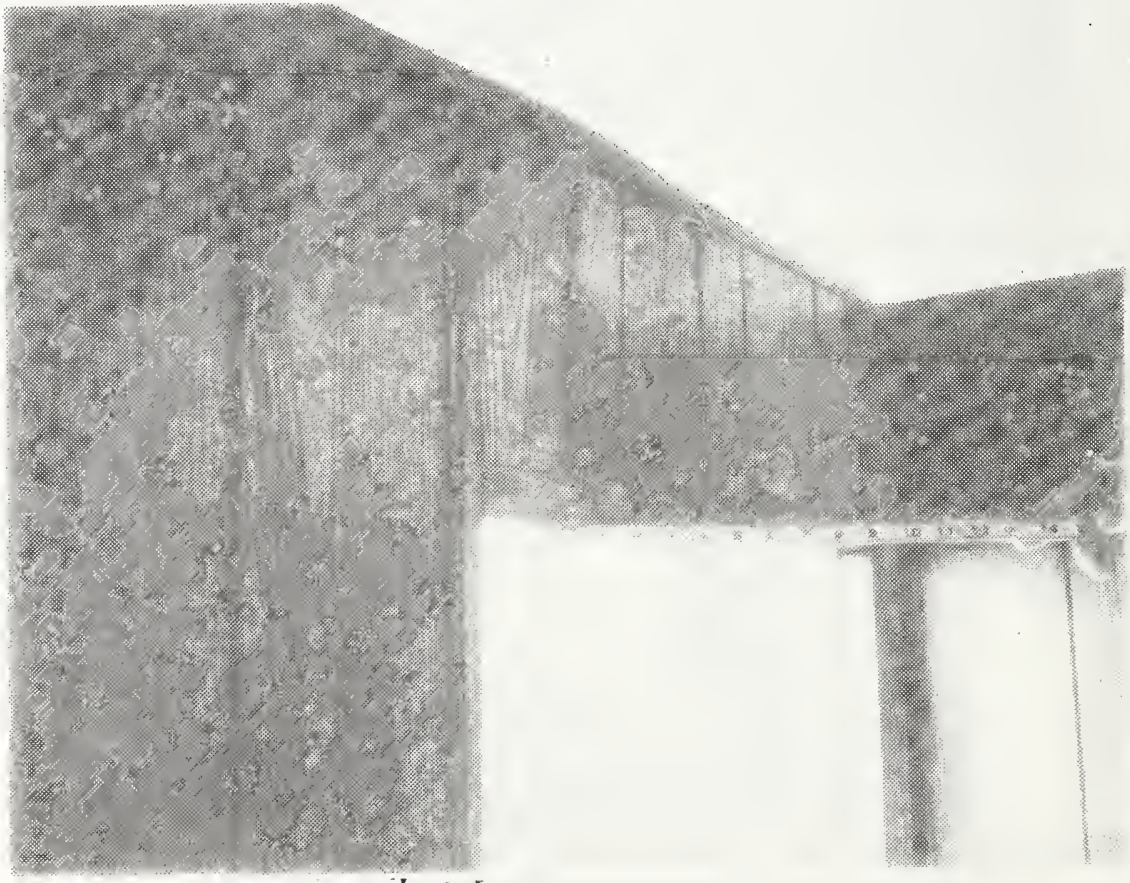

Figure C-55 Racked and Damaged Exterior Door Frame 


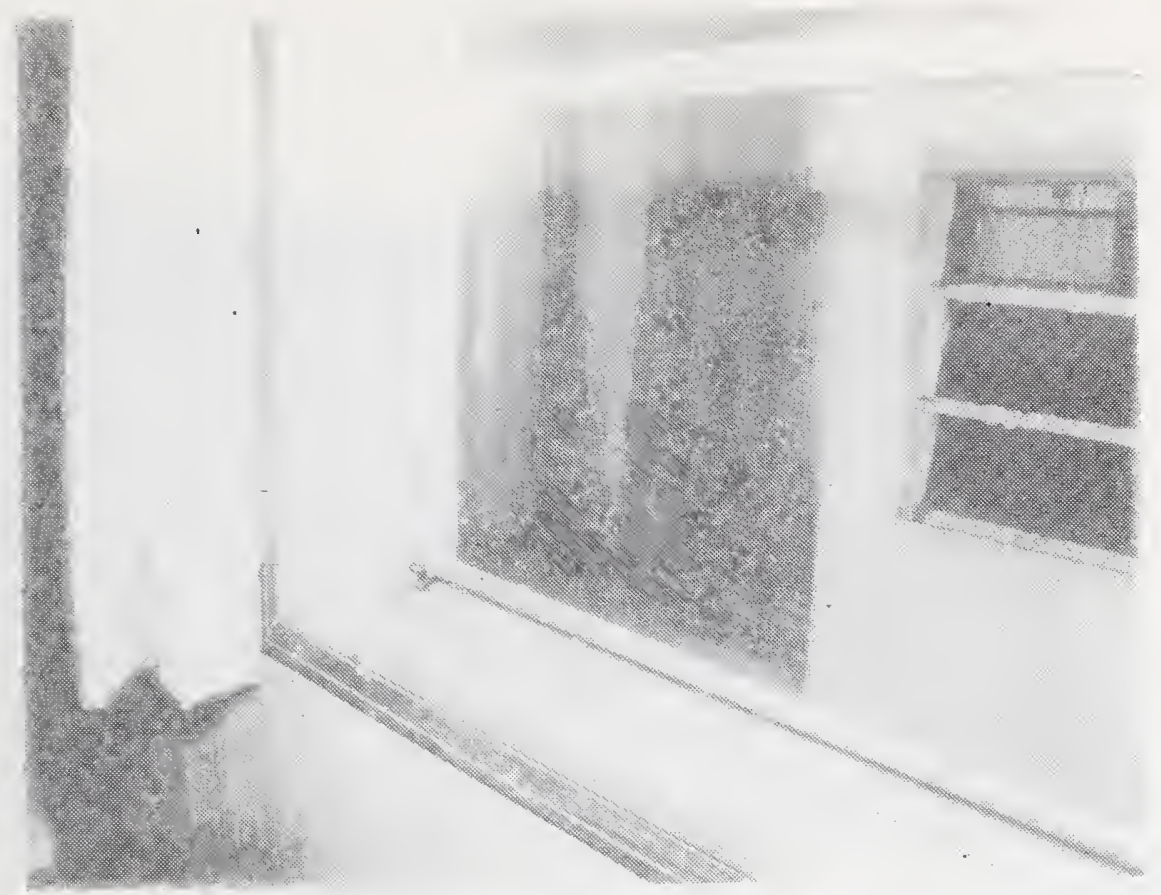

Figure C-56 Water Leak Through Closed Awning Type Windows (Interior Storm Windows)

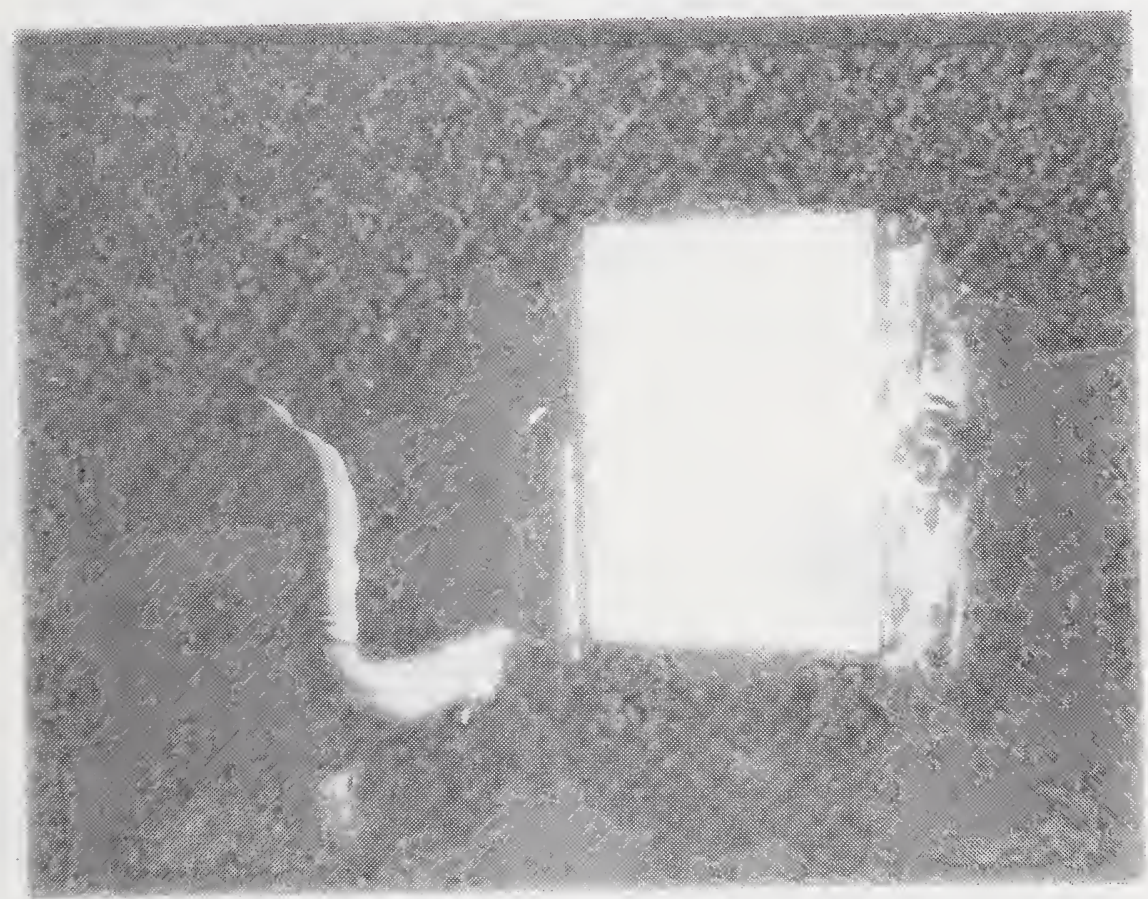

Figure C-57 Space for Air Leakage (Shows Light) 


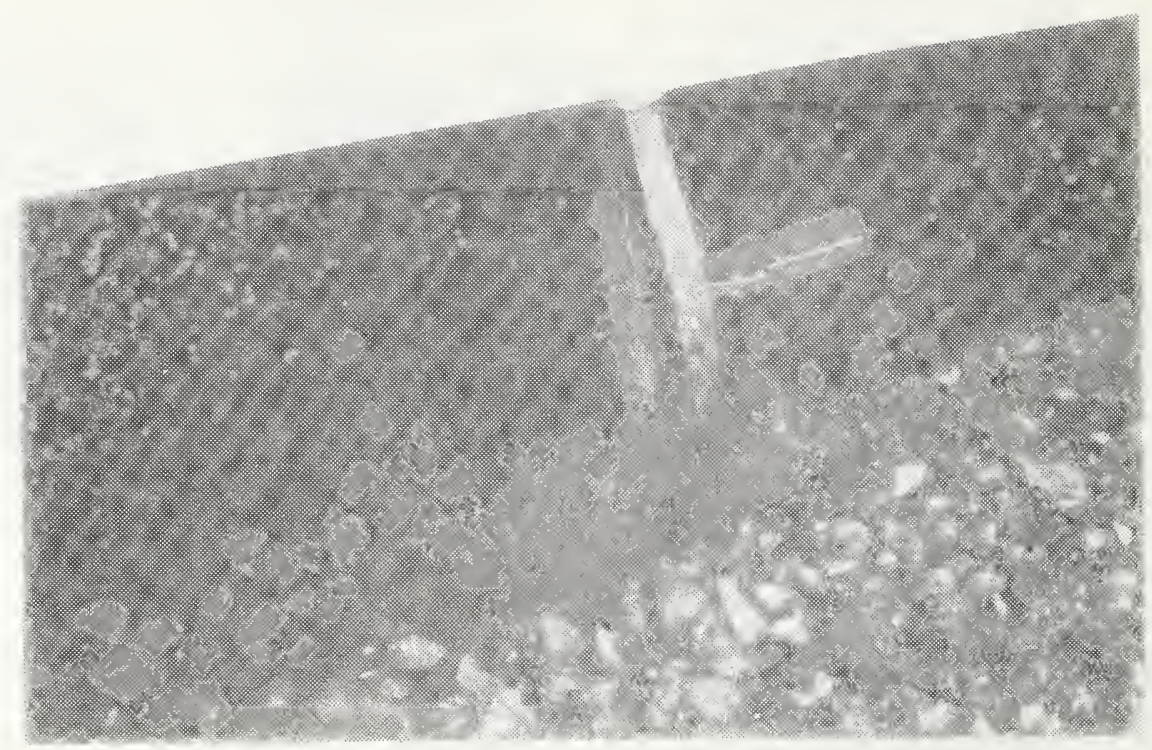

Figure C-58 Extensively Rusted Under-the-Skin Tie Down Strap

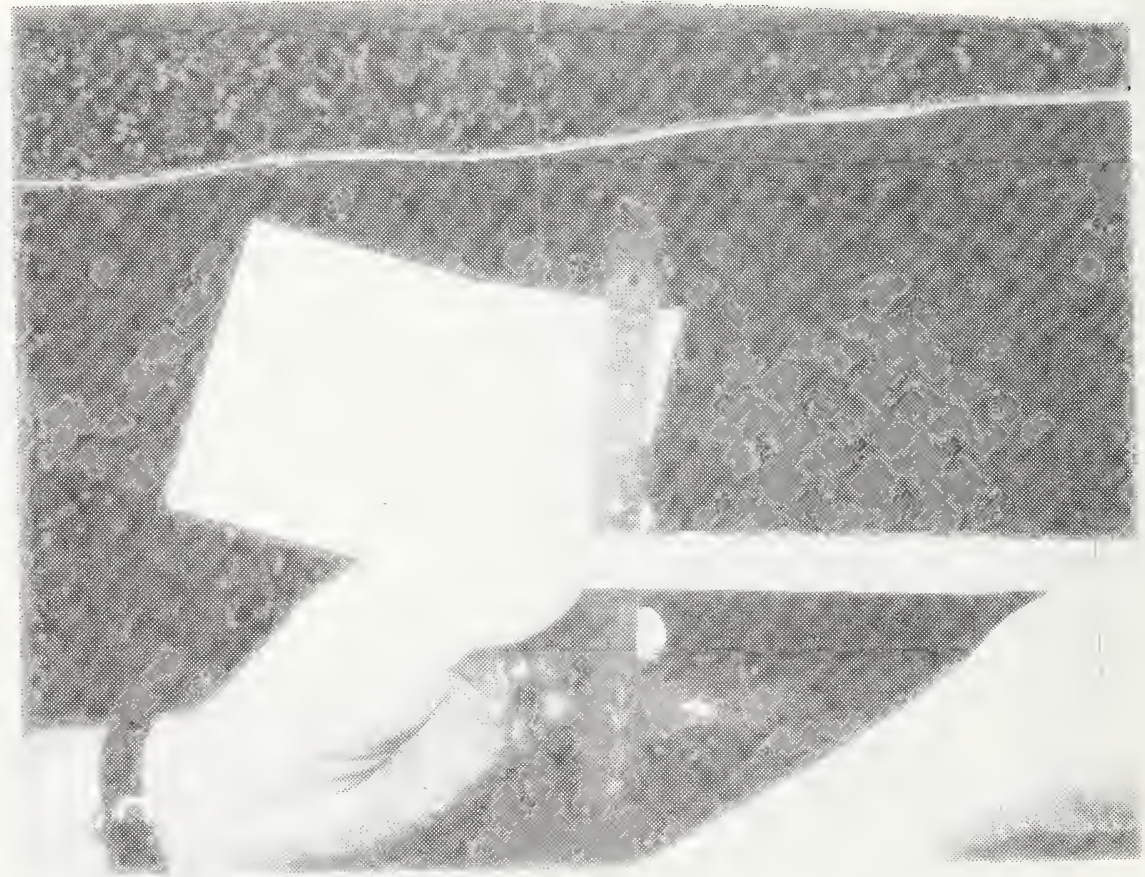

Figure C-59 Extensively Rusted and Undersized Under-the-Skin Tie Down Strap 


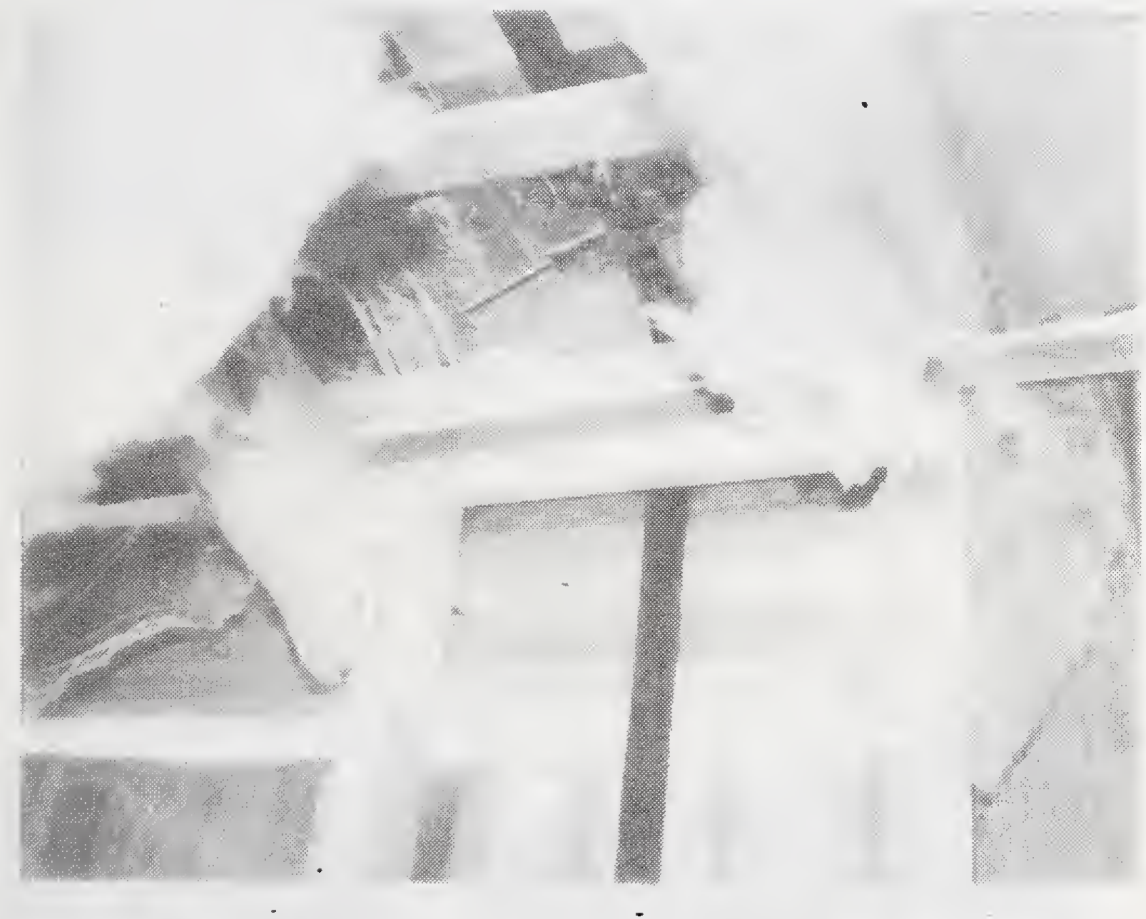

Figure C-60 Under-the-Skin Tie Down Strap Located Between Roof Trusses (Better Design Would Locate Tie Down Straps at Roof Trusses to Insure Load Transfer Between Walls). 


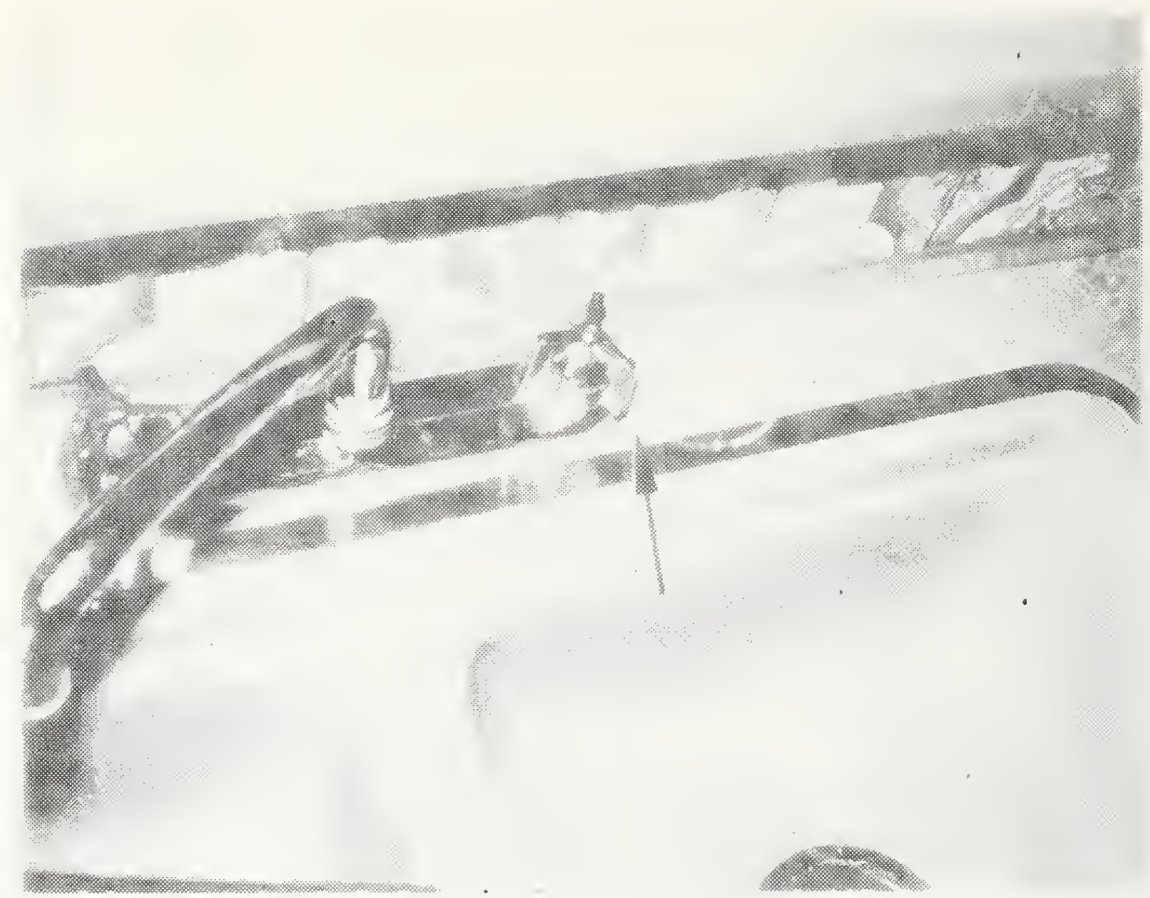

Figure C-61 Deterioration of Kitchen Counter Top Due to Water Leak at Faucet

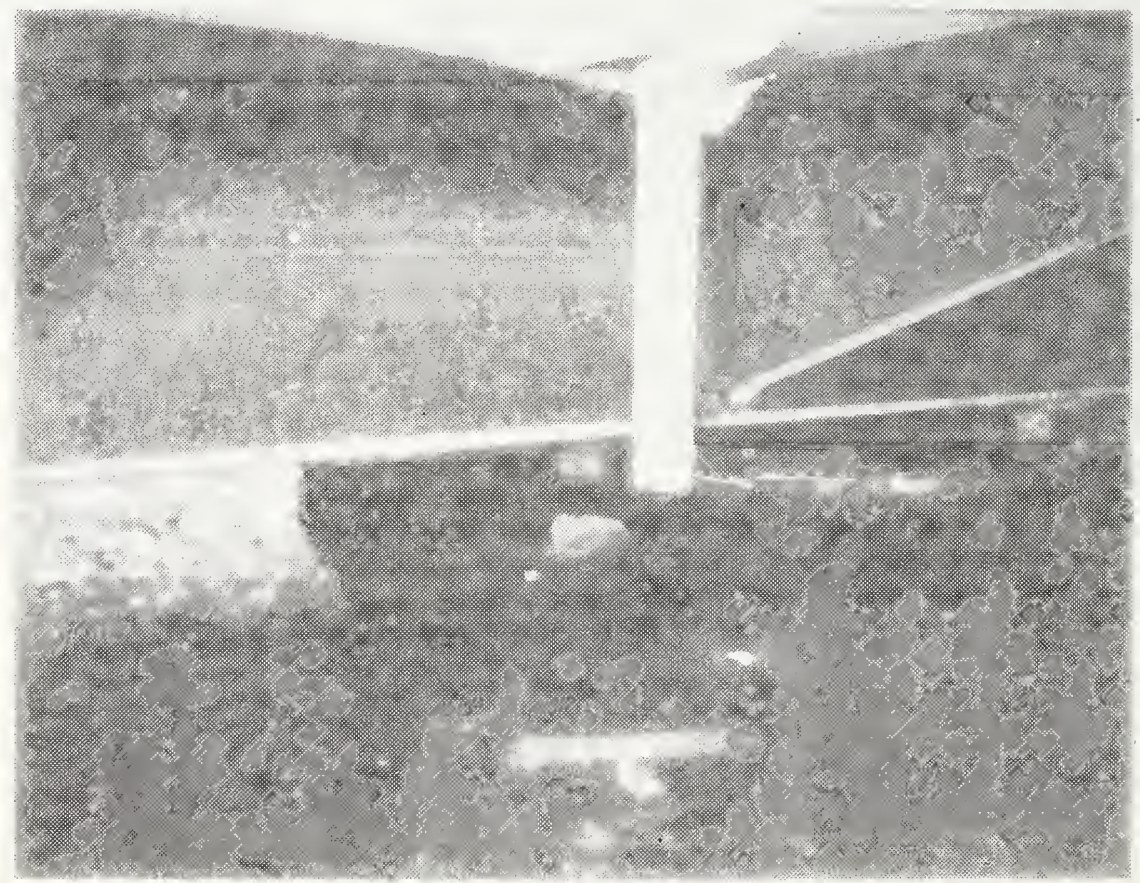

J Figure C-62 Hot Water Heater Pressure Relief Overflow Pipe With Threaded End. 

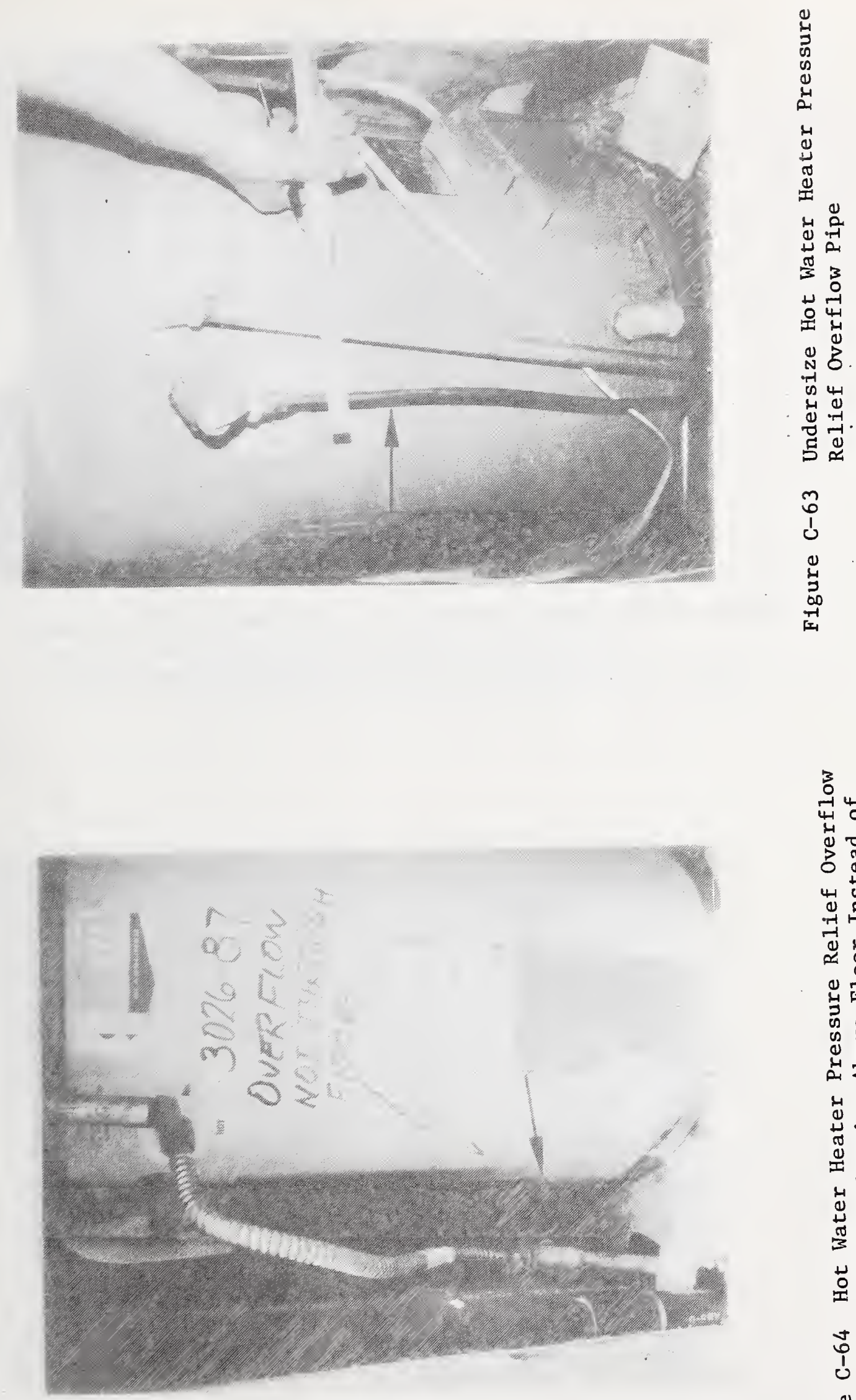

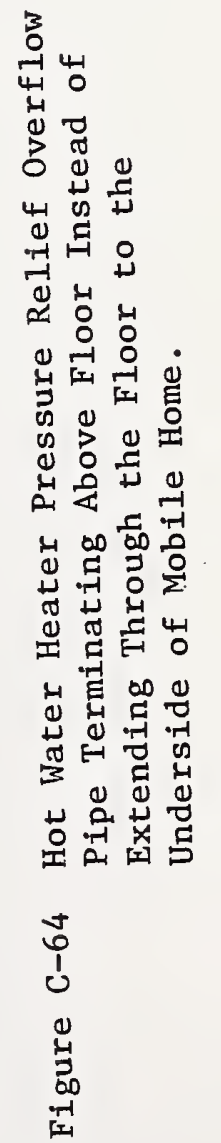




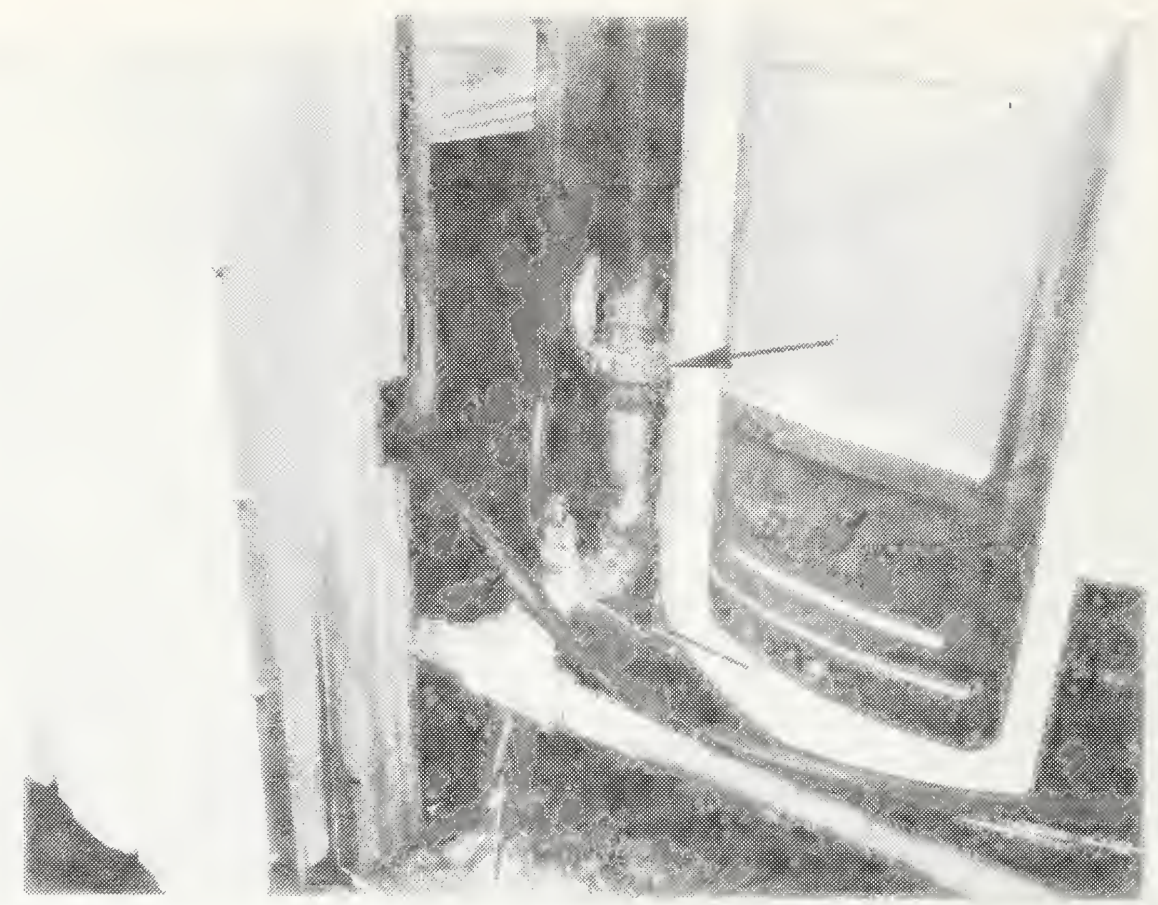

Figure C-65 Excessive Corrosion of Galvanized Steel Water Pipe in Hot Water Heater Compartment. Also, Electrical Cable Not adequately Supported

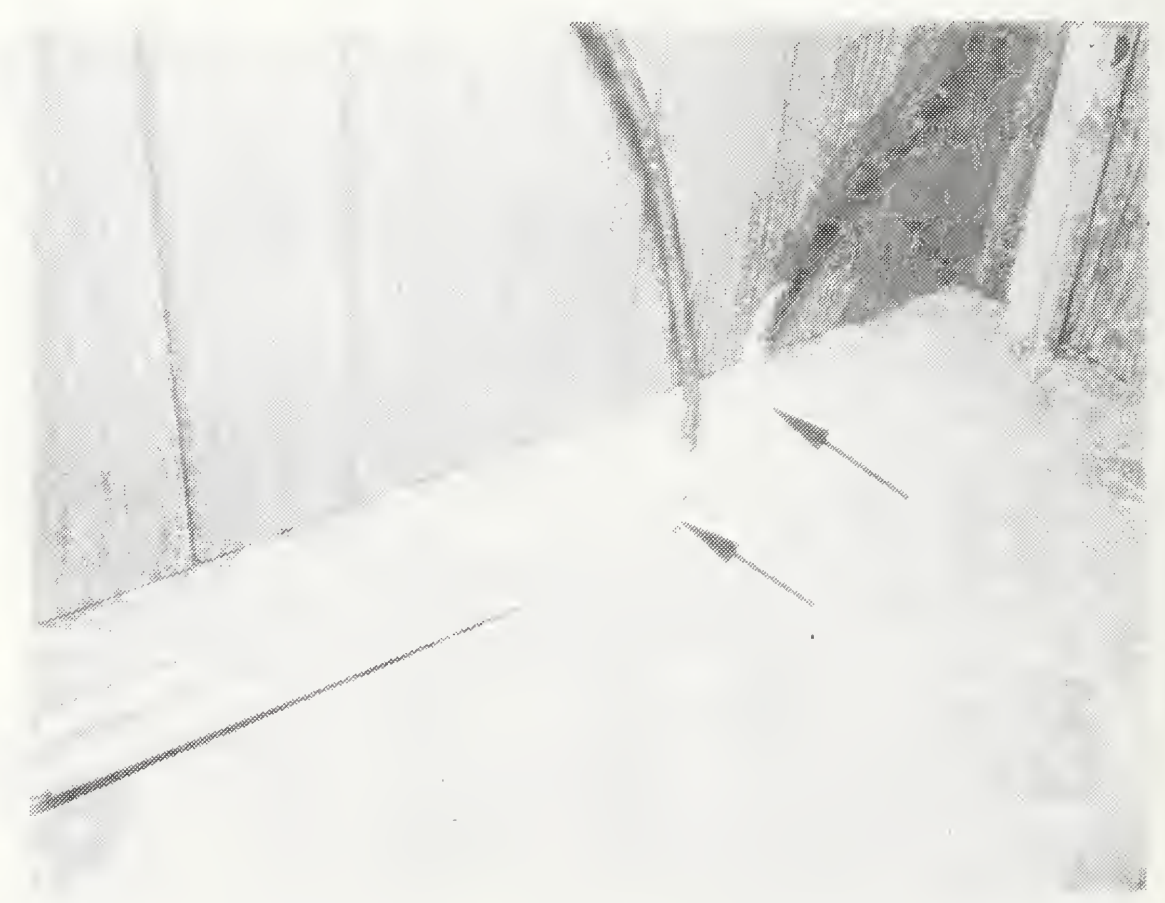

Figure C-66 Corrosion of Dissimilar Metals

(Copper to Galvanized Steel) Used

for Water Supply Under Bathroom Sink 


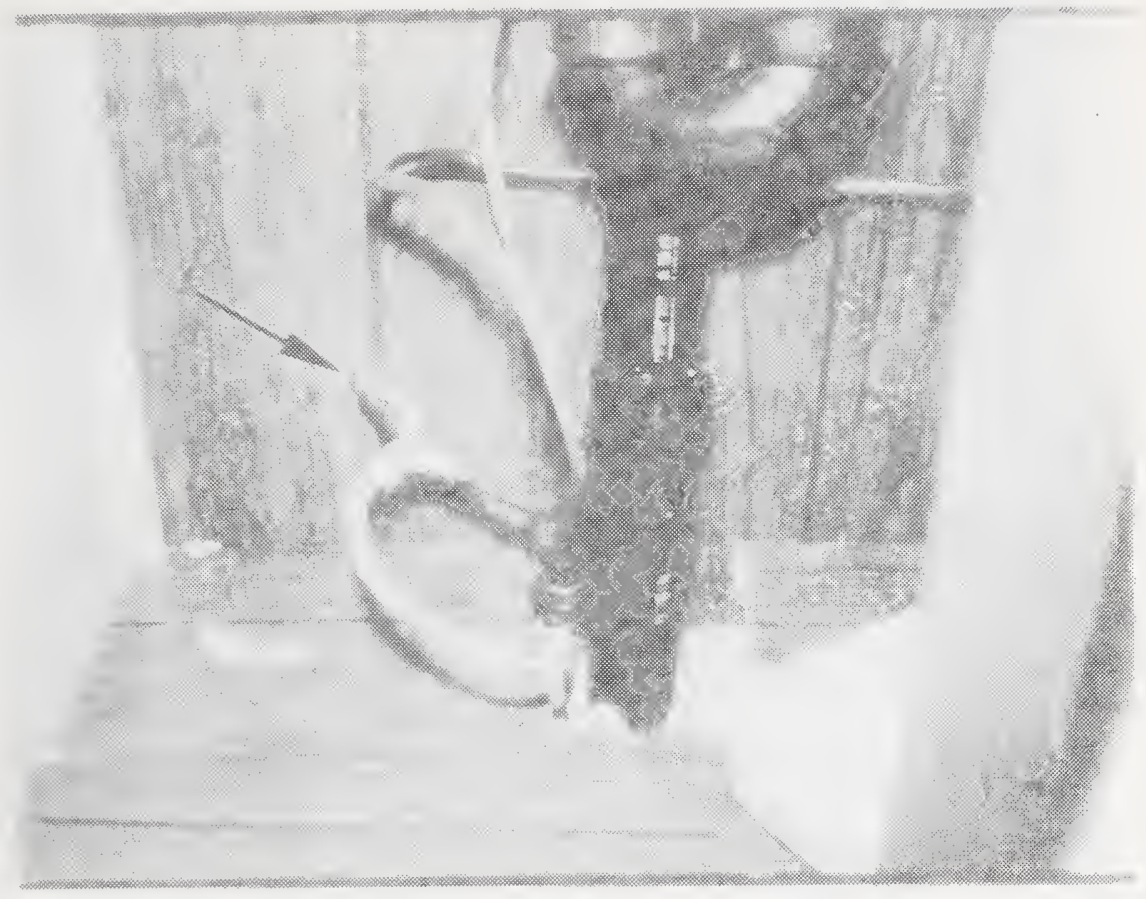

Figure C-67 Example of Poor Workmanship - Water
Supply Piping and Electrical Wiring Passing
Through the Same Undersize Wall Penetration-

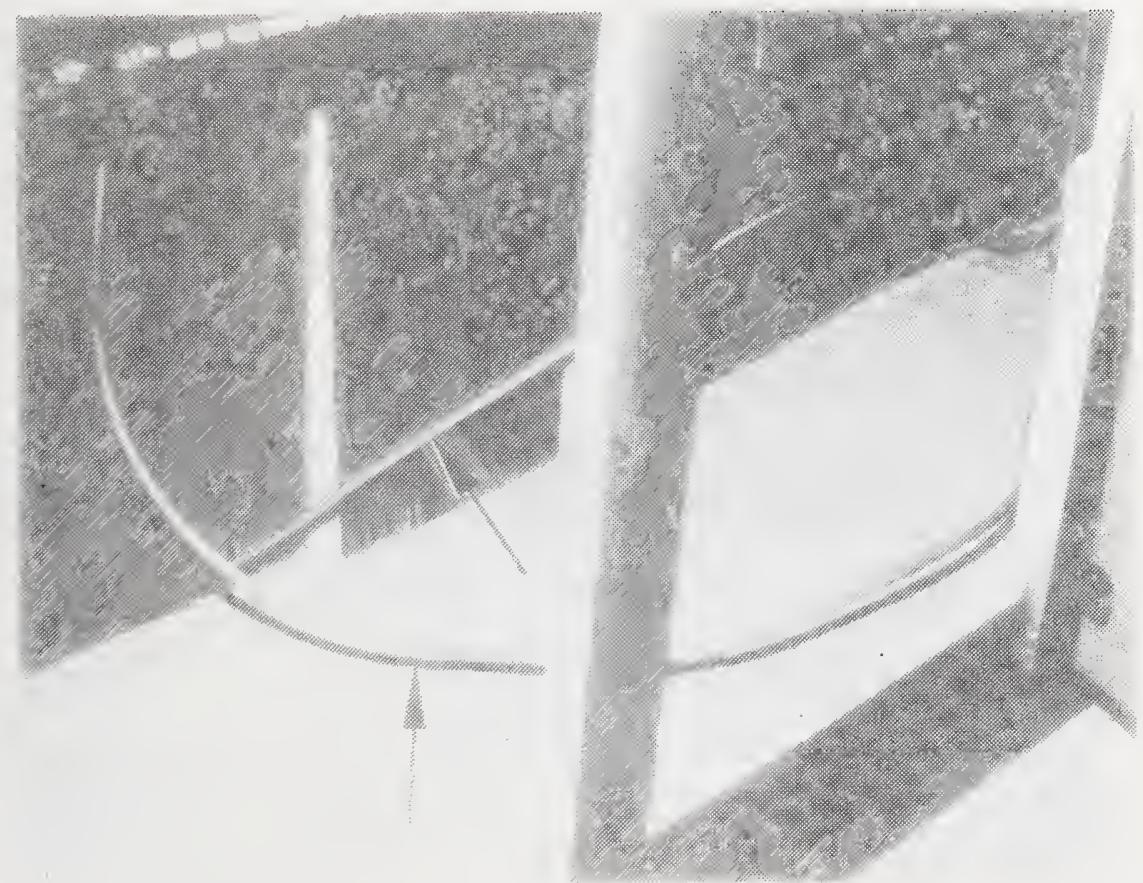

Figure C-68 Example of Poor Workmanship - Excessive Amount of Water Supply Piping Used Under Kitchen Sink 


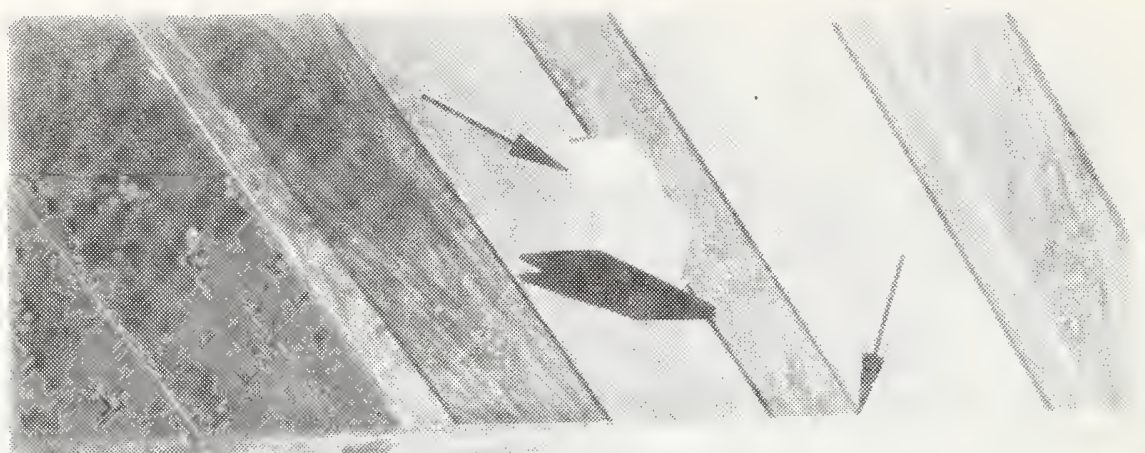

Figure C-69 Plumbing Pipe Running Along Inside Wall in Sleeping Quarters Covered With Lightweight Plastic Cover. Also, Electrical Box Inadequately Attached to Wall

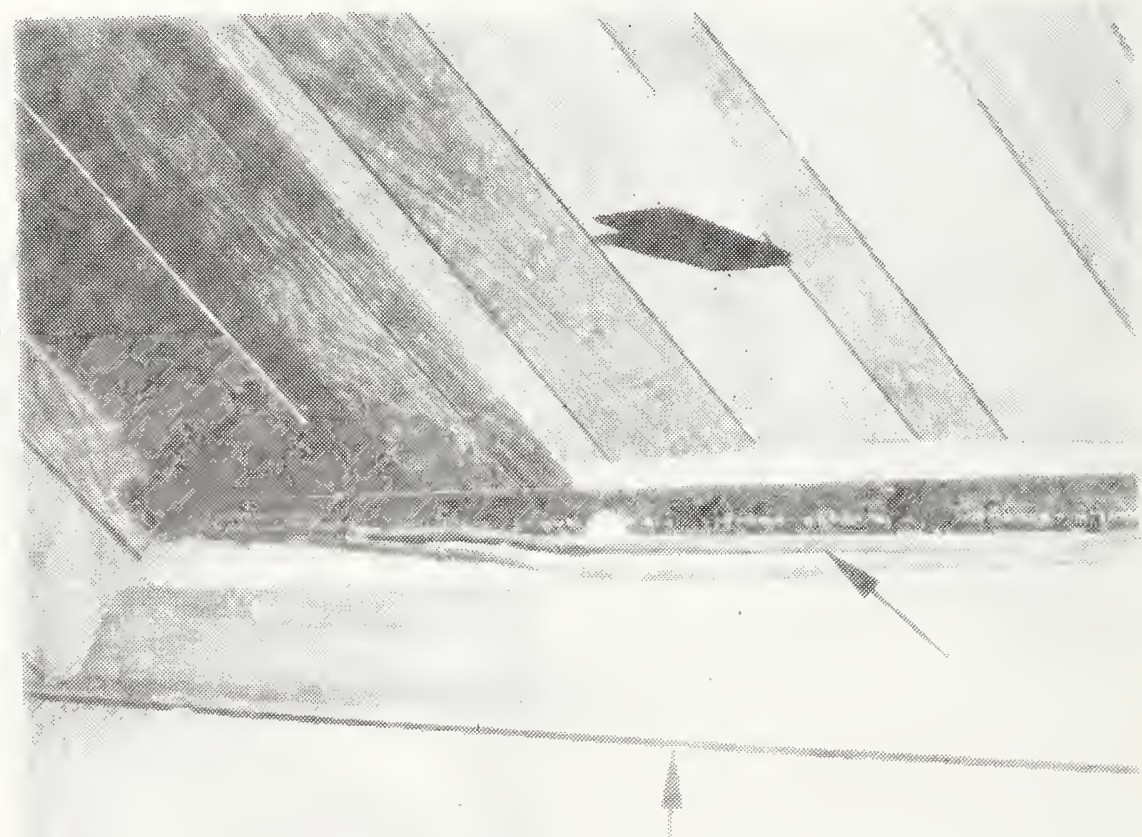

Figure C-70 Lightweight Plastic Pipe Cover Removed in Sleeping Quarters to Expose Plumbing Pipe Running Along Wall (See Figure C-69). 

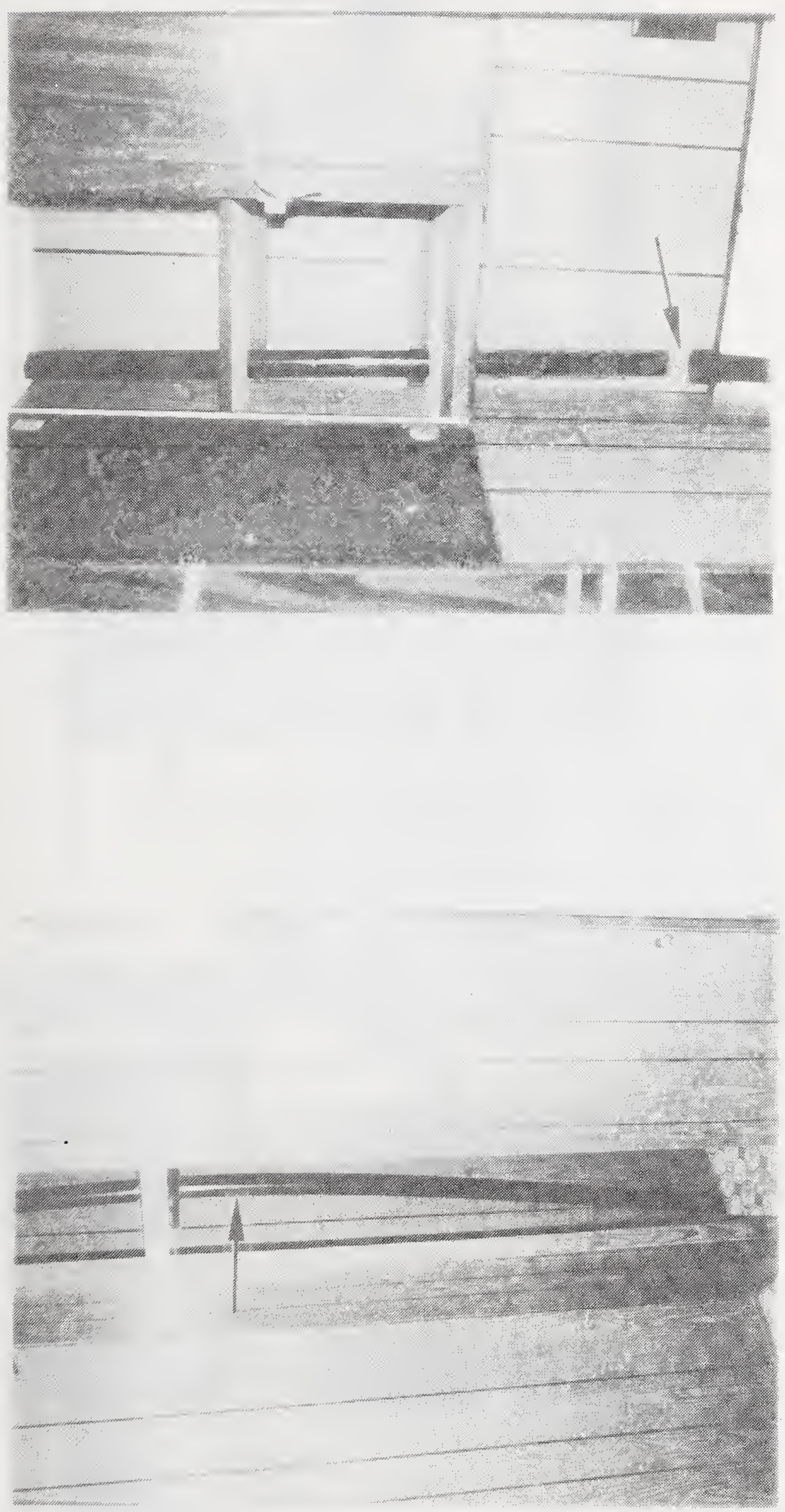


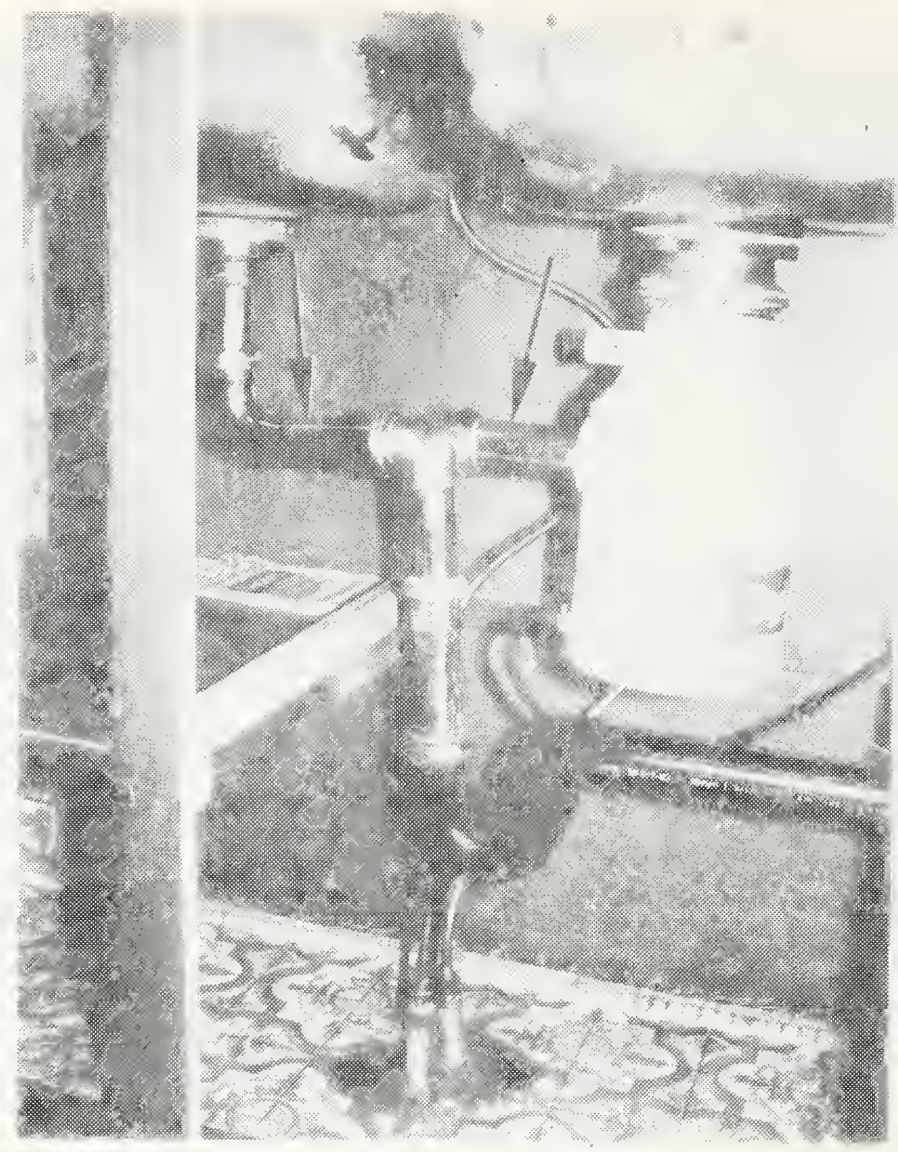

Figure C-73 Negative Slope of Drain Pipe Under Kitchen Sink
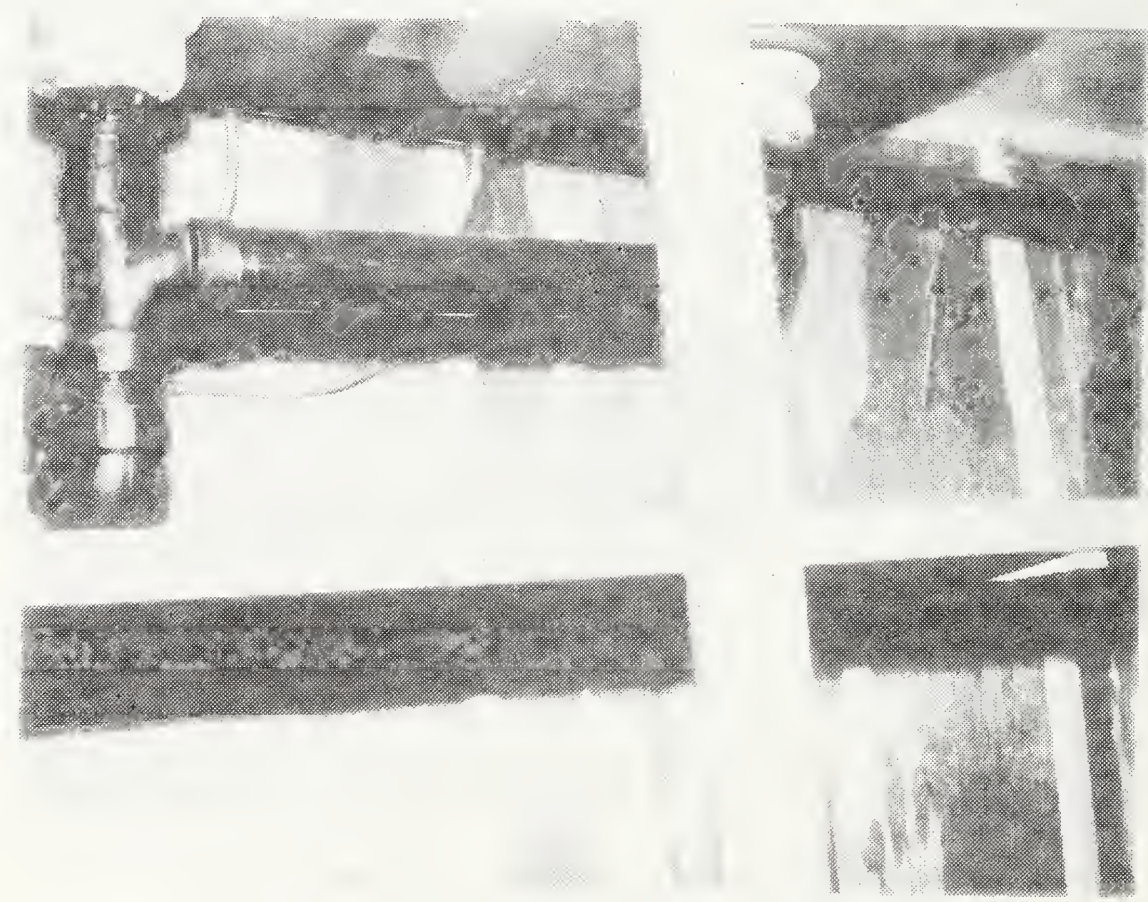

\section{Figure C-74 Negative Slope of Vent Pipe} Under Kitchen Sink 


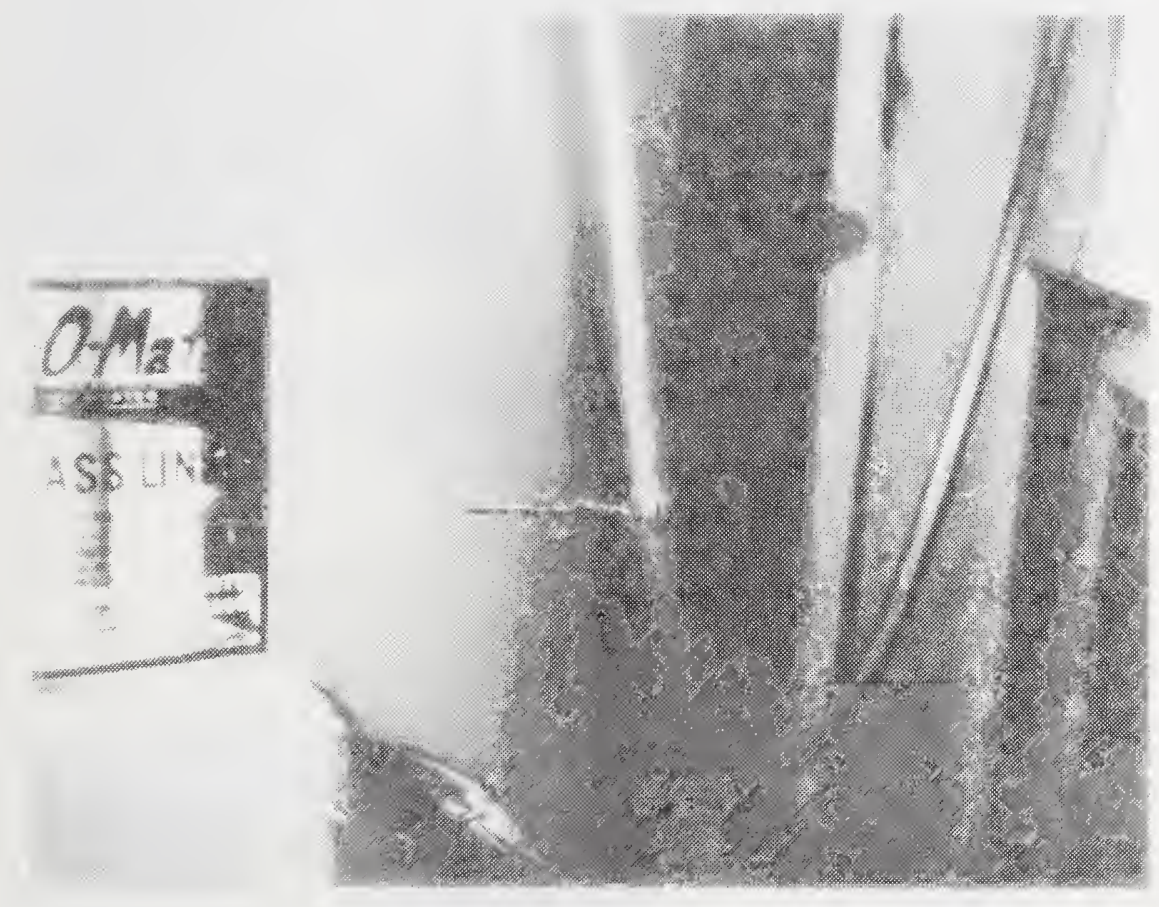

Figure C-75 Copper Water Supply Tubing Failure Due to Freezing in Hot Water Heater Compartment 


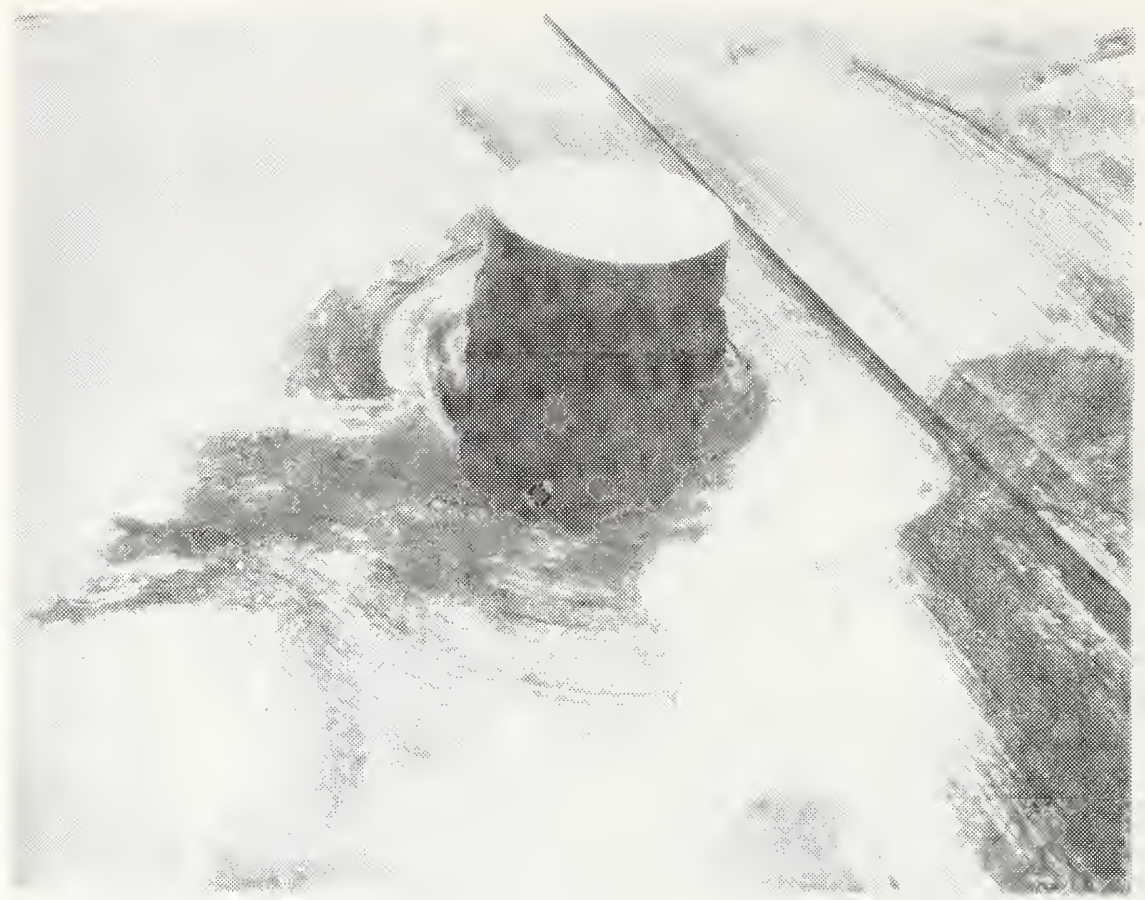

Figure C-76 Vent Cap on Roof Which is Not the Removable Type Required by ANSI A119.1 Standard

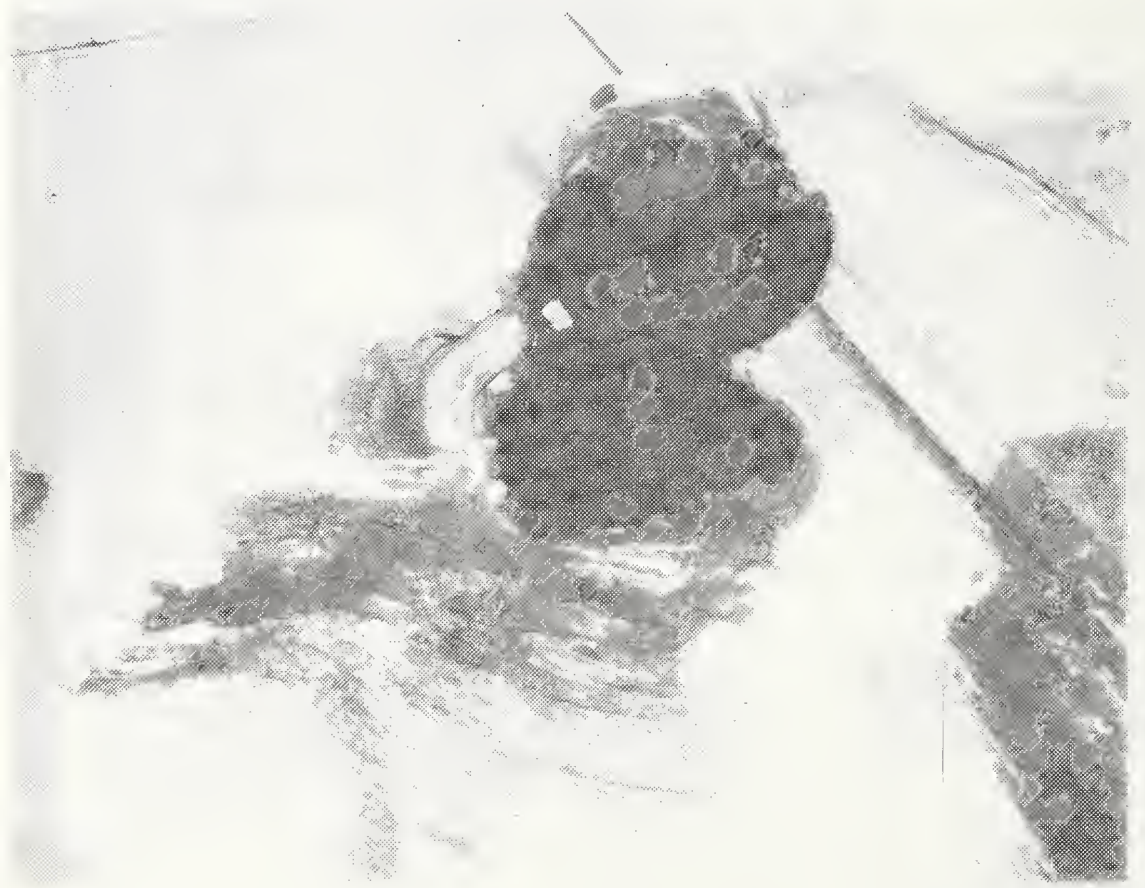

Figure C-77 Vent Cap Removal Damaged the Flashing. 


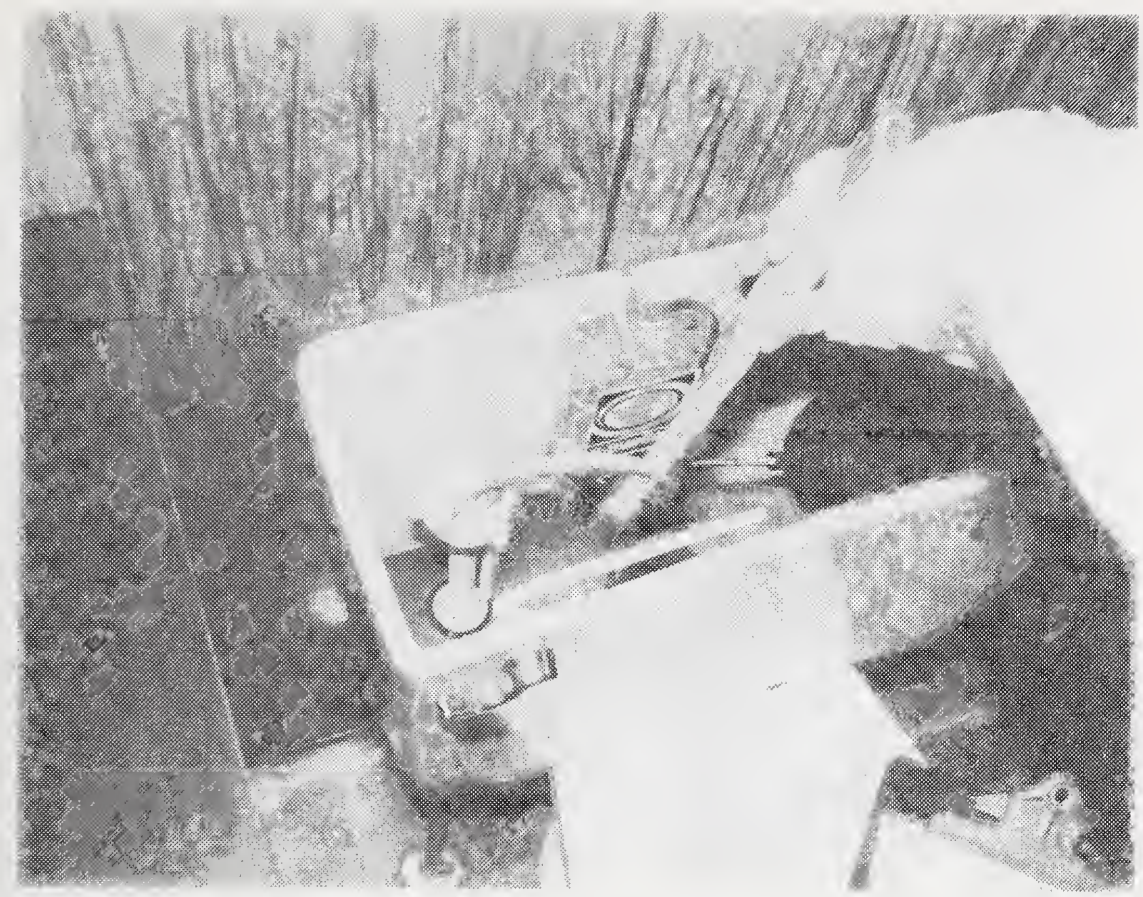

Figure C-78 Submerged Valve Flushing Device Which Could Allow Flush Tank Water to Back Flow Into The Potable Water Supply

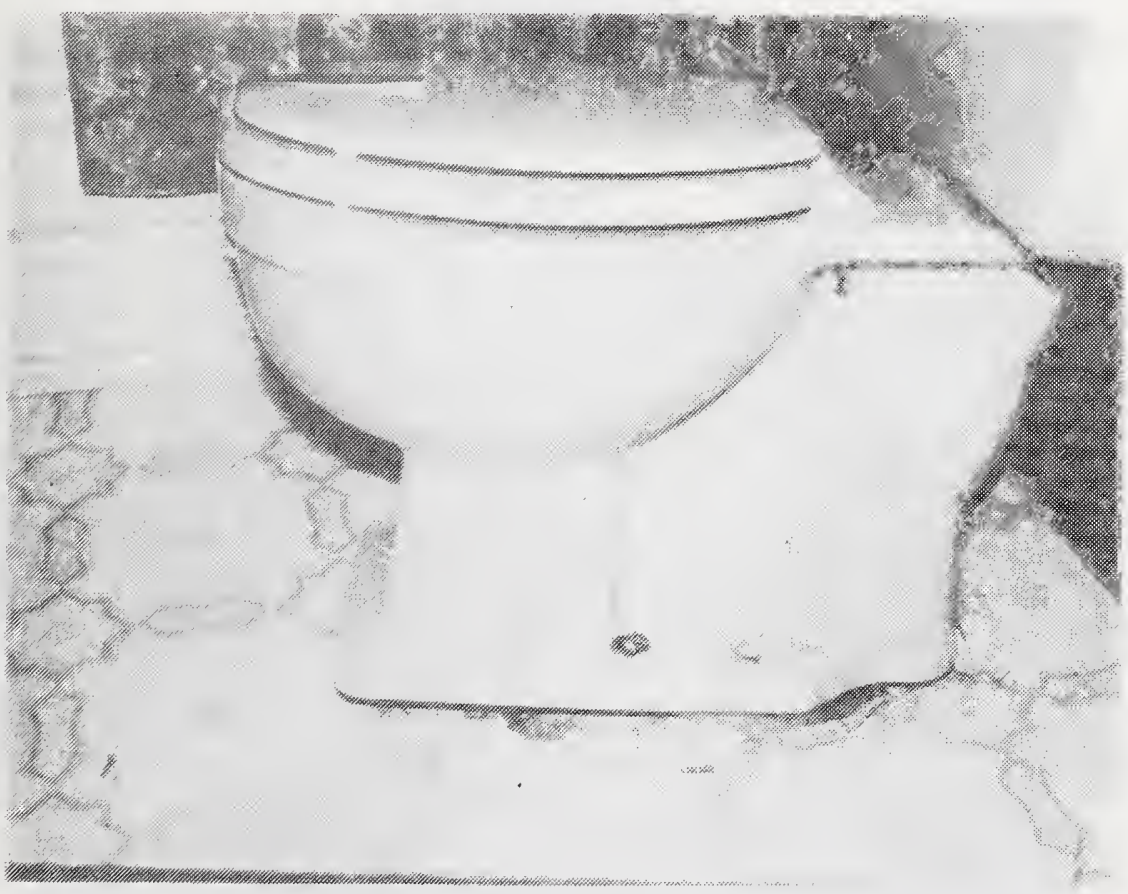

Figure C-79 Loose Toilet at Floor Connection. 

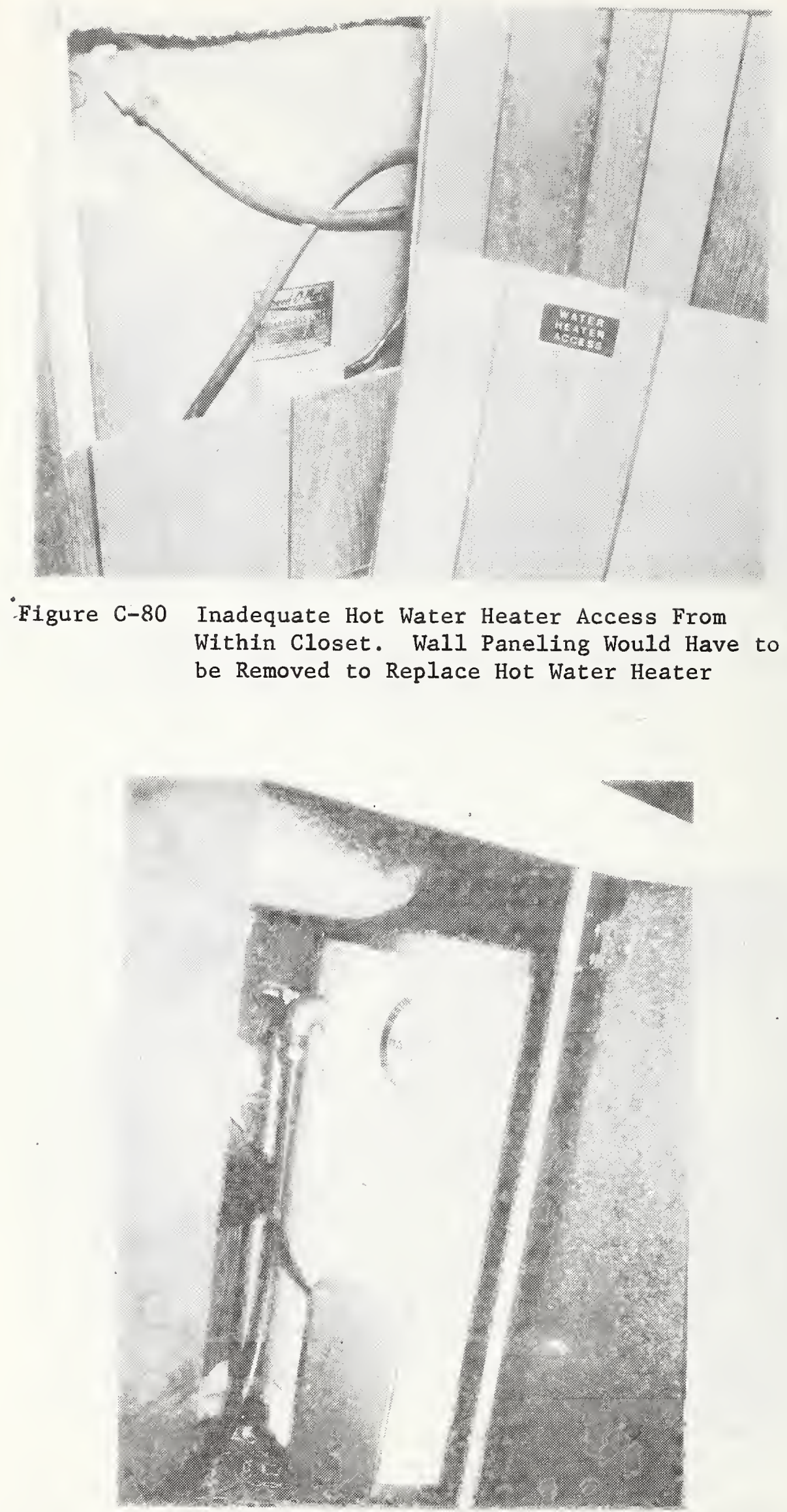

Figure C-81 Hot Water Heater Access Under Kitchen Cabinet. Kitchen Cabinetry would Have to be Removed to Replace Hot Water Heater 


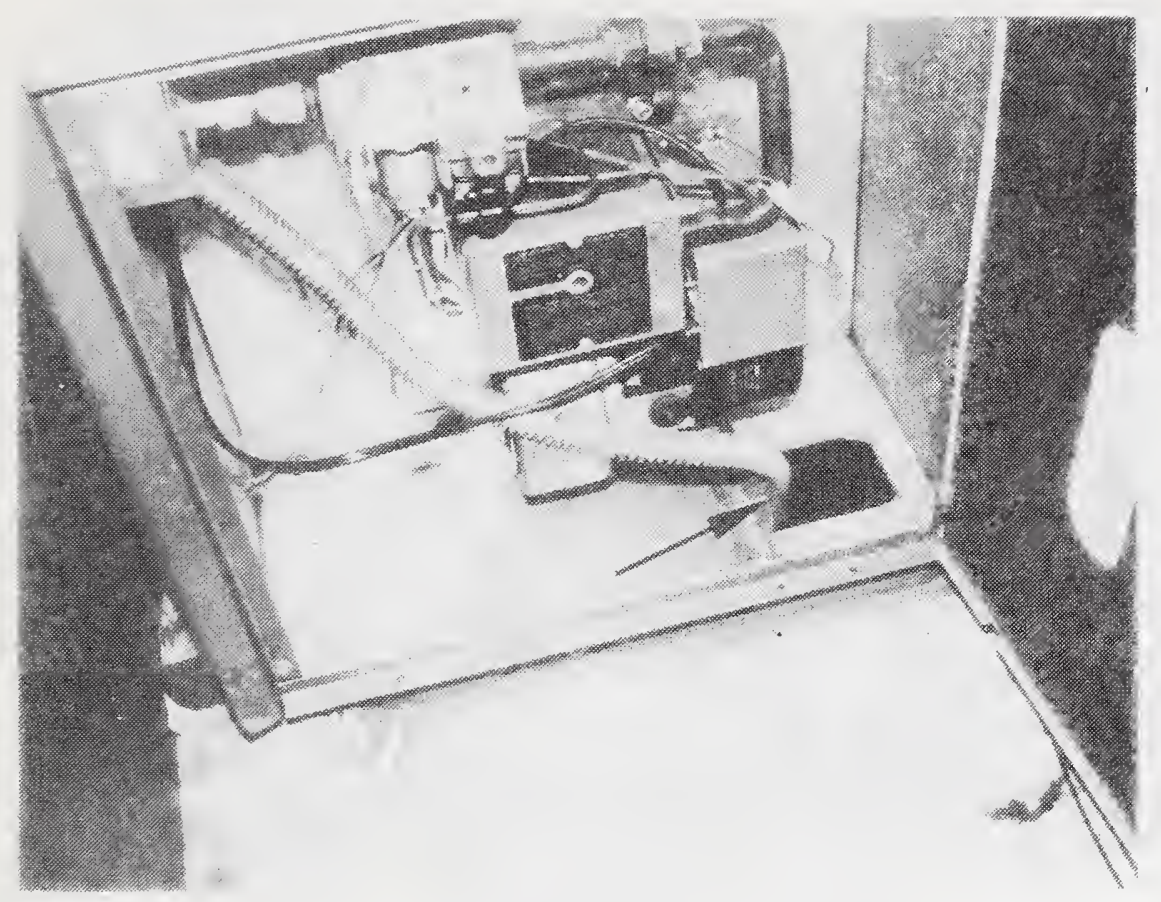

Figure C-82 Flexible Gas Connector on Furnace Through Floor to Gas Supply Piping

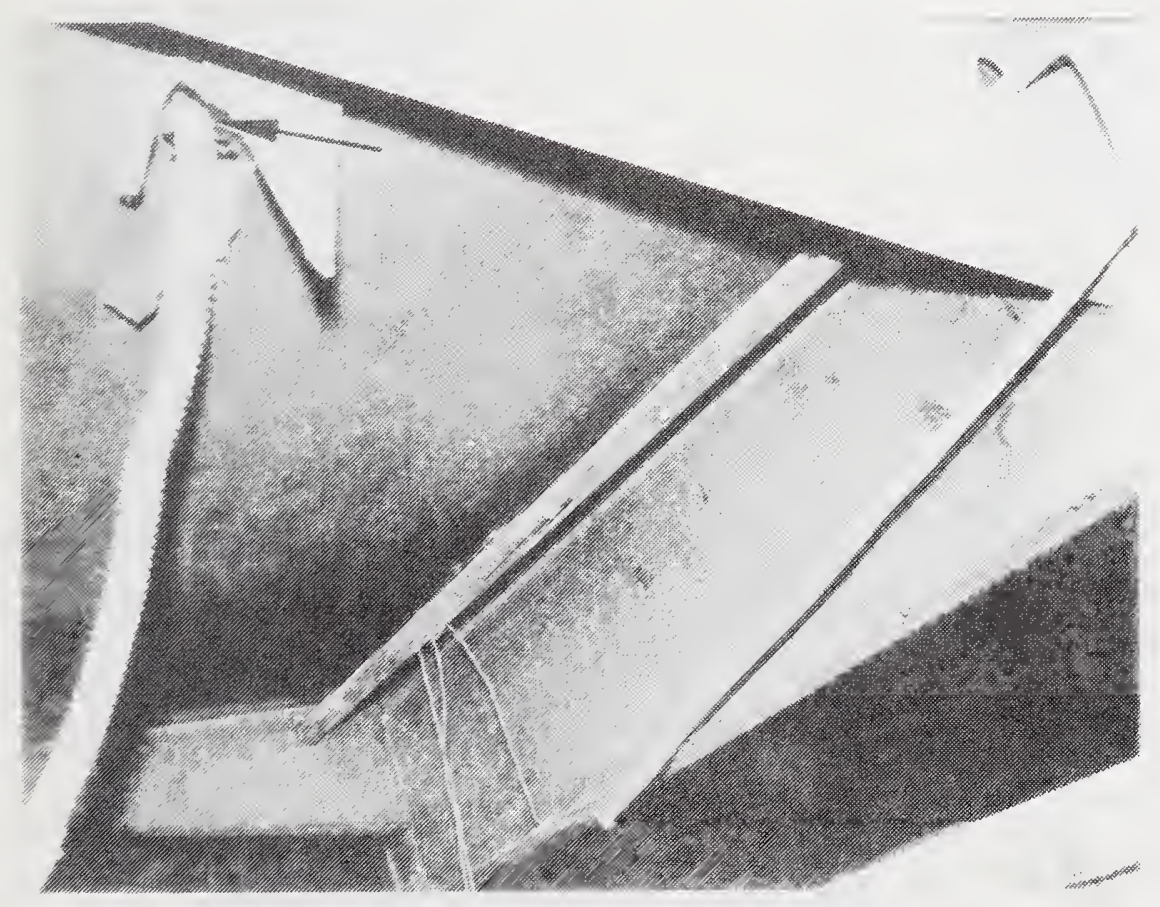

Figure C-83 Flexible Gas Connector Through Floor to Underside of Mobile Home 

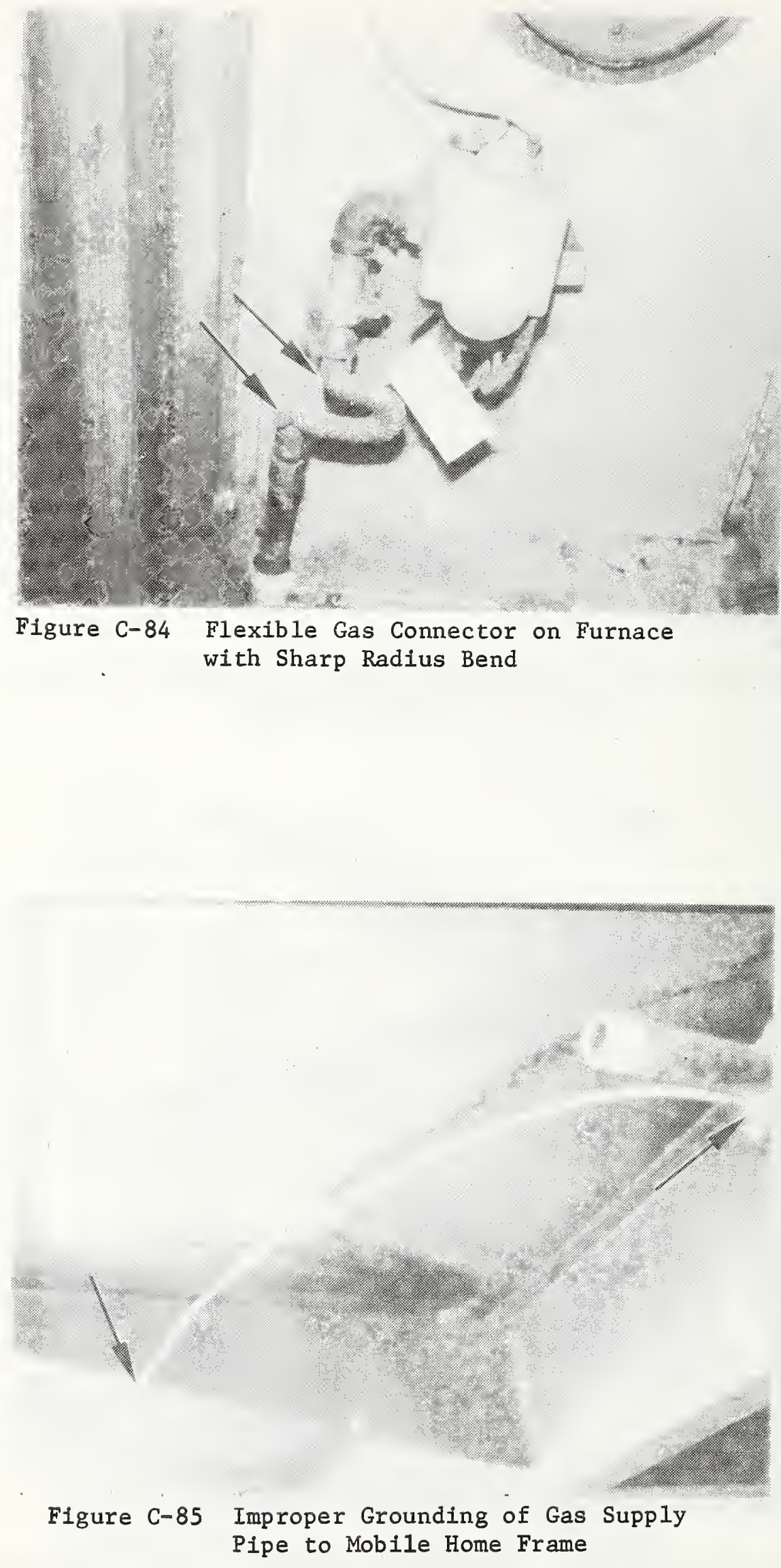


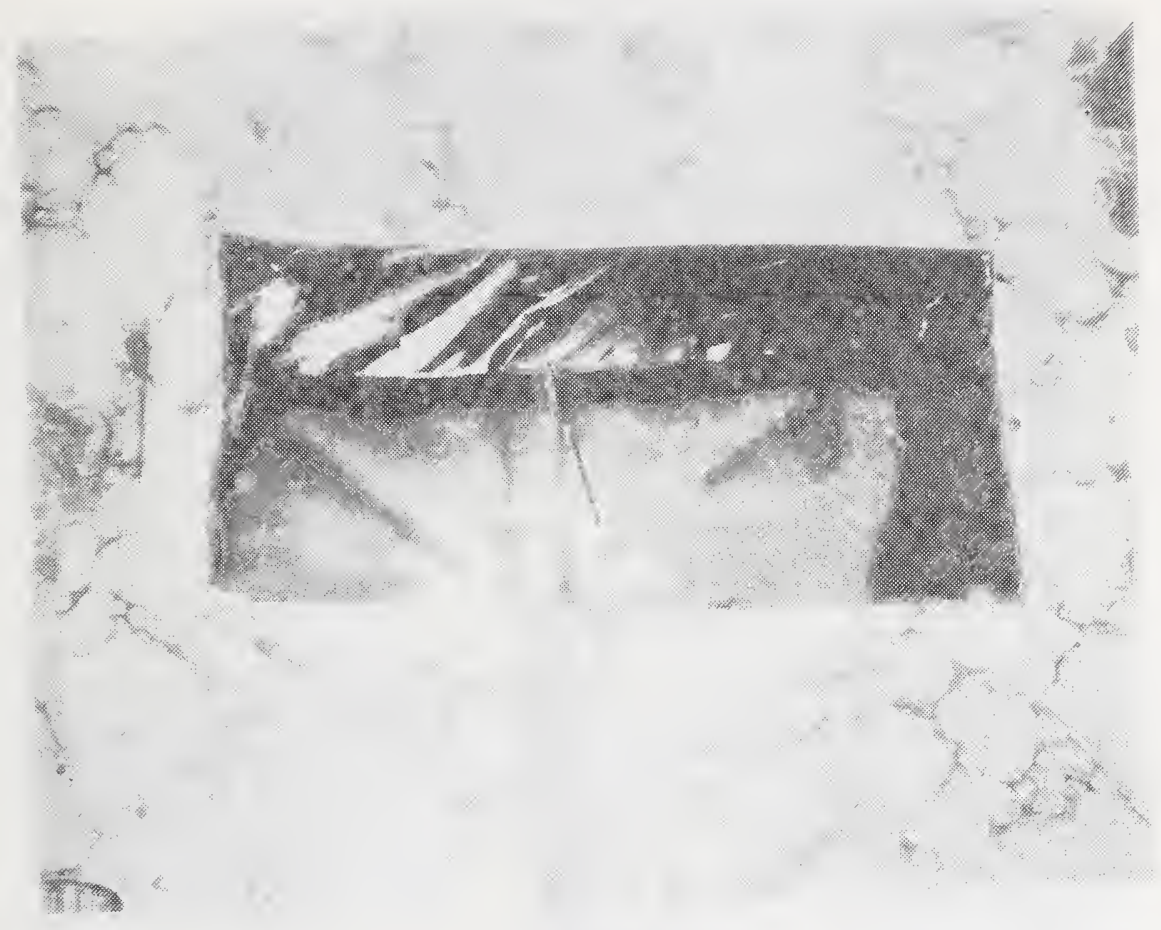
Figure C-86 Riser From Heat Duct in Floor to Register
Constructed of Fabric Material.

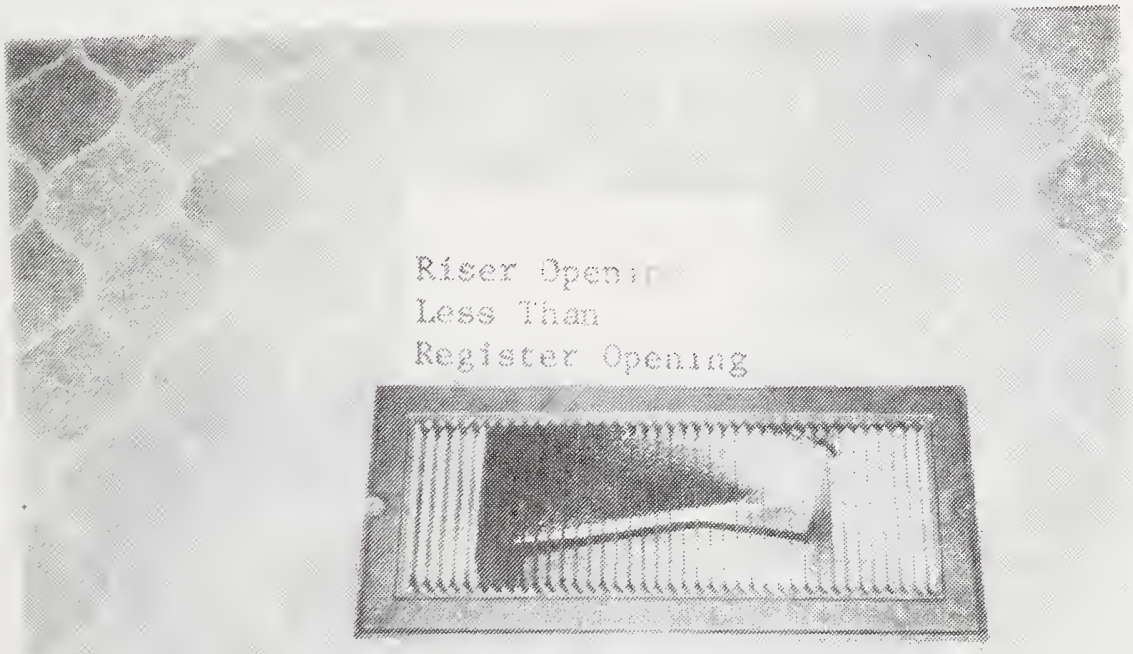

Figure Air Flow from Heat Duct Blocked by Sheet

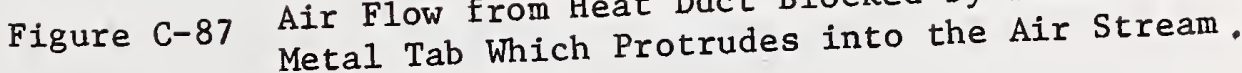




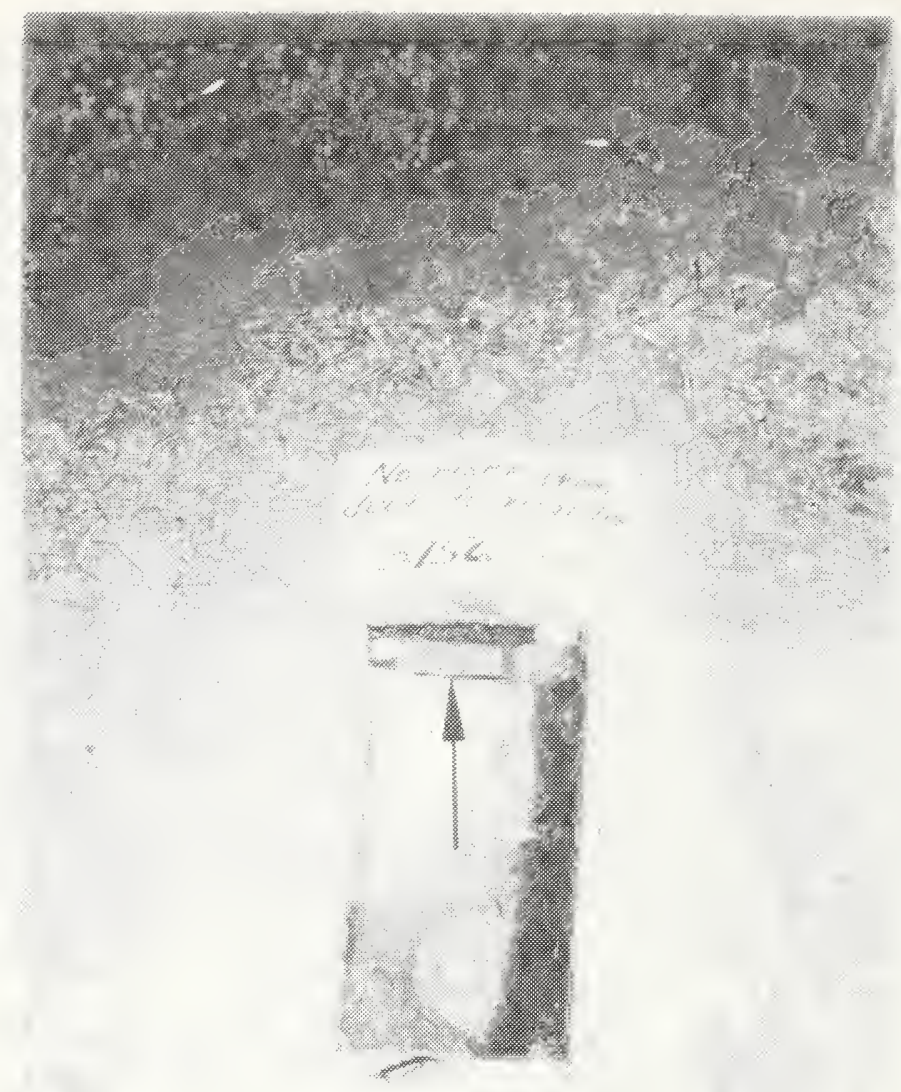

Figure C-88 Riser from Heat Duct to Floor Register Missing. Air Supply System Not Tight.

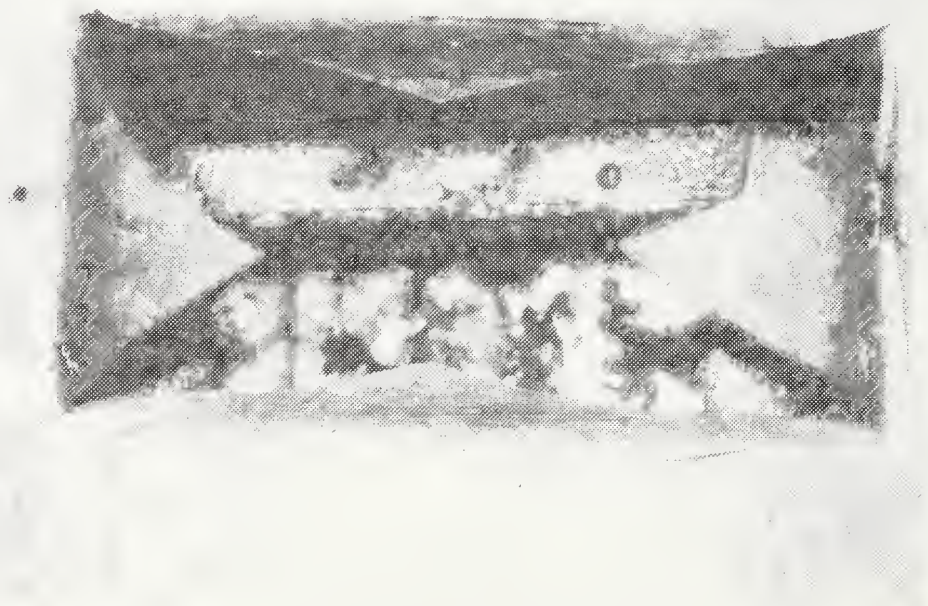

Figure C-89 Dirt and Flooring Material in Heat Duct Blocking Air Flow. 


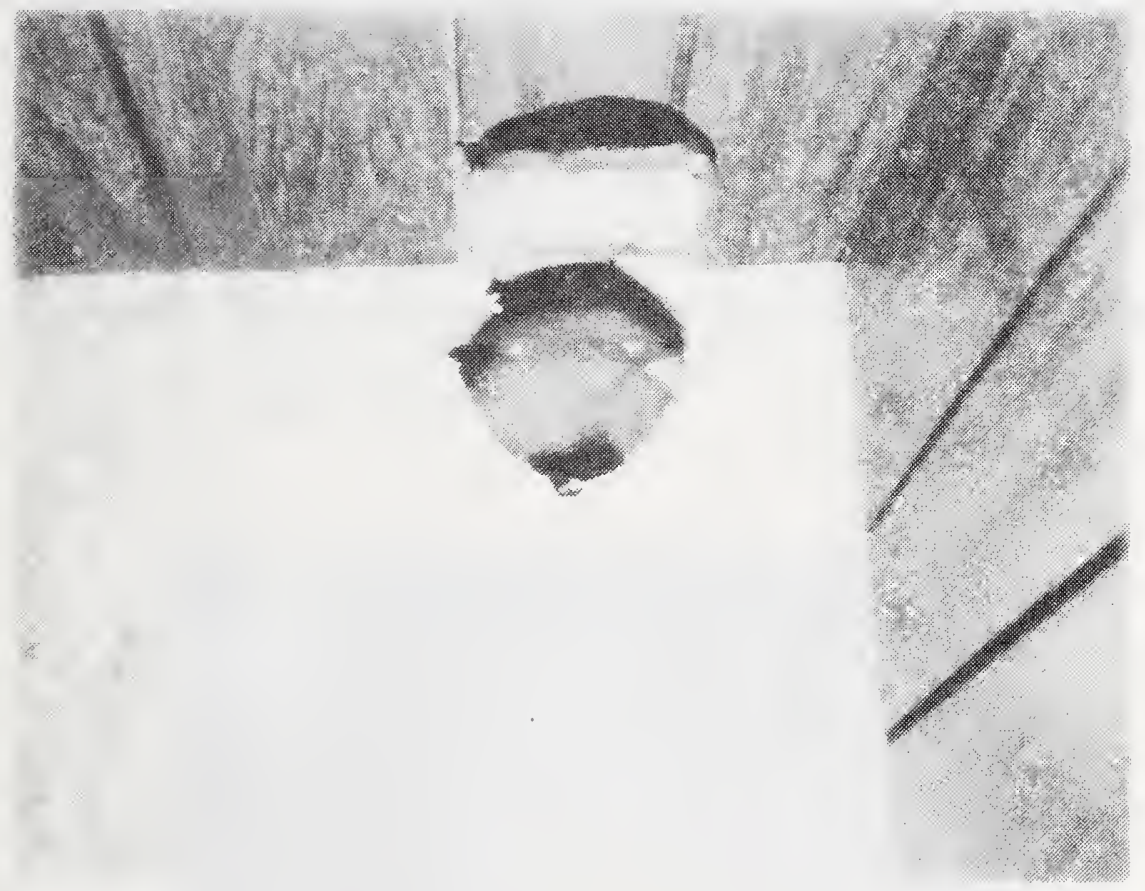

Figure C-90 Clothes Dryer Venting to Underside of Mobile Home (Probably Site Installed) 


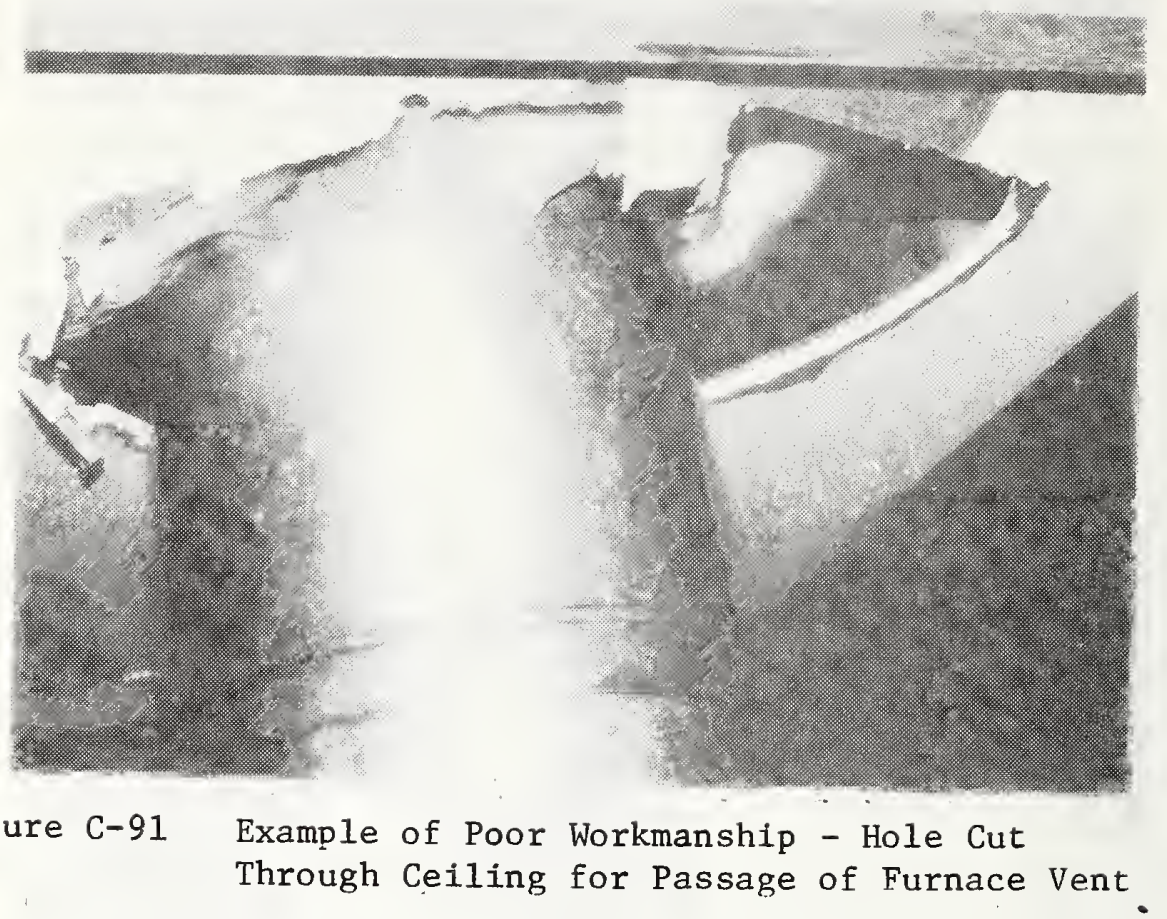

Figure C-91 Example of Poor Workmanship - Hole Cut Through Ceiling for Passage of Furnace Vent
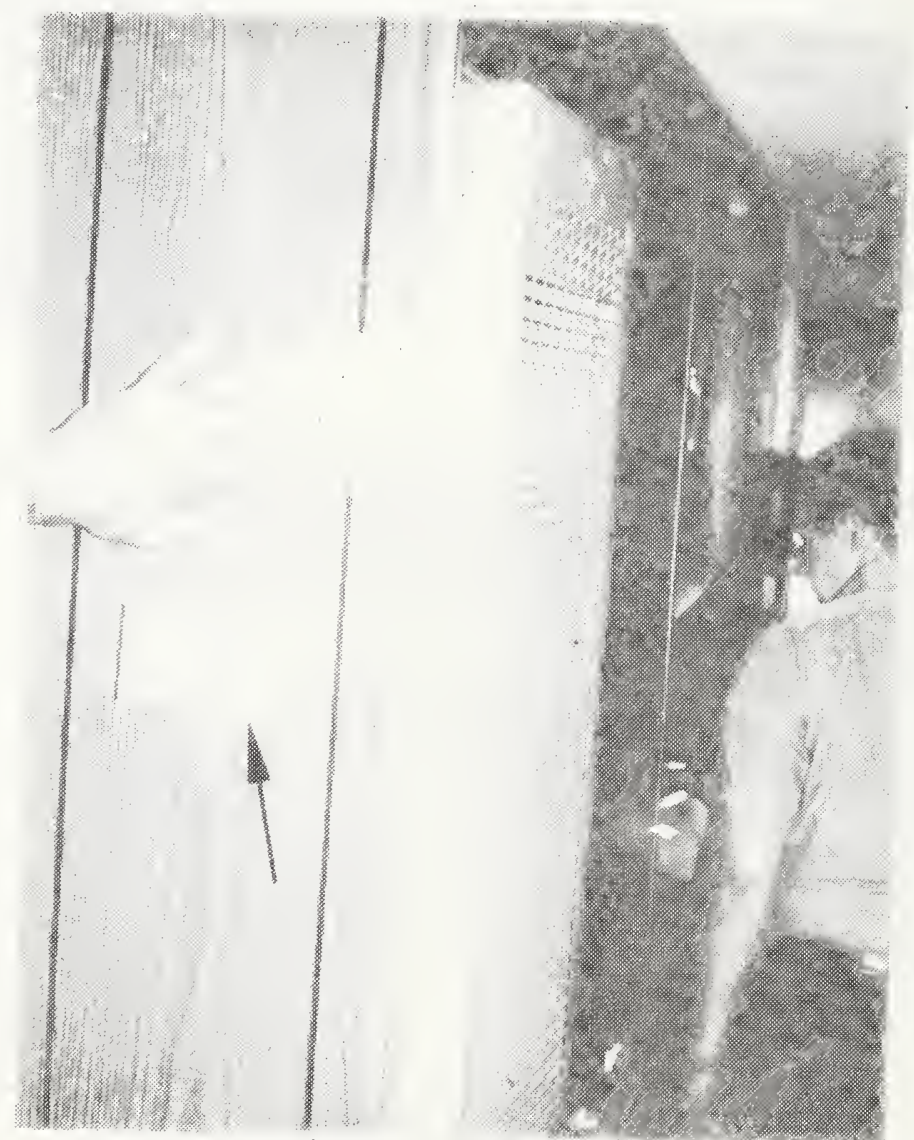

Figure C-92 Furnace Thermostat Located Adjacent to Furnace on Wa11 Common to Furnace Compartment Causes Problems of Temperature Control. 


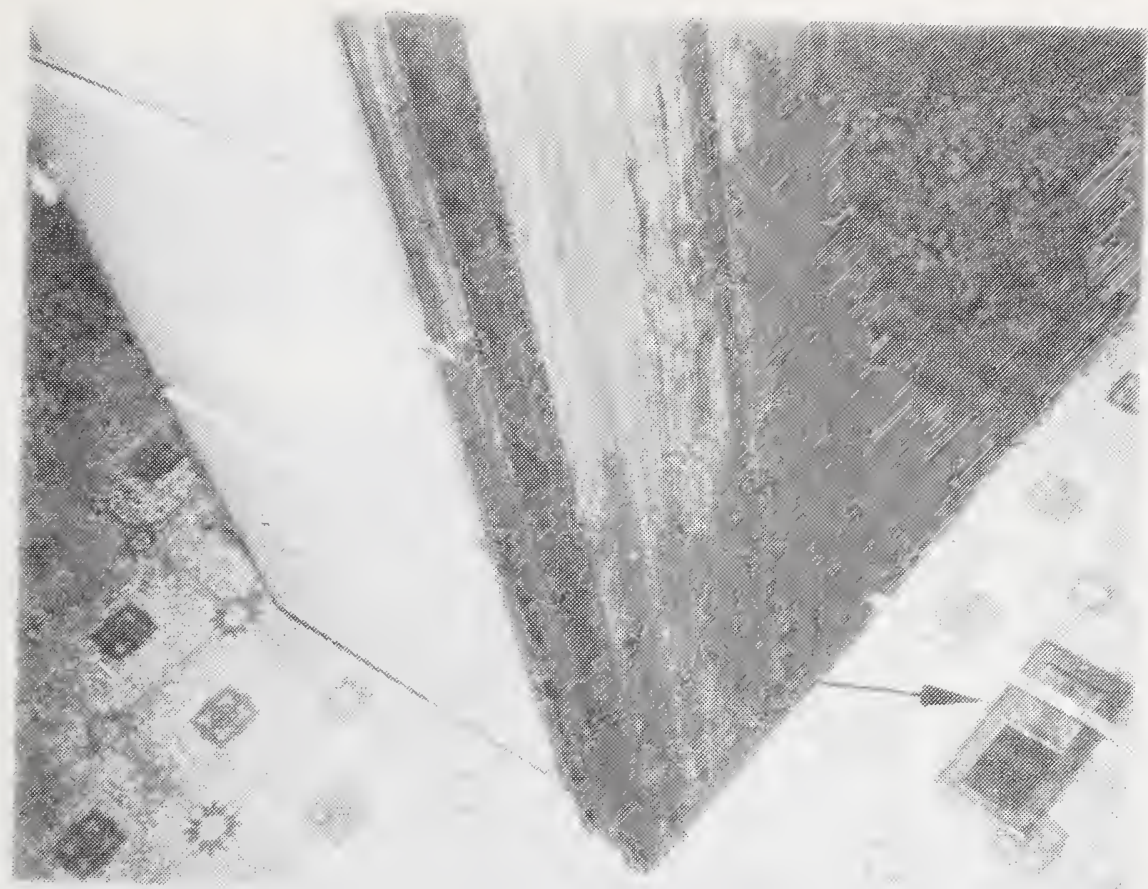

Figure C-93 Floor Register Located Eight Inches From Furnace Compartment Wall in Bedroom Creating Non-Uniform Distribution of Heat.

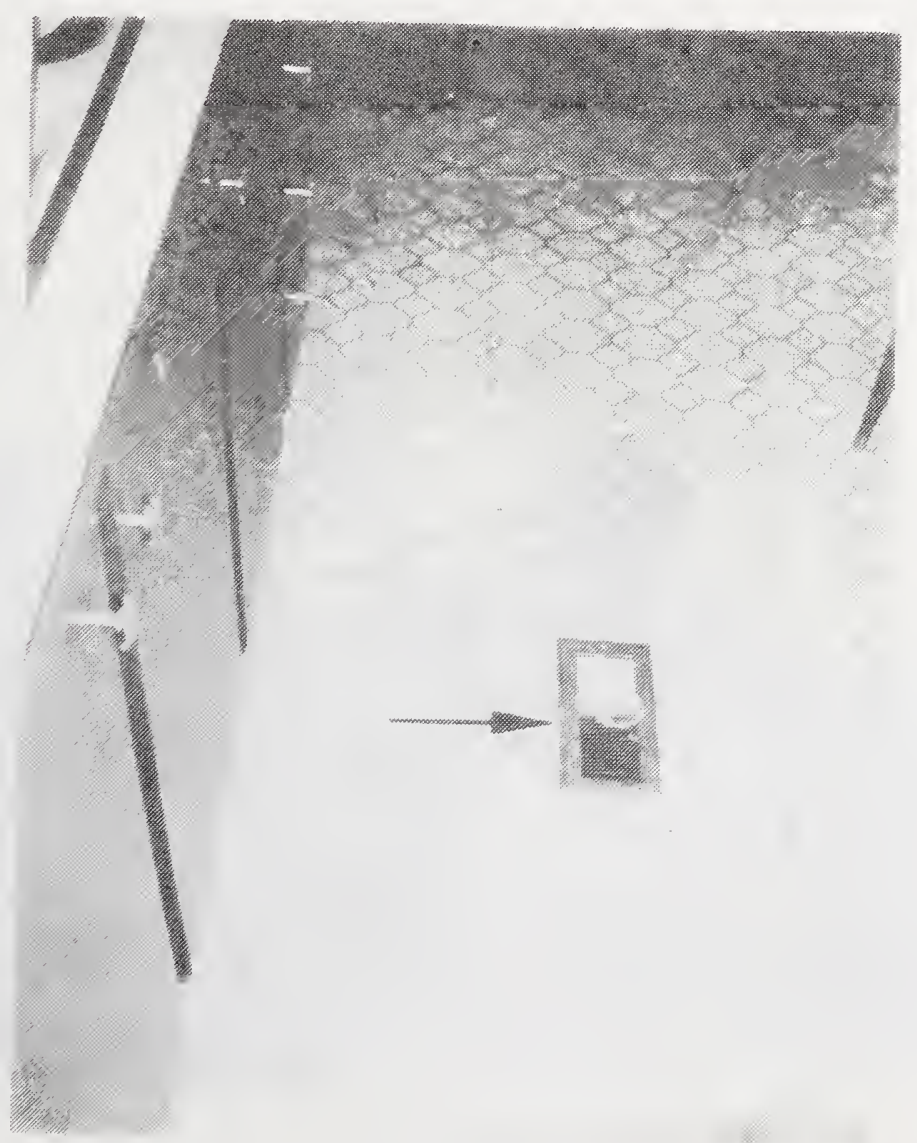

Figure C-94 Floor Register Location Adjacent to Kitchen Cabinets (high traffic area) constituting a Safety Hazard 

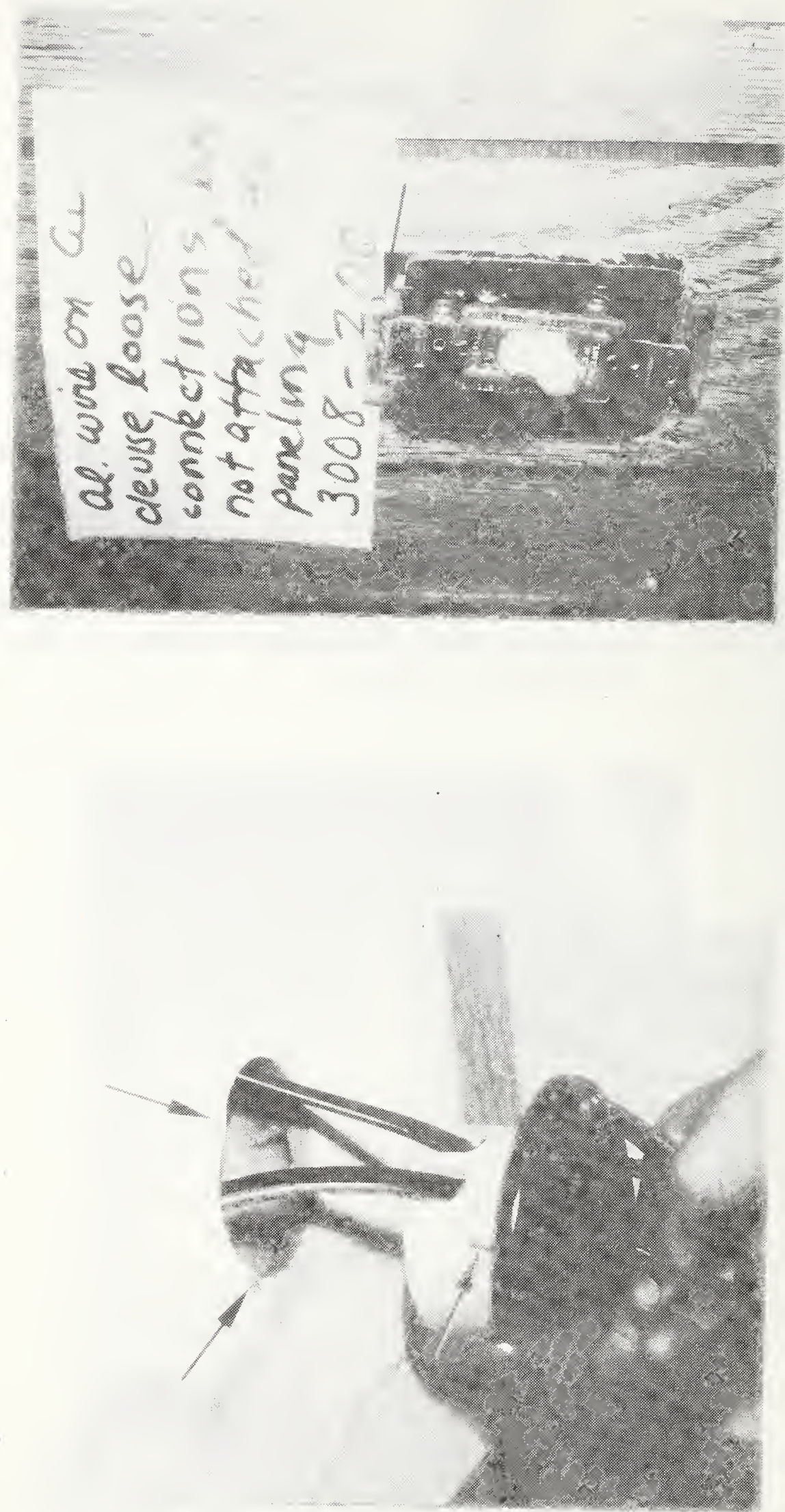


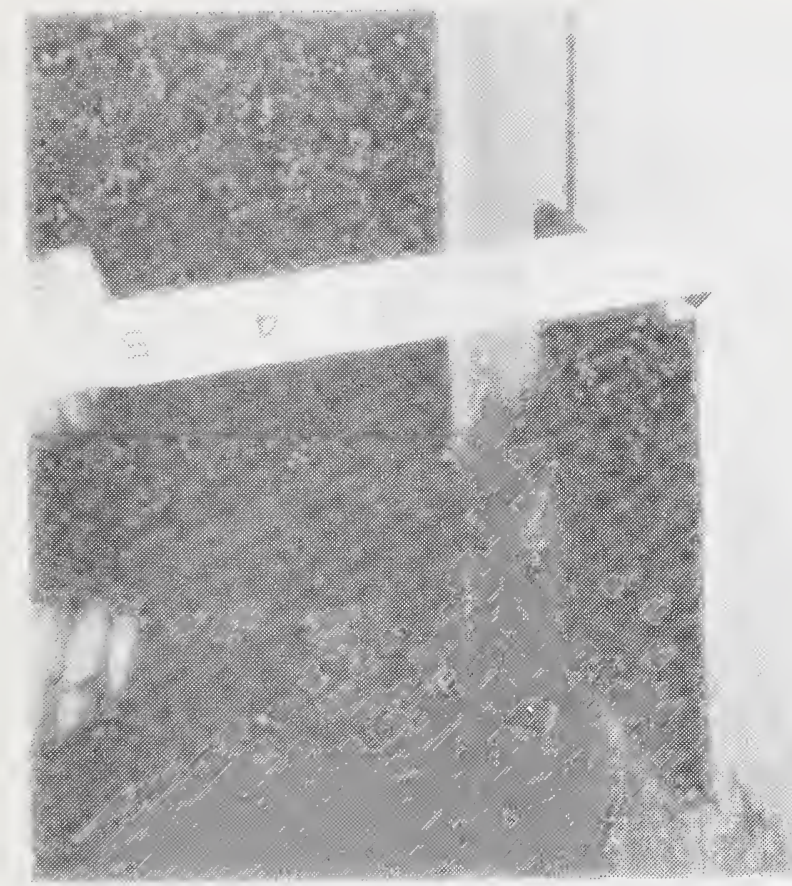

\section{Figure C-97 Loose Receptacle Box Attached Only to Wood Paneling}

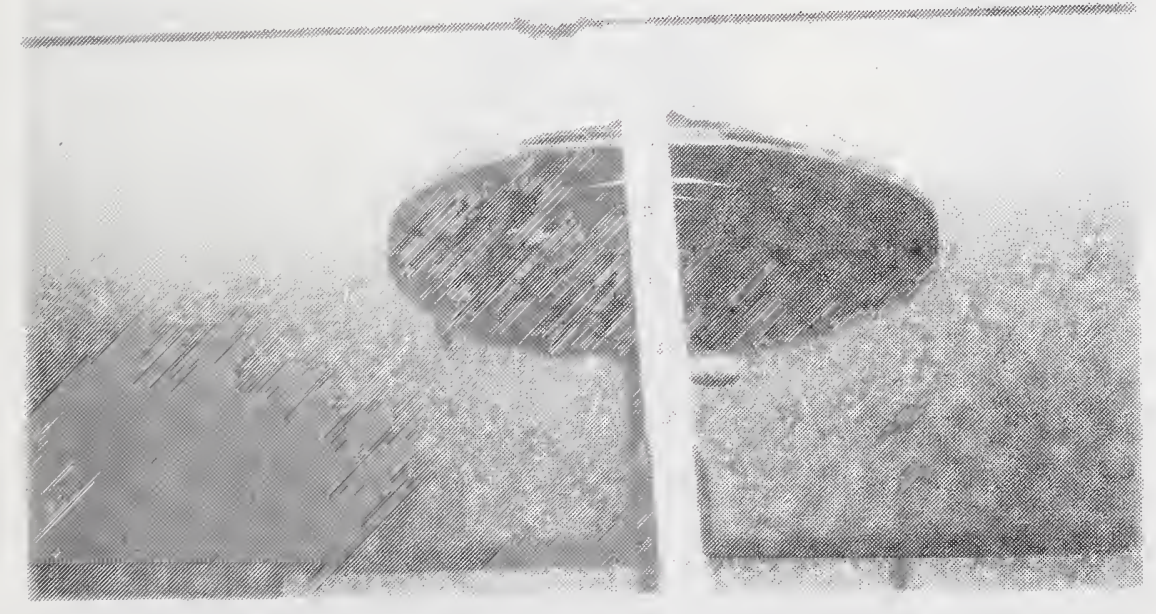

$$
\begin{aligned}
\text { Figure C-98 - Loose Exhaust Fan In } \\
\text { Ceiling }
\end{aligned}
$$




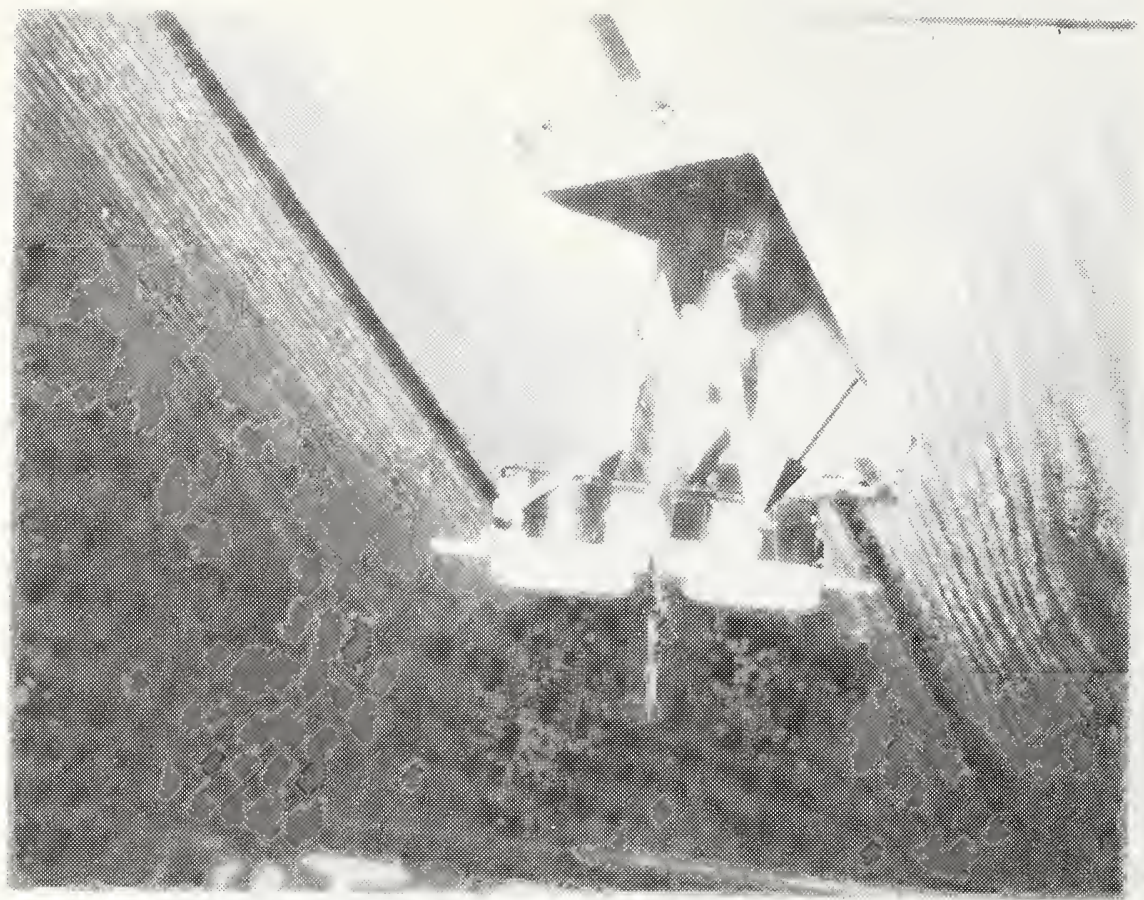

Figure C-99 - Overwrapped Aluminum Wire In Wall Receptacle

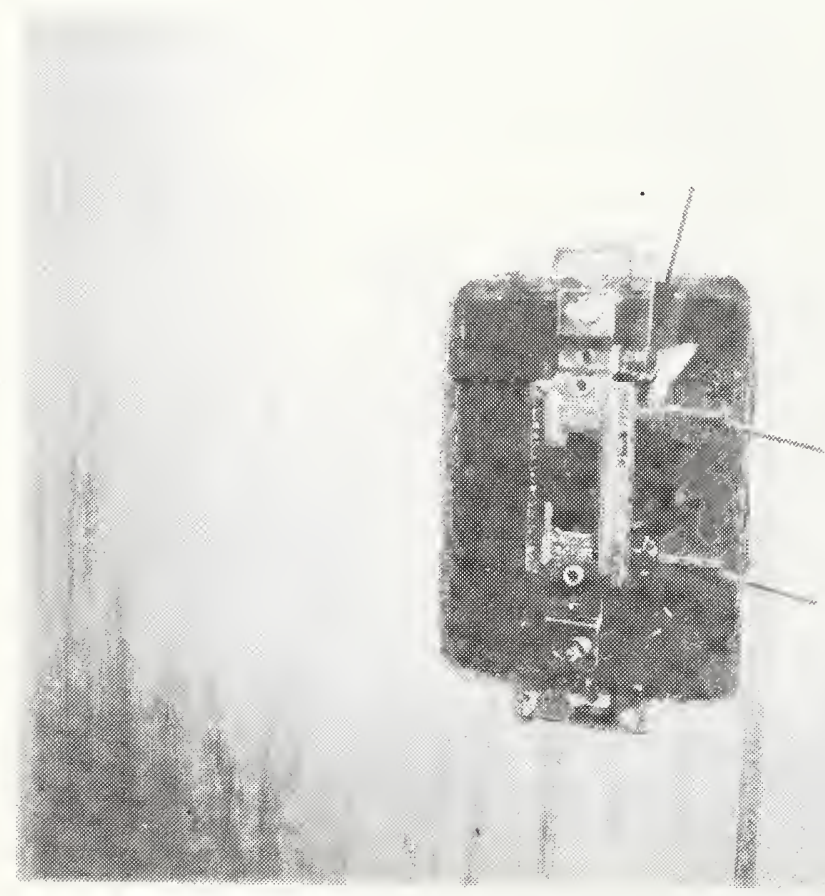

Figure C-100 - Loose Connections (Copper Wire) in Wall Switch 


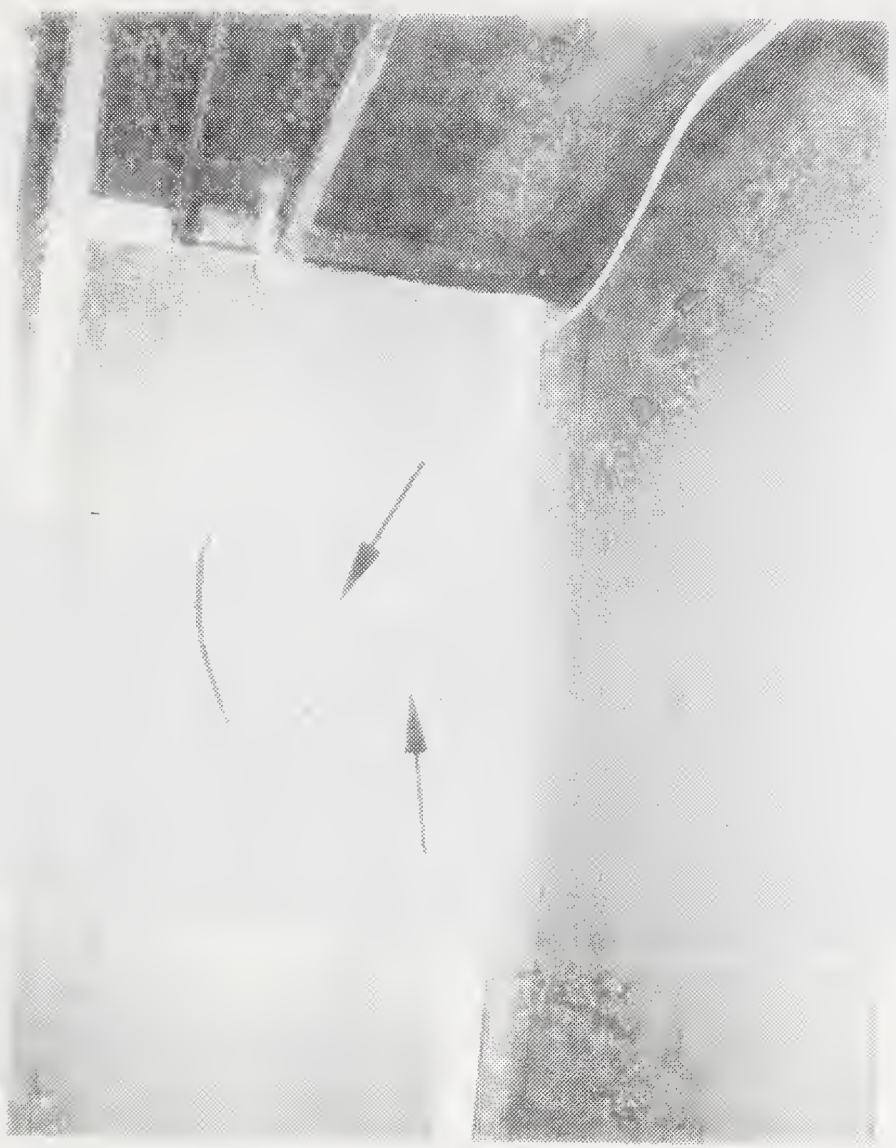

Figure C-101 Cable Inadequately Supported and Exposed in Bedroom Closet.

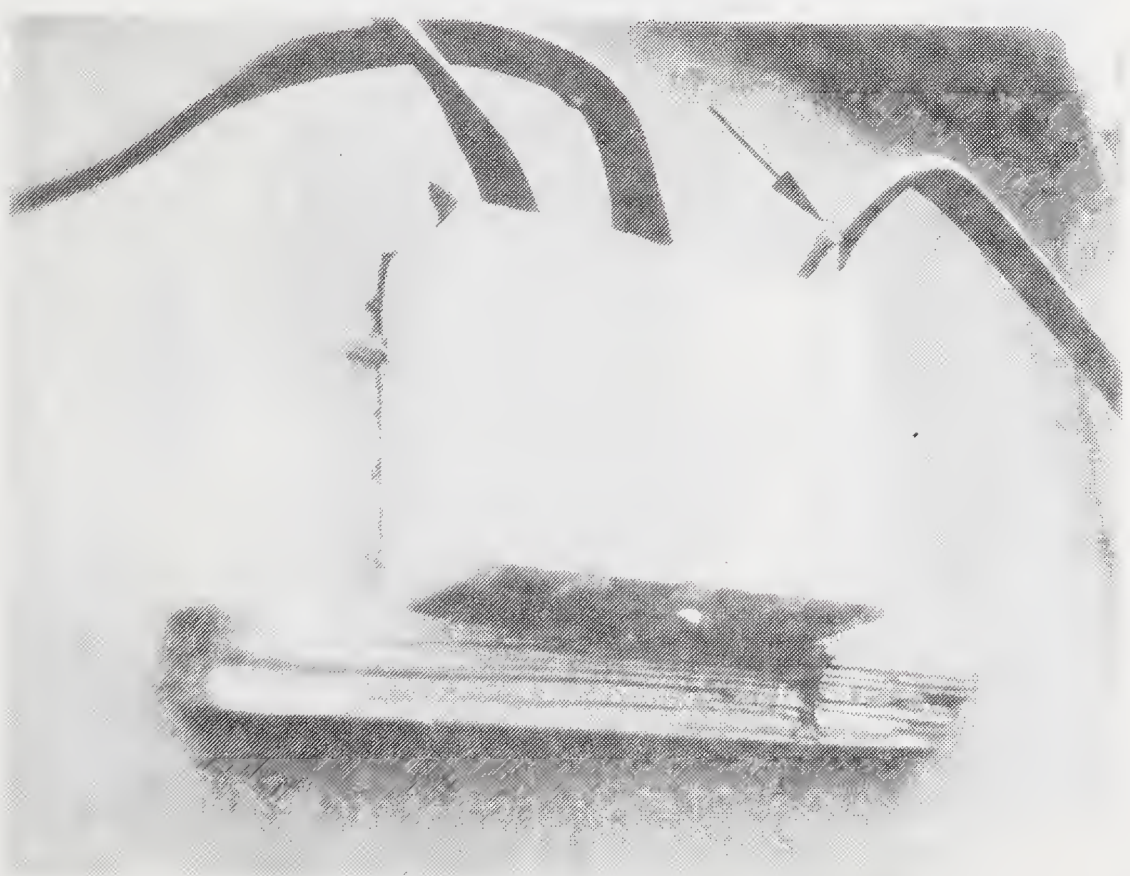

Figure C-102 - Cable Sheath Cut Short of Box 111 

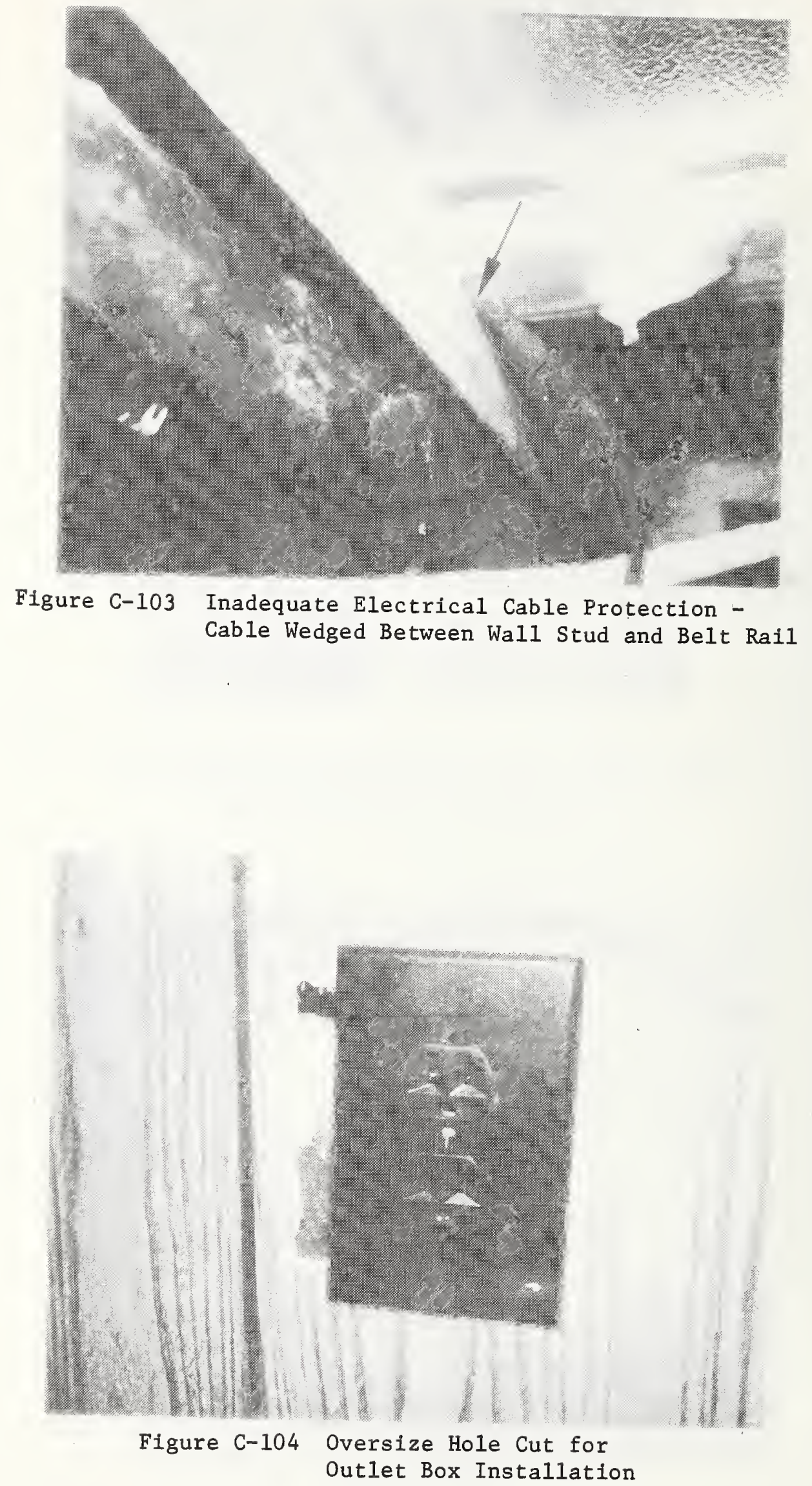


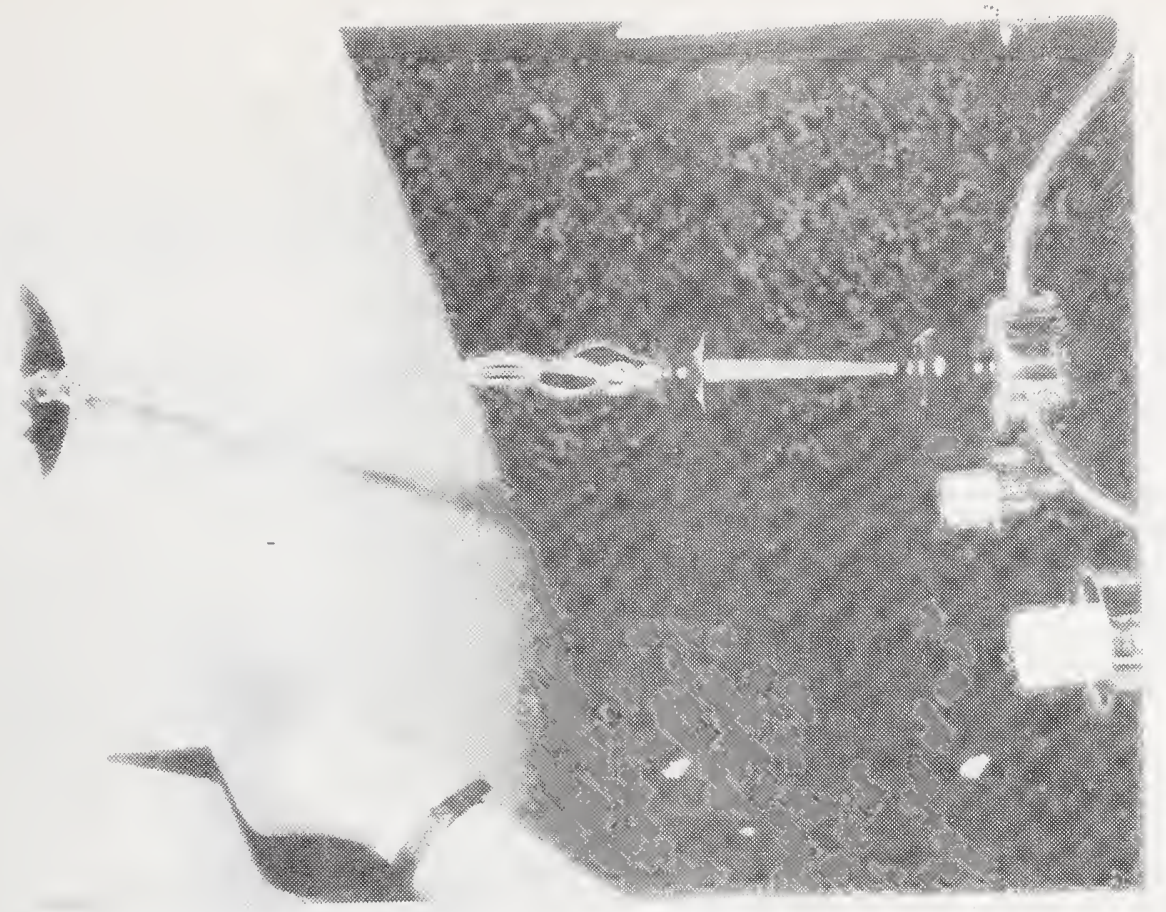

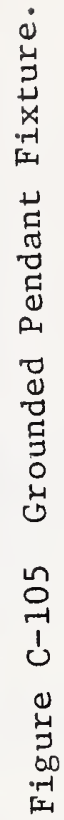

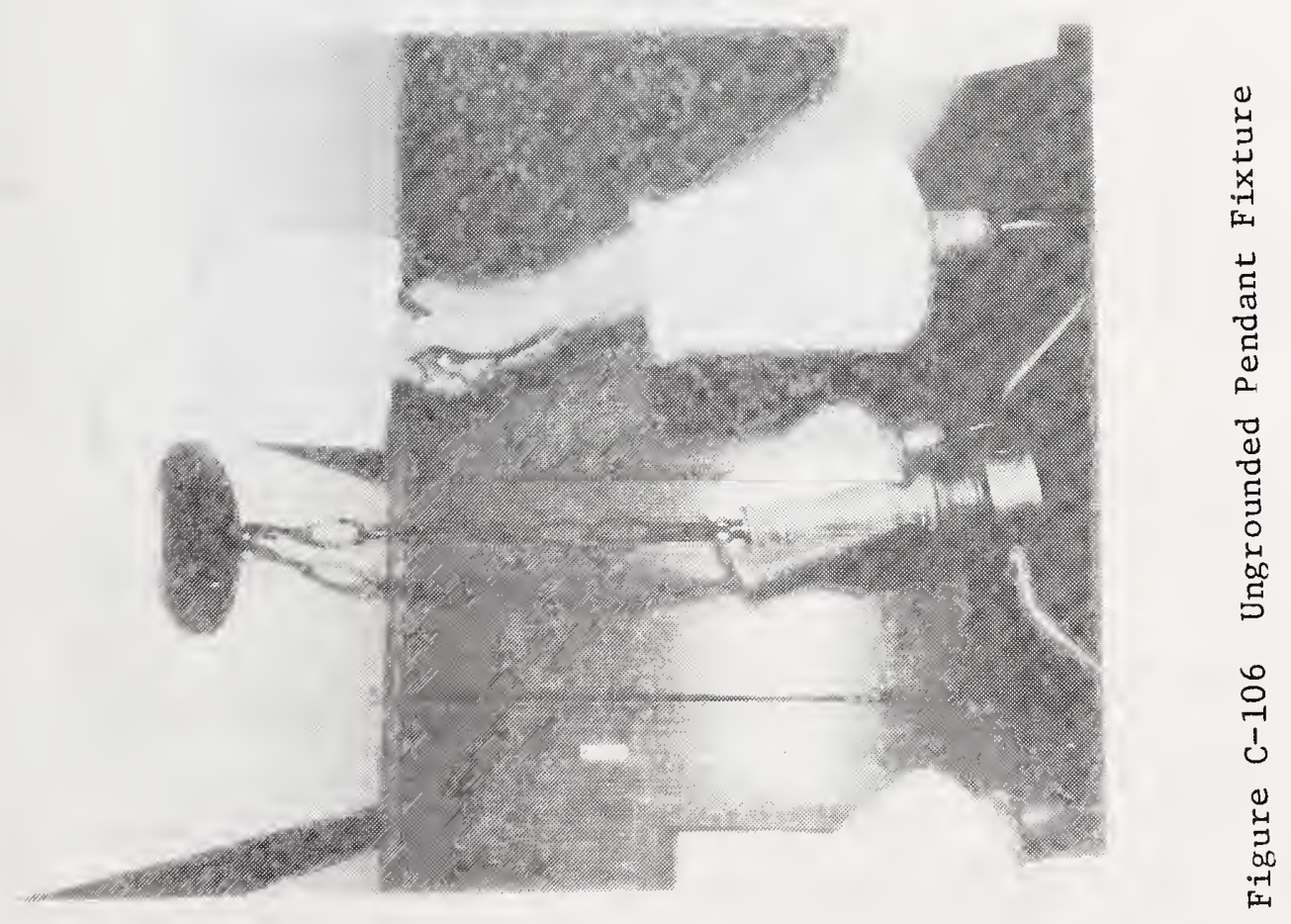




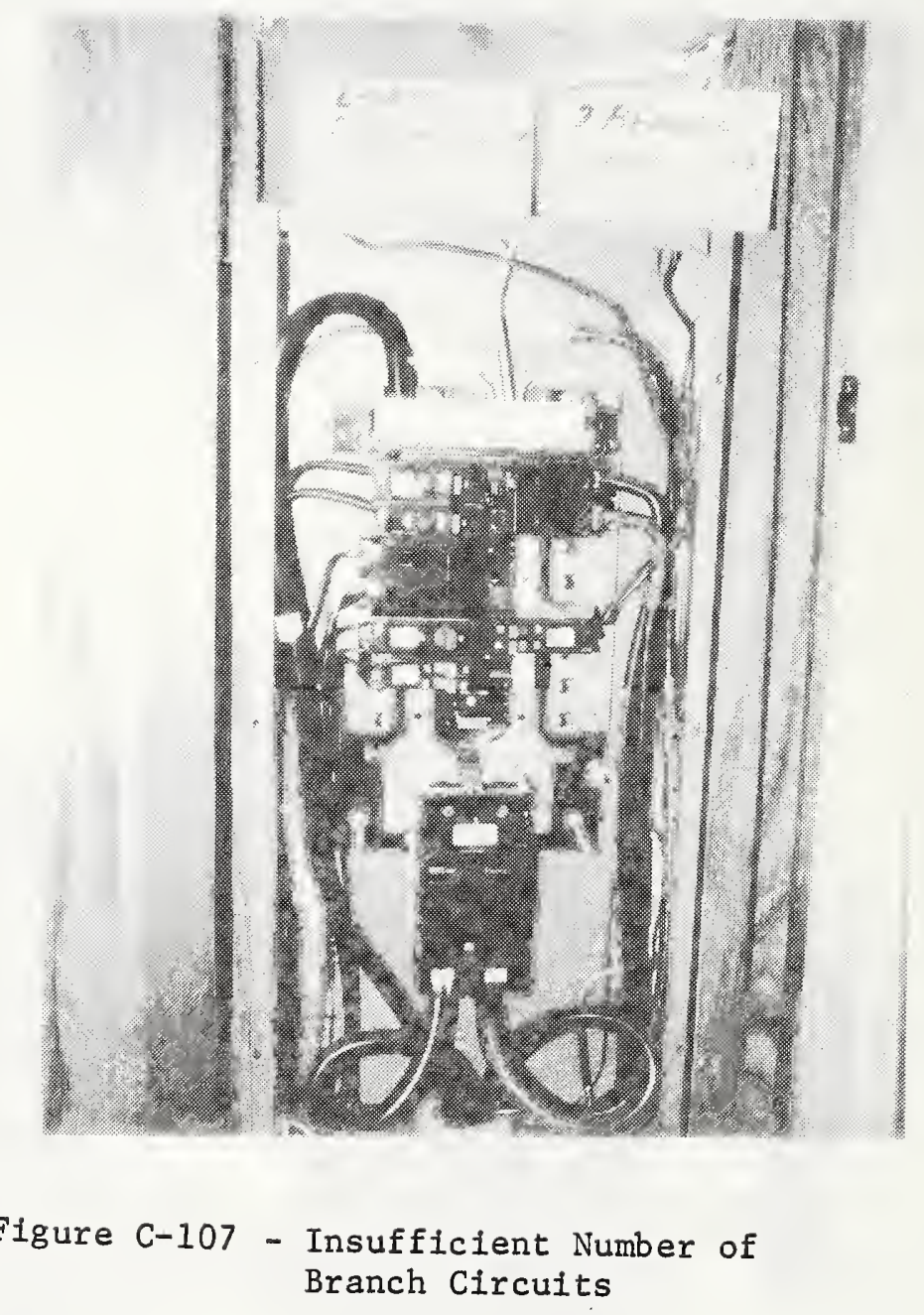


NBS-114A (REV. 7-73)

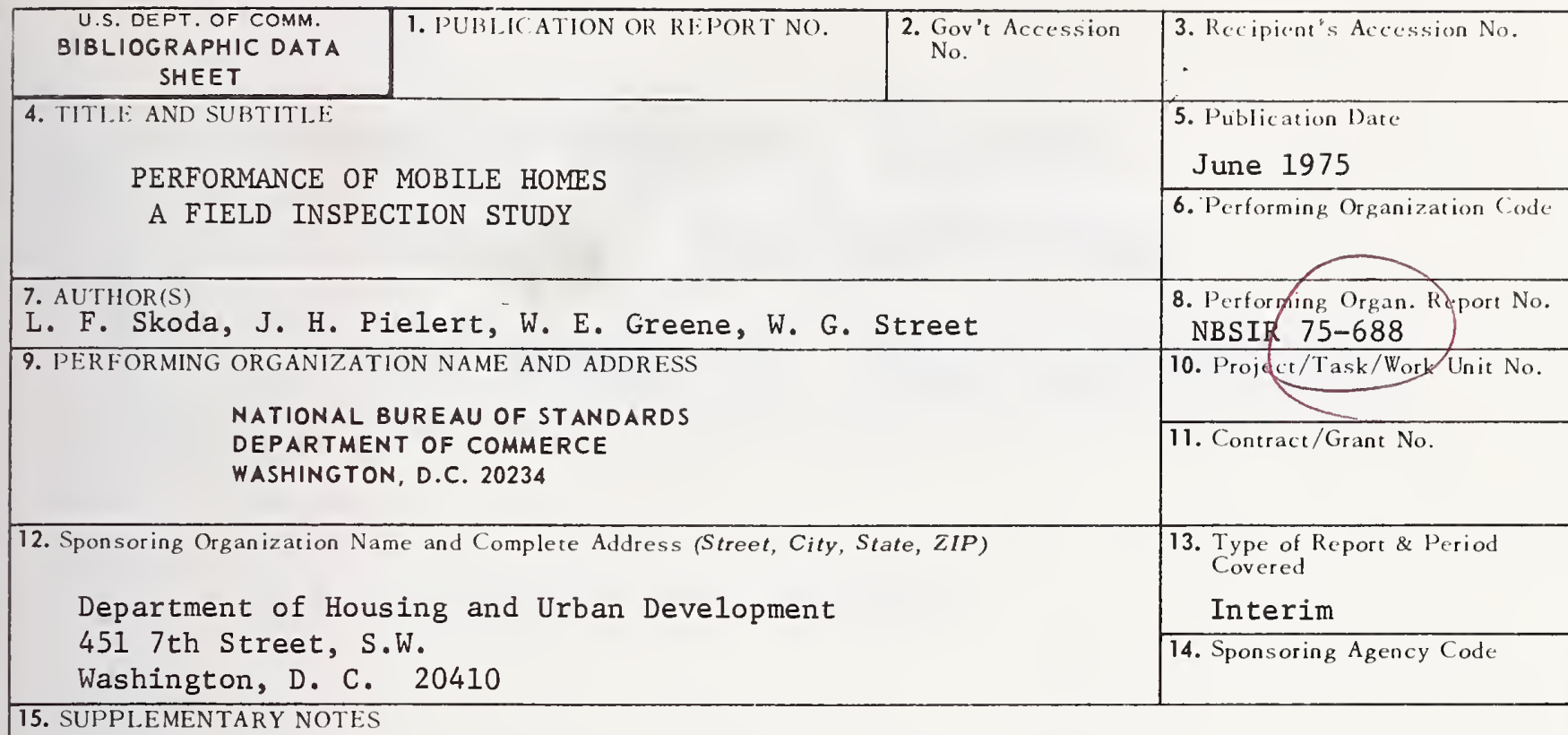

15. SUPPLEMENTARY NOTES

16. ABSTRACT (A 200-word or less factual summary of most significant information. If document includes a significant bibliography or literature survey, mention it here.)

A field inspection study of mobile homes was conducted for the Department of Housing and Urban Development. The objective of the study was to evaluate the causes of mobile home problems by physically inspecting available units at various locations in the United States. A total of 257 units were inspected consisting mostly of mobile homes purchased by HUD and used as temporary housing for victims of the 1972 Hurricane Agnes disaster. The total number of problems found was 3,528 for the 257 units inspected. Of these problems, 2120 were directly related to inadequacies in the ANSI A119.1 Standard for Mobile Homes or the mobile home enforcement process (plan review, certification of designs, plant inspection), 934 were routine maintenance problems, and 374 were attributed to mechanical/electrical appliances and equipment. This report presents a computer listing of all problems plus photographic examples of observed problems.

The number of mobile homes included in this study is small when compared to the total number of mobile homes now in use in the United States. Additionally, this was a problen oriented study and did not attempt to document the twany areas of satisfactory mobile home performance.

17. KEY WORDS (six to twelve entries; alphabetical order; capitalize only the first letter of the first key word unless a proper name; separated by semicolons)

Enforcement process; field inspection; house trailers; housing; Hurricane Agnes; mobile homes; performance data; standards.

18. AVAILABILITY

Unlimited

For Official Distribution. Do Not Release to NTIS

Order From Sup. of Doc., U.S. Government Printing Office Washington, D.C. 20402, SD Cat. No. C13

Urder From National Technical Intormation Service (NTIS) Springfield, Virginia 22151

\begin{tabular}{|l|l|}
\hline $\begin{array}{l}\text { 19. SECURITY CLASS } \\
\text { (THIS REPURT) } \\
\text { UNCL ASSIFIED }\end{array}$ & 21. NO. OF PAGES \\
\hline $\begin{array}{l}\text { 20. SECURITY CLASS } \\
\text { (THIS PAGE) } \\
\text { UNCLASSIFIED) }\end{array}$ & 22. Price \\
\hline
\end{tabular}


